\title{
Fuel Cycle System Analysis Handbook
}

Steven J. Piet

Brent W. Dixon

Dirk Gombert

Edward A. Hoffman

Gretchen A. Matthern

Kent A. Williams

June 2009

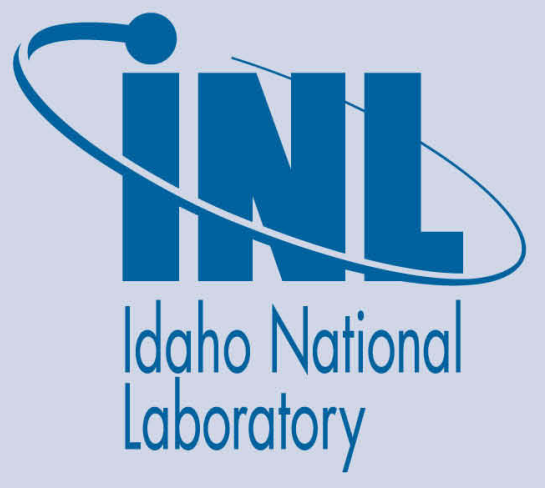

The INL is a U.S. Department of Energy National Laboratory operated by Battelle Energy Alliance 
INL/EXT-11-22619

AFCI-SYSA-AI-MI-DV-2009-000035

\title{
Fuel Cycle System Analysis Handbook
}

${ }^{1}$ ORNL

\author{
Steven J. Piet \\ Brent W. Dixon \\ Dirk Gombert \\ Edward A. Hoffman \\ Gretchen E. Matthern \\ Kent A. Williams ${ }^{1}$
}

June 2009

\author{
Idaho National Laboratory \\ Advanced Fuel Cycle Initiative \\ Idaho Falls, Idaho 83415
}

http://www.inl.gov

Prepared for the

U.S. Department of Energy

Office of Nuclear Energy

Under DOE Idaho Operations Office

Contract DE-AC07-05ID14517 


\section{DISCLAIMER}

This information was prepared as an account of work sponsored by an agency of the U.S. Government. Neither the U.S. Government nor any agency thereof, nor any of their employees, makes any warranty, expressed or implied, or assumes any legal liability or responsibility for the accuracy, completeness, or usefulness, of any information, apparatus, product, or process disclosed, or represents that its use would not infringe privately owned rights. References herein to any specific commercial product, process, or service by trade name, trade mark, manufacturer, or otherwise, does not necessarily constitute or imply its endorsement, recommendation, or favoring by the U.S. Government or any agency thereof. The views and opinions of authors expressed herein do not necessarily state or reflect those of the U.S. Government or any agency thereof. 


\section{SUMMARY}

This Handbook aims to improve understanding and communication regarding nuclear fuel cycle options. It is intended to assist DOE, Campaign Managers, and other presenters prepare presentations and reports. When looking for information, check here.

The Handbook generally includes few details of how calculations were performed, which can be found by consulting references provided to the reader. The Handbook emphasizes results in the form of graphics and diagrams, with only enough text to explain the graphic, to ensure that the messages associated with the graphic is clear, and to explain key assumptions and methods that cause the graphed results.

Some of the material is new and is not found in previous reports, for example:

- Section 3 has system-level mass flow diagrams for 0-tier (once-through), 1-tier (UOX to $\mathrm{CR}=0.50$ fast reactor), and 2-tier ( $\mathrm{UOX}$ to $\mathrm{MOX}-\mathrm{Pu}$ to $\mathrm{CR}=0.50$ fast reactor) scenarios - at both static and dynamic equilibrium.

- To help inform fast reactor transuranic (TRU) conversion ratio and uranium supply behavior, section 5 provides the sustainable fast reactor growth rate as a function of TRU conversion ratio.

- To help clarify the difference in recycling $\mathrm{Pu}, \mathrm{NpPu}, \mathrm{NpPuAm}$, and all-TRU, section 5 provides mass fraction, gamma, and neutron emission for those four cases for MOX, heterogeneous LWR IMF (assemblies mixing IMF and UOX pins), and a $\mathrm{CR}=0.50$ fast reactor. There are data for the first $10 \mathrm{LWR}$ recycle passes and equilibrium.

- Section 6 provides information on the cycle length, planned and unplanned outages, and TRU enrichment as a function of fast reactor TRU conversion ratio, as well as the dilution of TRU feedstock by uranium in making fast reactor fuel. (The recovered uranium is considered to be more pure than recovered TRU.) The latter parameter impacts the required TRU impurity limits specified by the Fuels Campaign.

- $\quad$ Section 7 provides flows for an 800-tonne UOX separation plant.

- To complement "tornado" economic uncertainty diagrams, which show at a glance combined uncertainty information, section 9.2 has a new set of simpler graphs that show the impact on fuel cycle costs for once through, 1-tier, and 2-tier scenarios as a function of key input parameters.

Other information is not new, but is assembled here to give the fuel cycle community a catalog of information, for example:

- Section 4 provides graphs of historical data on number, capacity, generated electricity, and capacity factor of the U.S. reactor fleet.

- Section 5 provides uranium ore need, required U235 enrichment, SWUs, decay heat, etc. as function of LWR UOX burnup. It also has a table of uranium resources, uranium cost as function of uranium used, and pictures of uranium, uranium pellet, and an LWR fuel assembly.

- Section 6 provides estimates of what fraction of individual LWRs and the entire U.S. LWR fleet can use MOX.

- Section 6 has diagrams intended to help improve understanding on points that have been observed to be unclear in previous reports, including the difference between static and dynamic equilibrium. 
- Section 8 has results from a request to identify long-term radiotoxicity and repository heat from no recycling, recycling $\mathrm{Pu}$, or recycling all TRU into reactors.

- Section 8 has pictures of dry storage casks.

- Throughout the document, there are key results from recent studies, primarily the once through, 1-tier, and 2-tier scenarios in the Dynamic Systems Analysis Report for Nuclear Fuel Recycle [DSARR2008] and follow-up clarifications.

Readers should be aware that there is a separate Transmutation Library that assembles in one place in a common format available results from previous U.S. transmutation analyses for a broad range of fuel cycle options. The Library provides key input parameters and the input and output mass fractions for 81 isotopes and elements. 


\section{CONTENTS}

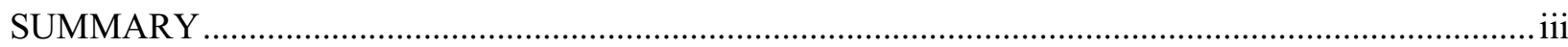

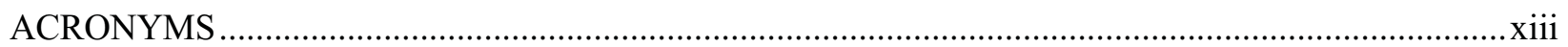

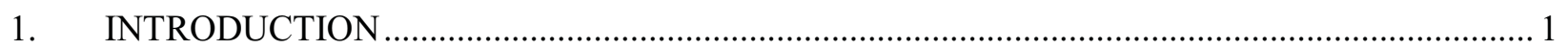

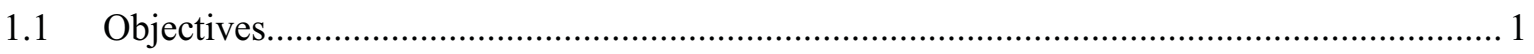

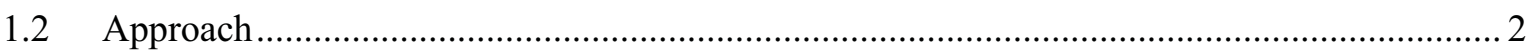

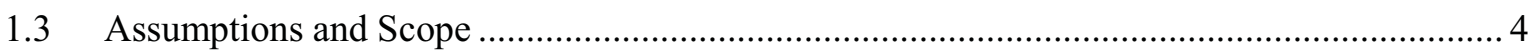

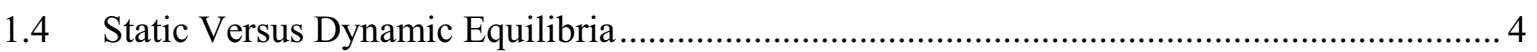

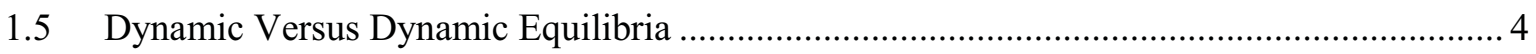

1.6 Separation and Waste Management Chemistry Considerations............................................ 5

1.7 Which Isotopes are Tracked in Fuel Cycle Simulation? ........................................................ 6

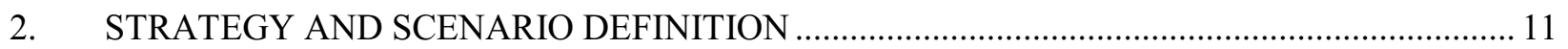

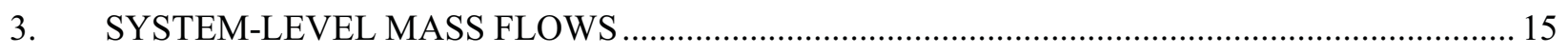

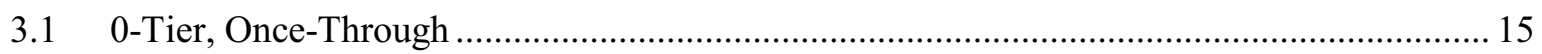

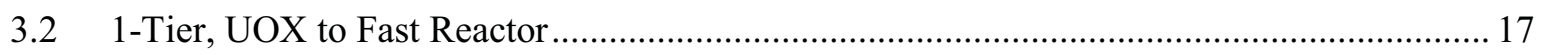

3.3 2-Tier, UOX to MOX-Pu to Fast Reactor.............................................................................. 22

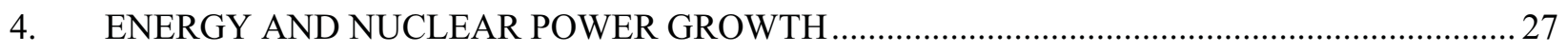

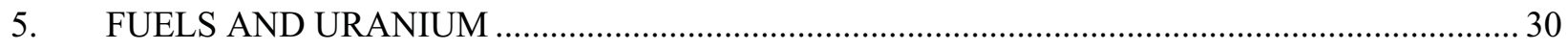

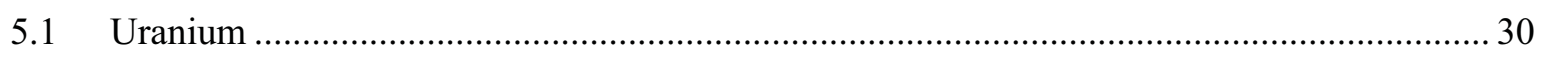

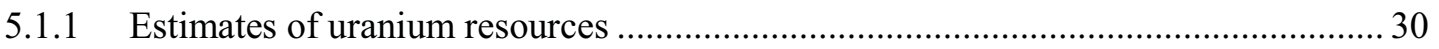

5.1.2 Estimates of uranium cost as uranium resources are used .................................... 31

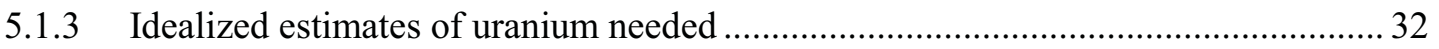

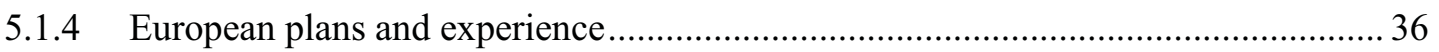

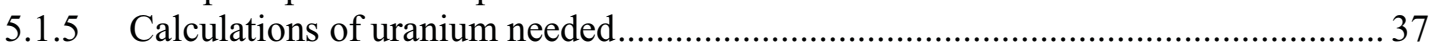

5.2 Multiple Recycles of One or More Transuranic Elements................................................... 40

5.3 Impact of LWR UOX Burnup on Heat Generation........................................................ 47

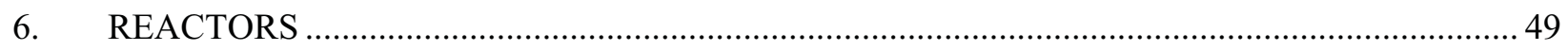

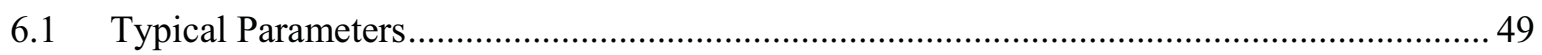

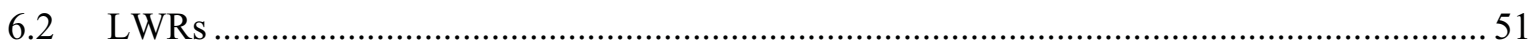

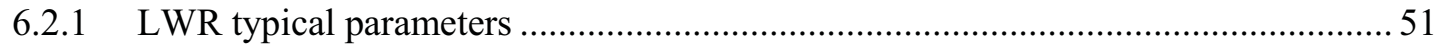

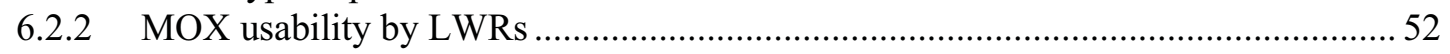

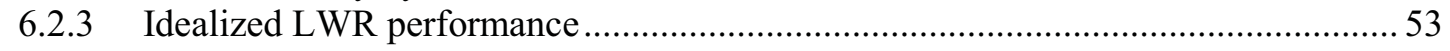

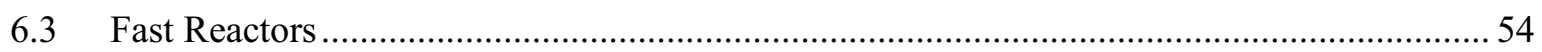

6.3.1 Fast reactor typical parameters ……...................................................... 54

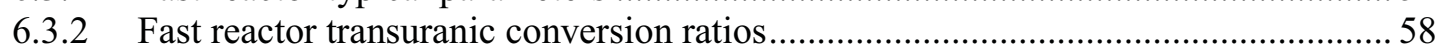

6.3.3 Dependences among conversion ratio, cycle length, and capacity factor...................59

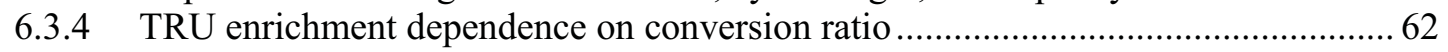

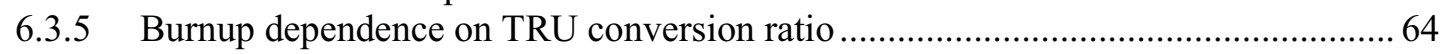

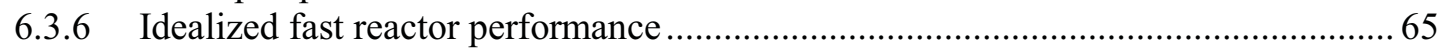




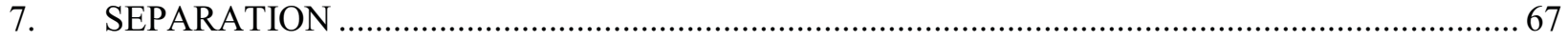

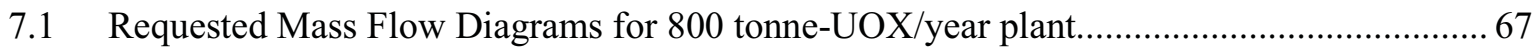

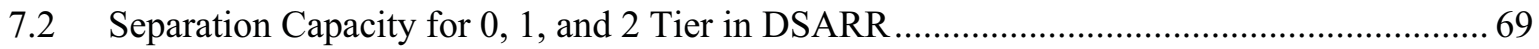

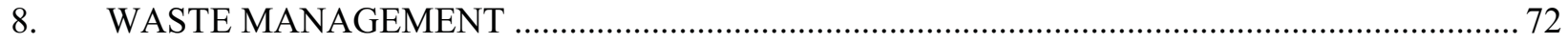

8.1 Basic Characterization of Used Nuclear Fuel .................................................................. 72

8.2 Used Nuclear Fuel, TRU, and Radiotoxicity …............................................................. 74

8.3 Radiotoxicity and Heat Impact from Minor Actinides....................................................... 78

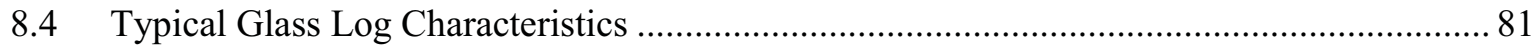

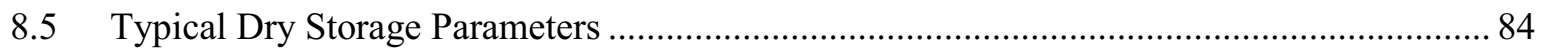

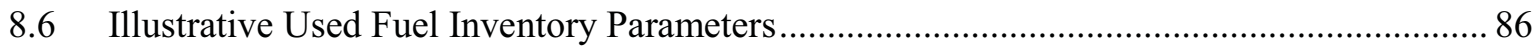

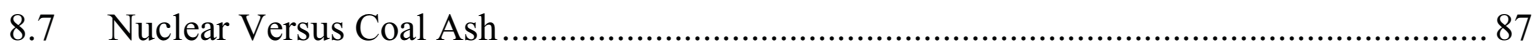

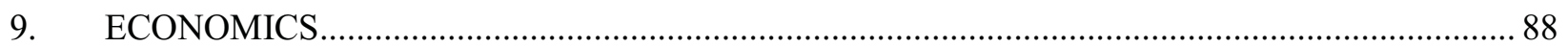

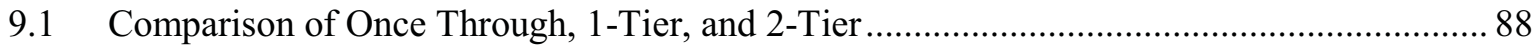

9.2 Impact of Uncertainties for Once Through, 1-Tier, and 2-Tier........................................... 94

9.3 Contribution to Fuel Cycle Cost for Once Through, 1-Tier, and 2-Tier ............................ 103

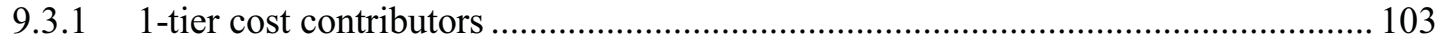

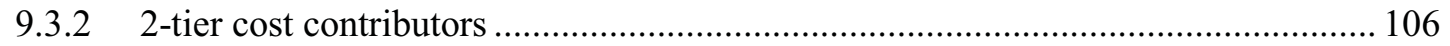

9.4 Closing the Gap between Recycle and Once Through.................................................. 106

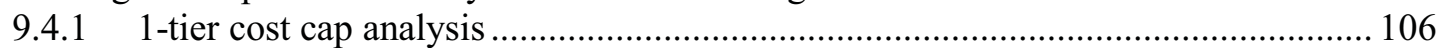

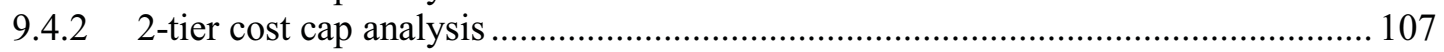

9.5 Dynamic versus Static Economic Comparisons at Different Conversion Ratios ................ 108

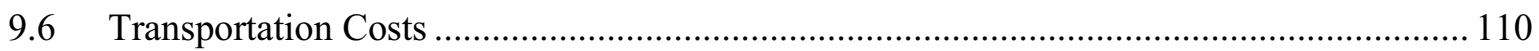

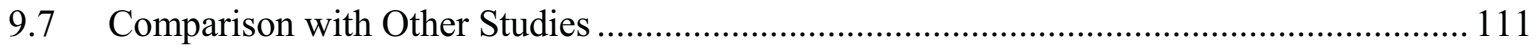

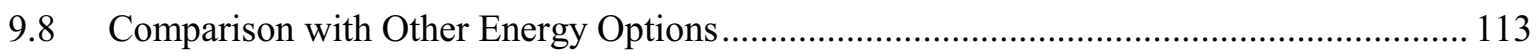

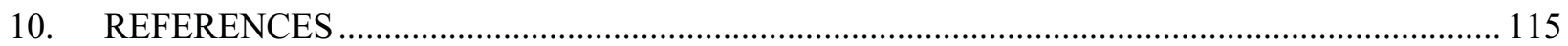

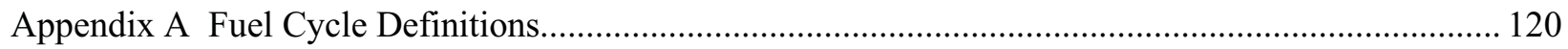

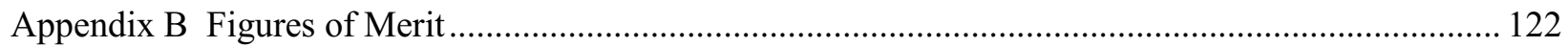

\section{FIGURES}

Figure 1-1. The nuclear fuel cycle as seen from the fuel cycle system analysis perspective in the

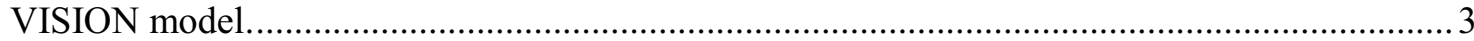

Figure 1-2. Periodic Table as seen from fuel cycle system analysis perspective. [Piet2009]..................... 6

Figure 1-3. Accumulation of transuranic elements from initial uranium (or thorium)........................... 10

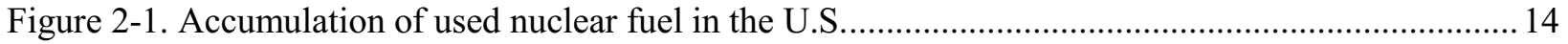

Figure 2-2. Trends for used fuel discharge, fuel burnup, and nuclear electricity generated..................... 14

Figure 3-1. Once through, static equilibrium using DSARR parameters.............................................. 16

Figure 3-2. Once through, dynamic equilibrium using DSARR input parameters ................................. 16 
Figure 3-3. 1-tier recycle (UOX to FR), static equilibrium using DSARR parameters

Figure 3-4. 1-tier recycle (UOX to FR), dynamic equilibrium using DSARR results $(1.75 \%$ nuclear growth/yr); the LWR/fast reactor partition has changed from static equilibrium.

Figure 3-5. 2-tier recycle (UOX to MOX-RU-Pu to FR), static equilibrium using DSARR parameters, except MOX recipe updated from MOX-NU-Pu to MOX-RU-Pu

Figure 3-6. 2-tier recycle (UOX to MOX-RU-Pu to FR), dynamic equilibrium using DSARR results $(1.75 \%$ nuclear growth/yr)

Figure 4-1. U.S. commercial nuclear power plants: (a) number, (b) capacity, (c) electricity generated, (d) percent of U.S. electricity generated by nuclear, and (e) average capacity factor.

Figure 4-2. Annual growth in U.S. total electricity..... .28

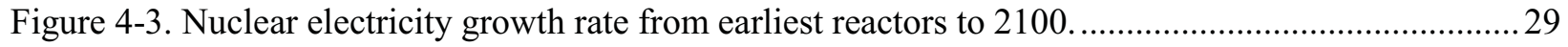

Figure 5-1. Illustrative pictures of uranium oxide, fuel pellet, and fuel assembly................................... 30

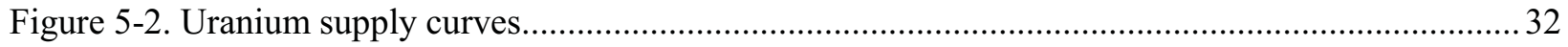

Figure 5-3. Percent of RU and DU from LWRs that are used as fast reactor fuel with fast reactors

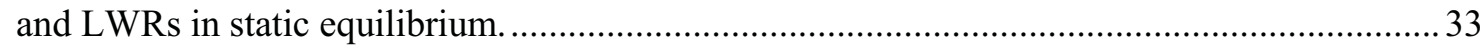

Figure 5-4. Annual uranium use for once-through LWR UOX as function of burnup............................. 34

Figure 5-5. Annual fuel and separative work units (SWU) for once through UOX as function of burnup.

Figure 5-6. Required U235 enrichment for once through UOX as function of burnup.

Figure 5-7. History of U.S. burnup for once through UOX as function of burnup. Government data do not extend past 2002. Burnup has been increasing $\sim 1 \mathrm{MW}$-day $/ \mathrm{kg}$ per year.

Figure 5-8. Static equilibrium versus VISION-calculated uranium improvement factors integrated over 2000-2100 relative to once-through uranium oxide in LWRs (51 GWth-day/tonne burnup).

Figure 5-9. Sustainable fast breeder reactor growth rate as a function of total turnaround time, assuming a fast reactor TRU CR of 1.3 is achievable. While fast breeders are displacing other reactors, the nuclear power growth rate will be lower than the fast breeder reactor growth rate shown here......

Figure 5-10. Required fast reactor TRU conversion ratio to allow nuclear power growth with requiring TRU supply from LWRs (and hence without uranium enrichment). While fast breeders are displacing other reactors, the nuclear power growth rate will be lower than the fast breeder reactor growth rate shown here.

Figure 5-11. Gamma energy emission as a function of number of recycles of $\mathrm{Pu}, \mathrm{NpPu}, \mathrm{NpPuAm}$, or all-TRU for heterogeneous IMF, MOX, or oxide-fueled $\mathrm{CR}=0.50$ fast reactor. "Eq" means equilibrium.

Figure 5-12. Neutron emission as a function of number of recycles of $\mathrm{Pu}, \mathrm{NpPu}, \mathrm{NpPuAm}$, or TRU for heterogeneous IMF, MOX, or oxide-fueled $\mathrm{CR}=0.50$ fast reactor. "Eq" means equilibrium.

Figure 5-13. Equilibrium isotopic mix of input metal fuel, as function of TRU conversion ratio. 
Figure 5-14. Equilibrium isotope mix of output fuel as function of which transuranic elements are recycled in an oxide-fueled fast reactor at $\mathrm{CR}=0.50$.

Figure 5-15. Equilibrium isotopic mix as function of which transuranic elements are recycled in LWR via homogeneous MOX or heterogeneous IMF (each assembly has a mix of UOX and IMF pins). 45

Figure 5-16. Equilibrium isotope mix as recycled in illustrative LWR and fast reactor cases. 46

Figure 5-17. Isotopic mix for MOX-TRU as a function of how many times transuranic material is

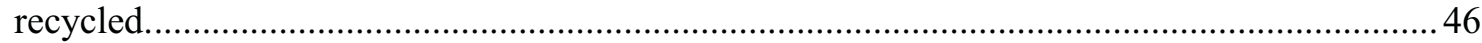

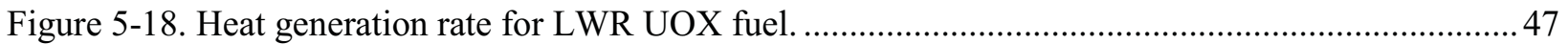

Figure 5-19. Heat generation of LWR UOX-33, UOX-51, MOX-Pu, and MOX-NpPu......................... 48

Figure 6-1. Fast reactor percentage of nuclear electricity generated for 1-tier DSARR parameters, static versus dynamic equilibrium. .58

Figure 6-2. Transuranics reduction between 2000 and 2100 with a 1-tier fuel cycle as a function of conversion ratio. [DSARR2008] 59

Figure 6-3. Reactivity swing as function of fast reactor TRU conversion ratio. [Hoffman2006] .............. 60

Figure 6-4. Planned outages and capacity factor as function of cycle length. ...................................... 61

Figure 6-5. Outages and capacity factor dependence on fast reactor TRU conversion ratio. 62

Figure 6-6. Transuranic enrichment dependence on fast reactor TRU conversion ratio. [Hoffman2006]

Figure 6-7. Dilution factor of TRU in total fuel as function of fast reactor TRU conversion ratio. 64

Figure 6-8. Burnup per initial heavy metal as function of fast reactor TRU conversion ratio; in these units burnup does not vary significantly from first to equilibrium recycle pass.

Figure 6-9. Burnup per mass of TRU in the initial fuel as function of fast reactor TRU conversion ratio.

Figure 7-1. Static equilibrium for first 800 tonne-UOX/yr separation plant in the 2-tier (UOX to MOX-RU-Pu to FR) strategy.....

Figure 7-2. Variant of figure 7-1 (800 tonne-UOX/yr separation plant) for all waste streams and minor actinides $(\mathrm{Np}, \mathrm{Am}$, and $\mathrm{Cm})$ to be made into HLW....

Figure 7-3. Variant of figure 7-1 (800 tonne-UOX/yr separation plant) maximizing recycle of materials and minimizing waste into HLW, requires cleaning lanthanides sufficient to meet Class C criteria.

Figure 7-4a. Nominal 1-tier separation capacity for used fuel, expressed in tonnes of iHM.................... 70

Figure 7-4b. Nominal 1-tier separation capacity for used fuel, expressed in tonnes of TRU................... 70

Figure 7-5a. Nominal 2-tier separation capacity for used fuel, expressed in tonnes of iHM.................... 71

Figure 7-5b. Nominal 2-tier separation capacity for used fuel, expressed in tonnes of TRU................... 71

Figure 8-1. Mass of fission products, uranium, transuranics, and decay products for $51 \mathrm{GWth}-$ day/tonne-iHM used uranium oxide fuel. $\mathrm{He}, \mathrm{Pb}$, and $\mathrm{Bi}$ are stable U/TRU decay products. Uranium is always $\sim 99 \%$ of the total mass and is difficult to see in the graph. ........ 72

Figure 8-2. Stable versus radioactive fission products for $51 \mathrm{GWth}-$ day/tonne-iHM used uranium oxide fuel. 
Figure 8-3. Transuranic elements and decay products for $51 \mathrm{GWth}$-day/tonne-iHM used uranium oxide fuel. Uranium is always $\sim 99 \%$ of the total mass and is not shown................................. 74

Figure 8-4. Location of used nuclear fuel for 0 -tier, once through...................................................... 75

Figure 8-5. Location of transuranic material for 0 -tier, once through. .................................................. 75

Figure 8-6. Location of radiotoxicity (evaluated 1000 years later) for 0 -tier, once through. .................... 75

Figure 8-7. Location of used nuclear fuel for 1-tier, $\mathrm{UOX}$ to $\mathrm{CR}=0.50$ fast reactor.............................. 76

Figure 8-8. Location of transuranic material for 1-tier, $\mathrm{UOX}$ to $\mathrm{CR}=0.50$ fast reactor.......................... 76

Figure 8-9. Location of radiotoxicity (evaluated 1000 years later) for 1-tier, $\mathrm{UOX}$ to $\mathrm{CR}=0.50$ fast

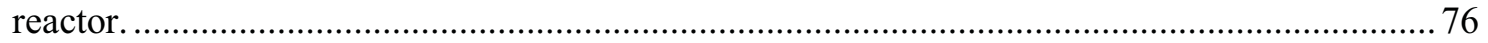

Figure 8-10. Location of used nuclear fuel for 2-tier, $\mathrm{UOX}$ to $\mathrm{MOX}-\mathrm{Pu}$ to $\mathrm{CR}=0.50$ fast reactor............. 77

Figure 8-11. Location of transuranic material for 2-tier, $\mathrm{UOX}$ to MOX-Pu to $\mathrm{CR}=0.50$ fast reactor.

Figure 8-12. Location of radiotoxicity (evaluated 1000 years later) for 2-tier, UOX to MOX-Pu to

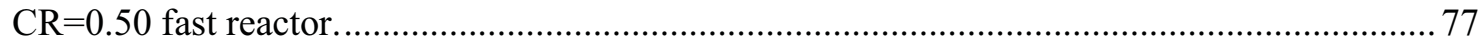

Figure 8-13. Radiotoxicity of fission product radiotoxicity from UOX-51 .......................................... 78

Figure 8-14. Radiotoxicity of fission product radiotoxicity from UOX-51 as function of minor

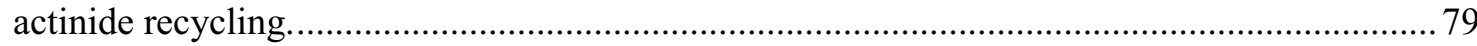

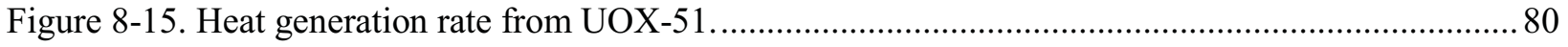

Figure 8-16. Heat generation rate from UOX-51 as function of minor actinide recycling...................... 81

Figure 8-17. Holtec International HI-STORM dry storage casks on storage pad, note vertical storage. [from Holtec International website]

Figure 8-18. Transnuclear NUHOMS design, note horizontal storage, thereby allowing stacking.

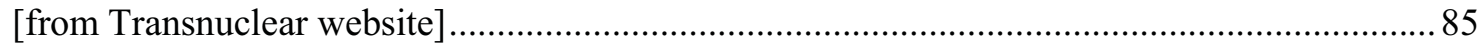

Figure 9-1. Total cost of electricity for once-through, 1-tier, and 2-tier cases. [Shropshire2009] ............. 88

Figure 9-2. Fuel cycle cost of electricity for once-through, 1-tier, and 2-tier cases; vertical lines show the average cost of each of the three options. [Shropshire2009]

Figure 9-3. Static equilibrium economic analysis for once through and 1-tier cases.

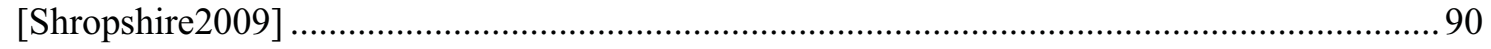

Figure 9-4. Static equilibrium economic analysis for the 2-tier case. [Shropshire2009] .........................91

Figure 9-5. Reactor cost of electricity for once-through, 1-tier, and 2-tier cases; vertical lines show the average cost of each of the three options. [Shropshire2009].....

Figure 9-6. Total cost of electricity (TCOE) for once-through, showing impact of uncertainties, which are treated as independent of each other. [Shropshire2009]

Figure 9-7. Fuel cycle component of the cost of electricity for once-through, showing impact of uncertainties, which are treated as independent of each other. [Shropshire2009]

Figure 9-8. Fuel cycle component of the cost of electricity for 1-tier recycle cases, showing impact of uncertainties, which are treated as independent of each other.

[Shropshire2009] 
Figure 9-9. Fuel cycle component of the cost of electricity for 2-tier recycle cases, showing impact of uncertainties, which are treated as independent of each other.

[Shropshire2009]

Figure 9-10. Influence of uranium ore cost uncertainty on once-through, 1-tier, and 2-tier fuel cycle cost, using data from [Shropshire2009]. Recall that most of the system-wide fuel in 1-tier and 2-tier remains nominal uranium oxide. .98

Figure 9-11. Influence of uranium enrichment cost uncertainty on once-through, 1-tier, and 2-tier fuel cycle cost, using data from [Shropshire2009]. 98

Figure 9-12. Influence of LWR UOX fuel fabrication cost uncertainty on once-through and 1-tier fuel cycle costs, using data from [Shropshire2009]....

Figure 9-13. Influence of LWR MOX fuel fabrication cost uncertainty on once-through, 1-tier, and 2-tier fuel cycle costs, using data from [Shropshire2009]. No data markers are shown on once through or 1-tier because they have no MOX and therefore they have no sensitivity to this input parameter.

Figure 9-14. Influence of cost uncertainties of aqueous separation (a) and electrochemical separation and metal fuel fabrication (b) cost on once-through, 1-tier, and 2-tier fuel cycle cost, using data from [Shropshire2009].

Figure 9-15. Influence of the cost uncertainty of depleted uranium disposition on once-through, 1tier, and 2-tier fuel cycle costs, using data from [Shropshire2009].

Figure 9-16. Influence of the cost uncertainty of managed decay storage (CsSr) on once-through, 1-tier, and 2-tier fuel cycle costs, using data from [Shropshire2009]. No data markers are shown on the once through curve because it has no managed decay storage, thus, it has no sensitivity to this input parameter..

Figure 9-17. Influence of the cost uncertainty of aqueous GTCC metal alloy waste conditioning on once-through, 1-tier, and 2-tier fuel cycle costs, using data from [Shropshire2009]. No data markers are shown on the once through curve because it has no GTCC metal alloy waste, thus, it has no sensitivity to this input parameter.

Figure 9-18. Influence of the cost uncertainty of electrochemical HLW metal alloy waste conditioning on once-through, 1-tier, and 2-tier fuel cycle costs, using data from [Shropshire2009]. No data markers are shown on the once through curve because it has no HLW metal alloy waste, thus, it has no sensitivity to this input parameter.

Figure 9-19. Influence of geologic repository cost uncertainty on once-through, 1-tier, and 2-tier fuel cycle costs, using data from [Shropshire2009]. Caution, the waste masses differ significantly among cases.

Figure 9-20. Contribution to fuel cycle cost for once-through; DUF6 is depleted uranium hexafluoride, the tails remaining after uranium enrichment.[Shropshire2009]

Figure 9-21. Contribution among LWR steps to fuel cycle cost for 1-tier showing that chemical separation cost dominates; DUF6 is depleted uranium hexafluoride, the tails remaining after uranium enrichment. [Shropshire2009].

Figure 9-22. Contribution among UREX-1a reprocessing steps to fuel cycle cost for 1-tier.

[Shropshire2009] $\mathrm{C} \& \mathrm{P}=$ conditioning and packaging, $\mathrm{FP}==$ fission products.

Figure 9-23. Contribution among fast reactor fuel cycle steps to fuel cycle cost for 1-tier, showing that separation and fabrication dominates disposal.[Shropshire2009] 
Figure 9-24. Contribution among fast reactor metal fuel separation and fuel fabrication to fuel cycle cost for 1-tier.[Shropshire2009] $\mathrm{C} \& \mathrm{P}=$ conditioning and packaging.

Figure 9-25. Contribution to fuel cycle cost for 2-tier, showing that MOX fabrication and aqueous

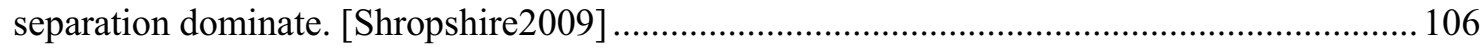

Figure 9-26. Closing the gap from 1-tier to once-through costs. [Shropshire2009] ............................... 107

Figure 9-27. Closing the gap from 2-tier to once-through costs. [Shropshire2009] ............................... 108

Figure 9-28. Dynamic analysis of the total annual cost of electricity and fuel cycle cost. [Shropshire2009]

Figure 9-29. Dynamic analysis (VISION) versus static (G4-ECON) total cost comparison for different fast reactor conversion ratios. [Shropshire2009]

Figure 9-30. Dynamic analysis (VISION) versus static (G4-ECON) fuel cycle cost comparison for different fast reactor conversion ratios. [Shropshire2009] .............................................. 110

Figure 9-31. Transportation costs. [Shropshire2009]

Figure 9-32. Probability distribution of total cost of electricity; all but the MIT case are a probability distribution. The MIT result is a point estimate, which is shown as a vertical line.[Shropshire2009]

Figure 9-33. Probability distribution of fuel cycle costs; all but the MIT case are a probability distribution. The MIT result is a point estimate, which is shown as a vertical line. [Shropshire2009]

Figure 9-34. Nuclear energy TCOE compared to other future baseline energy, shown as probability distributions. [Shropshire2009].

\section{TABLES}

Table 1-1. Factors Enabling or Inhibiting Development of Dynamic Equilibria...................................... 5

Table 1-2. Isotopes and Chemical Elements Tracked in the VISION Model ........................................... 8

Table 2-1. Fuel Cycle Strategies Analyzed in DSARR [Dixon2008] ..................................................... 11

Table 2-2. Overall Time Line and Specifications for Nominal Scenarios [DSARR2008,

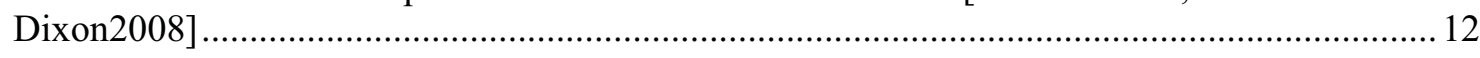

Table 2-3. Parameters Defining Representative Scenarios [DSARR2008] ............................................. 13

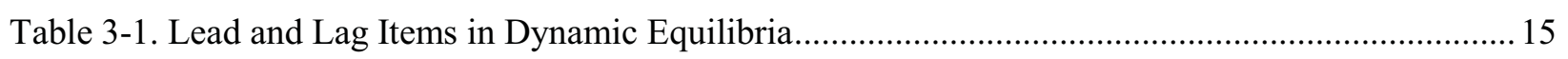

Table 3-2. Dynamic versus Static Equilibrium Comparison for Once Through...................................... 17

Table 3-3. Dynamic versus Static Equilibrium Comparison for 1-Tier, UOX to FR - Overall

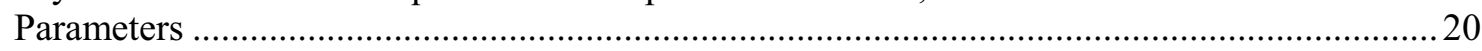

Table 3-4. Dynamic versus Static Equilibrium Comparison for 1-Tier, UOX to FR ..............................2

Table 3-5. Dynamic versus Static Equilibrium Comparison for 1-Tier, UOX to FR - Overall

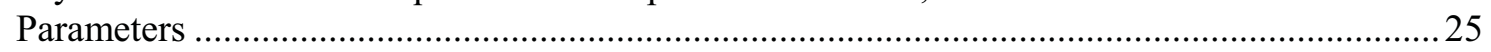

Table 3-6. Dynamic versus Static Equilibrium Comparison for 1-Tier, UOX to FR ...............................26

Table 5-1. World Potential Uranium Resources ....................................................................................... 31 
Table 6-1. Representative Parameters for Typical Nuclear Power Plant Types ...................................... 49

Table 6-2. Representative Derived Parameters for Typical Nuclear Power Plant Types ......................... 51

Table 6-3. Representative PWR Fuel Assembly Parameters in Transmutation Analyses [Hoffman2005] 52

Table 6-4. Thermal Reactor Safety Constraints on MOX/IMF [Todosow2005] ....................................53

Table 6-5. Void Coefficient Constraint on LWR [Youinou2009a] .........................................................53

Table 6-6. Idealized LWR Input used in Transmutation Analyses .53

Table 6-7. Representative Fast Reactor Assembly Dimensions used in Transmutation Analyses [Hoffman2006] .55

Table 6-8. Representative Metal-Fueled Assembly Design Parameters [Hoffman2006] .........................56

Table 6-9. Representative Oxide-Fueled Assembly Design Parameters [Hoffman2006].........................57

Table 6-10. Mass Balance of Startup and Equilibrium Fast Reactor Cores [Hoffman2006] ..................... 57

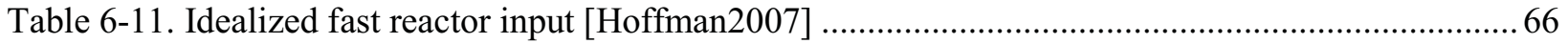

Table 8-1. When Disposed Material Falls to the Radiotoxicity of Natural Uranium Ore (years after disposal) 79

Table 8-2. Chemical Composition (Wt \%) of HLW Glasses [Table 1.5.1-14 from YMLA2008] ............. 81

Table 8-3. Approximate Mass of HLW per Canister [Table 1.5.1-15 from YMLA2008] …....................83

Table 8-4. Approximate Mass of HLW per Canister [Table 1.5.1-16 from YMLA2008] ....................... 83

Table 8-5. Waste Package Configurations [Table 1.5.2-1 from YMLA2008] …....................................85

Table 8-6. Breakdown of Waste Package Configurations [Table 1.5.2-2 from YMLA2008]................... 86

Table 8-7. Summary of Repository Inventory [Table 1.5.1-1 of YMLA2008] …...................................86

Table 8-9. Thermal Power of the Average and Bounding Pressurized Water Reactor and Boiling Water Reactor Fuel Assemblies [Table 1.5.1-11 of YMLA2008] 87

Table 9-1. Key Economic Input Parameters. [Shropshire2009] 


\section{ACRONYMS}

\begin{tabular}{|c|c|}
\hline ANL & Argonne National Laboratory \\
\hline BNL & Brookhaven National Laboratory \\
\hline BWR & Boiling Water Reactor \\
\hline $\mathrm{BU}$ & Burnup (MWth-day/kg-iHM or equivalently GWth-day/tonne-iHM) \\
\hline COEX & Co-extraction of $\mathrm{U}$ and $\mathrm{Pu}$ \\
\hline CR & Transuranic conversion ratio (similar but not identical to breeding ratio) \\
\hline $\mathrm{CY}$ & Calendar year (365.25 days) \\
\hline DU & Depleted uranium \\
\hline Echem & Electrochemical separation process (a.k.a. pyroprocessing) \\
\hline EFPD & Effective full power days = capacity factor times calendar days \\
\hline EFPY & Effective full power years = capacity factor times calendar years \\
\hline EU & Enriched uranium \\
\hline $\mathrm{Eq}$ & Equilibrium \\
\hline FP & Fission product \\
\hline FR & Fast reactor \\
\hline FR-ox & Oxide fast reactor fuel \\
\hline FR-mtl & Metal fast reactor fuel \\
\hline FR-NpPu & Fast reactor fuel with $\mathrm{Np}, \mathrm{Pu}$, and no other transuranic elements \\
\hline FR-NpPuAm & Fast reactor fuel with $\mathrm{Np}, \mathrm{Pu}, \mathrm{Am}$, and no other transuranic elements \\
\hline FR-Pu & Fast reactor fuel and no other transuranic elements \\
\hline FR-TRU & Fast reactor fuel with all the transuranic elements \\
\hline GWe & Gigawatt-electric (one billion watts of electricity) \\
\hline GWth & Gigawatt-thermal (one billion watts of heat) \\
\hline HTGR & High temperature cooled gas reactor \\
\hline HWR & Heavy water reactor \\
\hline $\mathrm{iHM}$ & Initial heavy metal (heavy metal in fresh, unirradiated fuel) \\
\hline IMF & Inert matrix fuel (uranium free) \\
\hline IMF-NpPu & Inert matrix fuel with $\mathrm{Np}, \mathrm{Pu}$, and no other transuranic elements \\
\hline IMF-NpPuAm & Inert matrix fuel with $\mathrm{Np}, \mathrm{Pu}, \mathrm{Am}$, and no other transuranic elements \\
\hline IMF-Pu & Inert matrix fuel and no other transuranic elements \\
\hline IMF-TRU & Inert matrix fuel with all the transuranic elements \\
\hline INL & $\begin{array}{l}\text { Idaho National Laboratory or its predecessor laboratories INEL (Idaho National } \\
\text { Engineering Laboratory) or INEEL (Idaho National Engineering and Environmental } \\
\text { Laboratory) }\end{array}$ \\
\hline Ln & Lanthanide elements \\
\hline LWR & Light water reactor \\
\hline MA & Minor actinides (Np, Am, Cm, Bk, Cf) \\
\hline MOX & Mixed oxide fuel \\
\hline $\mathrm{MOX}-\mathrm{NpPu}$ & Mixed oxide fuel with $\mathrm{Np}, \mathrm{Pu}$, and no other transuranic elements \\
\hline MOX-NpPuAm & Mixed oxide fuel with $\mathrm{Np}, \mathrm{Pu}, \mathrm{Am}$, and no other transuranic elements \\
\hline $\mathrm{MOX}-\mathrm{Pu}$ & Mixed oxide fuel with $\mathrm{Pu}$ and no other transuranic elements \\
\hline MOX-TRU & Mixed oxide fuel with all the transuranic elements \\
\hline MT & Not used because some studies use it as metric tonne others as million ton/tonnes \\
\hline MWe & Megawatt-electric (one million watts of electricity) \\
\hline MWth & Megawatt-thermal (one million watts of heat) \\
\hline NA & Not applicable \\
\hline
\end{tabular}




\begin{tabular}{|c|c|c|c|c|c|c|c|}
\hline NU & \multicolumn{7}{|l|}{ Natural uranium } \\
\hline ORNL & \multicolumn{7}{|c|}{ Oak Ride National Laboratory } \\
\hline $\mathrm{P}$ & \multicolumn{7}{|c|}{ Recycle pass (not to be confused with batch) } \\
\hline $\mathrm{P} 0$ or $\mathrm{p}=0$ & \multicolumn{7}{|c|}{ Unrecycled material, i.e., uranium-based fuel } \\
\hline $\mathrm{P} 1$ or $\mathrm{p}=1$ & \multicolumn{7}{|c|}{$\begin{array}{l}\text { Startup recycle pass, reactor in equilibrium with feed material from separated } \\
\text { uranium-based fuel, i.e., first use of recycled material }\end{array}$} \\
\hline Pn or $\mathrm{p}=\mathrm{n}$ & \multicolumn{7}{|c|}{$\begin{array}{l}\text { Nth recycle pass, reactor in equilibrium with feed material that has been through } \\
\text { reactors } n-1 \text { times }\end{array}$} \\
\hline PWR & \multicolumn{7}{|c|}{ Pressurized water reactor } \\
\hline RU & \multicolumn{7}{|l|}{ Recovered uranium } \\
\hline SFR & \multicolumn{7}{|c|}{ Sodium fast cooled reactor } \\
\hline SNF & \multicolumn{7}{|c|}{ Spent nuclear fuel (used fuel) } \\
\hline $\mathrm{t}$ & \multicolumn{7}{|l|}{ Time } \\
\hline TAD & \multicolumn{7}{|c|}{ Transportation, Aging, and Disposal package } \\
\hline TBD & \multicolumn{7}{|l|}{ To be determined } \\
\hline TM & \multicolumn{7}{|l|}{ Transition metal } \\
\hline Tonne & \multicolumn{7}{|l|}{$1000 \mathrm{~kg}$, metric ton } \\
\hline TRU & \multicolumn{7}{|l|}{ Transuranic elements } \\
\hline $\mathrm{UOX}$ or $\mathrm{UO}_{2}$ & \multicolumn{7}{|l|}{ Uranium oxide fuel } \\
\hline UOX-nn & \multicolumn{7}{|c|}{ Uranium oxide fuel with nn MWth-day/kg-iHM burnup } \\
\hline UREX & \multicolumn{7}{|c|}{ Uranium Extraction separation process } \\
\hline UREX+1 & UREX producing ... & $\mathrm{U}$ & Tc & $\mathrm{CsSr}$ & $\begin{array}{l}\text { TRU ( } \\
\text { without }\end{array}$ & $\begin{array}{l}\text { with or } \\
\text { t Ln) }\end{array}$ & Other fission products \\
\hline UREX+2 & UREX producing ... & $\mathrm{U}$ & Tc & $\mathrm{CsSr}$ & $\mathrm{NpPu}$ & $\mathrm{AmCm}+\mathrm{Ln}$ & Other fission products \\
\hline UREX+3 & UREX producing ... & $\mathrm{U}$ & Tc & $\mathrm{CsSr}$ & $\mathrm{NpPu}$ & $\mathrm{AmCm}$ & Other fission products \\
\hline UREX+4 & UREX producing ... & $\mathrm{U}$ & $\mathrm{Tc}$ & $\mathrm{CsSr}$ & $\mathrm{NpPu}$ & \begin{tabular}{l|l}
$\mathrm{Am}$ & $\mathrm{Cm}$ \\
\end{tabular} & Other fission products \\
\hline VHTR & Very high temperature & rec & tor & & & & \\
\hline VISION & Verifiable Fuel Cycle & Sin & llati & n dyna & iic fuel c & cycle model & \\
\hline $\mathrm{W}$ & Watt & & & & & & \\
\hline Yr & $\begin{array}{l}\text { Year (generally "year' } \\
\text { and effective full pow }\end{array}$ & & & $\begin{array}{l}\text { dar year } \\
\text { s obviou }\end{array}$ & $\begin{array}{l}\text { When the } \\
\text { s) }\end{array}$ & differentia & between calendar year \\
\hline
\end{tabular}




\section{FUEL CYCLE S YS TEMS ANALYS IS HANDBOOK}

\section{INTRODUCTION}

This Handbook aims to improve understanding and communication regarding nuclear fuel cycle options. The Handbook generally does not include details on calculations, which can be found by consulting references provided to the reader. The Handbook emphasizes graphics and diagrams, with only enough text to explain the graphic, to ensure that the messages associated with the graphic is clear, to explain key assumptions and methods that impact the graphed results, and to provide any cautions about using the graphic or over-generalizing its implications.

Because of the graphical focus of the Handbook, recognize several different types of diagrams.

- "Static equilibrium" is a description (such as mass flows) of an unchanging system in equilibrium with an unchanging environment, i.e., neither internal nor external changes. The static equilibrium is a theoretical concept that never happens in the real world but such calculations are nonetheless a useful way to understand and compare systems without the complexities of system or environmental changes. Also provides the relative values of the components of a given fuel cycle independent of when they occur in time, if the fuel cycle were to be run to completion. Static equilibrium tells us some of the end point characteristics of a fuel cycle

- "Dynamic equilibrium" is a description of a changing system in equilibrium with a changing environment, i.e., with internal and/or external changes. Dynamic equilibrium results can vary significantly from static equilibrium results. Although dynamic equilibrium calculations are also a theoretical concept, they are more representative of what the system is expected to look like toward the end of this century if a given fuel cycle is adopted. Dynamic equilibrium tells us the steady state condition of the system during the expansion phase that is envisioned in the latter half of the $21^{\text {st }}$ century.

- Plots of time-dependent parameters are depictions of one or more relevant parameters such as the number of fast reactors or uranium usage versus time. These are generally calculated by the VISION model [Jacobson2009, Jacobson2008, Jacobson2007, Jacobson2006, Yacout2006] for the time period 2000 to 2100 .

- Plots of parameters versus other parameters show tradeoffs.

\subsection{Objectives}

The Handbook provides a source to DOE of key results for 0-tier, 1-tier, and 2-tier fuel cycles, specifically to ...

- Catalog results of analyses requested by DOE and others, esp. "ad hoc" ones so that we have a repository of them. We want the results to be as internally consistent as possible, but nonetheless this will be a living document and assumptions for one purpose may be inappropriate for others.

- Make key assumptions understandable and reference able - thus providing a list of references that document "how to" do fuel cycle system analysis, including assumptions, parameters, methods, and software (and version) used. In this sense, it will be a useful reference for fuel cycle system analysts.

The Handbook is not ...

- A primer on fuel cycles or their system components

- A primer on how to do fuel cycle system analyses

- A technical basis document 
- A list of baseline fuel cycle parameters

- A comparison of fuel cycle options

- A comprehensive distillation of all system analysis results

- A totally consistent description of fuel cycle options - differences in assumptions will be noted, but no attempt has been made to reconcile assumptions that may differ from one purpose to another.

\subsection{Approach}

The first sections of the Handbook are the introduction, fuel cycle strategies, and system-level mass flows; each pertains to an entire fuel cycle system. The bulk of the Handbook follows the basic fuel cycle information and mass flow: nuclear energy growth, fuels (including uranium supply), reactors, separation, and finally waste management. Each section will eventually contain various results, with these additional pieces of information.

- The key inputs influencing those particular results.

- Where the detailed assumptions, parameters, methods, and software deviate from the assumptions used in Dynamic Systems Analysis Report for Nuclear Fuel Recycle (DSARR) [DSARR2008].

- If not a published report, the categorization of the "rigor" that was associated with the given analysis, e.g., was purpose quick and dirty, exploratory/scoping, screening/comparative calculation (where the emphasis is on relative values more than absolute), technical-report quality, design calculation.

Figure 1-1 shows the structure of the VISION model and the fuel cycle system analysis economic database.[Shropshire2008, EAWG2008, EAWG2007] The flow starts with fuel supply, goes to fuel fabrication, then reactors, separation, and then both fuel fabrication again and waste management. To the extent practical, the information in this Handbook is organized in the same fashion. 


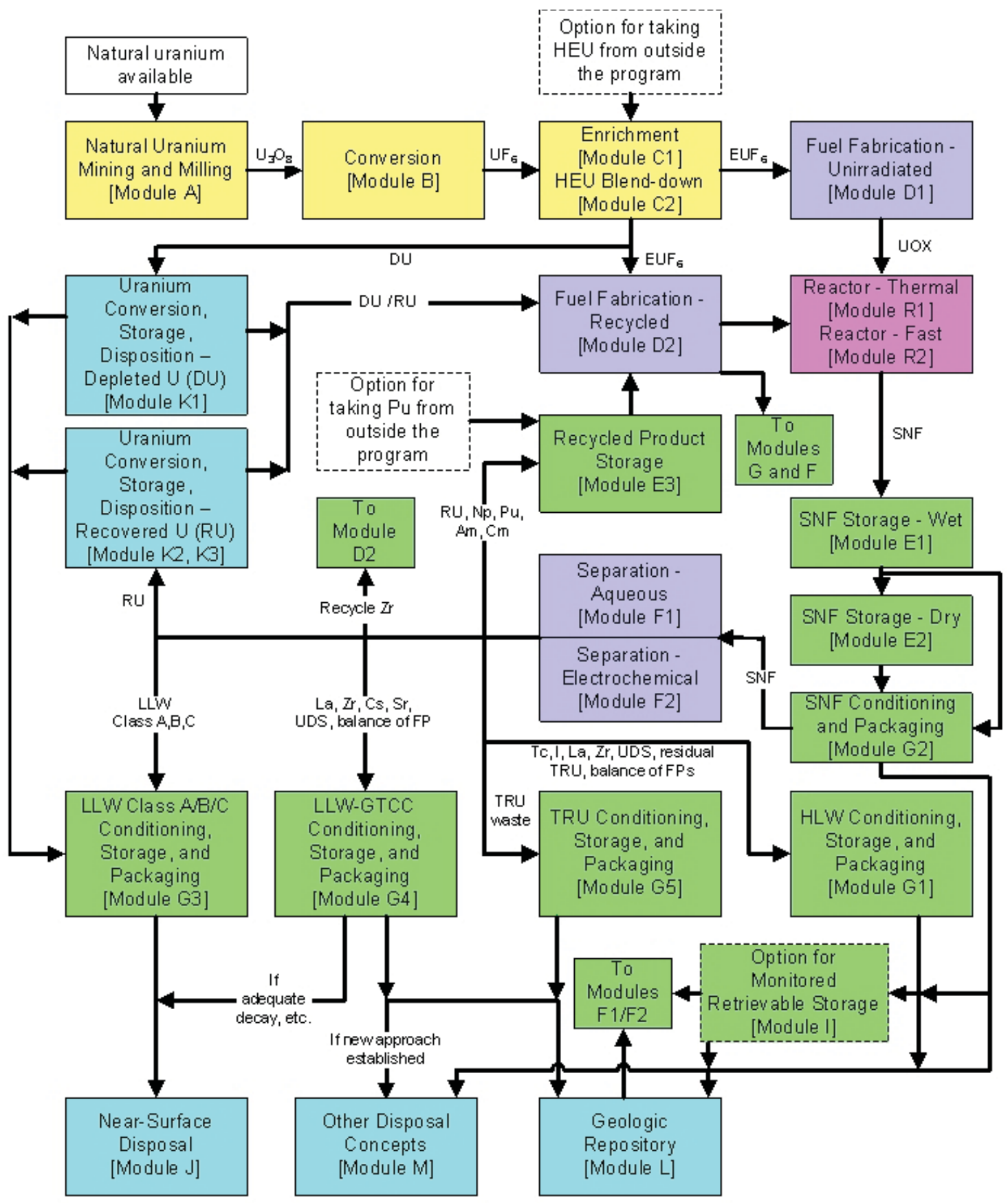

Transportation Processes for High-Level Radioactive Materials (SNF, HLW, TRU, LLW-GTCC, recycled fuel) [Module 01]

Transportation Processes for Low-Level Radioactive Materials (LLW-near-surface, unirradiated fuel, RU, DU, EU) [Module 02]

Figure 1-1. The nuclear fuel cycle as seen from the fuel cycle system analysis perspective in the VISION model. 


\subsection{Assumptions and Scope}

In drafting this Handbook, the following assumptions were made.

- Detailed explanations and justification belong in separate documents.

- The economic database will be kept separate, except for any assumptions required for expediency in using the economic data in current analyses that are not wanted in the economic database.

- Transmutation data such as reactor characteristics, charge and discharge mass fractions, computer codes, will be kept in a separate Excel library, which references individual reports documenting transmutation calculations.[Piet2008c] The Transmutation Library has all AFCI transmutation data results.

- Verification and validation of individual software will be kept separate.

\subsection{Static Versus Dynamic Equilibria}

Fuel cycle system analyses include both static and dynamic equilibria; they each have value. As noted above, static equilibria are easier to calculate, to understand, and to use to compare options if a nongrowth steady state comparison is appropriate. Dynamic equilibria tell the steady state condition of the system during the expansion phase, which is expected to be representative of the conditions envisioned in the latter half of the $21^{\text {st }}$ century.

Consider three examples of the differences; quantitative examples and diagrams appear in section 3.

First, assume in fast reactor cases that zirconium (fast reactor metal fuel alloy) and steel (fast reactor metal fuel cladding) are recycled. At static equilibrium, the only required makeup zirconium and steel would be the very small amount required to balance processing losses. In a dynamic system with increasing numbers of fast reactors, however, zirconium and steel would be required to supply the ever increasing numbers of fast reactors. The amount of makeup material required would increase as either the growth rate or recycle time lag from fuel fabrication back around to new fuel fabrication increase.

The second example is system evolution. A static equilibrium provides limited understanding about managing the system or how the system can evolve from one strategy to another. A dynamic equilibrium provides some insights into the sequencing of events. But, understanding the true system evolution requires a fully time dependent calculation.

The third example is economics. A static equilibrium is appropriate when discount rates, the time value of money, and cash flows are not addressed. A dynamic equilibrium comes closer to cash flows if the time value of money is accounted for since cash flows that lead others are given greater weight; cash flows that lag others are given less weight.

\subsection{Dynamic Versus Dynamic Equilibria}

Although dynamic equilibrium calculations are more realistic than static equilibrium calculations; a true dynamic equilibrium can only arise under certain circumstances that may not arise in a real system. Generally, so many things are varying, at different rates or with different starting times, that the system does not achieve a dynamic equilibrium. Table 1-1 lists factors that enable or inhibit development of dynamic equilibrium conditions. First, recognize that achieving dynamic equilibria is not a fuel cycle objective per se, although it can make management of the system easier. Rather, Table 1-1 is to help the reader recognize when equilibrium calculations are relatively more or less representative of potential conditions. The further from dynamic equilibrium a given scenario is, the more system dynamic timedependent calculations are warranted. 
Table 1-1. Factors Enabling or Inhibiting Development of Dynamic Equilibria

\begin{tabular}{|l|l|l|}
\hline Consideration & \multicolumn{1}{|c|}{$\begin{array}{c}\text { Accelerate or enable dynamic } \\
\text { equilibrium }\end{array}$} & \multicolumn{1}{c|}{$\begin{array}{c}\text { Retard or inhibit dynamic } \\
\text { equilibrium }\end{array}$} \\
\hline Time lags & $\begin{array}{l}\text { Shorter time lags in system, e.g., } \\
\text { fast reactor sites with co-located } \\
\text { reactors, separation, and } \\
\text { fabrication }\end{array}$ & Long time lags in system \\
\hline Size of facilities & Small, e.g., modular reactors & Large \\
\hline Nuclear power growth profile & Steady (fixed rate) & Variable growth \\
\hline Nuclear power growth rates & Very small & Moderate \\
\hline Number of perturbations & Few & Many \\
\hline Size of perturbations & Small & Large \\
\hline & & Realistic LWR retirement profile \\
\hline
\end{tabular}

\subsection{Separation and Waste Management Chemistry Considerations}

Fuel cycle system analyses now address the various potentially different chemical product and waste streams that result from fuel separation, rather than "lump" all materials together. Figure 1-2 shows the current typical chemical grouping of isotopes from aqueous separation of oxide fuel. Such groupings are user-controlled in various analytical tools so that future analyses can explore other possibilities.

For example, electrochemical separation is fundamentally different than aqueous separation. Some of the logical groups would nonetheless be the same, e.g., inert gases, transuranics, uranium. However, some would be different.

Separation of used fuel generally produces a stream of inert gases, $\mathrm{Kr}$ and $\mathrm{Xe}$. Gases $\mathrm{H} 3$ and $\mathrm{C} 14$ are considered separately because of their ubiquitous role in biological systems.

Some separation technologies produce a separate Group 1A/2A waste stream. The only Group 1A/2A elements of significance are $\mathrm{Rb}, \mathrm{Sr}, \mathrm{Cs}$, and $\mathrm{Ba}$; the mass, heat, radiotoxicity of others is negligible.

The only halogens of significance are $\mathrm{Br}$ and I for the same reasons.

Some separation options produce a separate lanthanide waste stream. Work in progress suggests that if TRU impurities in lanthanides are kept sufficiently low, they would qualify for near-surface burial.

The transition metals have subcategories.

- Zirconium is grouped by itself because the $\mathrm{Zr}$ in a system will be dominated by $\mathrm{Zr}$ cladding (LWR) and $\mathrm{Zr}$ metal alloy (FR metal fueled). So, by identifying the $\mathrm{Zr}$ fission product mass separately, it is easy to add the $\mathrm{Zr}$-fission product mass and the $\mathrm{Zr}$-clad/alloy mass together.

- Tc is grouped by itself because the uranium extraction (UREX) family of separation options can extract Tc as its own waste stream.

- Yttrium is not included with the transition metals because it tends to partition with the lanthanides due to its +3 valence.

- The amount of glass waste form depends in large part on the limited solubility of the transition metals Mo and Rh-Ru-Pd. Thus, the Transmutation Library tracks those elements separately from the other transition metals. 


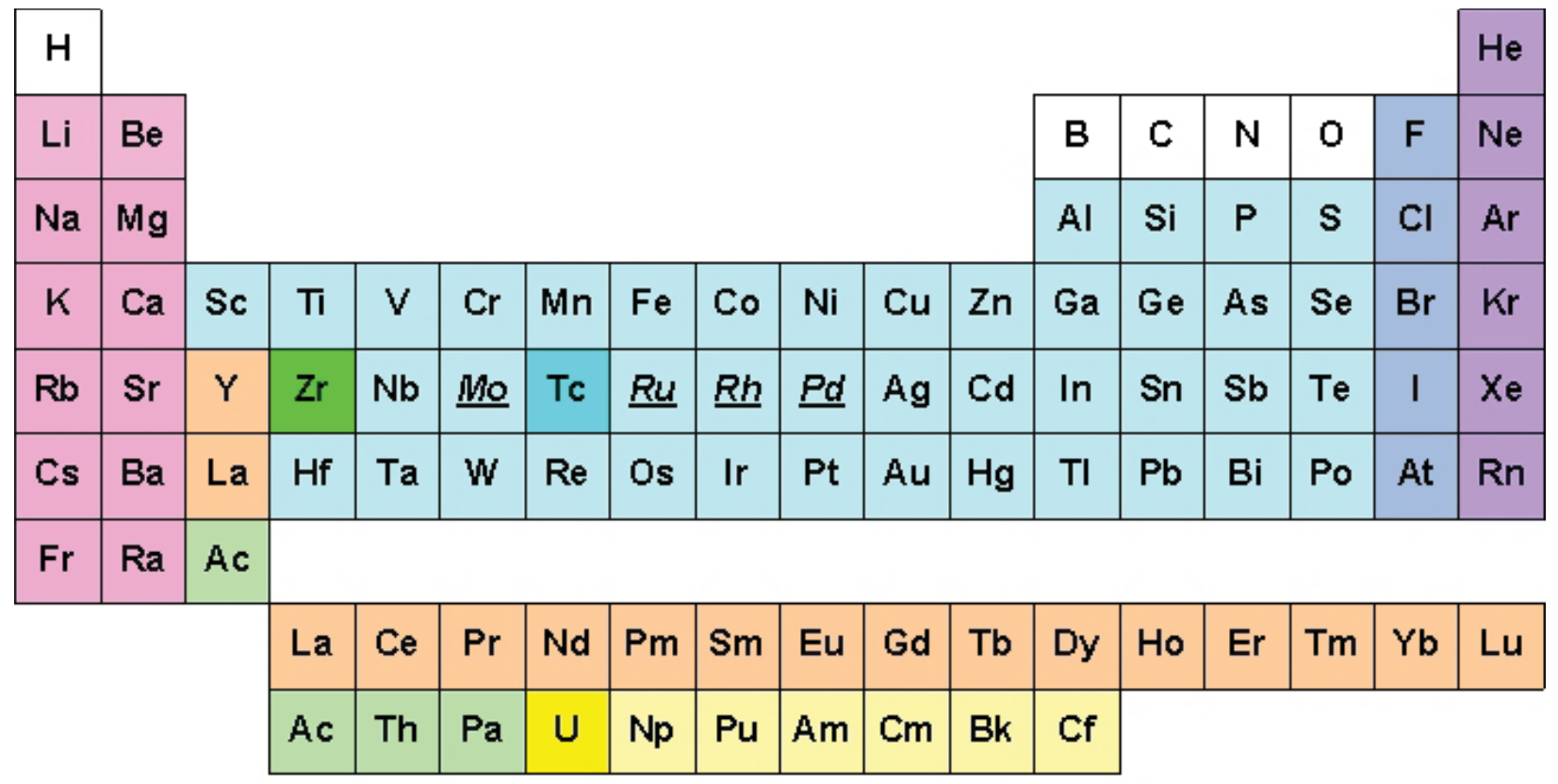

\begin{tabular}{|l|}
\hline $\begin{array}{l}M o \\
\text { in glass }\end{array}$ \\
\hline $\begin{array}{l}\text { The other transition metals of significance } \\
\text { are } \mathrm{Se}, \mathrm{Cd}, \mathrm{Sn}, \mathrm{Sb}\end{array}$ \\
\hline Lanthanides $+\mathrm{Y}$ tracked separately \\
\hline $\begin{array}{l}\text { Ac, Th, Pa are important actinide decay } \\
\text { chain elements }\end{array}$ \\
\hline In UREX+, U is removed separately \\
\hline TRU elements \\
\hline
\end{tabular}

\begin{tabular}{l}
\hline $\mathrm{H} 3$ and $\mathrm{C} 14$ are tracked separately \\
\hline $\begin{array}{l}\text { The only Group 1A/2A elements of } \\
\text { significance are } \mathrm{Rb}, \mathrm{Sr}, \mathrm{Cs}, \mathrm{Ba}\end{array}$ \\
\hline $\begin{array}{l}\text { The only Halogens of significance are } \mathrm{Br} \\
\text { and I }\end{array}$ \\
\hline $\begin{array}{l}\text { The only inert gases of significance are } \\
\mathrm{Kr} \text { and Xe }\end{array}$ \\
\hline In UREX+, Tc is removed separately. \\
\hline $\begin{array}{l}\text { Zr is tracked separately because its mass } \\
\text { is dominated by cladding, not fuel per se }\end{array}$ \\
\hline
\end{tabular}

Figure 1-2. Periodic Table as seen from fuel cycle system analysis perspective. [Piet2009]

\subsection{Which Isotopes are Tracked in Fuel Cycle Simulation?}

There are three sources of radioactivity in nuclear fuel cycles, as follows:

- In this report, "actinides" include uranium, transuranic elements, and decay products thereof. Literally, the term "actinides" should only refer to the elements Ac and above, thereby including uranium and transuranic elements, but not refer to decay products Ra-Fr-Rn-At-Po-Bi-Pb. The text is explicit if there is a possibility of misinterpretation. The "actinides" stem from nuclear reactions that occur inside nuclear systems such as critical reactors and accelerator or fusion driven subcritical blankets, primarily actinides result from $(n, \gamma)$ reactions on fuel isotopes, followed by various decay reactions.

- Fission products - these stem from the nuclear fission reaction, primarily (n,fission), followed by various decay reactions, primarily beta- and beta + decay.

- Activation products - these stem from nuclear reactions, primarily $(\mathrm{n}, \gamma)$ reactions, on non-fuel materials such as fuel cladding, fuel matrix, and structural materials. 
To date, virtually all fuel cycle system analyses have focused on the first two, namely those directly associated with the fuels themselves. Table 1-2 lists the isotopes considered in fuel cycle system analyses with the VISION model; the document that describes the Transmutation Library [Piet2008c] also documents how isotopes were selected and how completely they account for mass, heat, etc.

VISION analyses and Table 1-2 only include isotopes generated in fuel material and zirconium metal, but not isotopes generated from activation of zirconium alloy impurities, steel, or air. 
Table 1-2. Isotopes and Chemical Elements Tracked in the VISION Model

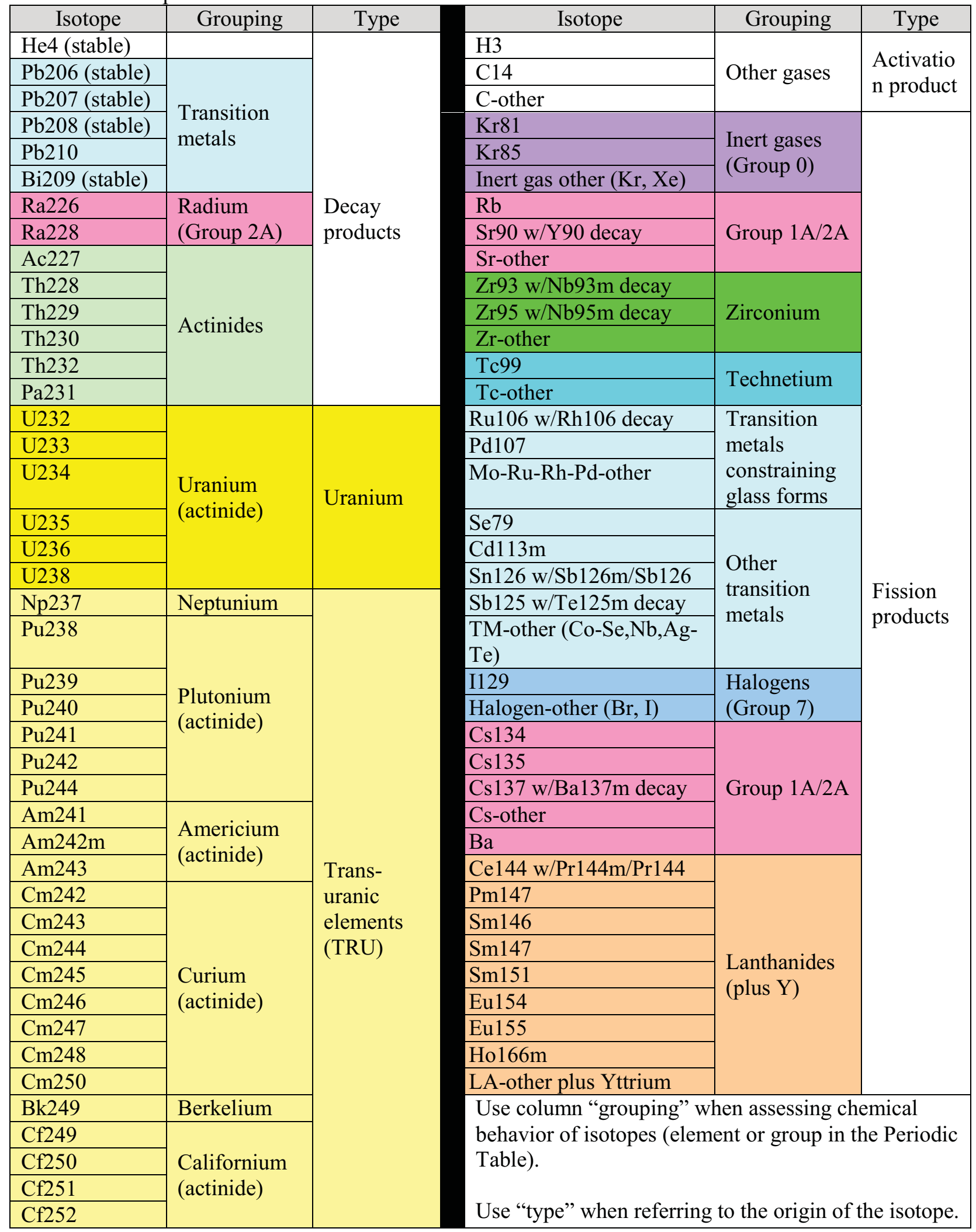


As the initial fuel materials sucessively absorb neutrons, they gain in mass. The increased number of neutrons in the nucleus eventually decrease the stability of the product isotope, which can decay via alpha, beta, or neutron decay. The net result is that initial fuel isotopes such as U235, U238, and Th232 lead to a mixture of isotopes extending up to Cf252 as shown in figure 1-3. Because all the isotopes in figure 1-3 are radioactive, they also give rise to decay products that extend down to the heaviest stable isotopes, which are $\mathrm{Pb} 206, \mathrm{~Pb} 207, \mathrm{~Pb} 208$, and $\mathrm{Bi209}$, which are not shown in the figure.

The mix of isotopes depends on a host of parameters. In no case are there significant isotopes accumulating in nuclear reactors above Cf252 because such isotopes are very short-lived.[Piet2009, Piet2008c] But, to be complete, fuel cycle assessments need to account for isotopes from the stable $\mathrm{Pb} 206, \mathrm{~Pb} 207, \mathrm{~Pb} 208, \mathrm{Bi} 209$ up to Cf252. Indeed, Table 1-2 includes all such isotopes with halflife greater than 0.5 years. (There are five minor exceptions, isotopes with halflife greater than 0.5 year, but with such low yield that they can be ignored, see Piet2009, Piet2008c.) The AFCI Transmutation Library allocates the mass of shorter-lived isotopes to appropriate longer-lived progeny isotopes.

When the isotopes in Table 1-3 decay, the alpha, beta, gamma, or neutron emission of any short-lived isotopes are accounted for so that the mass of such short-lived isotopes does not have to be tracked.[Piet2009, Piet2008c] 


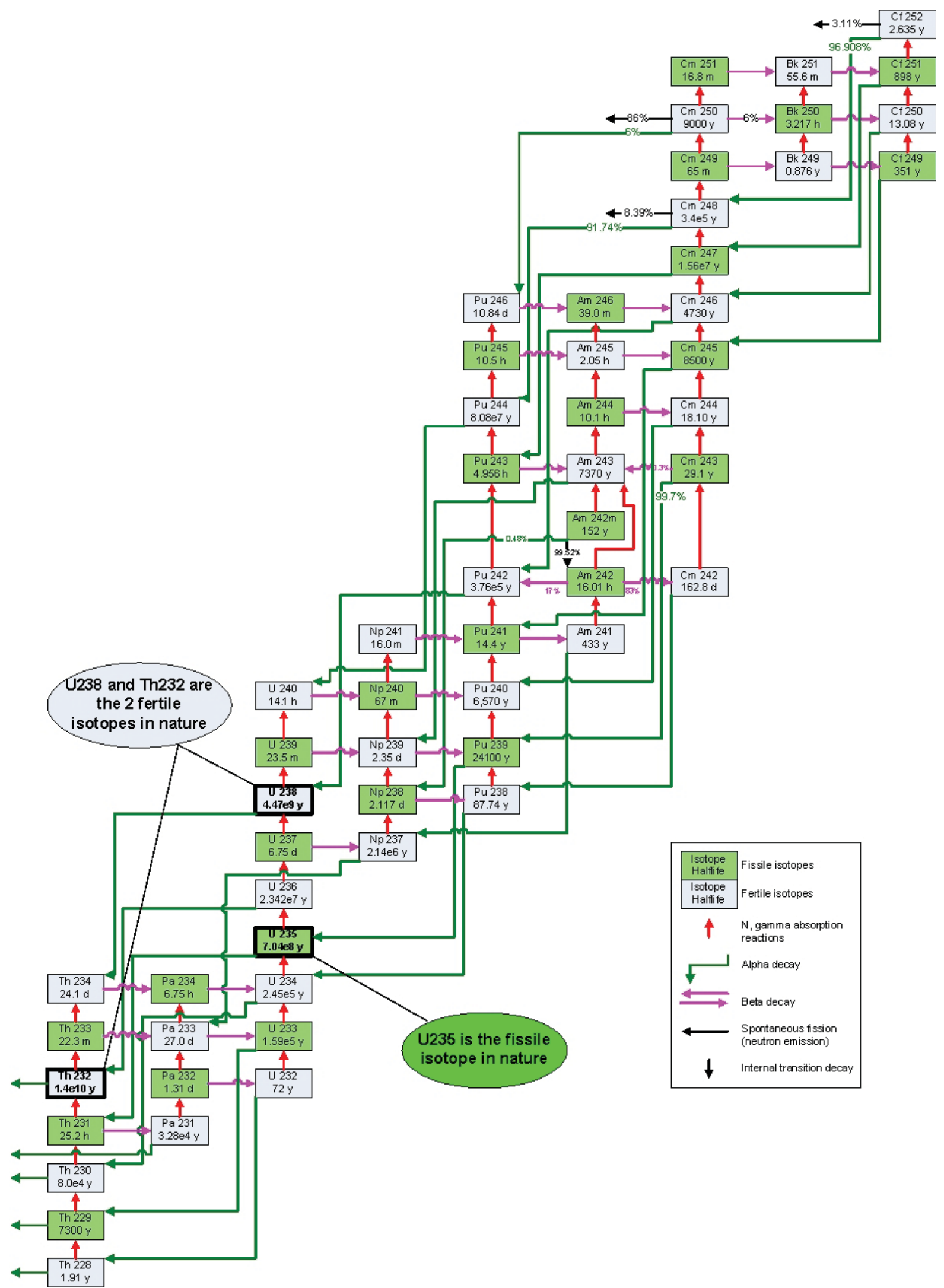

Figure 1-3. Accumulation of transuranic elements from initial uranium (or thorium). 


\section{STRATEGY AND SCENARIO DEFINITION}

Unless otherwise stated, the calculations in this Handbook are consistent with the methods and assumptions in the DSARR. [DSARR2008] Therefore, it is appropriate to give a brief synopsis of the assumptions and input parameters that define the strategies and scenarios analyzed. It is stressed that these assumptions and input parameters are not a baseline for the Advanced Fuel Cycle Initiative (AFCI). It is also stressed that the options included in the DSARR are only part of the full range of fuel cycle options that are possible.

The annual AFCI Comparison Report to Congress [DOE2006] describes a broad range of potential fuel cycle strategies. A strategy is a general approach to fuel management that identifies which materials are recycled (if any), the type of nuclear power plants or other transmuter systems, the type of used fuel processing technology, and which materials go to geologic disposal. This subsection identifies which fuel cycle strategies are analyzed in the DSARR report (see Table 2-1), which is the foundation for most of the calculations in this Handbook.

The fuel cycle strategies in the Comparison Report are as follows:

- Once-through - After one pass through a reactor, the components of used fuel are kept together and sent to a geologic repository.

- Recycle in thermal reactors only - Current international practice recycles plutonium only, with other transuranics elements sent to waste. Other options include recycle of additional transuranics.

- Recycle with a symbiotic mix of thermal and fast reactors; both generate electricity.

- Recycle in fast reactors only - Thermal reactors are eventually phased out and only fast reactors generate electricity and recycle fuel. All transuranics and all uranium are recycled.

Table 2-1. Fuel Cycle Strategies Analyzed in DSARR [Dixon2008]

\begin{tabular}{|c|c|c|c|c|c|c|}
\hline \multirow[b]{2}{*}{$\begin{array}{c}\text { Strategy } \rightarrow \\
\text { Class of } \\
\text { strategy } \rightarrow\end{array}$} & \multirow{2}{*}{$\begin{array}{l}\begin{array}{c}\text { Once } \\
\text { through }\end{array} \\
\begin{array}{l}\text { Fuel not } \\
\text { recycled }\end{array}\end{array}$} & \multicolumn{2}{|c|}{ Thermal reactors only [b] } & \multicolumn{2}{|c|}{$\begin{array}{l}\text { Symbiotic mix of thermal } \\
\text { and fast reactors }\end{array}$} & \multirow{2}{*}{$\begin{array}{c}\begin{array}{c}\text { Fast reactors } \\
\text { only }\end{array} \\
\\
\text { Recycle } \\
\text { repeatedly }\end{array}$} \\
\hline & & $\begin{array}{l}\text { Recycle } \\
\text { once }\end{array}$ & $\begin{array}{l}\text { Recycle } \\
\text { repeatedly }\end{array}$ & $\begin{array}{l}\text { Recycle } \\
\text { repeatedly in } \\
\text { thermal \& } \\
\text { fast reactors }\end{array}$ & $\begin{array}{c}\text { Recycle } \\
\text { repeatedly in } \\
\text { fast reactors } \\
\text { only }\end{array}$ & \\
\hline $\begin{array}{l}\text { Considered } \\
\text { in DSARR? }\end{array}$ & $\begin{array}{l}\text { Yes } \\
\text { Once } \\
\text { through } \\
\text { (This is the } \\
\text { current U.S. } \\
\text { approach) }\end{array}$ & No & No & $\begin{array}{l}\text { Yes [a] } \\
\text { 2-tier } \\
\text { (LWR UOX } \\
\text { to } 1 \text { recycle } \\
\text { as LWR } \\
\text { MOX, then } \\
\text { to repeated } \\
\text { fast reactor } \\
\text { recycling) }\end{array}$ & $\begin{array}{l}\text { Yes } \\
\text { 1-tier } \\
\text { (LWR UOX } \\
\text { directly to } \\
\text { repeated fast } \\
\text { reactor } \\
\text { recycling) }\end{array}$ & No \\
\hline $\begin{array}{l}\text { Thermal } \\
\text { reactors and } \\
\text { fuels used }\end{array}$ & $\begin{array}{l}\text { LWR with } \\
\text { UOX fuel }\end{array}$ & \multicolumn{3}{|c|}{$\begin{array}{l}\text { LWR with } \\
\text { UOX and MOX fuel }\end{array}$} & $\begin{array}{l}\text { LWR with } \\
\text { UOX fuel }\end{array}$ & \\
\hline $\begin{array}{l}\text { Fast reactors } \\
\text { and fuels } \\
\text { used }\end{array}$ & & & & \multicolumn{3}{|c|}{ Sodium cooled with metal or oxide fuel } \\
\hline $\begin{array}{l}\text { a. More than } \\
\text { b. To date, th } \\
\text { Future analys }\end{array}$ & $\begin{array}{l}\text { cle of LI } \\
\text { thermal } \\
y \text { addres }\end{array}$ & $\begin{array}{l}\text { In the } \\
\text { eceivin } \\
\text { vater or }\end{array}$ & $\begin{array}{l}\text { tors (i.e. } \\
\text { cant attent } \\
\text { led therme }\end{array}$ & $\begin{array}{l}\text { le pass of M } \\
\text { he LWR, wh } \\
\text { ors. }\end{array}$ & $\begin{array}{l}\text { was not an } \\
\text { dominates }\end{array}$ & $\begin{array}{l}\text { d in DSARR. } \\
\text { orld market. }\end{array}$ \\
\hline
\end{tabular}


Table 2-2 shows the overall time line assumed for the nominal DSARR analyses. Note the juxtaposition of several different times of events - legacy LWR retirement ("legacy" refers to the operating LWRs in 2000), repository, fast reactors, and used LWR fuel separation capacity.

Table 2-2. Overall Time Line and Specifications for Nominal Scenarios [DSARR2008, Dixon2008]

\begin{tabular}{|c|c|c|}
\hline 1 tier & 2 tier & Event \\
\hline \multicolumn{2}{|c|}{2000} & $\begin{array}{l}\text { Simulations start with } 86 \mathrm{GWe} \text {-year electricity generation, } 90 \% \text { average reactor } \\
\text { capacity factor, therefore } 95.6 \mathrm{GWe} \text { nuclear capacity. Since there were } 103 \text { operating } \\
\text { reactors, the average capacity is } 0.928 \mathrm{GWe} / \text { reactor. Nuclear market share was } 19.8 \% \text {. }\end{array}$ \\
\hline \multicolumn{2}{|c|}{$2000-2007$} & $\begin{array}{l}\text { Nuclear market share and effective number of reactors adjusted to approximate the } \\
\text { actual growth in nuclear electricity generation from uprates and restart of the } 104^{\text {th }} \\
\text { reactor }\end{array}$ \\
\hline \multicolumn{2}{|c|}{$2008-2014$} & No nuclear growth \\
\hline \multicolumn{2}{|c|}{2015} & New LWRs start coming on line; nuclear power grows at $1.75 \% /$ year \\
\hline \multicolumn{2}{|c|}{2017} & Yucca Mountain repository opens and starts accepting used commercial fuel \\
\hline \multicolumn{2}{|c|}{2020} & 1st LWR UOX separation unit (800 tonnes-iHM/yr) \\
\hline \multicolumn{2}{|c|}{2022} & 1st fast reactor ( $0.38 \mathrm{GWe}$ capacity) - 10 years with UPu fueling \\
\hline \multicolumn{2}{|c|}{2028} & First decommissioning of LWRs in operation before 2000. \\
\hline \multicolumn{2}{|c|}{2030} & 2nd LWR UOX separation unit (1600 tonnes-iHM/yr) \\
\hline $\mathrm{N} / \mathrm{A}$ & 2037 & $\begin{array}{l}1^{\text {st }} \text { MOX separation plant ( } 89 \text { tonnes-iHM/yr, i.e., } 1 / 9^{\text {th }} \text { the capacity of the first UOX } \\
\text { separation plant) }\end{array}$ \\
\hline $\begin{array}{c}2032- \\
2036\end{array}$ & $\begin{array}{c}2047- \\
2051\end{array}$ & $\begin{array}{l}\text { Fast reactor deployed } \leq 1 \mathrm{GWe} \text { capacity/yr at } 0.50 \mathrm{TRU} \text { conversion ratio, } \\
\text { with co-located fuel fabrication and separation plants }\end{array}$ \\
\hline $\begin{array}{c}2037- \\
2041\end{array}$ & $\begin{array}{l}2052- \\
2056\end{array}$ & $\begin{array}{l}\text { Fast reactor deployed } \leq 2 \mathrm{GWe} \text { capacity/yr at } 0.50 \mathrm{TRU} \text { conversion ratio, } \\
\text { with co-located fuel fabrication and separation plants }\end{array}$ \\
\hline \multicolumn{2}{|c|}{2038} & Yucca Mountain repository filled to 63,000 tonnes-UOX-iHM \\
\hline \multicolumn{2}{|c|}{$2040-2100$} & $\begin{array}{l}\text { Additional LWR UOX separation units as needed, in modules of } 1600 \text { tonnes-iHM/yr } \\
\text { tailored to eliminate used UOX fuel backlog by } 2100 \text {. Deploy } \leq 3000 \text { tonne-iHM/yr in } \\
\text { any given year. Total LWR UOX separation } \leq 6000 \text { tonne-iHM/yr in } 2060 \text {. [DOE- } \\
\text { NE2008] }\end{array}$ \\
\hline $\mathrm{N} / \mathrm{A}$ & $\begin{array}{l}2047- \\
2100\end{array}$ & $\begin{array}{l}\text { Additional LWR MOX separation units as needed, in modules of } 178 \text { tonnes-iHM/yr } \\
\text { (1/9 } 9^{\text {th }} \text { of corresponding UOX unit), offset } 17 \text { years from the corresponding UOX plant. }\end{array}$ \\
\hline 2042 & 2057 & $\begin{array}{l}\text { Fast reactor deployment limited only by supply of transuranic material; fast reactor fuel } \\
\text { fabrication and separation plants are co-located and co-deployed }\end{array}$ \\
\hline \multicolumn{2}{|c|}{2055} & Last legacy LWR decommissioned \\
\hline \multicolumn{2}{|c|}{2100} & Available backlog of used UOX (and MOX) processed \\
\hline
\end{tabular}

Table 2-3 lists the key parameters that define the scenarios analyzed in the DSARR report, other than those specifying introduction of used LWR separation capacity and fast reactors. With these parameters, the total recycle time for LWR used fuel is 11 years (10 years in wet storage for cooling, 0.5 years at separation facility, and 0.5 years being made into new fuel). The total recycle time for fast reactor used fuel is 2 years ( 1 year in wet storage for cooling, 0.5 years at separation facility, and 0.5 years being made into new fuel) assuming that separation and fuel fabrication are co-located with the reactor. 
Table 2-3. Parameters Defining Representative Scenarios [DSARR2008]

\begin{tabular}{|c|c|c|}
\hline Parameter & $\begin{array}{l}\text { DSARR } \\
\text { nominal } \\
\text { case }\end{array}$ & Comment \\
\hline $\begin{array}{l}\text { Nuclear power growth rate } \\
(\% / \text { year })\end{array}$ & $1.75 \%$ & $\begin{array}{l}\text { Calculated to match electricity generation levels in } \\
2060 \text { specified by DOE [DOE-NE2008] }\end{array}$ \\
\hline $\begin{array}{l}\text { Year nuclear growth starts, i.e., first new LWR } \\
\text { come on line }\end{array}$ & 2015 & $\begin{array}{l}\text { No nuclear growth from } 2007 \text { to } 2015 \text {, per DOE } \\
\text { [DOE-NE2008] }\end{array}$ \\
\hline LWRs burnup (MWth-day/kg-iHM) & 51 & $\begin{array}{l}\text { Consistent with fuel currently in reactors based on } \\
\text { burnup trends, and analysis of data at [DOE2004] }\end{array}$ \\
\hline Time at separation facility (years) & 0.5 & $\begin{array}{l}\text { Engineering estimate, including processing and } \\
\text { lead-lag storage }\end{array}$ \\
\hline Time at fuel fabrication facility (years) & 0.5 & $\begin{array}{l}\text { Engineering estimate, including processing and } \\
\text { lead-lag storage }\end{array}$ \\
\hline $\begin{array}{l}\text { Minimum cooling time for LWR used UOX fuel } \\
\text { before transport or offsite separation (years) }\end{array}$ & 10 & $\begin{array}{l}\text { Based on cooling needed prior to efficient } \\
\text { transportation, then rounded up to allow for higher } \\
\text { burnup fuels or MOX fuels without changing the } \\
\text { value }\end{array}$ \\
\hline LWR MOX fuel content & $\mathrm{U}-\mathrm{Pu}$ & $\begin{array}{l}\text { Per DOE.[DOE-NE2008] Minor actinides from } \\
\text { LWR used fuel are assumed to be separated and } \\
\text { stored until they can be included in fast reactor } \\
\text { fresh fuel. }\end{array}$ \\
\hline $\begin{array}{l}\text { Minimum cooling time for LWR used MOX fuel } \\
\text { before transport or offsite separation (years) }\end{array}$ & 10 & To be consistent with UOX \\
\hline Fast reactor conversion ratio & 0.50 & $\begin{array}{l}\text { Per Dr. Robert Hill, Director of the AFCI Fast } \\
\text { Reactor Campaign }\end{array}$ \\
\hline Fast reactor fuel type & Metal & $\begin{array}{l}\text { Selected to minimize fuel cycle delays otherwise } \\
\text { masking other behavior. Oxide is assessed via } \\
\text { sensitivity analyses. }\end{array}$ \\
\hline Fast reactor fuel burnup (MWth-day/kg-iHM) & 132 & $\begin{array}{l}\text { Hoffman } 2007 \text { a value for metal fuel at } 0.50 \\
\text { conversion ratio }\end{array}$ \\
\hline $\begin{array}{l}\text { Minimum cooling time for fast reactor used fuel } \\
\text { before separation (years) }\end{array}$ & 1.0 & $\begin{array}{l}\text { Based on onsite separations to minimize fuel cycle } \\
\text { delays. Experimental Breeder Reactor-II, fuel has } \\
\text { been moved from reactor to onsite separation in } \\
\text { less than } 1 \text { year. }\end{array}$ \\
\hline Reactor licensing time (years) & 2 & \multirow{2}{*}{$\begin{array}{l}\text { Provides approximate delay between reactor order } \\
\text { and operation }\end{array}$} \\
\hline Reactor construction time (years) & 4 & \\
\hline $\begin{array}{l}\text { Used LWR fuel permanently emplaced in Yucca } \\
\text { Mountain repository (tonnes-iHM) }\end{array}$ & 63,000 & Per DOE [DOE-NE2008] \\
\hline Assumed lifetime of existing 104 LWRs (years) & 60 & $\begin{array}{l}\text { Original license time was } 40 \text { years. As of } \\
\text { February 2008, about half have either received or } \\
\text { are under review for license extension to } 60 \\
\text { years.[NRC2008a] Most if not all of the rest are } \\
\text { expected to apply for license } \\
\text { extension.[NRC2008] }\end{array}$ \\
\hline $\begin{array}{l}\text { Retirement of existing } 104 \text { LWRs } \\
\text { First four LWR offline } \\
\text { Last legacy reactor offline }\end{array}$ & $\begin{array}{l}2029 \\
2055\end{array}$ & $\begin{array}{l}\text { Based on above assumption that all current } \\
\text { reactors' licenses include one } 20 \text { year extension. } \\
\text { This extension was applied to the data for each } \\
\text { reactor [NRC2008] to derive a histogram of } \\
\text { reactor retirements }\end{array}$ \\
\hline
\end{tabular}


As input to simulations, figure 2-1 shows the accumulation of used nuclear fuel in the U.S. DOE data stop at 2002.[DOE2004] The NEA has estimated accumulation through January 2009 as 60,150 tonnes.[NEI2009] Fuel has been accumulating consistently at $\sim 2100$ tonnes/year since $\sim 1990$. Figure $2-2$ shows that the increase in fuel burnup has allowed the rate of used fuel discharge to stay roughly constant even as the total nuclear electricity has increased. From 1990 through 2002, burnup has increased 38\%; electricity has increased $\sim 35 \%$; hence the mass of fuel discharged is approximately constant.

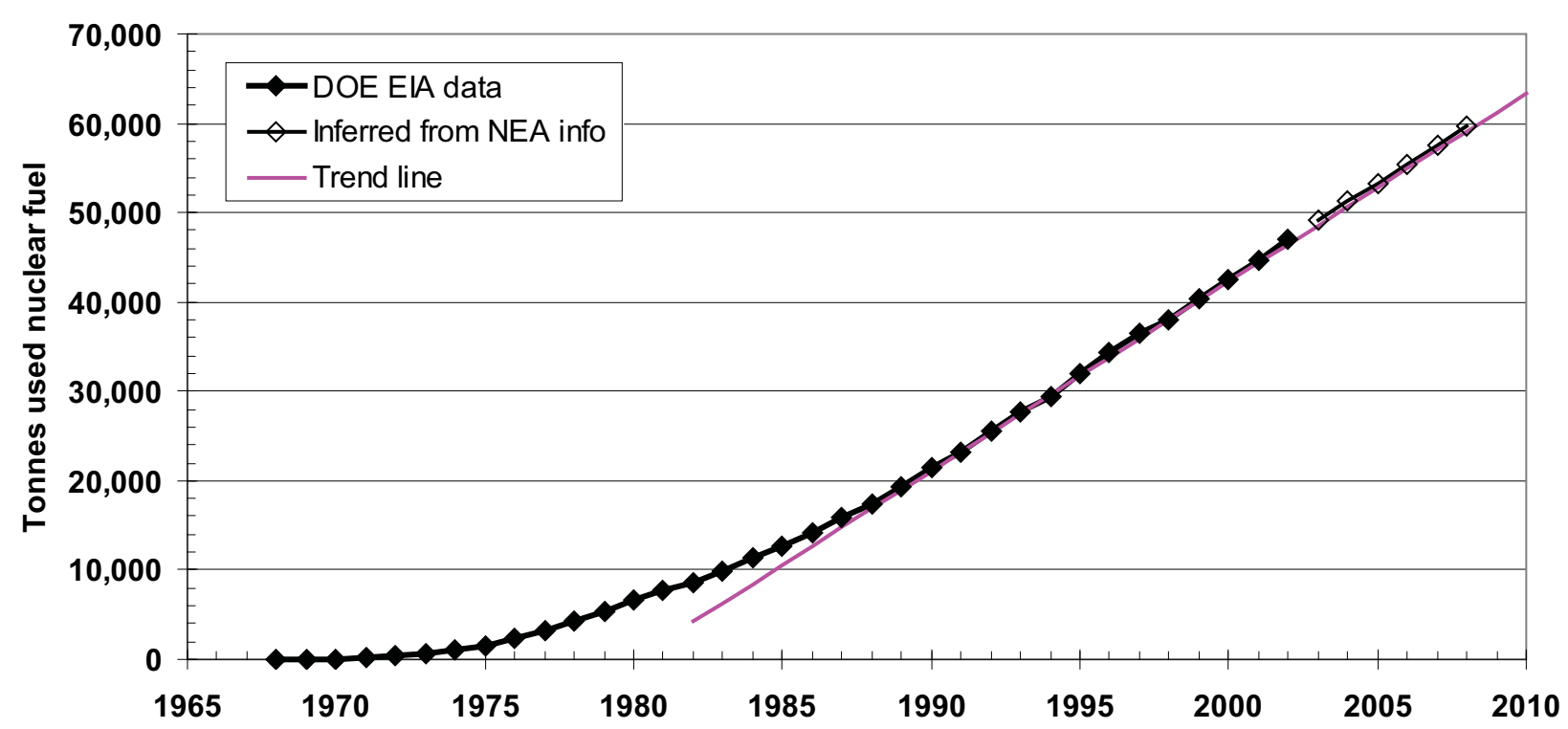

Figure 2-1. Accumulation of used nuclear fuel in the U.S.

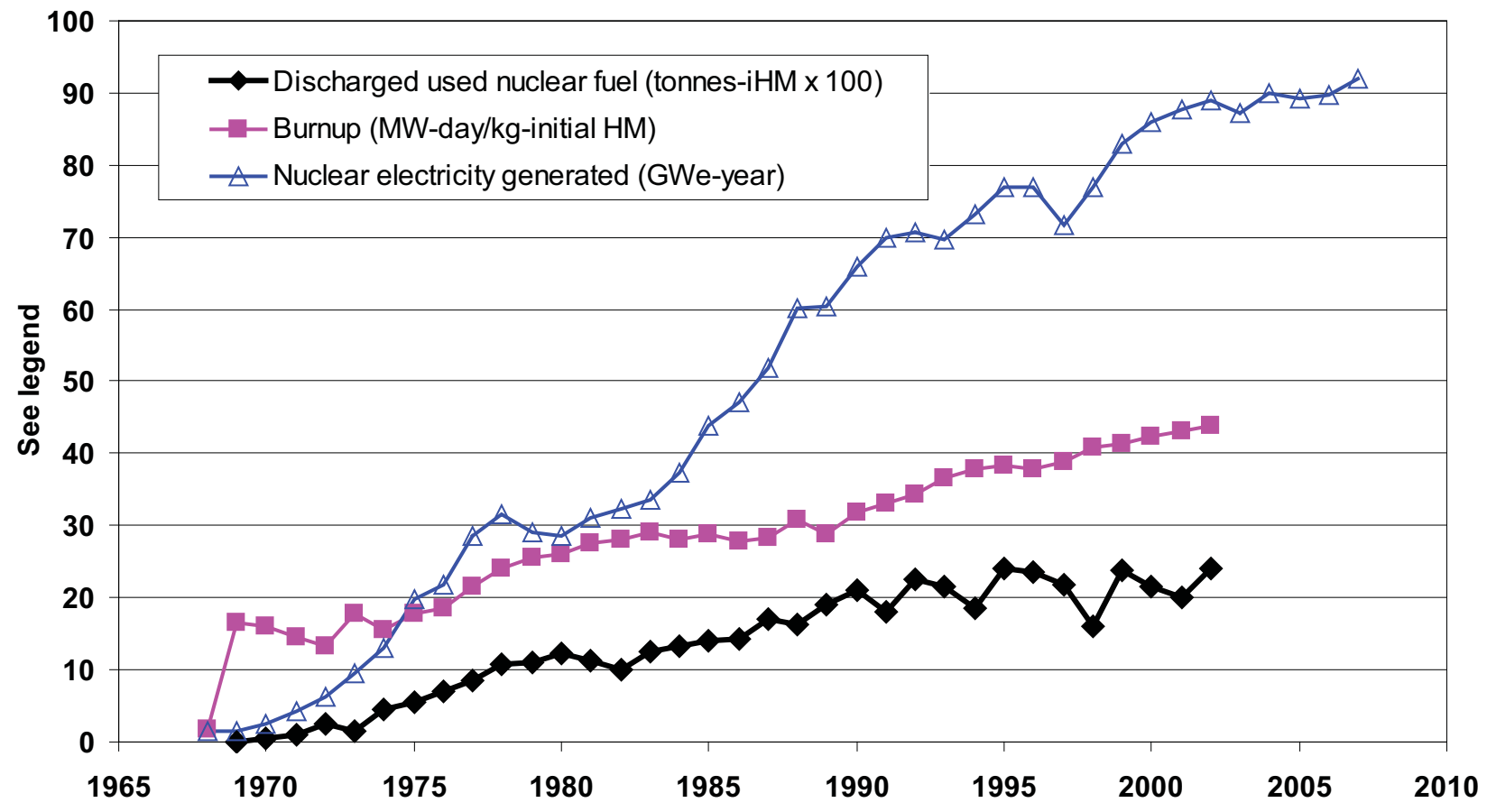

Figure 2-2. Trends for used fuel discharge, fuel burnup, and nuclear electricity generated. 


\section{SYSTEM-LEVEL MASS FLOWS}

This section summarizes overall mass flows in the 0,1 , and 2 tier options described in section 2 . For each option, two mass flow diagrams are provided - static equilibrium and dynamic equilibrium. The difference between static and dynamic equilibria is discussed in section 1.4. The dynamic equilibrium values come from the DSARR study at $1.75 \%$ /year nuclear power growth rate. They will be different for other growth rates.

There are several basic points to consider, as follows:

- Mass flow does not, by itself, measure cost, handling hazards, or waste management burdens. As an example, the mass flow of the lanthanide fission products is an order of magnitude higher than Tc fission products, but the lanthanides are minor contributors to long-term dose from a Yucca Mountain-type repository or to radiotoxicity relative to Tc.

- The mass flows include the mass of fuel, fuel cladding ( $\mathrm{Zr}$ in LWRs, steel in fast reactors), fuel matrix (assuming fast reactor metal fuel based on $\mathrm{Zr}$ ), and fuel assembly structure.

- There is one difference between these values and DSARR parameters. The DSARR calculations were done with MOX-Pu based on natural uranium (NU). The static equilibrium calculations were done with MOX-Pu based on recovered uranium from separation of used UOX fuel. Therefore, the $\mathrm{Pu}$ content is slightly different, $10.62 \% \mathrm{Pu}$ in MOX-RU-Pu and $9.80 \% \mathrm{Pu}$ in MOX-NU-Pu. This slightly shifts the MOX/UOX and FR/LWR ratios. The newer MOX-RU-Pu values were used because they more accurately reflect the intent of the 2-tier case and because the fission product breakdowns were available for them in the Transmutation Library but not for the older MOX-NU-Pu data.

Table 3-1 lists key lead and lag items in dynamic equilibria as shown in the system-level mass flow diagrams that follow.

Table 3-1. Lead and Lag Items in Dynamic Equilibria

\begin{tabular}{|l|l|l|}
\hline & \multicolumn{1}{|c|}{ Leading } & \multicolumn{1}{c|}{ Lagging } \\
\hline $\begin{array}{l}\text { Increase or decrease when } \\
\text { shifting from static to dynamic } \\
\text { equilibrium }\end{array}$ & $\begin{array}{l}\text { Increase, hence factor might be } \\
\text { more important than predicted by } \\
\text { static equilibrium }\end{array}$ & $\begin{array}{l}\text { Decrease, smaller impact than } \\
\text { might be predicted by static } \\
\text { equilibrium }\end{array}$ \\
\hline Material inputs & $\begin{array}{l}\text { Natural uranium (NU) } \\
\text { Depleted uranium (DU) } \\
\text { Enriched uranium (EU) } \\
\text { Zirconium and steel }\end{array}$ & \\
\hline Types of reactors & $\begin{array}{l}\text { Number of thermal reactors using } \\
\text { uranium oxide fuel }\end{array}$ & $\begin{array}{l}\text { Number of fast reactors } \\
\text { Thermal efficiency increases }\end{array}$ \\
\hline Types of facilities & Fabrication plants & Separation plants \\
\hline Material outputs & & Waste disposal \\
\hline
\end{tabular}

\section{$3.1 \quad 0$-Tier, Once-Through}

Figures 3-1 and 3-2 show the static and dynamic equilibrium mass flows for the 1-tier case. Table 3-2 compares overall parameters, showing the impact of viewing the once through option from static versus dynamic perspectives. The difference between the two is the quantity of material that is needed to supply the growing fleet. 
Mass flows (tonnes/year) for 1 GWe-year (8.766 TW-hr) at static equilibrium

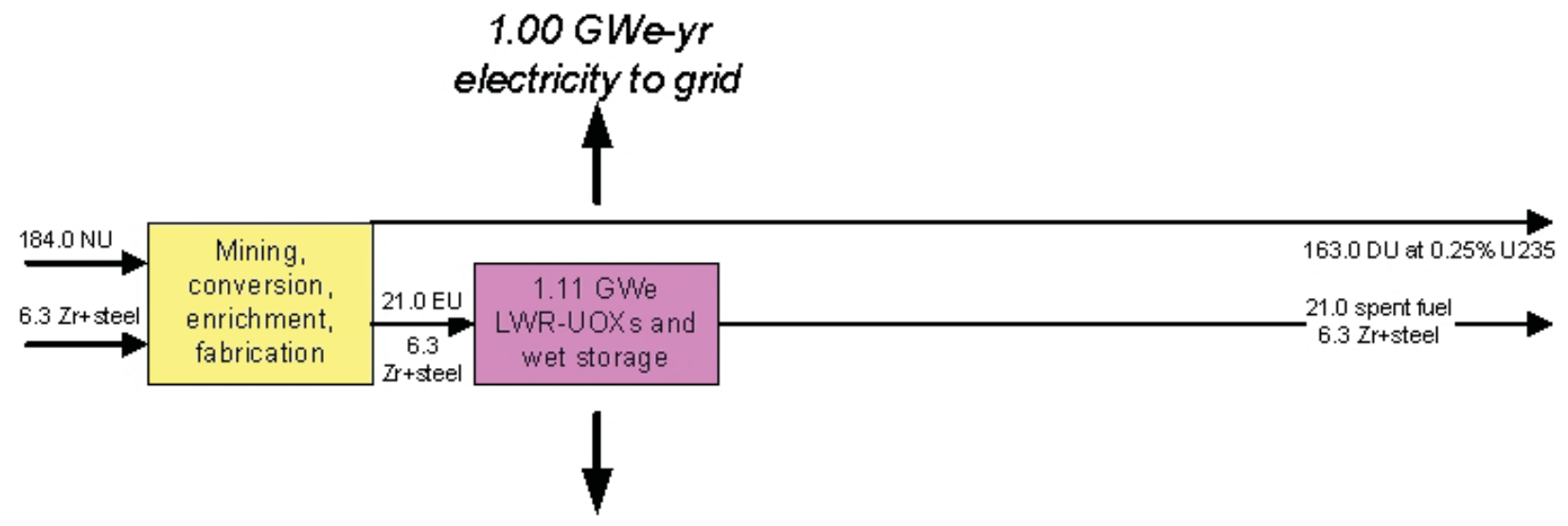

\subsection{GWth-yr heat \\ rejected to environment}

Figure 3-1. Once through, static equilibrium using DSARR parameters.

Mass flows (tonnes/year) for $1 \mathrm{GWe}$-year (8.766 TW-hr) at dynamic equilibrium calculated by VISION during $2091-2100$ at $1.75 \%$ growth

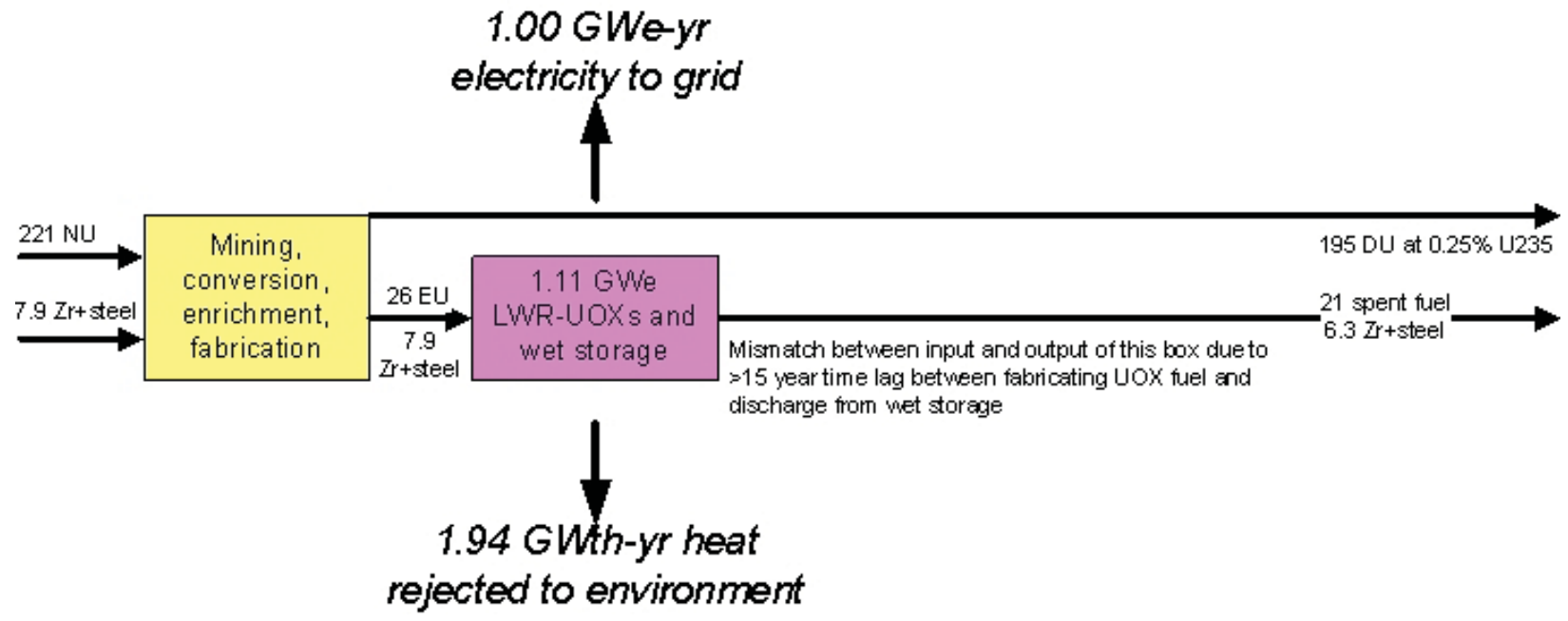

Figure 3-2. Once through, dynamic equilibrium using DSARR input parameters 
Table 3-2. Dynamic versus Static Equilibrium Comparison for Once Through

\begin{tabular}{|c|c|c|c|c|}
\hline Parameter & Static & $\begin{array}{c}\text { Dynamic at } \\
1.75 \% / y r \\
\text { growth }\end{array}$ & $\begin{array}{l}\text { Ratio of } \\
\text { Dynamic } \\
\text { to Static }\end{array}$ & Comment \\
\hline LWR-UOX GWe-yr & 1.00 & 1.00 & \multirow{3}{*}{1.00} & \multirow{3}{*}{$\begin{array}{l}\text { Direct result of } \\
\text { normalization to } 1 \\
\text { GWe-year }\end{array}$} \\
\hline LWR-UOX GWth-yr to environment & 1.94 & 1.94 & & \\
\hline Overall thermal efficiency & $34 \%$ & $34 \%$ & & \\
\hline Fresh $\mathrm{Zr}+$ steel required (tonnes-Zr-steel/yr) & 6.3 & 7.9 & \multirow{4}{*}{$\begin{array}{r}1.20 \\
\text { to } \\
1.25\end{array}$} & \multirow{4}{*}{$\begin{array}{l}\text { Parameters leading } \\
\text { reactor operation }\end{array}$} \\
\hline Tonnes-NU/yr & 184.0 & 221.4 & & \\
\hline Tonnes-DU/yr & 163.0 & 195.1 & & \\
\hline Tonnes-EU/yr & 21.0 & 26.4 & & \\
\hline Tonnes-spent-UOX-fuel/year as waste & 21.0 & 21.0 & \multirow{2}{*}{1.00} & \multirow{2}{*}{$\begin{array}{l}\text { Same as the } \\
\text { normalization }\end{array}$} \\
\hline $\mathrm{Zr}+$ steel to waste (tonnes-Zr-steel/yr) & 6.3 & 6.3 & & \\
\hline
\end{tabular}

\subsection{1-Tier, UOX to Fast Reactor}

Figures 3-3 and 3-4 show the static and dynamic equilibrium mass flows for the 1-tier case. Table 3-3 compares overall parameters, showing the impact of viewing the 1-tier option from static versus dynamic perspectives. Table 3-4 also compares static versus dynamic, but looking more into details. The rows are organized in sequential order starting with natural uranium and ending with FR fuel separation. The earlier ("leading") steps are increased in the dynamic equilibrium relative to static; the lagging steps are decreased relative to static equilibrium. However, the higher mass flows of leading steps require growth in the lagging steps in the future in order for the material to be completely utilized. 
Mass flows (tonnes/year) for 1 GWe-year (8.766 TW-hr) at static equilibrium

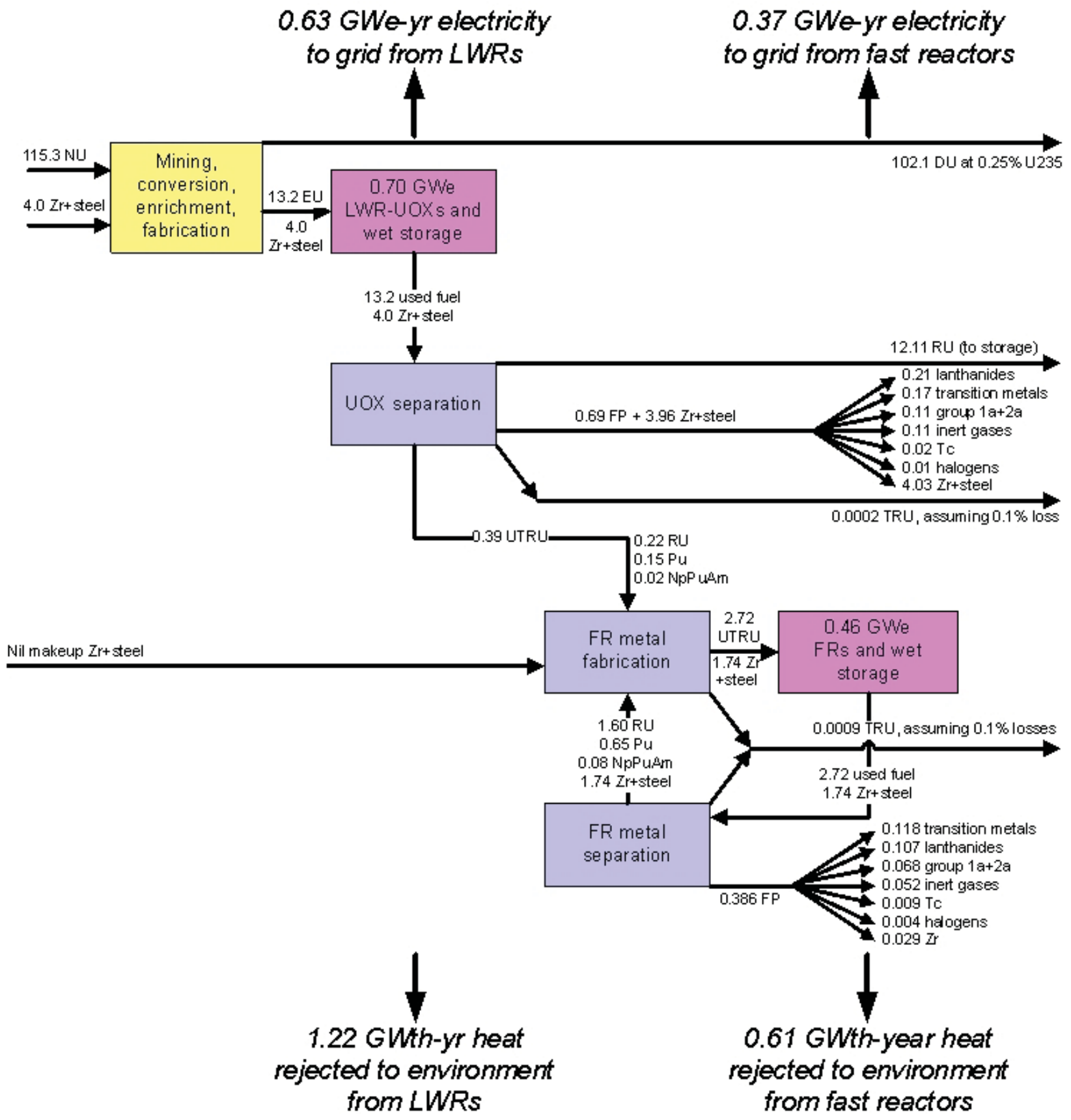

Figure 3-3. 1-tier recycle (UOX to FR), static equilibrium using DSARR parameters 
Mass flows (tonnes/year) for $1 \mathrm{GWe}$-year (8.766 TW-hr) at dynamic equilibrium calculated by VISION during $2091-2100$ at $1.75 \%$ growth

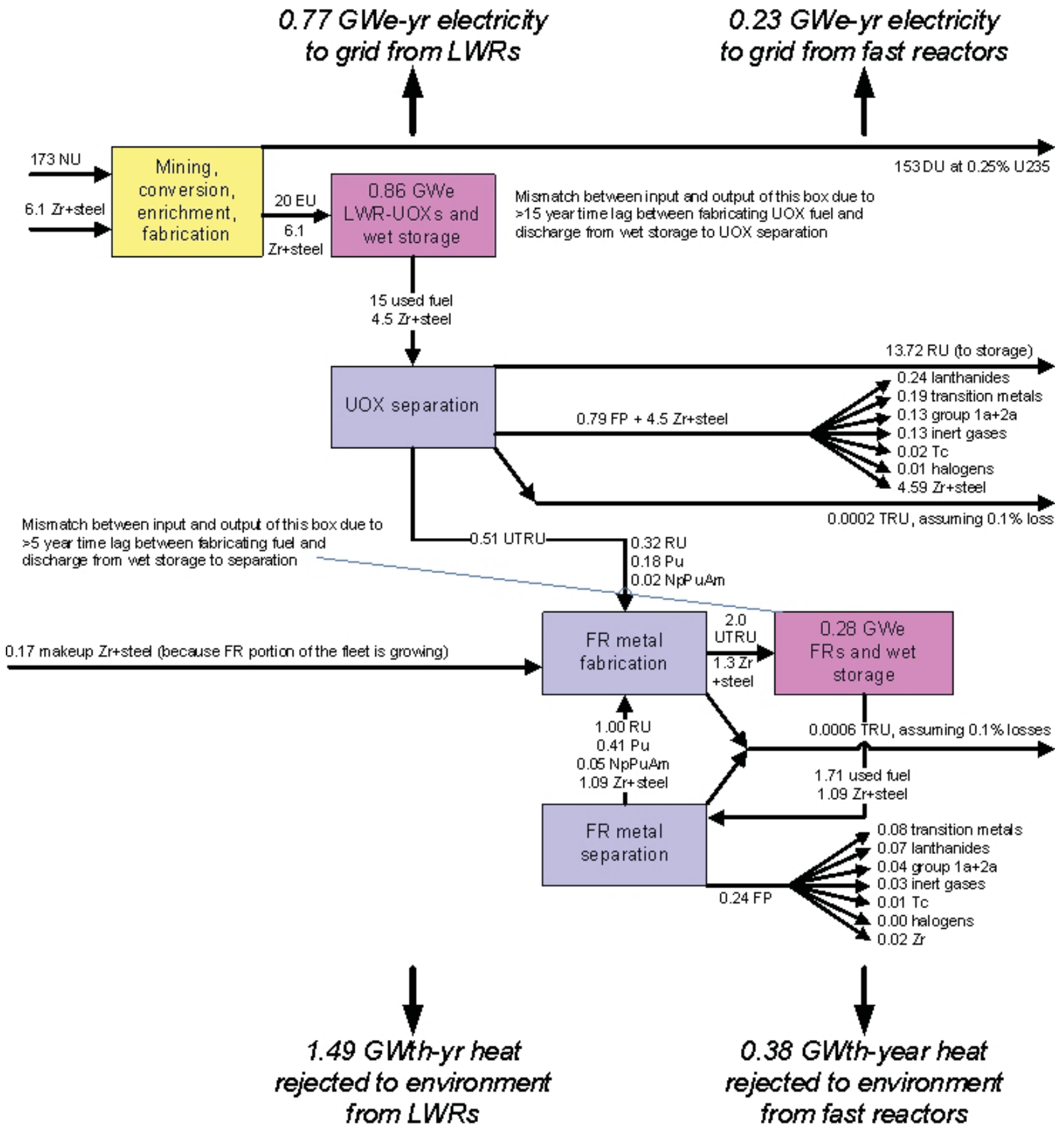

Figure 3-4. 1-tier recycle (UOX to FR), dynamic equilibrium using DSARR results (1.75\% nuclear growth/yr); the LWR/fast reactor partition has changed from static equilibrium. 
Table 3-3. Dynamic versus Static Equilibrium Comparison for 1-Tier, UOX to FR - Overall Parameters

\begin{tabular}{|l|r|r|r|l|}
\hline Parameter & Static & $\begin{array}{c}\text { Dynamic } \\
\text { @1.75\%/yr } \\
\text { growth }\end{array}$ & $\begin{array}{l}\text { Ratio of } \\
\text { Dynamic } \\
\text { to Static }\end{array}$ & Comment \\
\hline Totel electricity (GWe-yr) & 1.00 & 1.00 & 1.00 & Normalization \\
\hline $\begin{array}{l}\text { Total heat to environment } \\
\text { (GWth-yr) }\end{array}$ & 1.83 & 1.87 & 1.02 & $\begin{array}{l}\text { Slight increase because more } \\
\text { LWR, fewer FR }\end{array}$ \\
\hline Overall thermal efficiency & $35.4 \%$ & $34.8 \%$ & 0.98 & $\begin{array}{l}\text { Slight decrease because more } \\
\text { LWR, fewer FR }\end{array}$ \\
\hline & & & $\begin{array}{l}\text { Substantial increase because } \\
\text { more LWR requires more }\end{array}$ \\
Fresh Zr+steel required & & & $\begin{array}{l}\text { UOX fabrication, which uses } \\
\text { virgin Zr and steel. (FR are } \\
\text { assumed to recycle Zr and } \\
\text { steel.) }\end{array}$ \\
\hline $\begin{array}{l}\text { Tonnes-Zr-steel/yr) } \\
\text { (tonnes-RU/yr) }\end{array}$ & 12.1 & & 13.7 & $\begin{array}{l}\text { Increase because there is } \\
\text { relatively more UOX, less FR } \\
\text { to use RU }\end{array}$ \\
\hline
\end{tabular}


Table 3-4. Dynamic versus Static Equilibrium Comparison for 1-Tier, UOX to FR

\begin{tabular}{|c|c|c|c|c|}
\hline $\begin{array}{l}\text { Parameters, listed roughly in sequential order starting } \\
\text { with natural uranium, ending with masses from FR } \\
\text { separation. }\end{array}$ & Static & $\begin{array}{l}\text { Dynamic } \\
@ .75 \% / \mathrm{yr} \\
\text { growth }\end{array}$ & $\begin{array}{l}\text { Ratio of } \\
\text { Dynamic } \\
\text { to Static }\end{array}$ & Comment \\
\hline Tonnes-NU/yr & 115.3 & 173.1 & \multirow{5}{*}{$\begin{array}{r}1.49 \\
\text { to } \\
1.55\end{array}$} & \multirow{5}{*}{$\begin{array}{l}\text { Parameters } \\
\text { lead LWRs }\end{array}$} \\
\hline Tonnes-DU/yr & 102.1 & 152.6 & & \\
\hline Tonnes-EU/yr & 13.2 & 20.5 & & \\
\hline Mass into UOX fabrication (tonnes-HM/yr) & 13.2 & 20.5 & & \\
\hline $\begin{array}{l}\text { Mass of Zr+steel into UOX fabrication (tonnes-Zr- } \\
\text { steel/yr) }\end{array}$ & 4.0 & 6.1 & & \\
\hline Electricity from LWR-UOX (GWe-yr) & 0.63 & 0.77 & \multirow{2}{*}{1.23} & \multirow{2}{*}{$\begin{array}{l}\text { LWRs lead } \\
\text { FRs }\end{array}$} \\
\hline Heat rejection from LWR-UOX (GWth-yr) & 1.22 & 1.49 & & \\
\hline Mass into UOX separations (tonnes-iHM/yr) & 13.2 & 15.03 & \multirow{2}{*}{1.14} & \multirow{7}{*}{$\begin{array}{l}\text { Lag LWRs, } \\
\text { but lead FRs }\end{array}$} \\
\hline Mass of RU from UOX separations (tonnes-RU/yr) & 12.3 & 14.04 & & \\
\hline RU from UOX into FR fabrication (tonnes-RU/yr) & 0.22 & 0.32 & 1.48 & \\
\hline RU into storage (tonnes-RU/yr) & 12.1 & 13.72 & \multirow{4}{*}{$\begin{array}{r}1.13 \\
\text { to } \\
1.14\end{array}$} & \\
\hline $\begin{array}{l}\text { Mass of TRU from UOX into FR fabrication (tonnes- } \\
\text { RU/yr) }\end{array}$ & 0.17 & 0.20 & & \\
\hline Mass of FP from UOX separation (tonnes-FP/yr) & 0.69 & 0.79 & & \\
\hline $\begin{array}{l}\text { Mass of } \mathrm{Zr}+\text { steel into UOX sep to waste (tonnes-Zr- } \\
\text { steel/yr) }\end{array}$ & 4.0 & 4.5 & & \\
\hline Mass into FR fabrication (tonnes-HM/yr) & 2.72 & 1.98 & \multirow{2}{*}{0.73} & \multirow{2}{*}{$\begin{array}{l}\text { Lead FR, but } \\
\text { lag LWRs }\end{array}$} \\
\hline Mass of Zr-steel into FR fabrication (tonnes-Zr-steel/yr) & 1.74 & 1.27 & & \\
\hline $\begin{array}{l}\text { Makeup mass of } \mathrm{Zr}+\text { steel into FR fabrication (tonnes-Zr- } \\
\mathrm{SS} / \mathrm{yr} \text { ) or disposal }\end{array}$ & None & 0.17 & NA & \\
\hline Electricity from FR (GWe-yr) & 0.37 & 0.23 & \multirow{7}{*}{$\begin{array}{r}0.62 \\
\text { to } \\
0.63\end{array}$} & \multirow{7}{*}{$\begin{array}{l}\text { FRs lag } \\
\text { LWRs }\end{array}$} \\
\hline Heat rejection from FR (GWth-yr) & 0.61 & 0.38 & & \\
\hline Mass into FR separations (tonnes-iHM/yr) & 2.72 & 1.71 & & \\
\hline $\begin{array}{l}\text { Mass of RU from FR into FR fabrication (tonnes- } \\
\text { RU/yr) }\end{array}$ & 1.60 & 1.00 & & \\
\hline $\begin{array}{l}\text { Mass of TRU from FR into FR fabrication (tonnes- } \\
\text { RU/yr) }\end{array}$ & 0.73 & 0.46 & & \\
\hline Mass of FP from FR separation (tonnes-FP/yr) & 0.39 & 0.24 & & \\
\hline $\begin{array}{l}\text { Mass of Zr-steel from FR separations (tonnes-Zr- } \\
\text { steel/yr) }\end{array}$ & 1.74 & 1.09 & & \\
\hline
\end{tabular}




\subsection{2-Tier, UOX to MOX-Pu to Fast Reactor}

Figures 3-5 and 3-6 show the static and dynamic equilibrium mass flows for the 2-tier case. Table 3-5 compares overall parameters, showing the impact of viewing the 2-tier option from static versus dynamic perspectives. Table 3-6 also compares static versus dynamic, but looking more into details. The rows are organized in sequential order starting with natural uranium and ending with FR fuel separation. As with 1-tier, the earlier steps are increased in the dynamic equilibrium relative to static; the lagging steps are decreased relative to static equilibrium. 
Mass flows (tonnes/year) for 1 GWe-year (8.766 TW-hr) at static equilibrium

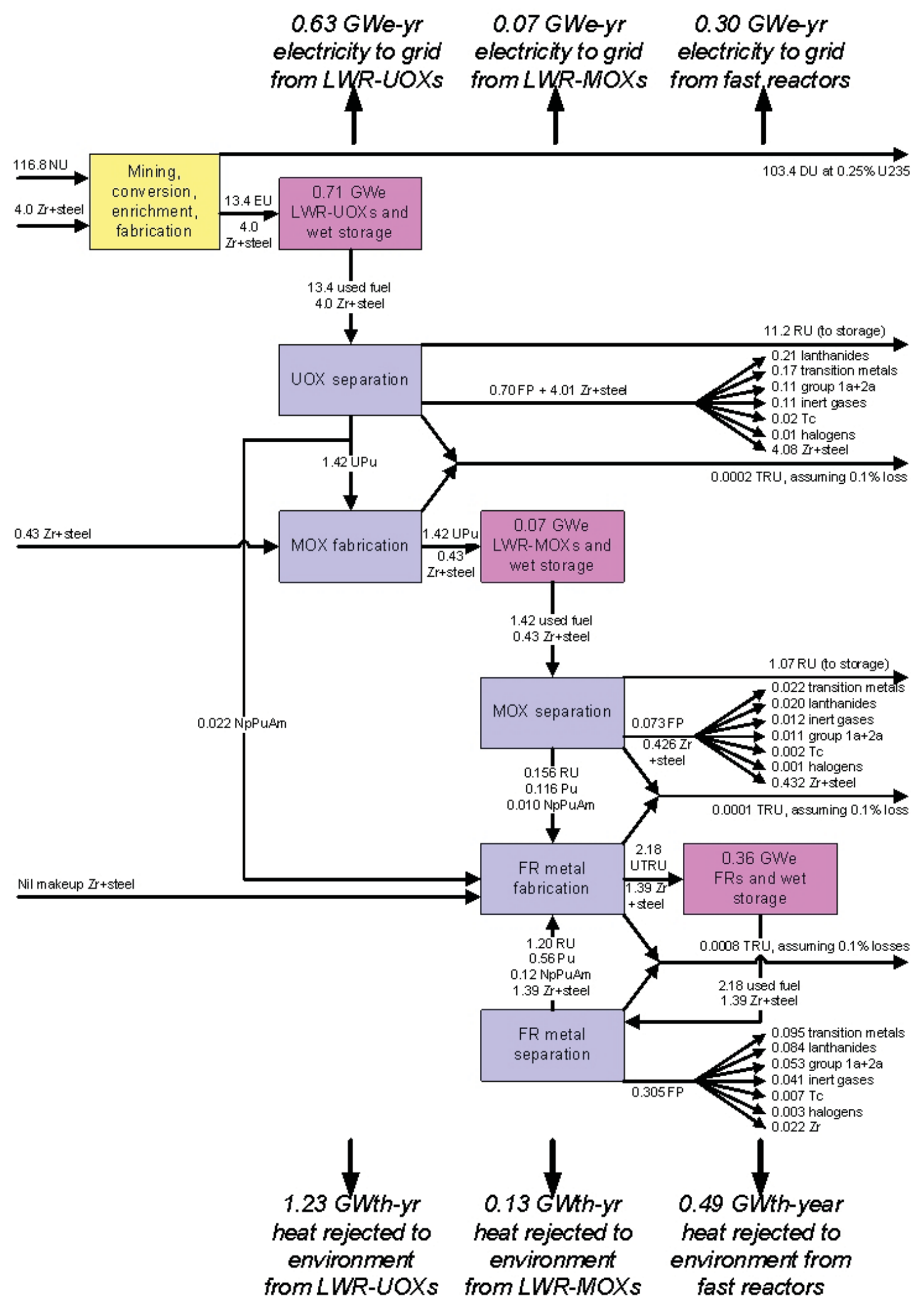

Figure 3-5. 2-tier recycle (UOX to MOX-RU-Pu to FR), static equilibrium using DSARR parameters, except MOX recipe updated from MOX-NU-Pu to MOX-RU-Pu 
Mass flows (tonnes/year) for 1 GWe-year (8.766 TW-hr) at dynamic equilibrium calculated by VISION during $2091-2100$ at $1.75 \%$ growth

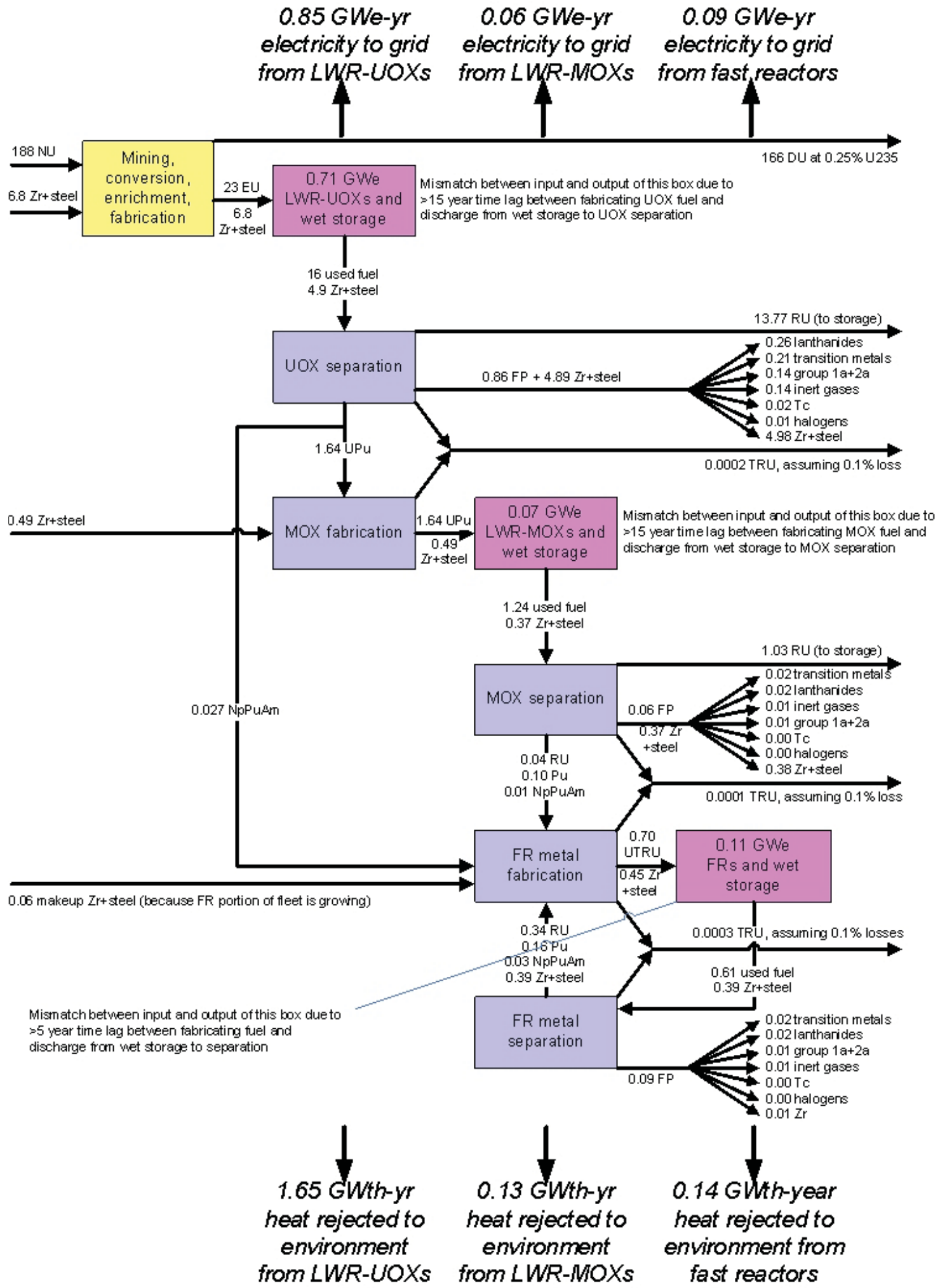

Figure 3-6. 2-tier recycle (UOX to MOX-RU-Pu to FR), dynamic equilibrium using DSARR results $(1.75 \%$ nuclear growth/yr) 
Table 3-5. Dynamic versus Static Equilibrium Comparison for 1-Tier, UOX to FR - Overall Parameters

\begin{tabular}{|l|r|r|r|l|}
\hline Parameter & Static & \multicolumn{1}{|c|}{$\begin{array}{l}\text { Dynamic } \\
\text { @ } \\
1.75 \% / y r \\
\text { growth }\end{array}$} & $\begin{array}{l}\text { Ratio of } \\
\text { Dynamic } \\
\text { to Static }\end{array}$ & Comment \\
\hline Total electricity (GWe-yr) & 1.00 & 1.00 & 1.00 & Normalization \\
\hline $\begin{array}{l}\text { Total heat to environment } \\
\text { (GWth-yr) }\end{array}$ & 1.85 & 1.91 & 1.03 & $\begin{array}{l}\text { Slight increase because more } \\
\text { LWR, fewer FR }\end{array}$ \\
\hline Overall thermal efficiency & $35.1 \%$ & $34.3 \%$ & 0.98 & $\begin{array}{l}\text { Slight decrease because more } \\
\text { LWR, fewer FR }\end{array}$ \\
\hline & & & & $\begin{array}{l}\text { Substantial increase because } \\
\text { more LWR requires more }\end{array}$ \\
$\begin{array}{l}\text { Fresh Zr+steel required } \\
\text { (tonnes-Zr-steel/yr) }\end{array}$ & 4.43 & 7.32 & $\begin{array}{l}\text { UOX and MOX fabrication, } \\
\text { both of which use virgin Zr } \\
\text { and steel. (FR are assumed to } \\
\text { recycle Zr and steel.) }\end{array}$ \\
\hline $\begin{array}{l}\text { Total mass of RU into storage } \\
\text { tonnes-RU/yr) }\end{array}$ & 12.28 & 14.80 & 1.61 & $\begin{array}{l}\text { Substantial increase because } \\
\text { there is relatively more UOX, } \\
\text { less MOX and FR to use RU }\end{array}$ \\
\hline $\begin{array}{l}\text { Zr+steel to waste } \\
\text { (tonnes-Zr-steel/yr) }\end{array}$ & 4.4 & 5.3 & 1.19 & $\begin{array}{l}\text { Fewer FR means less recycle } \\
\text { of Zr and steel. }\end{array}$ \\
\hline
\end{tabular}


Table 3-6. Dynamic versus Static Equilibrium Comparison for 1-Tier, UOX to FR

\begin{tabular}{|c|c|c|c|c|}
\hline $\begin{array}{l}\text { Parameters, listed roughly in sequential order starting with } \\
\text { natural uranium, ending with masses from FR separation. }\end{array}$ & Static & $\begin{array}{c}\text { Dynamic @ } \\
1.75 \% / y r \\
\text { growth }\end{array}$ & $\begin{array}{l}\text { Ratio of } \\
\text { Dynami } \\
\text { c to } \\
\text { Static }\end{array}$ & Comment \\
\hline Tonnes-NU/yr & 116.8 & 188.1 & \multirow{5}{*}{$\begin{array}{r}1.60 \\
\text { to } \\
1.69\end{array}$} & \multirow{5}{*}{$\begin{array}{l}\text { Parameters } \\
\text { lead LWRs }\end{array}$} \\
\hline Tonnes-DU/yr & 103.4 & 165.6 & & \\
\hline Tonnes-EU/yr & 13.4 & 22.6 & & \\
\hline Mass into UOX fabrication (tonnes-HM/yr) & 13.4 & 22.6 & & \\
\hline Mass of Zr+steel into UOX fabrication (tonnes-Zr-steel/yr) & 4.01 & 6.77 & & \\
\hline Electricity from LWR-UOX (GWe-yr) & 0.63 & 0.85 & \multirow[b]{2}{*}{1.34} & \multirow{2}{*}{$\begin{array}{l}\text { LWR-UOXs } \\
\text { lead LWR- } \\
\text { MOXs and } \\
\text { FRs }\end{array}$} \\
\hline Heat rejection from LWR-UOX (GWth-yr) & 1.23 & 1.65 & & \\
\hline Mass into UOX separation (tonnes-iHM/yr) & 13.36 & 16.30 & \multirow{2}{*}{1.22} & \multirow{8}{*}{$\begin{array}{l}\text { Lag LWR- } \\
\text { UOXs, but } \\
\text { lead others }\end{array}$} \\
\hline RU from UOX separation (tonnes-RU/yr) & 12.48 & 15.23 & & \\
\hline RU from UOX sep into MOX fab (tonnes-RU/yr) & 1.27 & 1.46 & 1.15 & \\
\hline RU from UOX sep into storage (tonnes-RU/yr) & 11.21 & 13.77 & \multirow{5}{*}{$\begin{array}{r}1.22 \\
\text { to } \\
1.23\end{array}$} & \\
\hline $\mathrm{Pu}$ from UOX into MOX fabrication (tonnes-Pu/yr) & 0.15 & 0.18 & & \\
\hline NpAmCm from UOX into FR fab (tonnes-TRU/yr) & 0.022 & 0.027 & & \\
\hline FP from UOX separation (tonnes-FP/yr) & 0.70 & 0.86 & & \\
\hline Mass of Zr+steel into UOX separations (tonnes-Zr-steel/yr) & 4.01 & 4.89 & & \\
\hline Mass into MOX fabrication (tonnes-HM/yr) & 1.42 & 1.64 & \multirow[b]{2}{*}{1.15} & \multirow{2}{*}{$\begin{array}{l}\text { Lead LWR- } \\
\text { MOX, lag } \\
\text { LWR-UOX }\end{array}$} \\
\hline Mass of $\mathrm{Zr}+$ steel into MOX fabrication (tonnes-Zr-steel/yr) & 0.43 & 0.49 & & \\
\hline Electricity from LWR-MOX (GWe-yr) & 0.07 & 0.06 & \multirow[b]{2}{*}{0.97} & \multirow{2}{*}{$\begin{array}{l}\text { LWR-MOXs } \\
\text { lag LWR- } \\
\text { UOXs, lead } \\
\text { FRs }\end{array}$} \\
\hline Heat rejection from LWR-MOX (GWth-yr) & 0.13 & 0.13 & & \\
\hline Mass into MOX separations (tonnes-iHM/yr) & 1.42 & 1.24 & \multirow[b]{2}{*}{0.87} & \multirow{2}{*}{$\begin{array}{l}\text { Lag LWR- } \\
\text { MOX, lead } \\
\text { FRs }\end{array}$} \\
\hline RU from MOX sep (tonnes-RU/yr) & 1.22 & 1.07 & & \\
\hline $\begin{array}{l}\text { RU from MOX sep into FR fabrication (tonnes- } \\
\text { RU/yr) }\end{array}$ & 0.16 & 0.04 & 0.26 & \\
\hline RU from MOX sep into storage (tonnes-RU/yr) & 1.07 & 1.03 & 0.96 & \\
\hline $\begin{array}{l}\text { TRU from MOX sep into FR fabrication (tonnes- } \\
\text { TRU/yr) }\end{array}$ & 0.13 & 0.11 & \multirow{3}{*}{0.87} & \multirow{3}{*}{$\begin{array}{l}\text { Lag LWR- } \\
\text { MOX, lead } \\
\text { FRs }\end{array}$} \\
\hline FP from MOX sep (tonnes-FP/year) & 0.07 & 0.06 & & \\
\hline Mass of $\mathrm{Zr}+$ steel into MOX separations (tonnes-Zr-steel/yr) & 0.43 & 0.37 & & \\
\hline Mass into FR fabrication (tonnes-HM/year) & 2.18 & 0.70 & \multirow[b]{2}{*}{0.32} & \multirow{2}{*}{$\begin{array}{l}\text { Lead FRs, lag } \\
\text { LWR-MOX }\end{array}$} \\
\hline Mass of $\mathrm{Zr}+$ steel into FR fabrication (tonnes-Zr-steel/yr) & 1.39 & 0.45 & & \\
\hline Makeup mass of $\mathrm{Zr}+$ steel into FR fab (tonnes-Zr-steel/yr) & None & 0.06 & NA & \\
\hline Electricity from FR (GWe-yr) & 0.30 & 0.09 & \multirow{7}{*}{$\begin{array}{r}0.28 \\
\text { to } \\
0.29\end{array}$} & \multirow{7}{*}{ FRs lag LWRs } \\
\hline Heat rejection from FR (GWth-yr) & 0.49 & 0.14 & & \\
\hline Mass into FR separation (tonnes-iHM/yr) & 2.18 & 0.61 & & \\
\hline RU from FR sep into FR fabrication (tonnes-RU/yr) & 1.20 & 0.34 & & \\
\hline TRU from FR sep into FR fabrication (tonnes-TRU/yr) & 0.68 & 0.19 & & \\
\hline FP from FR separation into waste (tonnes-FP/yr) & 0.31 & 0.09 & & \\
\hline Zr-steel from FR sep into FR fab (tonnes-Zr-steel/yr) & 1.39 & 0.39 & & \\
\hline
\end{tabular}




\section{ENERGY AND NUCLEAR POWER GROWTH}

System analysis is not intended to predict the future. We are trying to understand how candidate fuel cycles may perform under a range of postulated conditions. To help make the range of postulated conditions realistic, the team starts by considering historical data.

For context, figure 4-1 shows the number, capacity (GWe), net electricity (GWe-year), nuclear percent of U.S. electricity, and average capacity factor of U.S. commercial nuclear power.[DOE2007] There have been periods of high growth and so assessing candidate fuel cycles should consider their potential to support high growth.

(a) Number

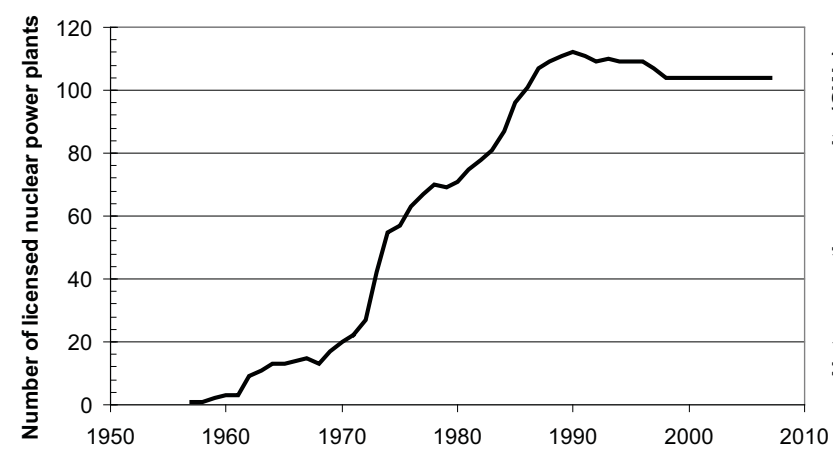

(c) electricity generated (GWe-year)

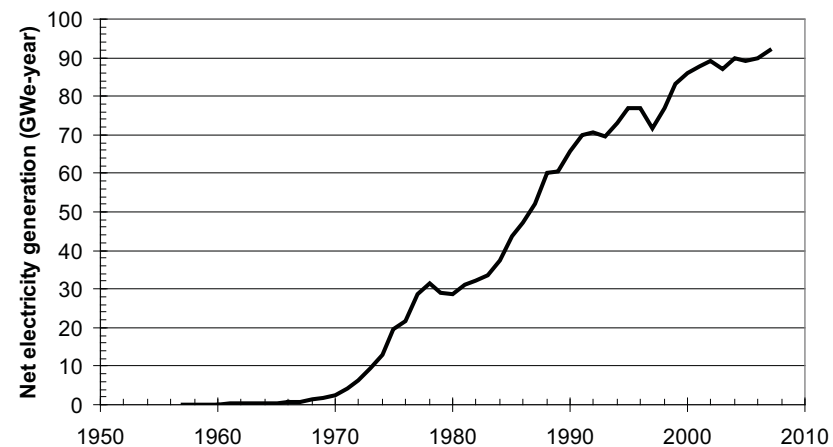

(e) capacity factor

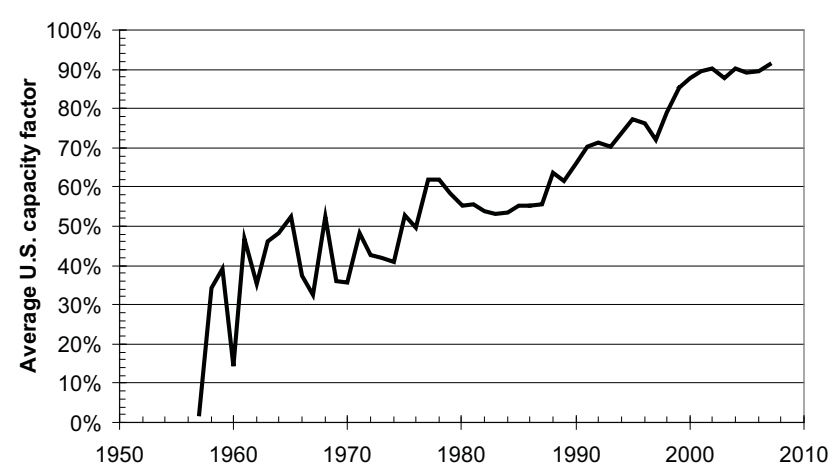

(b) nuclear generation capacity

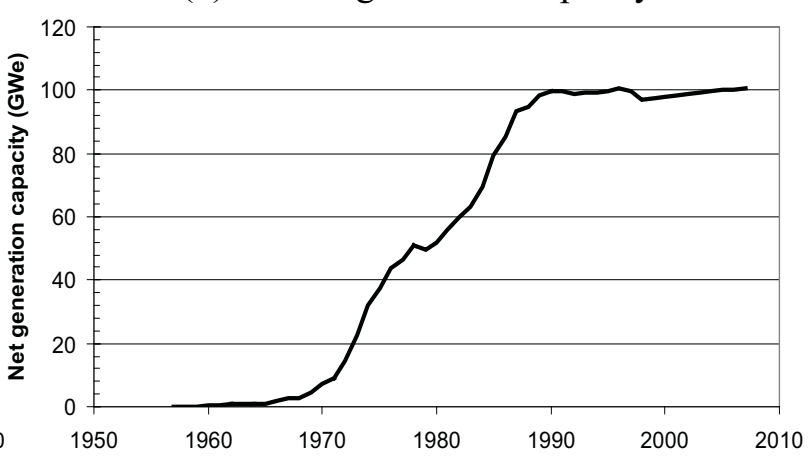

(d) nuclear share of electricity market

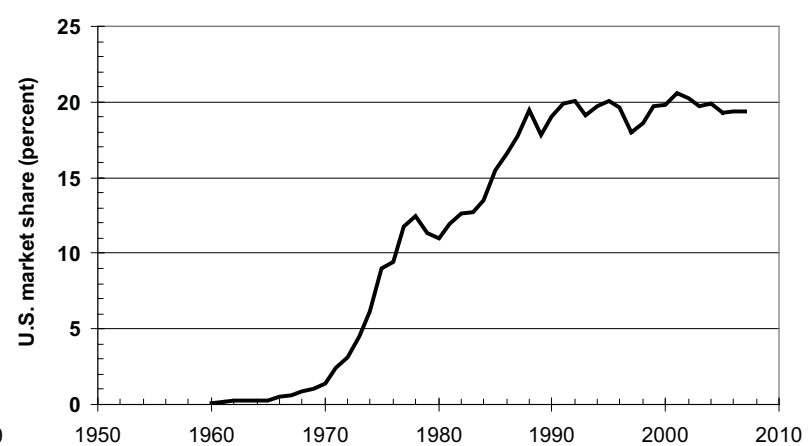

Figure 4-1. U.S. commercial nuclear power plants: (a) number, (b) capacity, (c) electricity generated, (d) percent of U.S. electricity generated by nuclear, and (e) average capacity factor. 
AFCI calculations into the future actually start in the year 2000. To match historical data from DOE Energy Information Administration,[DOE2007] all calculations used the following specifications for the year 2000:

- Nuclear electrical generation of 86.002 GWe-year, or 753.89 billion kW-hour. ${ }^{a}$

- Total electrical generation of $433.7 \mathrm{GWe}$-year, or 3802.11 billion kW-hour.

- Therefore, the nuclear market share of electricity generated was $19.83 \%$ in 2000 .

DSARR analyses base the amount of total electricity from the initial value (433.7 GWe-year), growing at a user-defined growth rate. The user-defined growth rate can be varied by year; however, to reduce complexity and better understand trends, the DSARR calculations were performed at a constant $1.2 \%$ year growth in total electricity, see figure 4-2. Although low relative to the last several decades, the assumed value of $1.2 \%$ year does match the average annual growth estimated by the Energy Information Administration (EIA) for 2007 to 2030.[DOE2007a] (Note: The early release of the 2008 EIA projections include an additional reduction in electricity demand growth. However, the EIA analysis does not include the potential for a shift from oil to electricity for the transportation sector later in the century.)

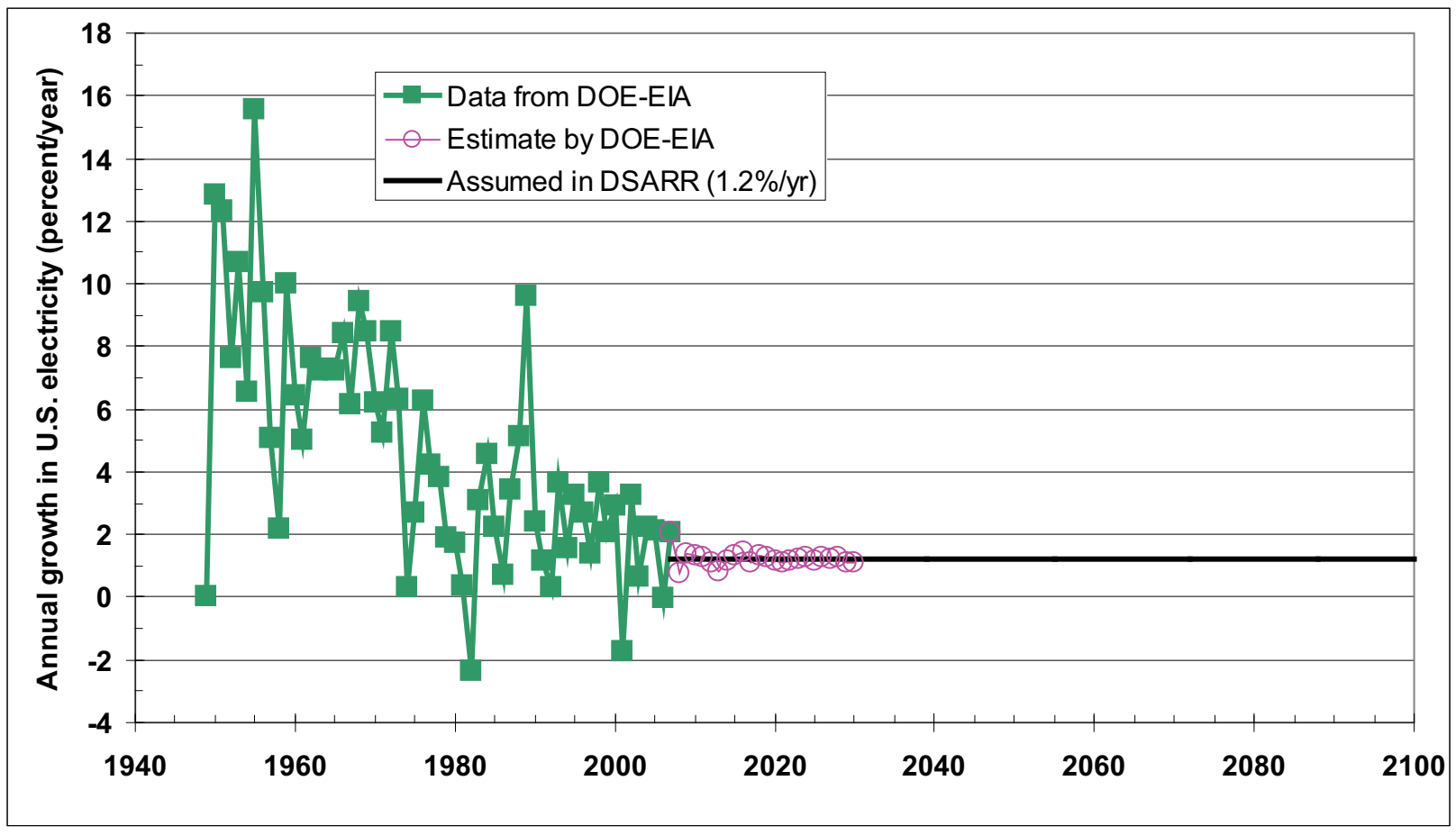

Figure 4-2. Annual growth in U.S. total electricity.

Three time periods were identified for DSARR analyses,[DOE-NE2008] as follows:

2000-2007 - initialize by matching actual nuclear electricity generation data as closely as possible

2007-2014 - no increase in nuclear electricity generation

2015-2100 - nuclear electricity generation

Per DOE, no additional increase in nuclear electricity generation is assumed until 2015. This is motivated by the lack of any current firm orders (as of May 2008) for new nuclear power plants and an implicit

\footnotetext{
${ }^{\text {a }}$ The total capacity in 2000 was about $97.9 \mathrm{GWe}$, for an average fleet capacity factor of $88 \%=86 \mathrm{GWe}-\mathrm{year} / 97.9 \mathrm{GWe}$.
} 
assumption that the first new reactors will take at least 6 years to come on line. However, the "no increase" assumption neglects the effective increase that is likely to occur from uprates of the existing 104 nuclear power plants and any increase of average capacity factor, as well as the completion of Watts Bar 2, scheduled for 2013.[TVA2008] Uprates can have a significant impact on nuclear growth. For example, in the first 5 months 2008, uprates have amounted to an addition of over $500 \mathrm{MWe}$ of generation capacity (or about half a reactor), while "pending" and "expected" uprates tracked by the NRC total an additional 2,600 MWe through 2011.[NRC2008]

Once a new period of reactor deployment starts, what growth rate should be assumed? DOE has specified a growth rate of $1.75 \%$ /year starting in 2015. Figure 4-3 shows historical data [DOE2007], projections to 2030 by DOE EIA [DOE2007a], and the DSARR assumption of $1.75 \% / y r$ starting in 2015. Figure 4-3 shows how modest are the DOE-EIA and DSARR estimates relative to historical data.

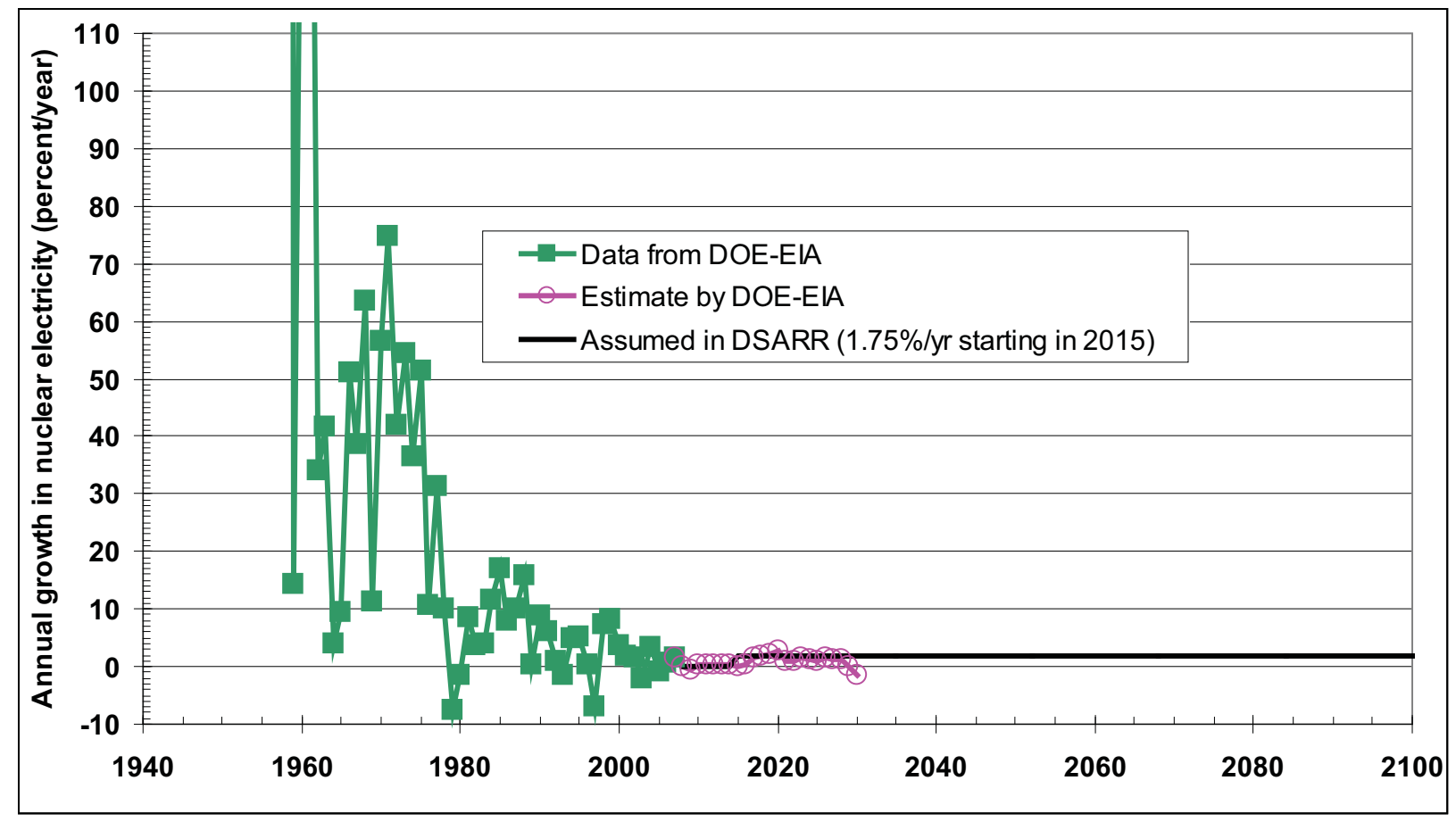

Figure 4-3. Nuclear electricity growth rate from earliest reactors to 2100. 


\section{FUELS AND URANIUM}

\subsection{Uranium}

The once-through fuel cycle consumes less than $1 \%$ of mined uranium, with the rest left in enrichment tails and used fuel. Recycling of used fuel allows for slightly more of the uranium to be consumed, but $100 \%$ of the depleted uranium from enrichment and $99 \%$ of the uranium recovered from used fuel remains unused at a fast reactor conversion ratio of 0.50 .

Uranium is a metal, which is in the oxide form in nature. Pure uranium oxide is a yellow powder, called yellowcake. Slightly enriched uranium is made into fuel pellets, placed in long metal rods, and the rods are grouped into box-like "assemblies." See figure 5-1.

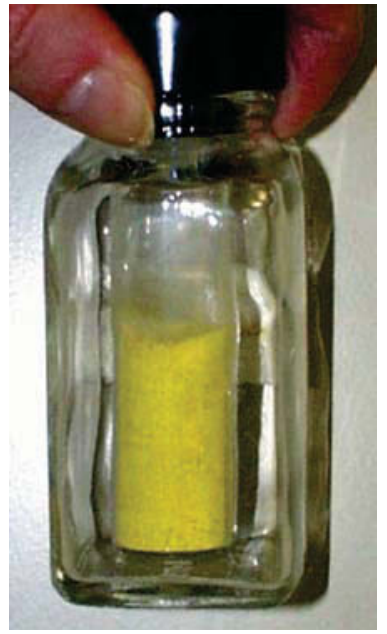

Yellowcake uranium

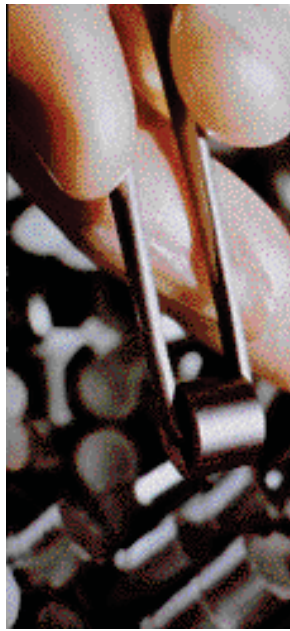

Fuel pellet

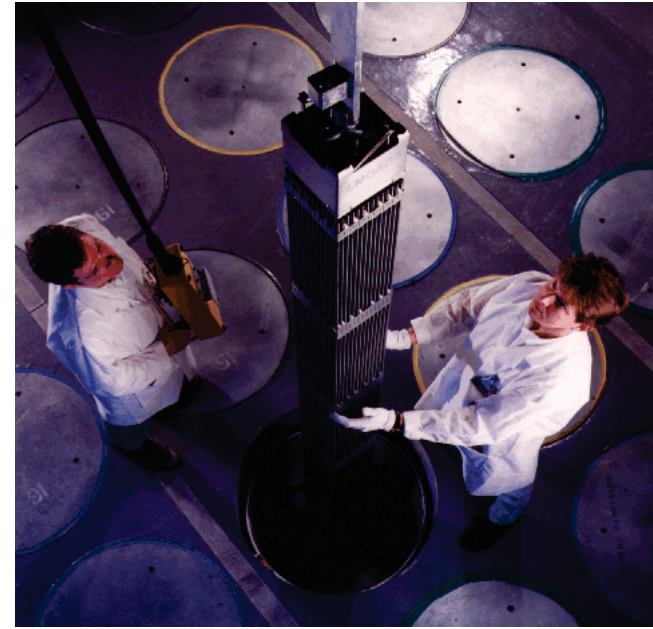

Fuel assembly

Figure 5-1. Illustrative pictures of uranium oxide, fuel pellet, and fuel assembly.

Nuclear fuel provides a lot of energy with little fuel mass, few structural materials, and little use of land. A power plant producing 1000 megawatts of electricity for $90 \%$ of the year requires 22 tons of uranium fuel or 1.6-3.3 million tonnes of coal. Such plants generate 7.9 million megawatt-hours in a year.

\subsubsection{Estimates of uranium resources}

Consider the range of estimates of world uranium resources in Table 5-1 relative to the 2006 production rate of 40,000 tonne-U. Note that the most recent OECD/IAEA Redbook did not increase the total estimated conventional resources relative to the last several estimates. Without nuclear power growth, that production rate would exhaust total estimated conventional resources $(16,000,000$ tonnes-U) in 400 years. That time scale can drop to within a century with modest nuclear power growth, but extend many centuries if unconventional resources become practical. 
Table 5-1. World Potential Uranium Resources

\begin{tabular}{|c|c|c|}
\hline Conventional resources & Reference & $\begin{array}{l}\text { Million } \\
\text { Tonnes U }\end{array}$ \\
\hline Reasonably assured resource, at $<\$ 130 / \mathrm{kg}-\mathrm{U}\left(<\$ 50 / \mathrm{lb} \mathrm{U}_{3} 0_{8}\right)$ & Redbook2007 & 3.3 \\
\hline Inferred resources, at $<\$ 130 / \mathrm{kg}-\mathrm{U}\left(<\$ 50 / \mathrm{lb} \mathrm{U} \mathrm{U}_{3}\right)$ & Redbook2007 & 2.1 \\
\hline Prognosticated resources, at $<\$ 130 / \mathrm{kg}-\mathrm{U}\left(<\$ 50 / \mathrm{lb} \mathrm{U}_{3} 0_{8}\right)$ & Redbook2007 & 2.8 \\
\hline Speculative resources, at $<\$ 130 / \mathrm{kg}-\mathrm{U}\left(<\$ 50 / \mathrm{lb} \mathrm{U}_{3} 0_{8}\right)$ & Redbook2007 & 4.8 \\
\hline \multicolumn{3}{|l|}{ Total estimated conventional resources } \\
\hline Above 4 categories, $<\$ 130 / \mathrm{kg}-\mathrm{U}\left(<\$ 50 / \mathrm{lb} \mathrm{U}_{3} 0_{8}\right)$ & Redbook2007 & 13 \\
\hline Above 4 categories, plus "cost range unassigned" & Redbook2007 & 16 \\
\hline Undiscovered + known $<\$ 130 / \mathrm{kg}-\mathrm{U}\left(\$ 50 / \mathrm{lb}-\mathrm{U}_{3} \mathrm{O}_{8}\right)$ & Herring2004 & 15 \\
\hline Undiscovered + known $<\$ 130 / \mathrm{kg}-\mathrm{U}\left(\$ 50 / \mathrm{lb}-\mathrm{U}_{3} \mathrm{O}_{8}\right)$ & Steyn 2003 & 16 \\
\hline Unconventional resources & Reference & Tonnes U \\
\hline Uranium in sandstone deposits & Herring2004 & 180 \\
\hline Uranium in volcanic deposits & Herring2004 & 2,000 \\
\hline Uranium from seawater & Herring2004 & 4,200 \\
\hline Uranium in phosphate deposits & Herring2004 & 800,000 \\
\hline
\end{tabular}

\subsubsection{Estimates of uranium cost as uranium resources are used}

Figure 5-2 shows estimates of uranium cost as a function of accumulated uranium used. Recall that total estimated conventional resources are $\sim 16$ million tonnes; these cost curves range up to 100 million tonnes because simulations of world uranium use through this century can reach tens of millions of tonnes. For example, recent world nuclear electricity scenarios through 2095 require 24-40 million tonnes.[Kim2008] This exceeds the total estimated conventional resources in previous Table 5-1. 


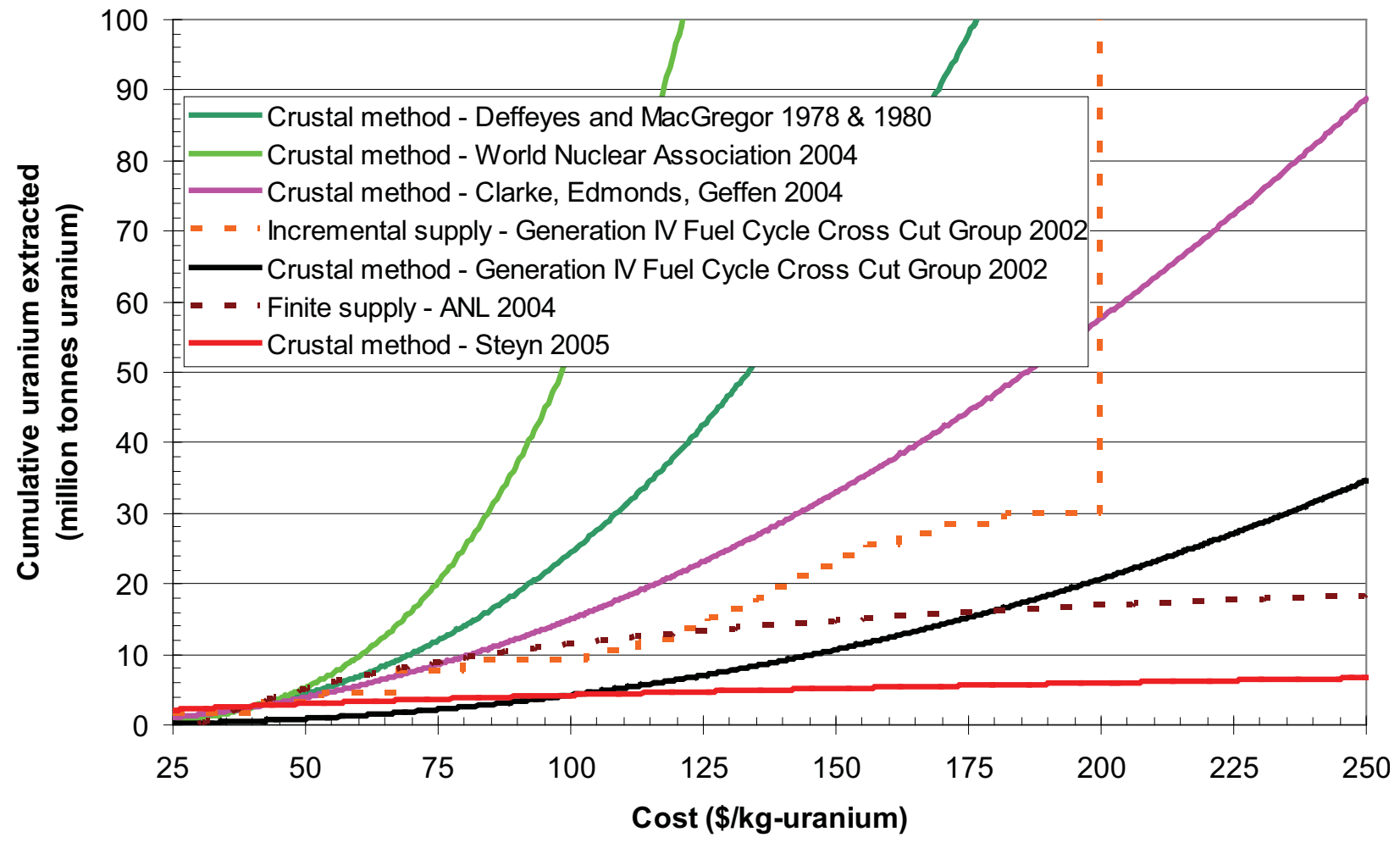

Figure 5-2. Uranium supply curves.

\subsubsection{Idealized estimates of uranium needed}

All uranium isotopes are radioactive, and chemically toxic. Thus, uranium that is not consumed as fuel is radioactive and chemical waste. So, the more U-235 and U-238 consumed, the less waste. There are several forms of uranium relevant to fuel cycles:

$\mathrm{NU}=$ natural uranium, $0.7 \% \mathrm{U}-235,99.3 \% \mathrm{U}-238$

$\mathrm{EU}=$ uranium enriched in U-235, e.g., LWRs use uranium oxide fuel that is typically $4.3 \% \mathrm{U}-$ 235 for a burnup of $\sim 51 \mathrm{GWth}-$ day/tonne of heavy metal.

$\mathrm{DU}=$ uranium depleted in U-235, e.g. typically $0.2-0.3 \% \mathrm{U}-235$.

For 1-tier fuel cycles, figure 5-3 shows how much RU and DU would be consumed as fuel at static equilibrium. Uranium not consumed as fuel is either put into storage for future use or disposed as waste. At the DSARR nominal value of 0.50 TRU conversion ratio, only $1.3 \%$ of the RU and none of the DU are reused as fuel. (Uranium in discharged fast reactor fuel is assumed recycled into new fast reactor fuel.) Use of RU increases to $4.2 \%$ at fast reactor TRU conversion ratio of 0.75 . With fast reactor TRU conversion ratio $\sim 0.99,100 \%$ of the $\mathrm{RU}$ is used as fuel but some of the DU is not. Above TRU conversion ratio $\sim 0.999$, all of the uranium (both RU and DU) is used as fuel (other than processing losses). 


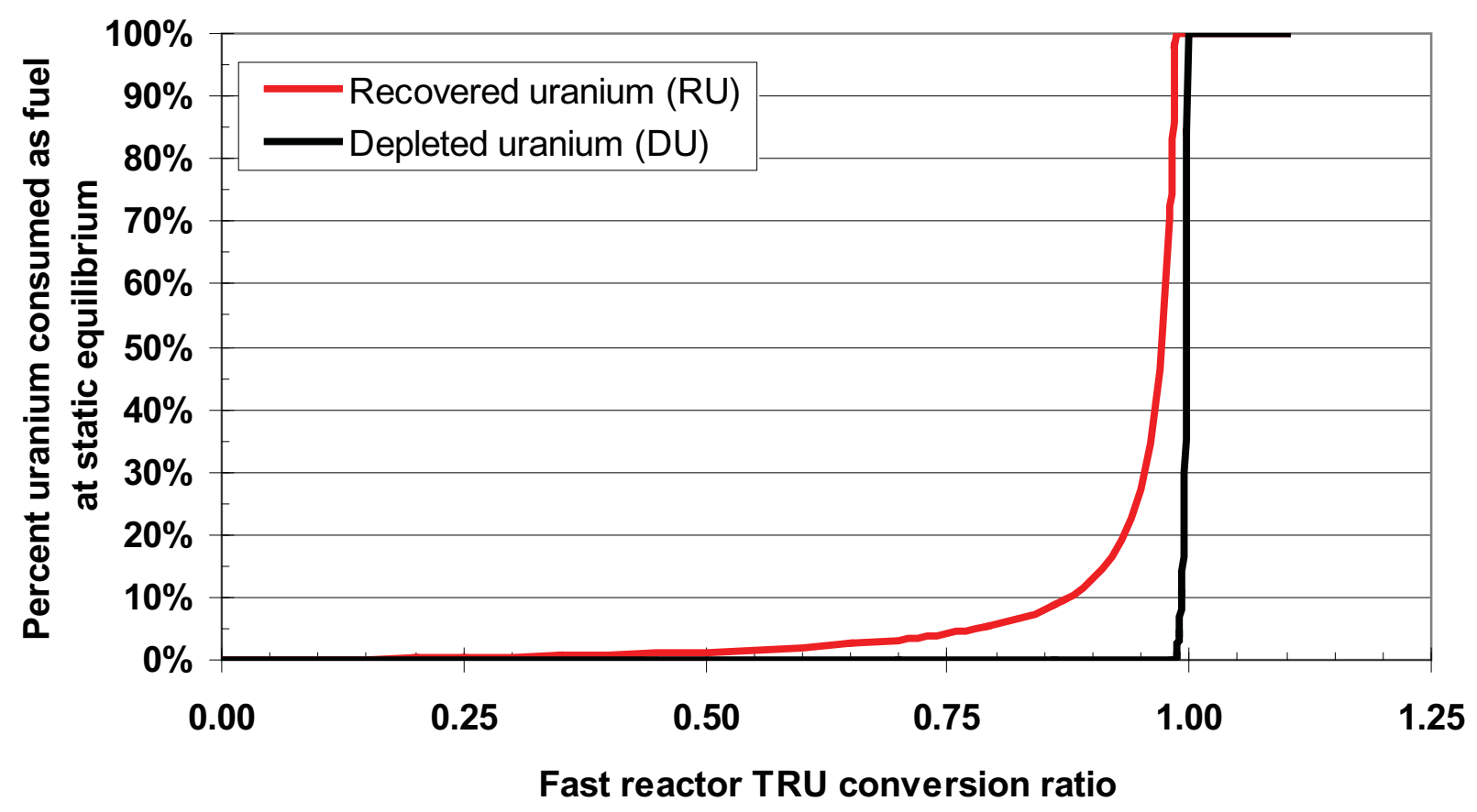

Figure 5-3. Percent of RU and DU from LWRs that are used as fast reactor fuel with fast reactors and LWRs in static equilibrium.

Using the Transmutation Library UOX burnup correlation to relate $\%$ U235 to burnup, we can calculate figure 5-4 using these parameters: $0.71 \%$ U235 natural uranium, $0.25 \%$ U235 enrichment tails, 1 GWe/year reactor capacity, $90 \%$ reactor capacity factor, and $34 \%$ thermal efficiency. There is a broad minimum in the requirement of uranium ore/year; the actual minimum for the above parameters is at 56 GWth-day/tonne-iHM, but burnups from 43 to 77 are within $1 \%$ of the minimum. Thus, there is little potential for uranium ore improvement versus current values. The value from increased burnup is reduction of refueling downtime. But, this may be reaching a limit because some downtime is required for maintenance activities other than refueling. 


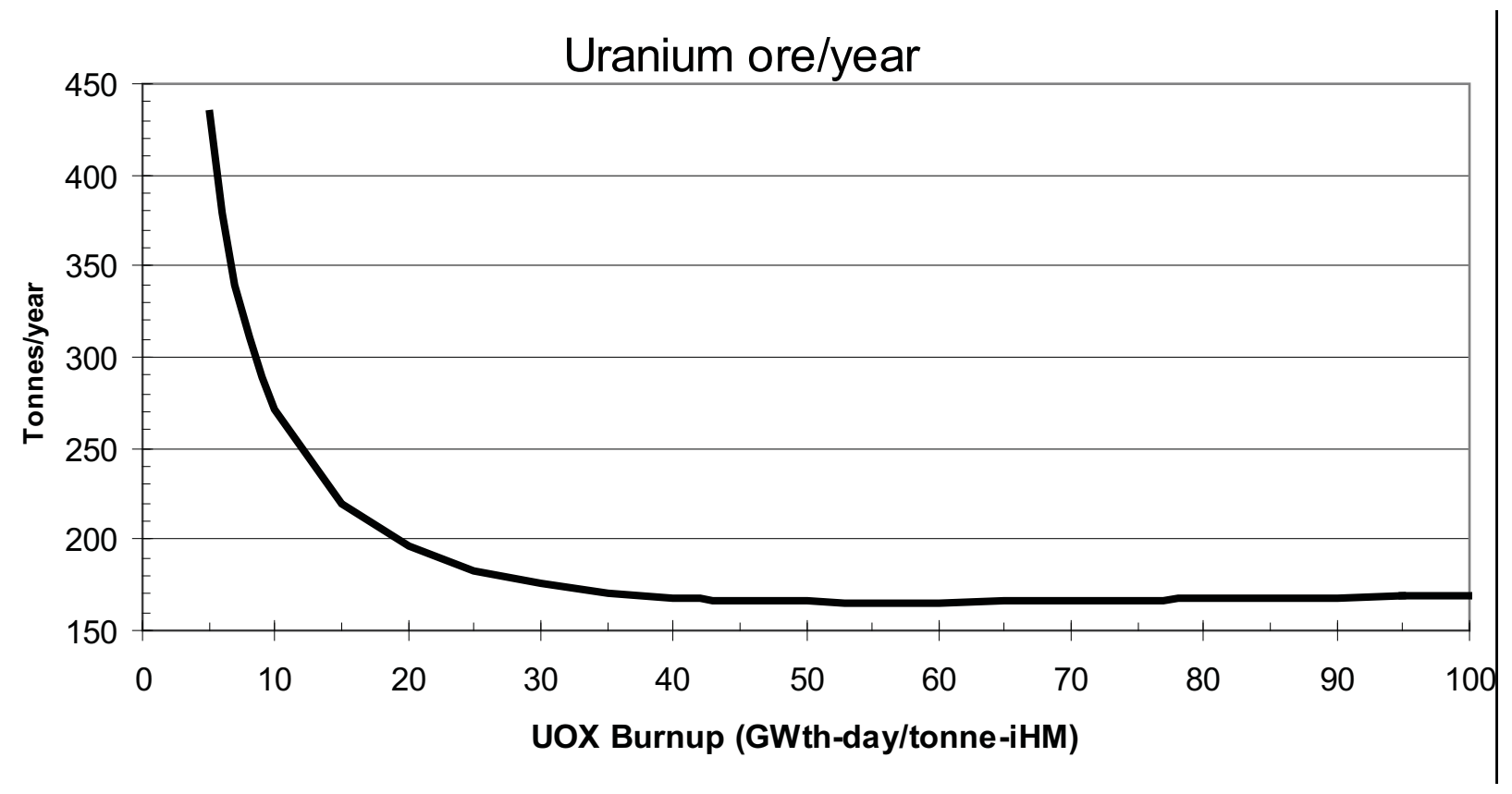

Figure 5-4. Annual uranium use for once-through LWR UOX as function of burnup.

The above graph means that going above $\sim 56 \mathrm{GWth}$-day/tonne from a uranium conservation stand-point provides diminishing returns. There are other factors such as SWUs (see below), mass of used fuel (see below), and downtime for refueling. Refueling downtime ceases to matter once downtime for maintenance of other things dominates total downtime. The current burnup $(\sim 50)$ is getting close.

Now consider a 3-batch fuel management producing $51 \mathrm{GWth}$-day/tonne-iHM discharge burnup. Figure 5-5 shows the mass of fuel (i.e. the mass of enriched uranium input and the mass of used fuel discharged) and SWUs/year. As SWUs are less expensive, the optimum burnup can shift further to the right. (The optimum tails can also slightly decrease, shifting figure 5-2 above slightly.) If the mass of discharged fuel is a primary concern, then the optimum burnup can also shift to the right. Remember, however, that long-lived fission product yields depend only on the number of fissions, hence energy produced, so longlived waste metrics other than uranium fuel mass are independent of burnup. 


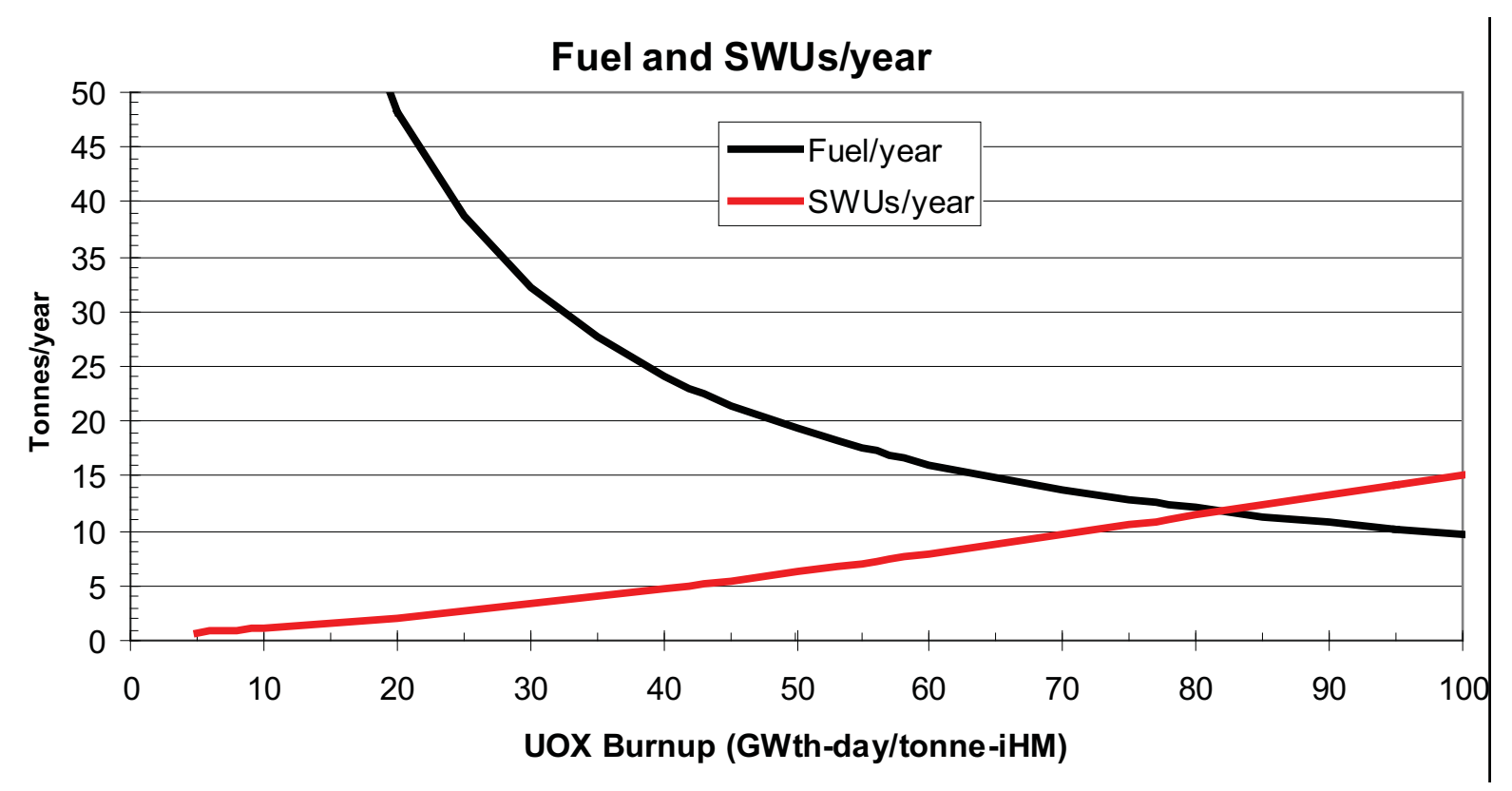

Figure 5-5. Annual fuel and separative work units (SWU) for once through UOX as function of burnup.

Figure 5-6 shows the U235 enrichment as function of burnup. Current enrichment and fuel fabrication facilities in the U.S. are licensed only to $5 \%$. That limits burnup to $\sim 60 \mathrm{GW}$ th-day/tonne until/unless safety analyses, licensing upgrades, and perhaps facility upgrades allow exceeding 5\%. New enrichment plants are reporting applying for licenses above 5\%.

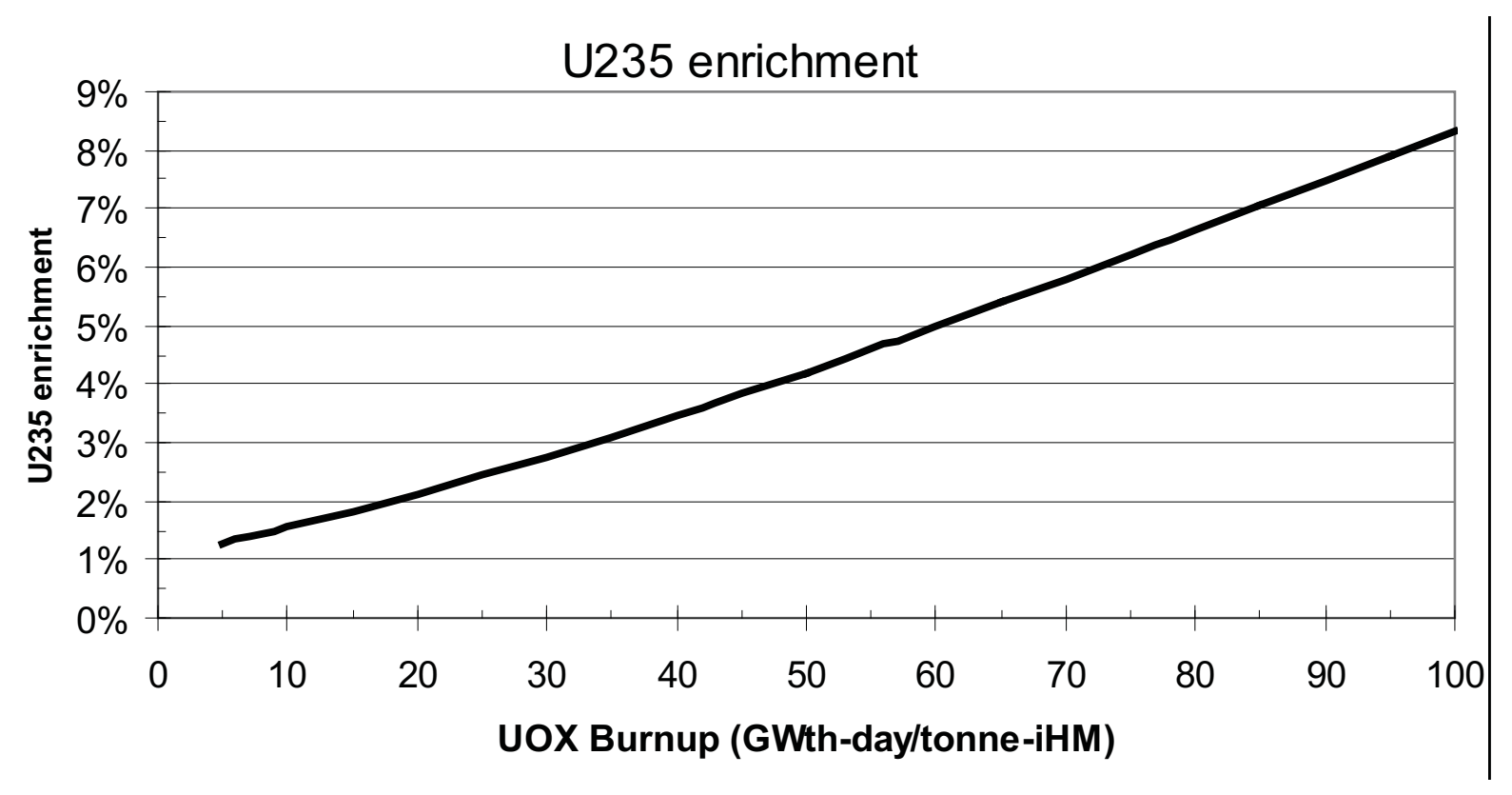

Figure 5-6. Required U235 enrichment for once through UOX as function of burnup.

Figure 5-7 shows the history of U.S. burnup.[DOE2004] For the past several decades, the annual increase in burnup has averaged $\sim 1 \mathrm{GW}$ th-day/tonne-iHM. 


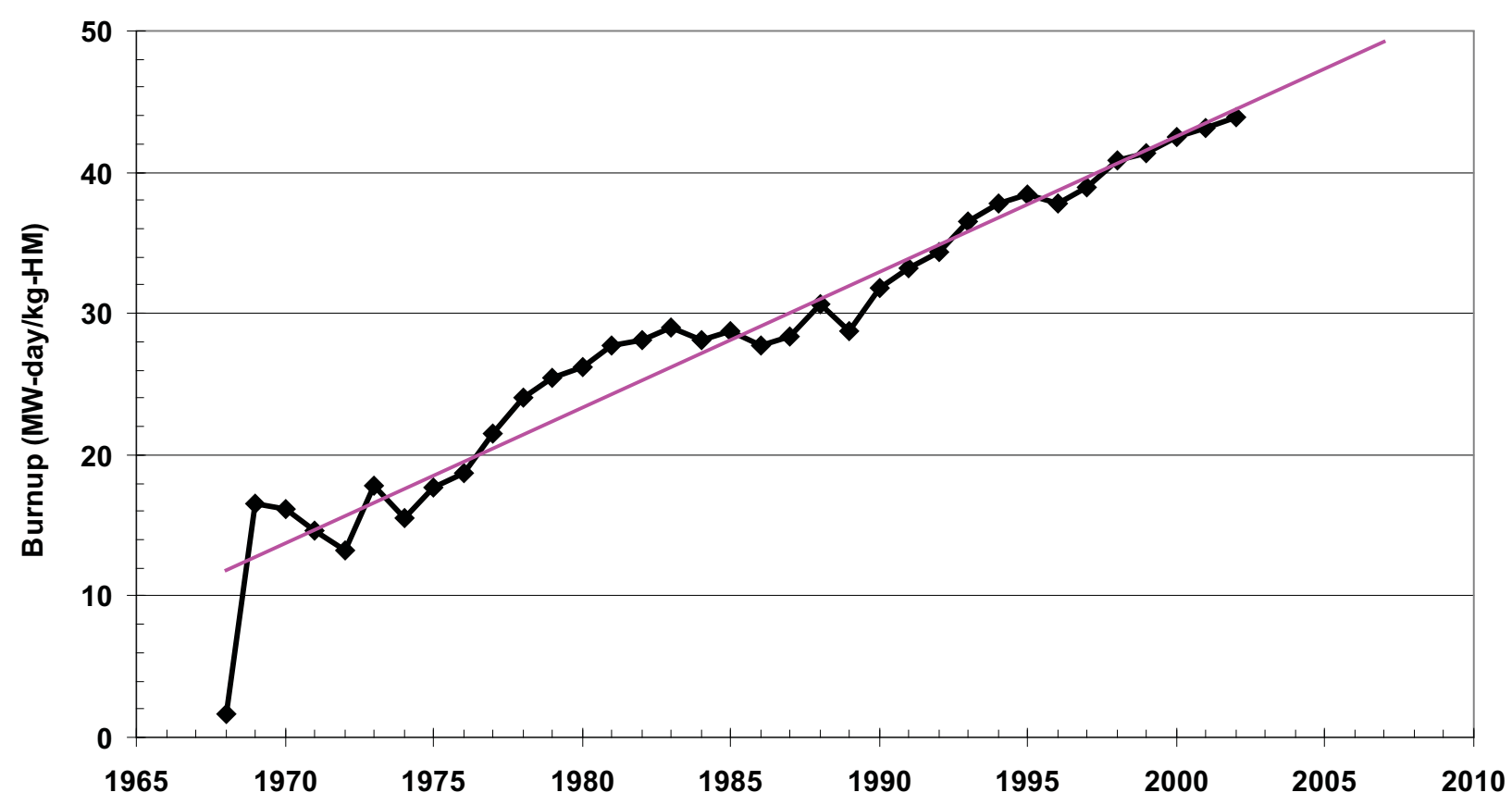

Figure 5-7. History of U.S. burnup for once through UOX as function of burnup. Government data do not extend past 2002. Burnup has been increasing 1 MW-day/kg per year.

\subsubsection{European plans and experience}

The French are not recycling uranium.[WISE2007]

"No use of reprocessed uranium in French reactors in the near future.

The uranium recovered from reprocessing of spent fuel in France is not expected to be used for the manufacture of nuclear fuel in the near future. French utility EdF rather has made provisions for longterm storage of the reprocessed uranium for 250 years. This was revealed in a report of the French Court of Auditors on the decommissioning of nuclear facilities and the management of radioactive wastes.

Usage of the reprocessed uranium (REPU) is problematic for several reasons: since the REPU is contaminated with the artificial uranium isotopes U-232 and U-236, special precautions are necessary during processing: the U-232 and its decay products cause elevated radiation doses for the plant personnel, and the U-236 as a neutron absorber requires higher enrichment levels to achieve the same reactivity. In consequence, use of the REPU is not very attractive at present market conditions: conversion is three times more expensive than conversion of natural uranium, and enrichment cannot be done in France's sole enrichment plant (Eurodif gazeous diffusion plant), since the REPU would contaminate the plant's circuits. For production of two test refueling batches for the Cruas nuclear power plant, the REPU was enriched in a foreign (presumably Russian) centrifuge enrichment plant.

Of the $1050 \mathrm{t}$ of spent uranium oxide fuel annually generated in France, $850 \mathrm{t}$ are being reprocessed at La Hague, at present. (In addition, $100 \mathrm{t}$ of spent MOX fuel arise, which are not reprocessed at all.) From reprocessing of uranium oxide fuel, approx. $816 \mathrm{t}$ of uranium and $8.5 \mathrm{t}$ of plutonium are recovered. Of the uranium recovered, approx. $650 \mathrm{t}$ are converted to the more stable oxide form for long-term storage, awaiting future uses. 
The uranium recovered in the former Marcoule reprocessing plant has never been recycled into nuclear fuel at all. It still stays at Marcoule, in the liquid form of uranyl nitrate, $3800 \mathrm{t}$ owned by EdF, and 4800 t owned by CEA and Cogéma."

The Russians are recycling uranium.[WNND2009]

"MSZ produces fuel assemblies for both Russian and Western European reactors using fresh uranium as well as recycled uranium recovered from reprocessing. The plant produces fuel assemblies for VVER-440, VVER-1000, RBMK-1000, BN-600 and reactor units for the Russian navy.”

\subsubsection{Calculations of uranium needed}

As noted above, either U-235 or U-238 is the ultimate fuel supply. (This report does not address thorium fuel cycle options.) For systems in static equilibrium with TRU conversion ratio of 1 and above, close to $100 \%$ of the energy content in the original uranium ore can be used, but about $1 \%$ is used in the oncethrough fuel cycle. Thus, 100-fold improvement in uranium usage ("uranium improvement factors") is theoretically possible relative to once-through. The DSARR nominal TRU conversion ratio of 0.50 gives an uranium improvement factor (at static equilibrium) of 1.5 ; less than $2 \%$ of the original uranium ore energy content is used.

However, the static equilibrium performance is never achieved in practice. Using the VISION model, figure 5-8 shows the uranium improvement factor integrated over the time period 2000-2100, compared with the static equilibrium uranium improvement factors. (The curves should increase dramatically as the fast reactor TRU conversion ratio increases beyond the values considered in this study.) The dynamic uranium improvement factors are lower than the static equilibrium factors because of the slowness in building fast reactors, the required cooling time (assumed 10 years) between discharge of TRU-laden used LWR fuel and recovery of useful material from that fuel, the sequester of 63,000 tonnes of used fuel in a geologic repository (assumed in DSARR), and the need for useful recycle material to make repeated passes through a reactor (so that losses compound).

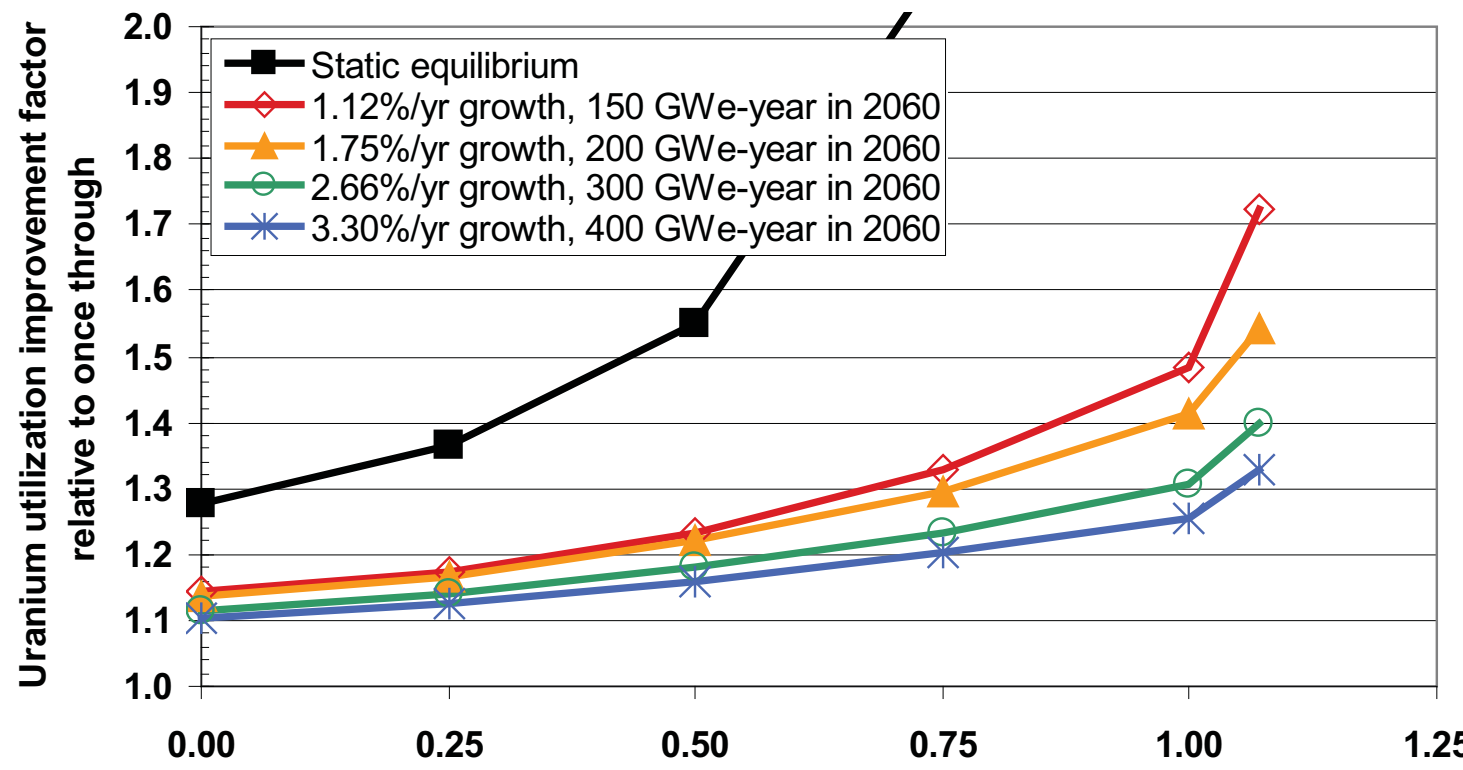

Fast reactor TRU conversion ratio

Figure 5-8. Static equilibrium versus VISION-calculated uranium improvement factors integrated over 2000-2100 relative to once-through uranium oxide in LWRs (51 GWth-day/tonne burnup). 
The simulations build FRs too slowly to dramatically change the uranium requirements for the remainder of the century. However, even if all resources were applied to maximize FR deployment and conversion ratio, the time to commercialize the technology would still result in a very large number of LWRs requiring a lot of uranium during the remainder of this century and well into the next century. More fast reactors means less uranium requirements, but there are limits to the benefit during the remainder of this century. As described below, the situation could be improved by minimizing turnaround recycle time, having a high TRU conversion ratio, and starting as soon as possible.

Burner fast reactors, MOX, re-enrichment, improved uranium enrichment, and different burnups offer limited (but relatively near-term) improvement in uranium use. If the growth of world nuclear power is high or the desired time horizon for uranium sustainability is greater than 2100 , there are only three longterm solutions - unconventional uranium resources, thorium, or deployment of fast reactors with a high TRU conversion ratio.

Previous figure 5-8 shows that a TRU conversion ratio of 1.07 is not sufficient to dramatically reduce uranium ore requirements relative to once-through; the dynamic improvement factors remain below 2.0 even though the static improvement factor at 1.07 would be $\sim 100 \mathrm{x}$. At 1.07 , the increase in TRU supply from fast reactors themselves is not sufficient to grow fast reactors enough to meet increased demand and displace LWRs. So, LWRs remain in the fleet, restricting the uranium improvement factor.

It is possible to estimate how large the TRU conversion ratio must be to support fast reactor growth without depending on TRU from LWRs. Consider an idealized system in which there are no LWRs, the desired nuclear power growth rate is $m$, the time that TRU is in fast reactors is $t_{R}$, the time between fast reactor discharge and re-insertion is $t_{F}$, and isotope decay is ignored. Then, the required TRU conversion ratio $C R$ such that LWR are not required to supply TRU, can then be expressed as

$$
C R=e^{m\left(t_{F}+t_{R}\right)}
$$

Thus, $t_{F}+t_{R}$ is the total turnaround time. As an example, if $m=0$, then $C R=1$ and the system is in balance with no LWRs. Or, if one wants $m>0$, then $C R>1$. The higher the desired growth rate, the higher the required CR. In addition, because new fast reactors (growing at rate $m$ ) must have $t_{R}-1$ additional years' worth of fuel to start up, equation 1 must be multiplied by another term.

$$
C R=e^{m\left(t_{F}+t_{R}\right)}\left(1+m\left(t_{R}-1\right)\right)
$$

At the DSARR nominal growth rate of $1.75 \% / y r$, the time lags in the system are important.

$$
\begin{aligned}
& \text { If } t_{F}=2 \text { (example for onsite recycling) and } t_{R}=4 \text {, then } C R=1.17 \text { is required } \\
& \text { If } t_{F}=11 \text { (example for offsite recycling) and } t_{R}=4 \text {, then } C R=1.36 \text { is required }
\end{aligned}
$$

If instead the desired nuclear power growth rate is 3.3\%/yr, the required TRU conversion ratios are 1.22 (onsite) or 1.63 (offsite). If the CR is lower than these values, LWR persist in the system to supply additional TRU, and the potential for uranium improvement is inhibited.

Superphenix had a breeding ratio about 1.2 and would be expected to have a TRU conversion ratio somewhat higher. (The breeding ratio is fissile produced/fissile destroyed; TRU conversion ratio is TRU produced/TRU destroyed. These are related but not identical. As TRU isotopes are bred from U238, only fissile TRU count toward breeding ratio, but all TRU count toward TRU CR.) Figure 5-9 shows the sustainable fast breeder reactor growth rate assuming a TRU CR of 1.3 is possible; the growth rate is 
based on the population of fast reactors only. The minimum total turnaround time is probably $\sim 5$ years, e.g., 3-4 years in reactor plus 1-2 years from reactor discharge to re-insertion. Note that during the introduction of fast breeder reactors, their growth rate must be larger than the growth of nuclear power because they must displace the existing reactor fleet. Thus, the breeder reactor growth rate in figure 5-9 would be lower than the nuclear power growth rate.

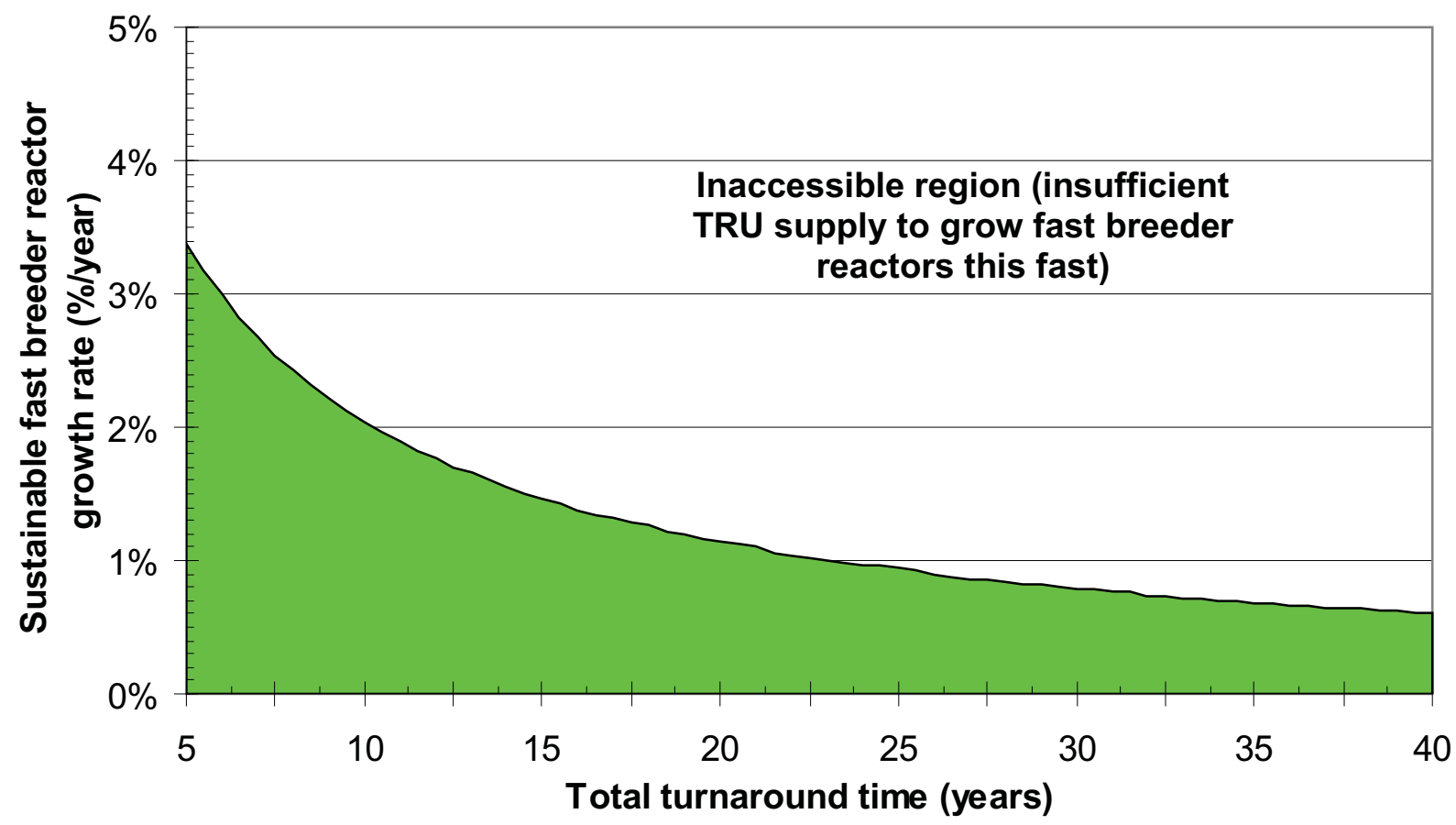

Figure 5-9. Sustainable fast breeder reactor growth rate as a function of total turnaround time, assuming a fast reactor TRU CR of 1.3 is achievable. While fast breeders are displacing other reactors, the nuclear power growth rate will be lower than the fast breeder reactor growth rate shown here.

TRU conversion ratios up to $\sim 1.9$ are theoretically possible because Pu239 provides 2.9 neutrons per fission. (One neutron must be used to cause the next generation of fissions.) Therefore, figure 5-10 shows the sustainable fast breeder reactor growth rate for conversion ratios up to 1.9. 


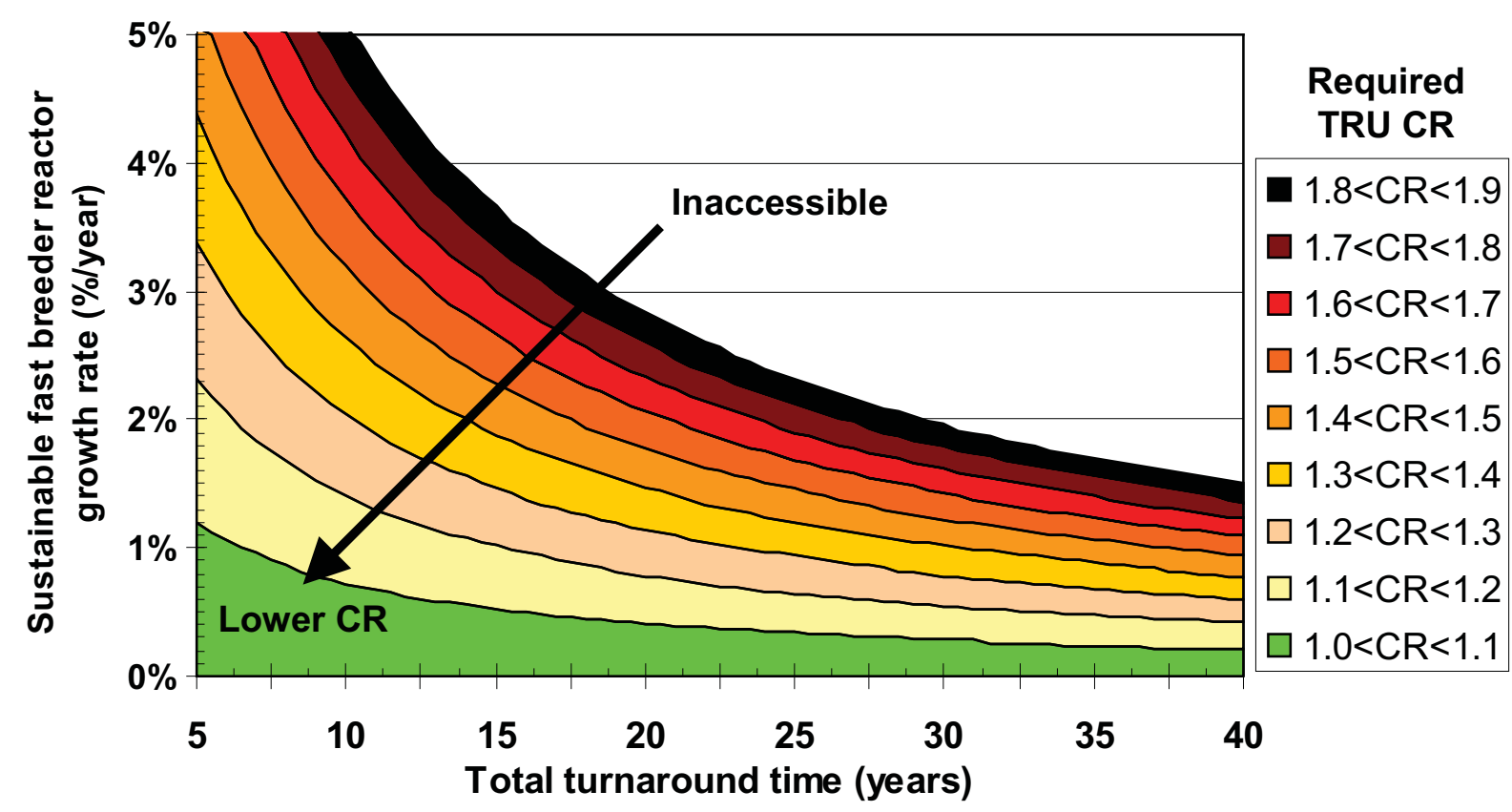

Figure 5-10. Required fast reactor TRU conversion ratio to allow nuclear power growth with requiring TRU supply from LWRs (and hence without uranium enrichment). While fast breeders are displacing other reactors, the nuclear power growth rate will be lower than the fast breeder reactor growth rate shown here.

\subsection{Multiple Recycles of One or More Transuranic Elements}

The mix of isotopes in recycled material depends on the reactor, the TRU conversion ratio, which transuranic elements are recycled, and how many times material has been recycled. To minimize the chance of mis-understandings, when considering isotopic composition of recycled material, there are three important considerations.

First, how are the compositions normalized? Options include "per kg-TRU", "per kg-HM", and "per burnup" depending on purpose. Fuels with recycled material vary from $\sim 1 \%$ TRU to $\sim 100 \%$ TRU, thus the per-kg-TRU and per-kg-HM comparisons can look significantly different. And, neither of those normalizations by themselves suggest how much mass must be separated, fabricated, or irradiated. So, another normalization can be "per MWth-day", i.e., per burnup. In this case, instead of a heat output of $\mathrm{W} / \mathrm{kg}$-TRU, the units would be W(heat) per fission energy produced (W-full-power-year).

Second, what are the relevant metrics to compare fuel compositions? The isotopic mix determines a host of parameters, including the waste management burden, separation and fabrication difficulties, and proliferation resistance.

- Heat, gamma, site-specific dose, and site-independent radiotoxicity of material not recycled.

- Heat, gamma, and neutron emission during separation and fabrication.

- "Pu quality", heat, gamma, and neutron emission impacting detection of stolen material, difficulty in making a weapon, etc.

Third, what exact cases are compared? Results vary as conversion ratio changes, the moderator ratio in LWRs changes, etc. For illustrative purposes, the following graphs compare these cases: 
MOX - Homogeneous MOX with one or more TRU and U235-enriched uranium.[Youinou2009] The total TRU content is limited to $10 \%$ (Pu recycled) or $8 \%(\mathrm{NpPu}, \mathrm{NpPuAm}$, or all-TRU recycled).

IMF - Heterogeneous IMF, i.e., assemblies have a mix of roughly three-quarters IMF pins (no uranium, all TRU) and one-quarter UOX pins (4.3\% enriched U235).[Pope2009]

FR - homogeneous oxide-fueled FR at conversion ratio of 0.50.[Hoffman2007]

Consider figure 5-11 and 5-12, which show how recycle of transuranic material impacts gamma and neutron emission as a function of which TRU elements are recycled, how many times the material is recycled, and which of three illustrative reactor types are used. Subsequent fractions show how the mass fraction of isotopes U234 to Cf252 for discharged material. All graphs show mass fraction with a log scale.

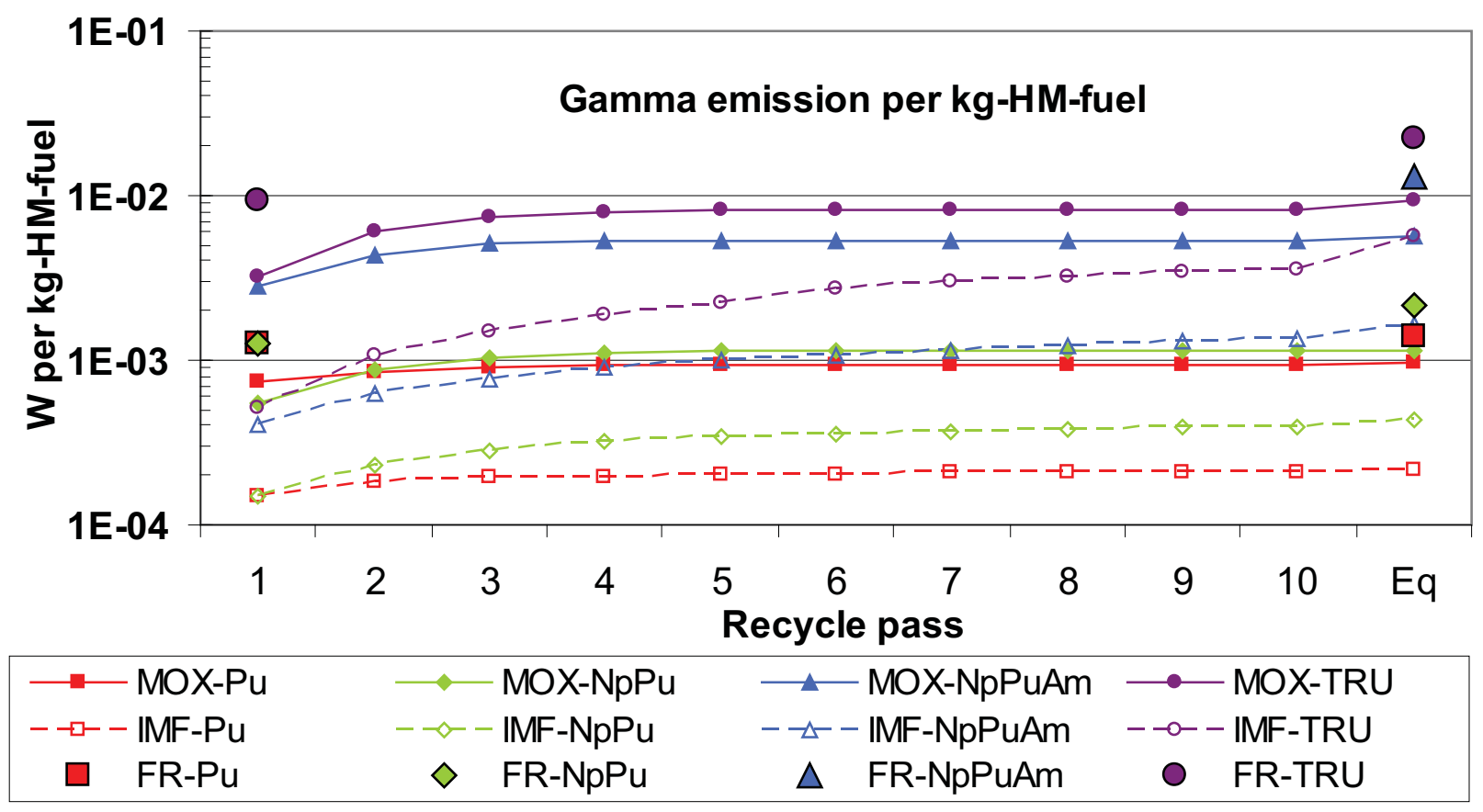

Figure 5-11. Gamma energy emission as a function of number of recycles of $\mathrm{Pu}, \mathrm{NpPu}, \mathrm{NpPuAm}$, or allTRU for heterogeneous IMF, MOX, or oxide-fueled $\mathrm{CR}=0.50$ fast reactor. "Eq" means equilibrium. 


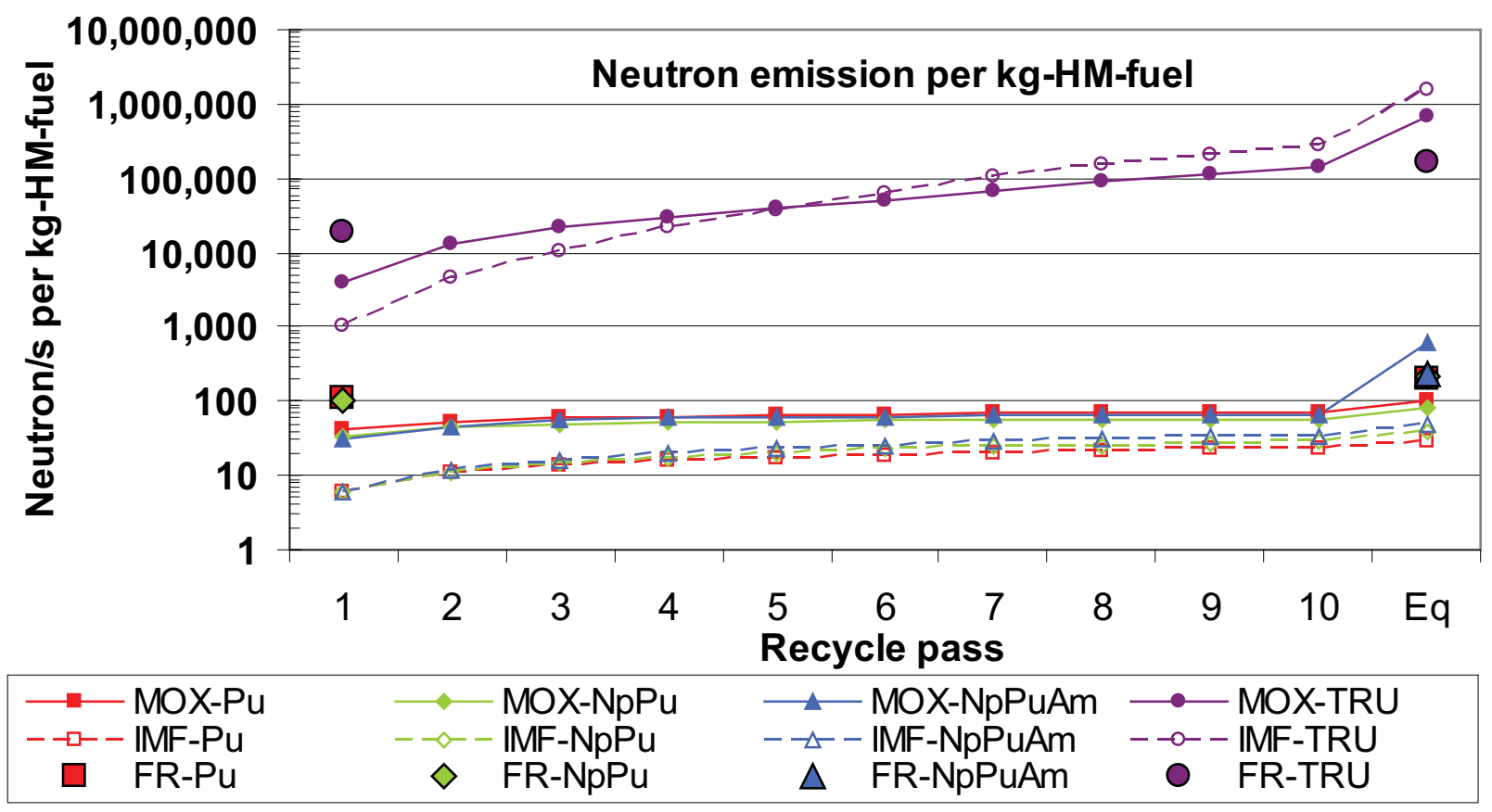

Figure 5-12. Neutron emission as a function of number of recycles of $\mathrm{Pu}, \mathrm{NpPu}, \mathrm{NpPuAm}$, or TRU for heterogeneous IMF, MOX, or oxide-fueled $\mathrm{CR}=0.50$ fast reactor. "Eq" means equilibrium.

Figure 5-13 shows how the fast reactor TRU conversion factor changes the mix of isotopes; data from the Transmutation Library [Piet2008c] from data calculated for [Hoffman2007a]. All cases shown are for fast reactor with metal fuel, equilibrium recycle pass. Note two important trends, as follows:

- As fast reactor TRU conversion ratio increases, the inventory of higher transuranic isotopes decrease. This causes the neutron emission (dominated by the highest transuranics such as Cf252) to decrease substantially for higher conversion ratio.

- Because higher conversion ratio produces more Pu239 from U238, the mass fraction of those isotopes are mostly unchanged. Said another way, as conversion ratio increases the "quality" of the $\mathrm{Pu}$ isotopes increases - fewer fertile Pu isotopes. 


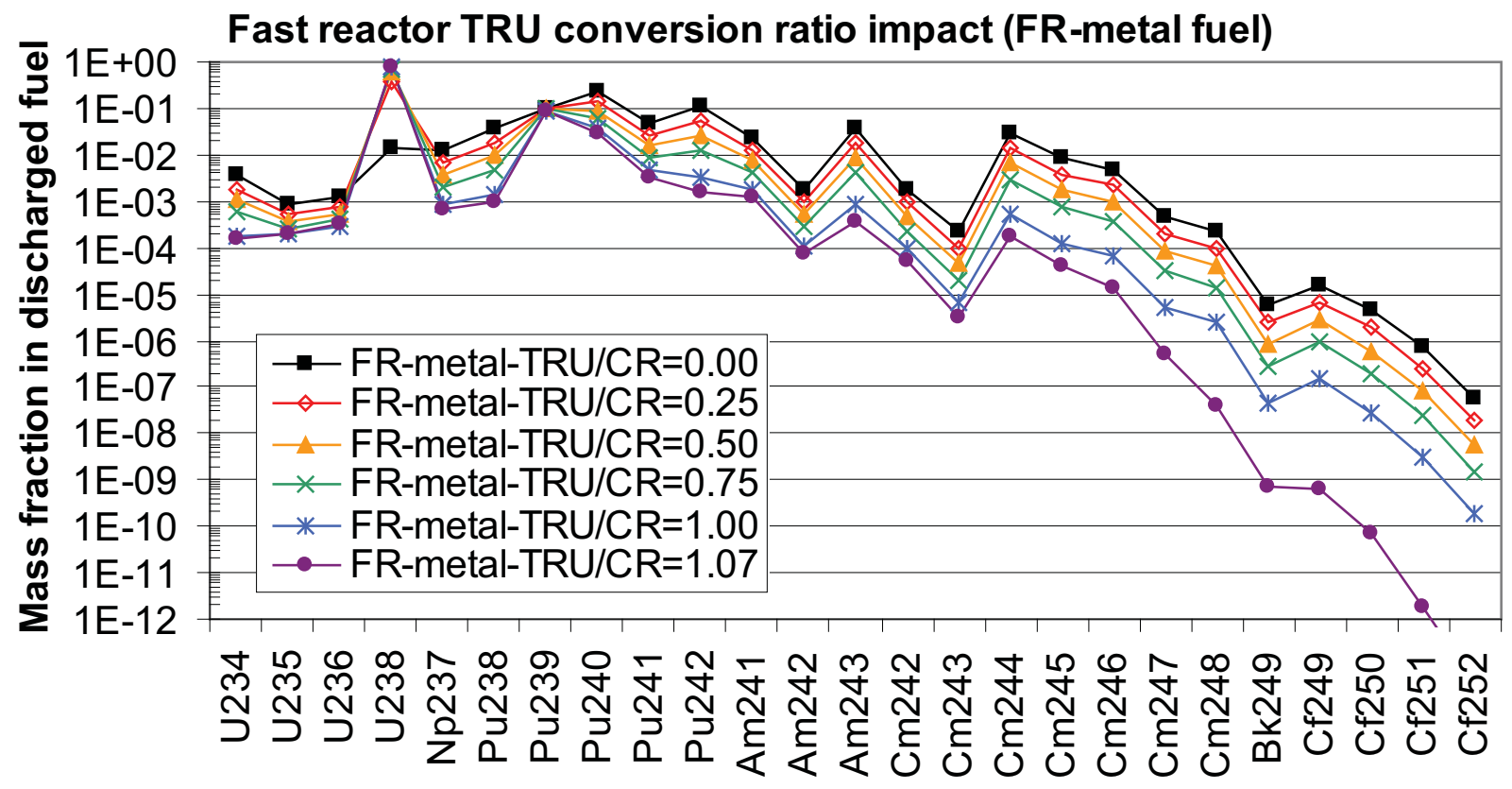

Figure 5-13. Equilibrium isotopic mix of input metal fuel, as function of TRU conversion ratio.

Figure 5-14 shows the impact of recycling $\mathrm{Pu}, \mathrm{NpPu}, \mathrm{NpPuAm}$, and all TRU elements. Data taken from the Transmutation Library,[Piet2008c] compiled from calculations described in [Asgari2007]. All cases shown are for oxide fast reactor fuel, fast reactor TRU conversion ratio of 0.50 , and equilibrium recycle pass. Note three important trends, as follows:

- The only noticeable difference between $\mathrm{Pu}$ and $\mathrm{NpPu}$ is at $\mathrm{Np} 237$ and Pu238. Recycling Np naturally increases Np237 and increases Pu238 due to neutron absorption by Np237.

- Recycling Am increases the inventory of Am isotopes, but less than an order of magnitude. So, there is a slight gamma emission penalty relative to $\mathrm{Pu}$ or $\mathrm{NpPu}$.

- Recycling $\mathrm{Cm}$ increases the inventory of $\mathrm{Cm}$ isotopes by orders of magnitude. The neutron emitters are found preferentially among the $\mathrm{Cm}$ isotopes, so, recycling $\mathrm{Cm}$ leads to substantially higher neutron emission. 


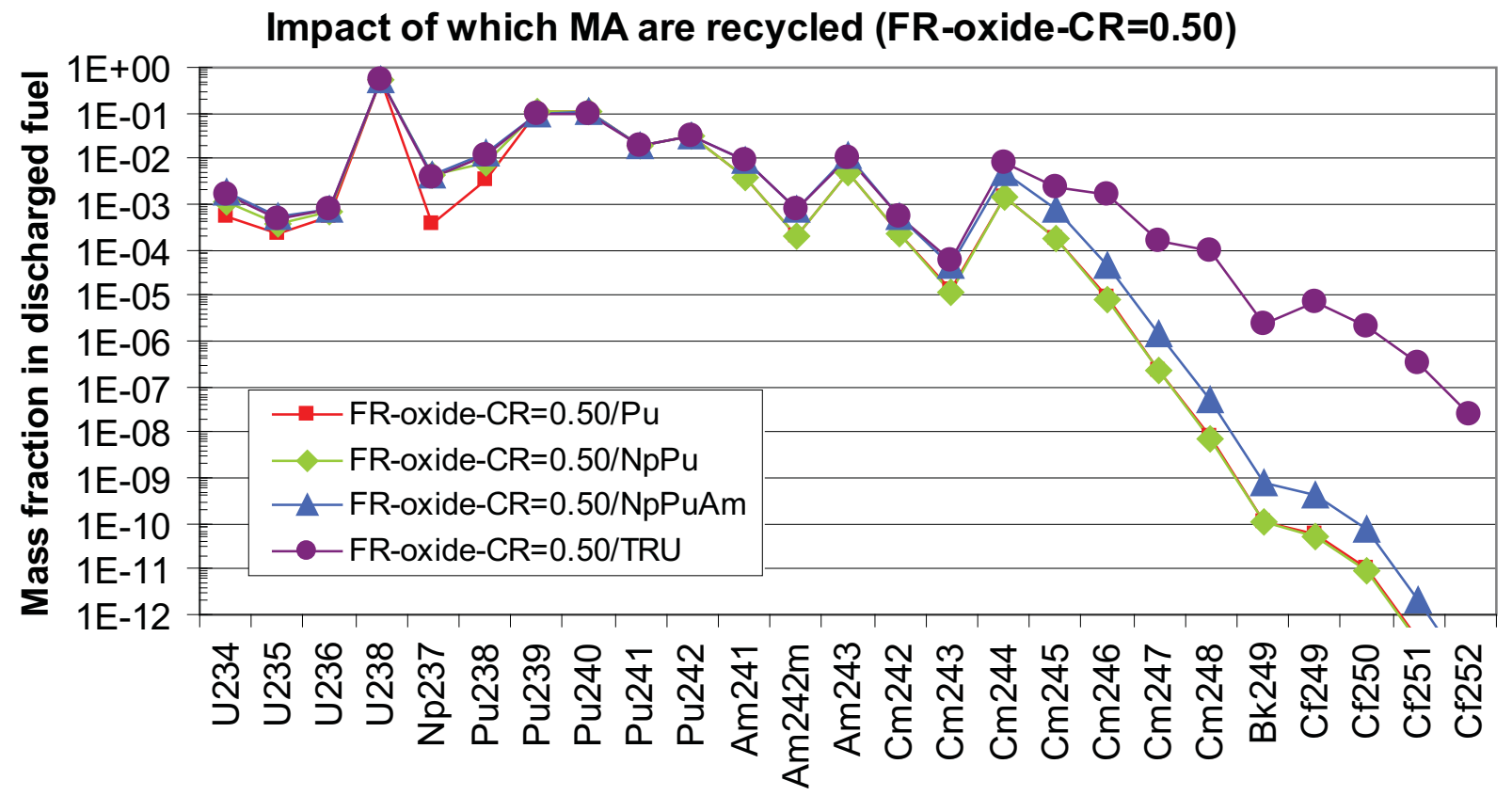

Figure 5-14. Equilibrium isotope mix of output fuel as function of which transuranic elements are recycled in an oxide-fueled fast reactor at $\mathrm{CR}=0.50$.

Figure 5-15 is analogous to figure 5-14, except it shows the impact of recycling $\mathrm{Pu}, \mathrm{NpPu}, \mathrm{NpPuAm}$, and all TRU elements for IMF in an LWR instead of fast reactor. Data are from the Transmutation Library,[Piet2008] from calculations described in [Ferrer2007b]. All cases shown are for heterogeneous assemblies (roughly 3/4 of each assembly are IMF pins, 1/4 are enriched UOX pins). Each case requires addition of U235 to enable recycle of the transuranics that remain after the previous recycle. Note four important trends, as follows:

- The only noticeable difference between $\mathrm{Pu}$ and $\mathrm{NpPu}$ is at $\mathrm{Pu} 238$, which increases due to neutron absorption by Np237.

- Recycling Am increases the inventory of Am isotopes, but less than an order of magnitude, less so than in thermal reactors. So, there is a slight gamma emission penalty relative to $\mathrm{Pu}$ or $\mathrm{NpPu}$.

- Recycling $\mathrm{Cm}$ increases the inventory of $\mathrm{Cm}$ isotopes by orders of magnitude, as is the case in fast reactors. The neutron emitters are found preferentially among the $\mathrm{Cm}$ isotopes, so, recycling Cm leads to substantially higher neutron emission.

- Unlike fast reactors (figure 5-14), the mass fraction does not continue to drop among the Cf isotopes. 


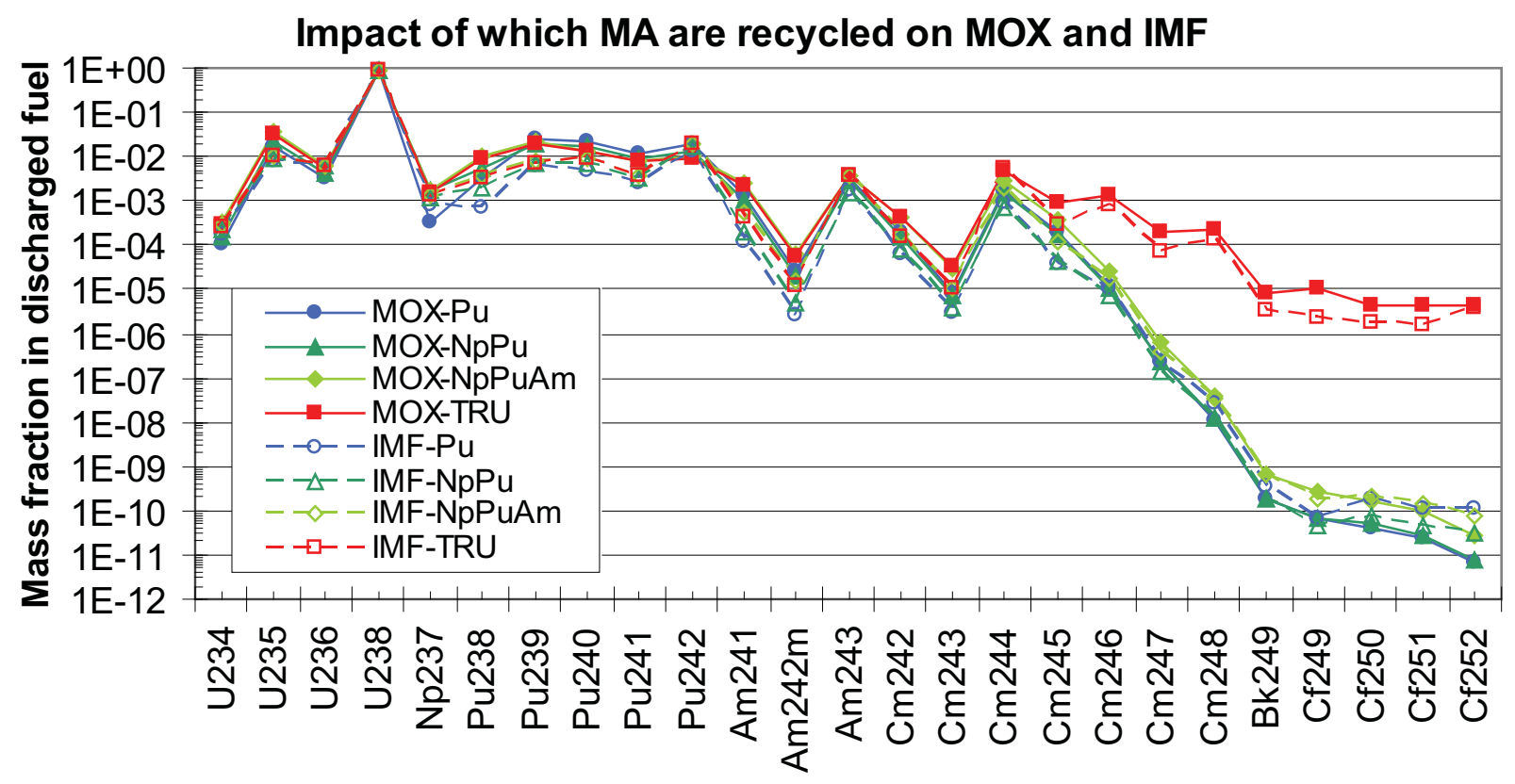

Figure 5-15. Equilibrium isotopic mix as function of which transuranic elements are recycled in LWR via homogeneous MOX or heterogeneous IMF (each assembly has a mix of UOX and IMF pins).

Figure 5-16 compares the equilibrium recycle of all transuranics from fast reactor (oxide fuel, $\mathrm{CR}=0.50$ ) and IMF in LWRs. (These two curves are the same as the "TRU" curve in the previous two figures. Note the scale change.) Multiple recycling of transuranics is possible in both thermal and fast reactor systems, but there are two penalties. Note three important trends, as follows:

- Fissile support is required in the thermal reactor, so the U235 fraction is an order of magnitude higher in LWR-IMF than in the fast reactor. This relates to the orders of magnitude better uranium utilization in fast reactors than in LWRs, a major advantage for fast reactors.

- The depression of fissile isotopes in LWR-IMF are generally somewhat more pronounced than in FR, note for example fissile Am242m, Cm245, and Cm247 are relatively more reduced in LWRIMF than in FR.

- The production of the higher Cf isotopes is higher in the LWR, leading to the neutron emission penalty of TRU recycling in LWRs versus FR. This is another advantage for fast reactors. 


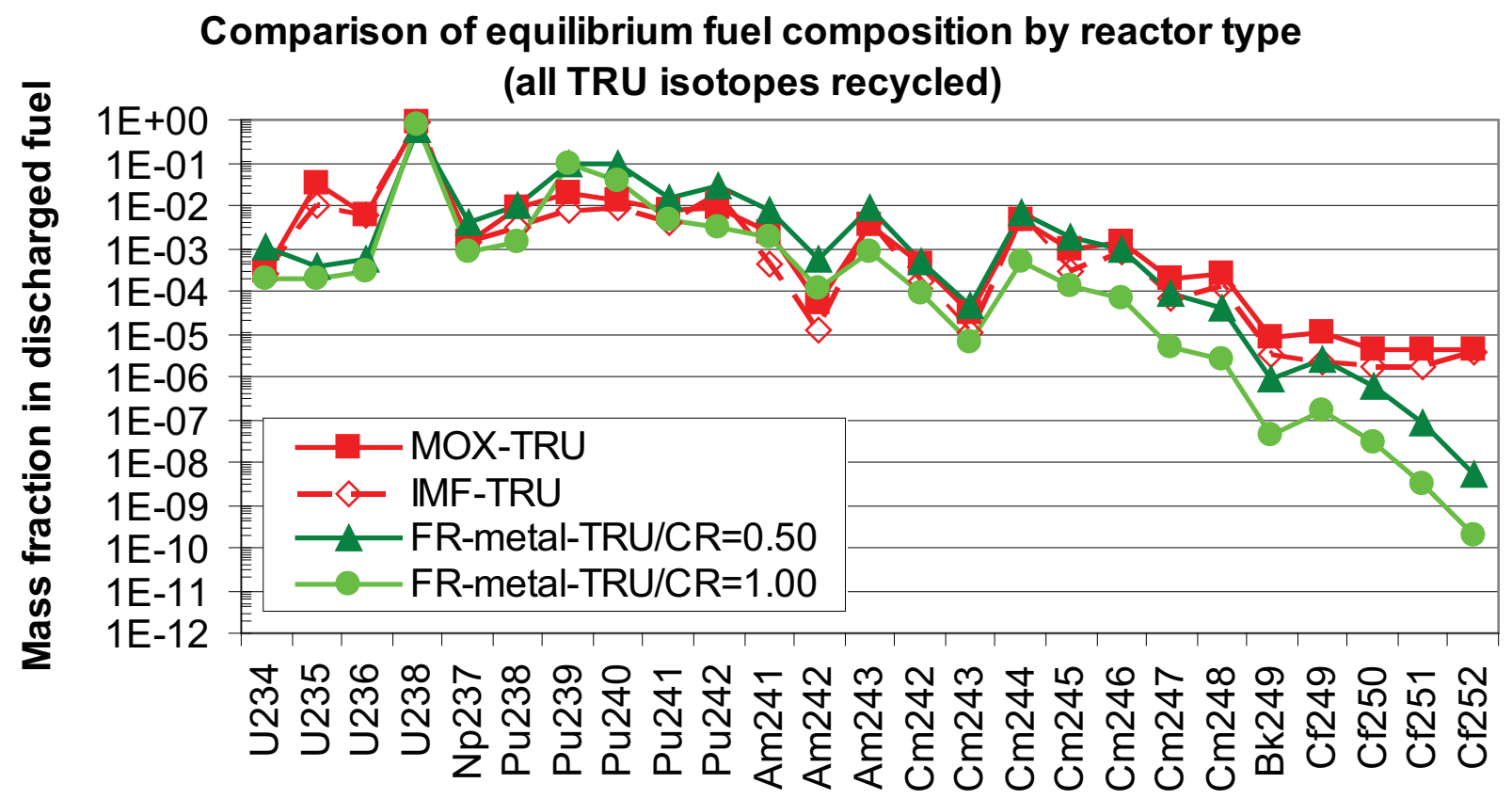

Figure 5-16. Equilibrium isotope mix as recycled in illustrative LWR and fast reactor cases.

Figure 5-17 shows the final figure in this subsection; it shows the evolution of the recycle mix as TRU material is repeatedly recycled. In particular, the $\mathrm{Cf}$ isotopes increase three orders of magnitude between the first recycle and equilibrium. The Eq (equilibrium) curve is the same as in the previous two figures.

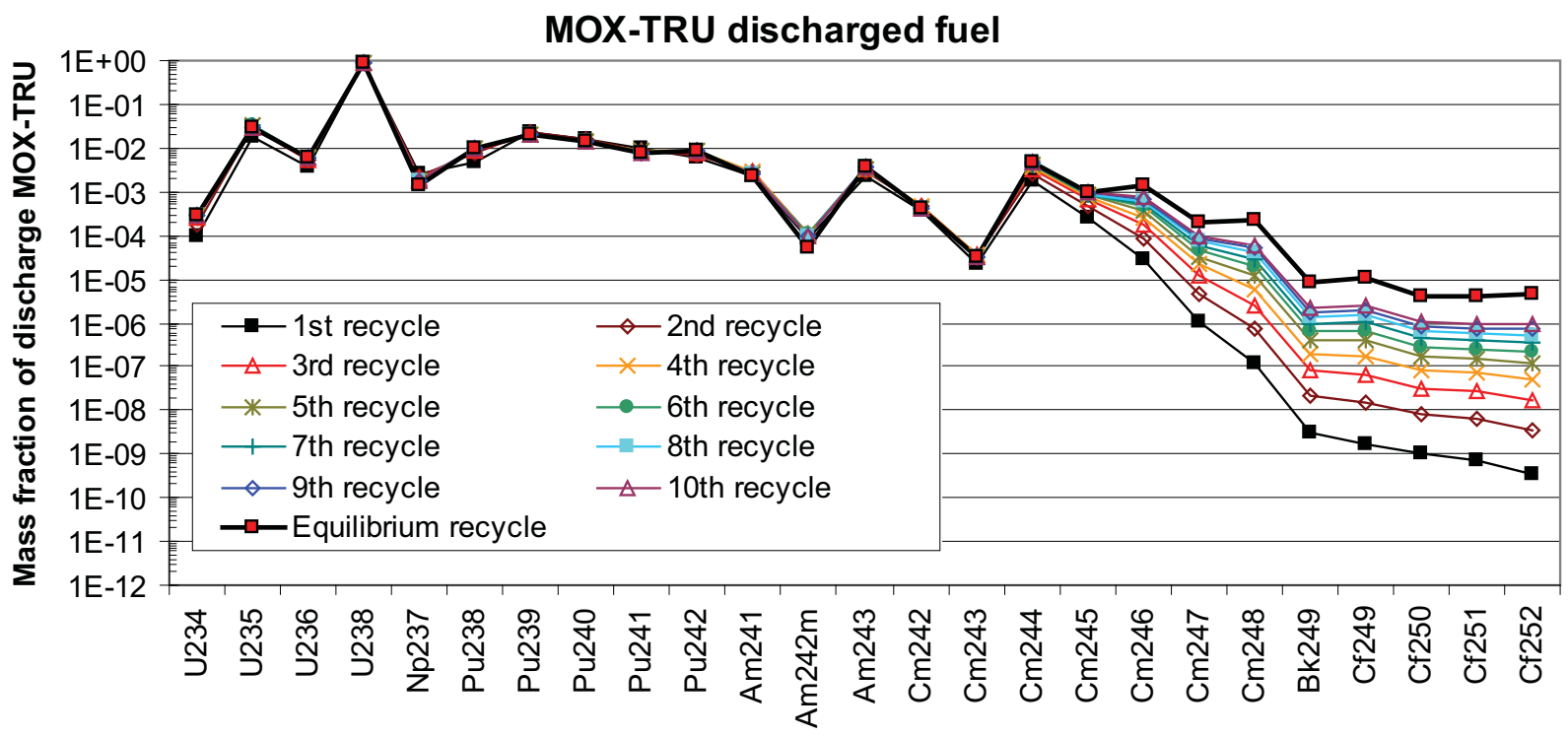

Figure 5-17. Isotopic mix for MOX-TRU as a function of how many times transuranic material is recycled. 


\subsection{Impact of LWR UOX Burnup on Heat Generation}

The ratio of burnups is $1.54(51 / 33)$; therefore, to obtain the same amount of electricity at UOX-33 as UOX-51 requires 1.54 times more UOX-33 mass of fuel.

Figure 5-18 shows the heat generation rate for LWR UOX fuel at burnups of 33 and 51 . The heat generation rate per unit mass for UOX-51 is generally 1.0 to 1.5 times the heat rate for UOX-33.

Therefore, the total heat generation (mass times heat/mass) for the cases is roughly independent of burnup. Radiotoxicity follows the same behavior.

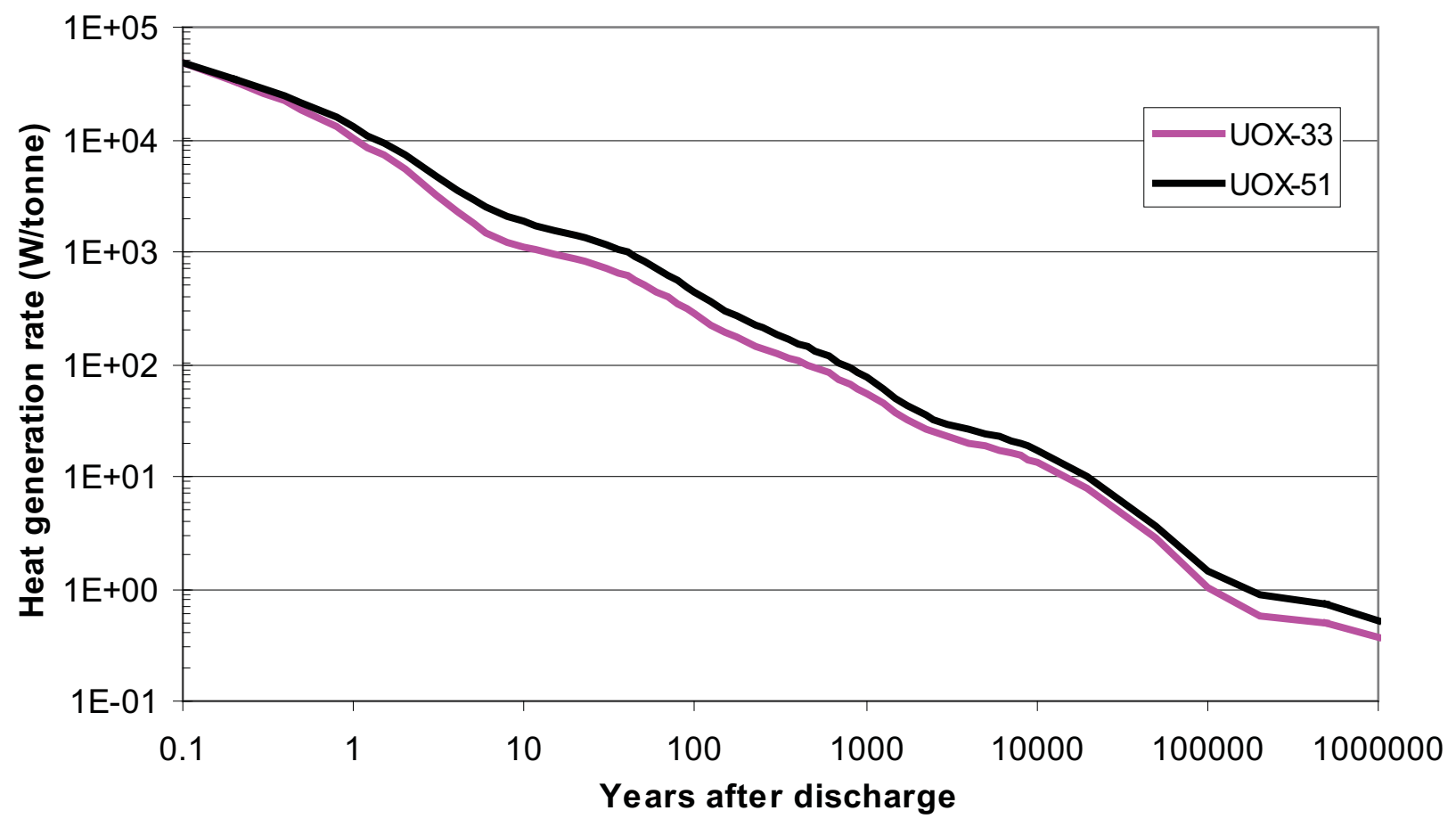

Figure 5-18. Heat generation rate for LWR UOX fuel.

One situation in which the heat per mass matters is transportation. Consider the impact using French criteria (source unknown). They transport used UOX-33 fuel at 1.3 years, which works out to about $8,100 \mathrm{~W} /$ tonne. They separate used UOX-33 fuel at 3.3 years, which works out to 3,000 W/tonne. Figure 5-19 shows the heat generation rate of some candidate LWR fuels in the time period 0.1 to 100 years, which is potentially relevant to transportation. If the criteria derived from French practice is a guide (which may not be appropriate because regulations differ), then the time at which used fuel could be transported varies from 1.3 years (UOX-33), 1.8 years (UOX-51), 3.3 years (MOX-Pu at 50 burnup), to 7.4 years (MOX-NpPu at 50 burnup). MOX requires much longer times than UOX because of the higher transuranic content. MOX-NpPu is higher than MOX-Pu because of the Pu238 generated from the Np. If the criteria derived from French practice is a guide (which may not be appropriate because technologies differ), then the time at which used fuel could be separated varies from 3.3 years (UOX-33), 4.8 years (UOX-51), 60 years (MOX-Pu), to over 100 years (MOX-NpPu). 


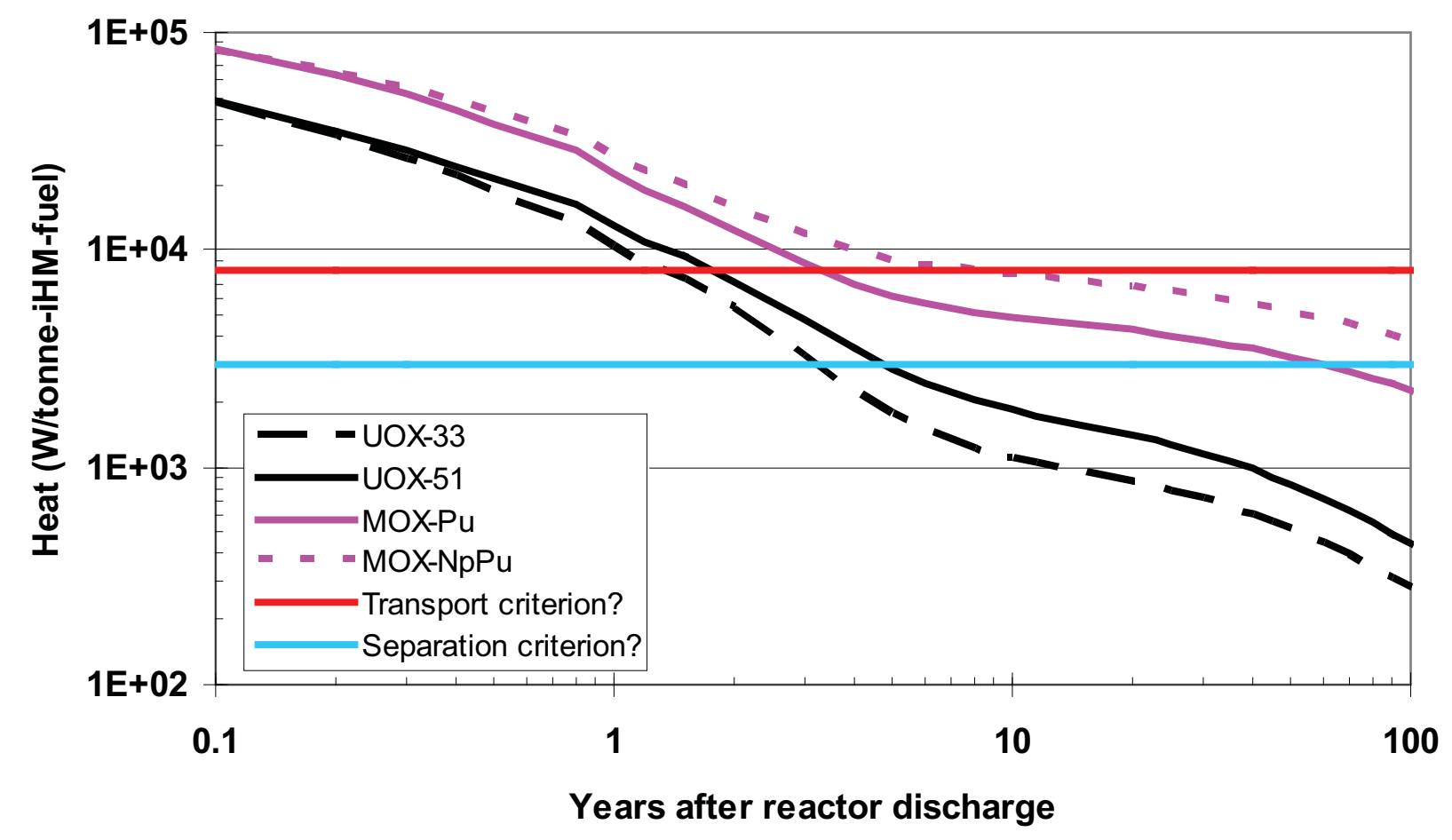

Figure 5-19. Heat generation of LWR UOX-33, UOX-51, MOX-Pu, and MOX-NpPu. 


\section{REACTORS}

\subsection{Typical Parameters}

Table 6-1 has some typical parameters for many types of reactors. Using these parameters, most of the fuel requirements for the reactor can be determined. All values are approximate; values in parameters are ranges.

Table 6-1. Representative Parameters for Typical Nuclear Power Plant Types

\begin{tabular}{|c|c|c|c|c|c|c|}
\hline & Variable & PWR & BWR & FR & HWR & VHTR \\
\hline Reactor Size (MWe) & $P_{e}$ & $\begin{array}{l}1000- \\
1500\end{array}$ & $\begin{array}{l}1000- \\
1500\end{array}$ & $400-1500$ & $750-1000$ & $165-286$ \\
\hline Reactor Size (MWth) & $P_{t}$ & $\begin{array}{l}2900- \\
4400\end{array}$ & $\begin{array}{l}2900- \\
4400\end{array}$ & $1000-3800$ & $2250-3000$ & $400-600$ \\
\hline $\begin{array}{l}\text { Specific power } \\
\text { (MWth/Tonnes-iHM) }\end{array}$ & $p$ & $33-39$ & $\sim 30$ & $\begin{array}{l}70 \\
(37-225)\end{array}$ & $\sim 33$ & $\sim 100$ \\
\hline $\begin{array}{l}\text { Average Uranium or } \\
\text { TRU Enrichment }\end{array}$ & & $\sim 4 \%$ & $\sim 4 \%$ & $\begin{array}{l}\sim 25 \% \\
(0-100 \%)\end{array}$ & $\begin{array}{l}\text { Natural } \\
(0.7 \%)\end{array}$ & $\sim 14 \%$ \\
\hline $\begin{array}{l}\text { Capacity factor } \\
\text { (Effective Full Power } \\
\text { Years/calendar year) }\end{array}$ & $C F$ & $>90 \%$ & $>90 \%$ & $\begin{array}{l}\text { Assumed } \\
85 \% \text {, but } \\
>90 \% \\
\text { possible }\end{array}$ & $>90 \%$ & $>90 \%$ \\
\hline $\begin{array}{l}\text { Average Discharge } \\
\text { Burnup } \\
\text { (MWth-day/kg-iHM) } \\
\text { (GWth-day/tonne-iHM) }\end{array}$ & $\overline{B U}$ & $\begin{array}{l}50 \\
\text { (higher } \\
\text { possible) }\end{array}$ & $\begin{array}{l}45 \\
\text { (higher } \\
\text { possible) }\end{array}$ & $\begin{array}{l}100-150 \\
(70-300)\end{array}$ & $\begin{array}{l}7 \\
\text { (higher with } \\
\text { LEU) }\end{array}$ & $\begin{array}{l}100 \\
\text { (higher } \\
\text { for other } \\
\text { concepts) }\end{array}$ \\
\hline $\begin{array}{l}\text { Cycle Length } \\
\text { (EFPY) }\end{array}$ & $C L$ & $1.5-2$ & $1.5-2$ & $\begin{array}{l}1.0 \\
(0.5-2.0)\end{array}$ & $\begin{array}{l}\text { On-line } \\
\text { Refueling }\end{array}$ & $\begin{array}{l}1.5 \text { or } \\
\text { on-line } \\
\text { refueling }\end{array}$ \\
\hline $\begin{array}{l}\text { Plant Configuration } \\
\text { (Units, } \\
\text { Reactors per Unit, } \\
\text { Turbines per Unit) }\end{array}$ & & $2,1,1$ & $2,1,1$ & $\begin{array}{l}2,1,1,- \\
\text { large } \\
3,2,1- \\
\text { small }\end{array}$ & multi-units & $\begin{array}{l}\text { modular, } \\
4,1,1\end{array}$ \\
\hline \multicolumn{7}{|c|}{$\begin{array}{l}\text { - Parameters for PWR, BWR, and HWR reflect constructed reactors and modest extrapolations } \\
\text { thereof according to new variations entering the market. } \\
\text { - Parameters for FR and VHTR reflect designs with varying degrees of detail. }\end{array}$} \\
\hline
\end{tabular}

The net thermal efficiency is a function of the thermal efficiency corrected for the average houseload and is the ratio of the net electric power to the thermal power.

$$
\eta_{e}=\frac{P_{e}}{P_{t}}
$$

The initial core inventory is determined by the specific power of the fuel and the thermal power level of the reactor.

$$
F_{\text {core }} \alpha \frac{P_{\text {therm }}}{p}
$$


Although core inventory is more commonly quoted in terms of the specific inventory per unit of electrical output, which is inversely related to the thermal efficiency and specific power.

$$
f_{\text {core }} \alpha \frac{1}{\eta_{e} p}
$$

The average annual fuel requirements are determined by the average discharge burnup and the specific power density.

$$
\dot{F} \alpha \frac{P_{\text {therm }} C F}{\overline{B U}}
$$

The core residence time of the average fuel assembly is determined by the average discharge burnup and the specific power.

$$
T_{\text {fuel }} \alpha \frac{\overline{B U}}{p C F}
$$

The average cycle length is determined by the assumed fraction of the core that is replaced during each refueling outage. The average burnup (and enrichment) are just that - averages over an assembly or over the core as appropriate. Burnup and enrichment vary significantly within assemblies.

Generally, this is assumed to be a simple fraction such as $1 / 3,1 / 4,1 / 5$, etc. However, in practice it is more likely that a target cycle length is set and the fuel batches are adjusted to achieve the required reactivity while maintaining fuel integrity, which leads to a refueling fraction of something like 1/2.6 where on average approximately $70 \%$ of the assemblies reside in the core for 3 cycles and $30 \%$ of the assemblies reside in the core for 2 cycles. The average discharge burnup is roughly the same since those that are in the core for shorter periods operate at higher average power densities. A core is referred to as a 3 -batch core if $1 / 3$ of the assemblies are removed each cycle and therefore the average assembly is in the core for 3 cycles and the core is a mix of assemblies that are in the core for their first cycle (fresh fuel), $2^{\text {nd }}$ cycle, or third and final cycle (discharged at the end of the cycle and replaced with fresh fuel). The equivalent number of batches or cycles the average fuel assembly is in the core is the average fuel residence time divided by the cycle length.

$$
N_{\text {batch }}=\frac{T_{\text {fuel }}}{C L}
$$

The average quantity or batch size of fuel required to replace the fuel being discharged at the end of each cycle is simply the average annual fuel requirements and the cycle length.

$$
F_{\text {batch }}=\dot{F} \cdot C L
$$

The times utilized in reactor analysis are either calendar time or effective full power operation time. The times are related by the average capacity factor, which accounts for planned and unplanned operation below full power. There are different methods that are utilized to account for the fact that the reactor will on average be operating at less the full power. Typical, the reactor is modeled as operating at full power for a given time which is followed by a specific down time, where the cycle length is the sum of the operation and down time and the capacity factor is the fraction of time at full power. The other typical method is to assume that the reactor operates at a reduce power level for the entire cycle length without any down time. Typically, the assumptions makes little difference in the results, but the assumption is 
rarely reported and can lead to using improper values to determine fuel loading, cycle length, and other related parameters.

The energy generated by a fission varies somewhat with the isotope and energy of the neutron causing the fission. However, a good first order approximation is $1 \mathrm{MWth}$-day of energy per gram of heavy metal fissioned. This means that the complete fission of $1 \mathrm{~kg}$ of heavy metal would produce 1,000 MWthday $/ \mathrm{kg}$. Therefore, if we take the average discharge burnup in MWth-day $/ \mathrm{kg}$ and divide it by 1,000, we get the fraction of the material that was fissioned. The typical LWR burnup of $50 \mathrm{MWth}-\mathrm{day} / \mathrm{kg}$ is approximately $5 \%$ burnup or 50 grams of the initial heavy metal fissioned. Since the fission products are virtually all of the mass of the heavy metal, there is 1 gram of fission products produced per MWth-day of thermal energy generated by the reactor. This allows for easy determination of the energy generation required to destroy a given quantity of material without the need to perform a single reactor physics calculations. When it is transuranic material and it is placed in a uranium matrix, there will be addition energy generated from the direct fission of the uranium and the indirect fission of the uranium by conversion to transuranics.

Table 6-2 includes some of the common parameters that are calculated from the above parameters.

Table 6-2. Representative Derived Parameters for Typical Nuclear Power Plant Types

\begin{tabular}{|l|l|l|l|l|l|l|}
\hline & Variable & \multicolumn{1}{|c|}{ PWR } & BWR & \multicolumn{1}{|c|}{ FR } & \multicolumn{1}{|c|}{ HWR } & \multicolumn{1}{|c|}{ VHTR } \\
\hline Thermal Efficiency & $\eta_{e}$ & $\sim 34 \%$ & $\sim 34 \%$ & $38 \%-41 \%$ & $\sim 34 \%$ & $41 \%-48 \%$ \\
\hline $\begin{array}{l}\text { Initial Core Inventory } \\
\text { (Tonnes-iHM/GWe) }\end{array}$ & $F_{\text {core }}$ & $70-90$ & $80-100$ & $\begin{array}{l}40 \\
(10-70)\end{array}$ & $\sim 90$ & $\sim 24$ \\
\hline $\begin{array}{l}\text { Annual Fuel Requirements } \\
\text { (Tonnes-iHM/yr) }\end{array}$ & $\dot{F}$ & $20-30$ & $20-30$ & $3-4$ & $\sim 100$ & $\sim 1$ \\
\hline Fuel Residence Time (EFPY) & $T_{\text {fuel }}$ & $3.5-4$ & $3.5-4$ & $4-5$ & $<1$ & $\sim 3$ \\
\hline $\begin{array}{l}\text { Reload Requirements } \\
\text { (Tonnes-iHM/cycle) }\end{array}$ & $F_{\text {batch }}$ & $30-60$ & $30-60$ & $2-35$ & $\sim 8$ & $\sim 2$ \\
\hline \begin{tabular}{l} 
Fuel Batches \\
\hline
\end{tabular} & $N_{\text {batch }}$ & $1.8-2.8$ & $2-3$ & $3-7$ & On-line & 2 \\
\hline $\begin{array}{l}\text { Parameters for PWR, BWR, and HWR reflect constructed reactors and modest extrapolations } \\
\text { thereof according to new variations entering the market. } \\
\text { Parameters for FR and VHTR reflect designs with varying degrees of detail. }\end{array}$ \\
\hline
\end{tabular}

\subsection{LWRs}

\subsubsection{LWR typical parameters}

Light water reactors essentially consist of two types of reactors being pressurized water reactors (PWRs) where the water remains liquid throughout the reactor and the boiling water reactors (BWRs) where the water boils as it traverses the reactor. These two types of reactors have very different designs, but generally have very roughly the same enrichment requirements, fuel requirements, and other fuel performance. There are currently more PWRs in the U.S. and these reactors can use simpler physics models to analyze their performance and unless otherwise specified LWR and PWR are synonymous.

Table 6-3 provides some generic parameters used for the analysis of PWRs. There is no standard design for a PWR and there are some variations in power level, active core length, and power density, but the standard 17x17 Westinghouse PWR fuel bundle is the most common arrangement. The analysis is typical 
a 2 dimensional infinite lattice calculation with a specific power level used to deplete the fuel bundle. This data then implies certain attributes of the PWR.

$$
P_{\text {therm }} \propto \frac{\bar{p}}{C F} N_{\text {assy }} L_{\text {active }} A_{\text {cross }}
$$

Table 6-3. Representative PWR Fuel Assembly Parameters in Transmutation Analyses [Hoffman2005]

\begin{tabular}{|c|c|c|}
\hline & UOX or MOX & IMF \\
\hline Assembly size & $17 \times 17$ pins & $17 \times 17$ pins \\
\hline Number of fuel pins & 264 & 264 \\
\hline Number of guide tubes (GT) & 24 & 24 \\
\hline Number of instrumentation tubes (IT) & 1 & 1 \\
\hline Fuel rod pitch $(\mathrm{cm})$ & 1.2598 & 1.2598 \\
\hline Inter-assembly gap $(\mathrm{cm})$ & 0.08 & 0.08 \\
\hline $\mathrm{ZrO}_{2}$ hole $^{\mathrm{a}}$ radius $(\mathrm{cm})$ & $\mathrm{N} / \mathrm{A}$ & $\begin{array}{l}0.2048\left(1^{\text {st }} \text { recycle }\right) \\
0.1930\left(2^{\text {nd }} \text { recycle }\right) \\
0.0929 \text { (eq. recycle) }\end{array}$ \\
\hline Fuel pellet radius $(\mathrm{cm})$ & 0.4096 & 0.4096 \\
\hline Clad inner radius $(\mathrm{cm})$ & 0.4178 & 0.4178 \\
\hline Clad outer radius $(\mathrm{cm})$ & 0.4750 & 0.4750 \\
\hline $\begin{array}{l}\text { Smeared fuel density }\left(\mathrm{g} / \mathrm{cm}^{3}\right) \\
\text { (pellet at } 95 \% \text { T.D., } 1.2 \% \text { pellet dishing) }\end{array}$ & 9.88 & $\begin{array}{l}5.60\left(1^{\text {st }} \text { recycle }\right) \\
6.00\left(2^{\text {nd }} \text { recycle }\right) \\
8.70(\text { eq. recycle })\end{array}$ \\
\hline Fuel mass (kg HM/assembly) & 461.3 & $\begin{array}{c}42.1\left(1^{\text {st }} \text { recycle }\right) \\
64.3\left(2^{\text {nd }} \text { recycle }\right) \\
310.0 \text { (eq. recycle })\end{array}$ \\
\hline Zircaloy-4 clad density $\left(\mathrm{g} / \mathrm{cm}^{3}\right)$ & 6.5 & 6.5 \\
\hline GT/IT inner radius $(\mathrm{cm})$ & 0.5715 & 0.5715 \\
\hline GT/IT outer radius $(\mathrm{cm})$ & 0.6121 & 0.6121 \\
\hline Specific power density (MW/tonne-iHM) & $33.69^{\mathrm{b}}$ & $\begin{array}{c}368.9^{\mathrm{b}}\left(1^{\text {st }} \text { recycle }\right) \\
201.9\left(2^{\text {nd }} \text { recycle }\right) \\
48.3\left(3^{\text {rd }} \text { recycle }\right)\end{array}$ \\
\hline Discharge burnup (GWt-day/tonne-iHM) & 50 & $\begin{array}{c}553\left(1^{\text {st }} \text { recycle }\right) \\
303\left(2^{\text {nd }} \text { recycle }\right) \\
72\left(3^{\text {rd }} \text { recycle }\right)\end{array}$ \\
\hline Fuel temperature $(\mathrm{K})$ & 900.0 & 900.0 \\
\hline Cladding temperature $(\mathrm{K})$ & 581.0 & 581.0 \\
\hline Bulk coolant temperature $(\mathrm{K})$ & 581.0 & 581.0 \\
\hline Nominal coolant density $\left(\mathrm{g} / \mathrm{cm}^{3}\right)$ & 0.72 & 0.72 \\
\hline
\end{tabular}

\subsubsection{MOX usability by LWRs}

Some existing LWRs are not designed to use MOX. Some can use MOX for part of their fuel. Some can use MOX for all of their fuel. M. Todosow estimated that about $16 \%$ of the fuel in the existing LWR fleet can be MOX, see Table 6-4. VISION models the overall average fleet, not individual reactors. 
Thus, the simulations start with 17 MOX-capable LWRs; the other 86 can use only UOX. All new LWRs deployed during the simulation are assumed MOX-capable.

Table 6-4. Thermal Reactor Safety Constraints on MOX/IMF [Todosow2005]

\begin{tabular}{|l|c|c|c|}
\hline \multirow{2}{*}{} & \multicolumn{3}{|c|}{ single-pass MOX } \\
\cline { 2 - 4 } & $\begin{array}{c}\% \text { of reactors } \\
\text { that can use }\end{array}$ & $\begin{array}{c}\% \text { of all fuel in fleet } \\
\text { (\% reactors x \% core) }\end{array}$ \\
\hline Current PWRs and BWRs & $50 \%$ & $33 \%$ & $16 \%$ \\
\hline Future PWRs and BWRs & $100 \%$ & $100 \%$ & $100 \%$ \\
\hline
\end{tabular}

One of the factors influencing the ability to use MOX or other fuels in reactors is their impact on physics safety parameters such as void coefficient. There are now estimates [Youinou2009a] of the maximum amount of TRU in LWRs, see Table 6-5. This is based on his work with the 100\% MOX-Pu EPR core design, which has a moderation ratio of 2.5 , slightly higher than typical U.S. LWRs (2.0). Future work would be required to clarify void coefficients for typical U.S. LWRs. If indeed results are similar with U.S. LWRs, there are serious limitations on MOX.

Table 6-5. Void Coefficient Constraint on LWR [Youinou2009a]

\begin{tabular}{|c|c|c|}
\hline & \multicolumn{2}{|c|}{ Limit on TRU fraction } \\
\hline Recycled material & $1^{\text {st }}$ recycle & Nth recycle \\
\hline MOX-Pu with recycled uranium & $\mathrm{Pu} 12 \%$ & $\mathrm{Pu} 10-11 \%$ \\
\hline MOX-NpPu with recycled uranium & \multicolumn{2}{|c|}{ Similar to NpPuAm with Am limit applying to Np } \\
\hline MOX-NpPuAm with recycled uranium & $\begin{array}{l}\mathrm{Pu} 8-10 \% \\
\mathrm{Am} 1.5-1.0 \% \text { (less Am tolerable as } \\
\mathrm{Pu} \text { increases) }\end{array}$ & $\begin{array}{l}\mathrm{Pu} 6.5 \% \\
\mathrm{Am} 1.0 \%\end{array}$ \\
\hline MOX-TRU with recycled uranium & \multicolumn{2}{|l|}{ Similar to MOX-NpPuAm } \\
\hline
\end{tabular}

\subsubsection{Idealized LWR performance}

The idealized LWR will require a source of new fuel to start up the reactor and then regular refueling based on the design cycle length and design discharge burnup. Table 6-6 is the generic input for the idealized LWR and the resulting time dependent behavior.

Table 6-6. Idealized LWR Input used in Transmutation Analyses

\begin{tabular}{|l|r|l|}
\hline Input Parameters & \multicolumn{1}{|c|}{ Value } & \multicolumn{1}{c|}{ Unit } \\
\hline Power Level & 2,941 & MW \\
\hline Specific power & 0.039 & MWth / kg-iHM \\
\hline Capacity factor & $90 \%$ & \\
\hline Design discharge burnup & 50 & MWth-day/ kg-iHM \\
\hline Cycle length & 549 & days / cycle \\
\hline Reactor lifetime & 60 & years \\
\hline
\end{tabular}

Once an LWR is built it will require approximately 1,206 tonne-iHM of fuel over its 60 year life time. The first and last years of a reactor's operation require use of fuel that will not achieve the normal burnup as its fuel residence time will be less. So, the average over the reactor lifetime will be slightly less than the nominal burnup through most of the reactor's life. The average discharge burnup will be approximately $48 \mathrm{MWth}$-day/kg-iHM for a nominal burnup of $50 \mathrm{MWth}-\mathrm{day} / \mathrm{kg}$-iHM; individual fuel batch burnups will range from $\sim 19$ (first batch discharged) to $50 \mathrm{MWth}-\mathrm{day} / \mathrm{kg}-\mathrm{iHM}$. 
The LWR will require $\sim 10,000$ tonnes of natural uranium. The first core load will be much larger than the average fuel batch and at the end of life the entire core load will be discharged as spent fuel. The average discharge burnup of the spent fuel will increase from a low value at the end of the first cycle ( $\sim 1 / 3$ of the designed discharge burnup) to the design value around the $3^{\text {rd }}$ cycle. At the end of life, the entire core will be discharged and will contain fuel that has been partially burned (as low as about $1 / 3$ design burnup) to fuel that has been fully burned and would have been discharged if the reactor had run for another cycle and the average burnup of the fuel in the reactor at the end of life is about $2 / 3$ of the design burnup.

\subsection{Fast Reactors}

\subsubsection{Fast reactor typical parameters}

Reactors are generically grouped into fast and thermal reactors which are distinguished on whether the fission neutrons, which are created at high energy are slowed significantly and the bulk of the fissions are produced at energies nearer the thermal equilibrium energy or are the neutrons slowed as little as possible and most fissions occur from neutrons at energies nearer the energy at which they were born. Thermal reactors contain large amounts of light elements like hydrogen or deuterium in the form of water or carbon in the form of graphite. Fast reactors have very low concentrations of these and are cooled by liquid metals or helium.

Fast reactors general have similar performance regardless of the details of the design concept. The sodium-cooled fast reactor is the most common concept and has the most operational experience. For this handbook, "fast reactor" will be synonymous with sodium-cooled fast reactor unless otherwise specified.

The fast reactor has the flexibility to be designed such that it can produce much greater quantities of transuranic material than it consumes or consume much greater quantities of transuranic material than it produces. This balance is generally described in terms of the transuranic conversion ratio or conversion ratio. This measures the transuranic isotopes produced to the number destroyed in the reactor. Different fast reactors with the same conversion ratio will generally have similar performance. The TRU conversion ratio is defined as atoms of TRU produced divided by atoms of TRU consumed, which is essentially atoms of uranium consumed minus directly fissioned uranium divided by the atoms of TRU that are fissioned. This neglects the direct fission of uranium, while includes conversion then fission of uranium. From a mass balance point of view this is the same.

$$
C R=\frac{\Delta A_{U \rightarrow T R U}}{\Delta A_{T R U \rightarrow \text { non-TRU }}} \sim \frac{\Delta A_{U}-\Delta A_{U}^{\text {fis }}}{\Delta A_{T R U}^{f i s}}
$$

Since many of the system studies are concerned about mass and energy flows and balances, a more simple term can be defined which is related to the conversion ratio. The effective conversion ratio, which is generally very close to the conversion ratio, is the change in mass of uranium relative to the change in mass of heavy metal. The change in the heavy metal mass is determined by the quantity of material fissioned. The change in uranium mass is the quantity of uranium that was either directly fissioned or converted to transuranic material. The difference is the net quantity of transuranic elements that was fissioned. This allows for a lot of simple mass and energy balances. We know that every gram of heavy metal fissioned produces approximately 1 MWth-day of energy and now we know how many grams of uranium will be fissioned in the process of net destruction of one gram of initial transuranics.

$$
C R_{\text {eff }}=\frac{\Delta M_{U}}{\Delta M_{H M}}
$$


The energy generated and mass fissioned is the sum of the contributions from the uranium and the transuranics. The mass balance is the fission of heavy metal, which is the only way that mass is consumed, which equals sum of the net change in mass of the uranium and transuranics.

$$
\Delta M_{H M}=\Delta M_{U}+\Delta M_{T R U}
$$

The net change in transuranic is related to the net change in heavy metal (fission energy) by a simple relationship with the effective conversion ratio, where the thermal energy generated as the result of a net consumption of 1 gram of TRU in MWth-days is the following. As can be seen, the energy generated goes to infinity as the $\mathrm{CR}_{\text {eff }}$ goes to 1 , which is expected for a breeder reactor that is not a net consumer of TRU.

$$
E_{T R U}=\frac{1}{1-C R_{e f f}}
$$

There are no reference fast reactor designs. There are many concepts and designs may have blankets. Table 6-7, 8, 9, and 10 provide some dimensions from a set of physics studies that intended to summarize the design and performance that might be seen if the fast reactor was developed for a range of conversion ratios from zero to breakeven, although most past concepts were developed to produce more fissile material than they produced (i.e., breeders) and would include blankets and have conversion ratios well above 1.0.

Table 6-7. Representative Fast Reactor Assembly Dimensions used in Transmutation Analyses [Hoffman2006]

\begin{tabular}{|l|c|}
\hline & Metal or Oxide \\
\hline Assembly pitch, cm & 16.142 \\
\hline Inter-assembly gap, cm & 0.432 \\
\hline Duct outside flat-to flat distance, cm & 15.710 \\
\hline Duct material & HT9 \\
\hline Duct thickness, cm & 0.394 \\
\hline
\end{tabular}


Table 6-8. Representative Metal-Fueled Assembly Design Parameters [Hoffman2006]

\begin{tabular}{|c|c|c|c|c|c|c|c|c|c|}
\hline & \multicolumn{2}{|c|}{ S-PRISM } & \multicolumn{7}{|c|}{ Compact Core } \\
\hline & \multirow{2}{*}{ Driver } & \multirow{2}{*}{ Blanket } & \multirow{2}{*}{1.0} & \multirow{2}{*}{0.75} & \multirow{2}{*}{0.50} & \multirow{2}{*}{0.25} & \multicolumn{3}{|c|}{0.00} \\
\hline & & & & & & & Inner & Middle & Outer \\
\hline $\begin{array}{l}\text { Fuel pins per } \\
\text { assembly }\end{array}$ & 271 & 127 & 271 & 271 & 324 & 540 & 540 & 540 & 547 \\
\hline Spacer type [a] & Wire & Wire & Wire & Wire & Grid & Grid & Grid & Grid & Wire \\
\hline $\begin{array}{l}\text { Structural pins } \\
\text { per assembly }\end{array}$ & 0 & 0 & 0 & 0 & 7 & 7 & 7 & 7 & 0 \\
\hline \multicolumn{10}{|c|}{ Pin data } \\
\hline Bond material & $\mathrm{Na}$ & $\mathrm{Na}$ & $\mathrm{Na}$ & $\mathrm{Na}$ & $\mathrm{Na}$ & $\mathrm{Na}$ & $\mathrm{Na}$ & $\mathrm{Na}$ & $\mathrm{Na}$ \\
\hline Height (core), $\mathrm{cm}$ & 101.60 & 101.60 & 101.60 & 101.60 & 101.60 & 101.60 & 101.60 & 101.60 & 101.60 \\
\hline $\begin{array}{l}\text { Height (plenum), } \\
\mathrm{cm}\end{array}$ & 191.14 & 191.14 & 191.14 & 191.14 & 191.14 & 191.14 & 191.14 & 191.14 & 191.14 \\
\hline $\begin{array}{l}\text { Overall pin } \\
\text { length, } \mathrm{cm}\end{array}$ & 407.04 & 407.04 & 407.04 & 407.04 & 407.04 & 407.04 & 407.04 & 407.04 & 407.04 \\
\hline $\begin{array}{l}\text { Fuel smeared } \\
\text { density, \% TD }\end{array}$ & 75 & 85 & 75 & 75 & 75 & 75 & 75 & 75 & 75 \\
\hline $\begin{array}{l}\text { Fabrication } \\
\text { density, \% TD }\end{array}$ & 100 & 100 & 100 & 100 & 100 & 100 & 100 & 100 & 100 \\
\hline Pin diameter, $\mathrm{cm}$ & 0.744 & 1.201 & 0.808 & 0.755 & 0.623 & 0.464 & 0.449 & 0.494 & 0.539 \\
\hline $\begin{array}{l}\text { Pin pitch-to- } \\
\text { diameter ratio }\end{array}$ & 1.191 & 1.078 & 1.100 & 1.176 & 1.293 & 1.357 & 1.400 & 1.273 & 1.167 \\
\hline $\begin{array}{l}\text { Cladding } \\
\text { thickness, cm }\end{array}$ & 0.0559 & 0.0559 & 0.0559 & 0.0559 & 0.0559 & 0.0559 & 0.0559 & 0.0559 & 0.0559 \\
\hline $\begin{array}{l}\text { Wire wrap } \\
\text { diameter, cm }\end{array}$ & 0.1422 & 0.0940 & 0.0805 & 0.1329 & N/A & N/A & $\mathrm{N} / \mathrm{A}$ & N/A & 0.0900 \\
\hline \multicolumn{10}{|c|}{ Volume fraction, $\%$} \\
\hline Fuel & 28.30 & 44.61 & 34.26 & 29.30 & 22.08 & 17.44 & 16.04 & 20.60 & 26.05 \\
\hline Bond & 9.43 & 7.87 & 11.42 & 9.77 & 7.36 & 5.81 & 5.35 & 6.87 & 8.68 \\
\hline Structure & 25.70 & 20.97 & 25.73 & 25.68 & 26.41 & 29.15 & 28.53 & 30.45 & 31.36 \\
\hline Coolant & 36.57 & 26.54 & 28.59 & 35.25 & 44.15 & 47.60 & 50.08 & 42.09 & 33.90 \\
\hline
\end{tabular}


Table 6-9. Representative Oxide-Fueled Assembly Design Parameters [Hoffman2006]

\begin{tabular}{|c|c|c|c|c|c|c|c|c|c|}
\hline & \multicolumn{2}{|c|}{ S-PRISM } & \multicolumn{7}{|c|}{ Compact Core } \\
\hline & \multirow{2}{*}{ Driver } & \multirow{2}{*}{ Blanket } & \multirow{2}{*}{1.0} & \multirow{2}{*}{0.75} & \multirow{2}{*}{0.50} & \multirow{2}{*}{0.25} & \multicolumn{3}{|c|}{0.00} \\
\hline & & & & & & & Inner & Middle & Outer \\
\hline $\begin{array}{l}\text { Fuel pins per } \\
\text { assembly }\end{array}$ & 217 & 127 & 271 & 271 & 324 & 324 & 324 & 324 & 324 \\
\hline Spacer type & Wire & Wire & Wire & Wire & Grid & Grid & Grid & Grid & Grid \\
\hline $\begin{array}{l}\text { Structural pins } \\
\text { per assembly }\end{array}$ & 0 & 0 & 0 & 0 & 7 & 7 & 7 & 7 & 7 \\
\hline \multicolumn{10}{|c|}{ Pin data } \\
\hline Bond material & $\mathrm{He}$ & $\mathrm{He}$ & $\mathrm{He}$ & $\mathrm{He}$ & $\mathrm{He}$ & $\mathrm{He}$ & $\mathrm{He}$ & $\mathrm{He}$ & $\mathrm{He}$ \\
\hline Height (core), cm & 137.16 & 137.16 & 137.16 & 137.16 & 137.16 & 137.16 & 137.16 & 137.16 & 137.16 \\
\hline $\begin{array}{l}\text { Height (plenum), } \\
\mathrm{cm}\end{array}$ & 170.82 & 191.14 & 170.82 & 170.82 & 170.82 & 170.82 & 170.82 & 170.82 & 170.82 \\
\hline $\begin{array}{l}\text { Overall pin } \\
\text { length, } \mathrm{cm}\end{array}$ & 422.28 & 407.04 & 422.28 & 422.28 & 422.28 & 422.28 & 422.28 & 422.28 & 422.28 \\
\hline $\begin{array}{l}\text { Fuel smeared } \\
\text { density, \% TD }\end{array}$ & 85 & 93 & 85 & 85 & 85 & 85 & 85 & 85 & 85 \\
\hline $\begin{array}{l}\text { Fabrication } \\
\text { density, \% TD }\end{array}$ & 89.4 & 95.4 & 89.4 & 89.4 & 89.4 & 89.4 & 89.4 & 89.4 & 89.4 \\
\hline Pin diameter, $\mathrm{cm}$ & 0.894 & 0.954 & 0.868 & 0.808 & 0.658 & 0.556 & 0.438 & 0.460 & 0.482 \\
\hline $\begin{array}{l}\text { Pin pitch-to- } \\
\text { diameter ratio }\end{array}$ & 0.991 & 1.295 & 1.023 & 1.099 & 1.224 & 1.448 & 1.839 & 1.751 & 1.672 \\
\hline $\begin{array}{l}\text { Cladding } \\
\text { thickness, cm }\end{array}$ & 1.1642 & 1.0782 & 0.0635 & 0.0635 & 0.0635 & 0.0635 & 0.0635 & 0.0635 & 0.0635 \\
\hline $\begin{array}{l}\text { Wire wrap } \\
\text { diameter, } \mathrm{cm}\end{array}$ & 0.1727 & 0.1294 & 0.0198 & 0.0797 & N/A & N/A & N/A & N/A & N/A \\
\hline \multicolumn{10}{|c|}{ Volume fraction, $\%$} \\
\hline Fuel & 37.63 & 51.17 & 49.29 & 41.65 & 30.22 & 19.73 & 10.36 & 11.87 & 13.49 \\
\hline Bond & 1.95 & 1.32 & 2.55 & 2.16 & 1.56 & 1.02 & 0.54 & 0.61 & 0.70 \\
\hline Structure & 25.85 & 20.97 & 28.58 & 27.71 & 29.22 & 26.22 & 22.75 & 23.40 & 24.04 \\
\hline Coolant & 34.57 & 26.54 & 19.58 & 28.48 & 39.00 & 53.02 & 66.35 & 64.11 & 61.77 \\
\hline
\end{tabular}

Table 6-10. Mass Balance of Startup and Equilibrium Fast Reactor Cores [Hoffman2006]

\begin{tabular}{|c|c|c|c|c|c|c|c|c|c|c|}
\hline & \multicolumn{5}{|c|}{ Metal } & \multicolumn{5}{|c|}{ Oxide } \\
\hline \multicolumn{11}{|l|}{ Equilibrium Core } \\
\hline Conversion Ratio & 1.00 & 0.75 & 0.50 & 0.25 & 0.00 & 1.00 & 0.75 & 0.50 & 0.25 & 0.00 \\
\hline HM Inventory (kg TRU / MWth) & 16.75 & 13.44 & 9.45 & 6.17 & 3.62 & 19.28 & 15.25 & 10.91 & 6.86 & 3.91 \\
\hline TRU Inventory (kg TRU / MWth) & 2.45 & 2.86 & 3.08 & 3.36 & 3.57 & 3.49 & 3.88 & 4.08 & 4.00 & 3.88 \\
\hline HM Makeup Feed Rate (kg/MWth-yr) & 0.38 & 0.39 & 0.39 & 0.38 & 0.39 & 0.39 & 0.39 & 0.39 & 0.39 & 0.39 \\
\hline TRU Makeup Feed Rate (kg/MWth-yr) & -0.02 & 0.08 & 0.18 & 0.29 & 0.40 & 0.00 & 0.07 & 0.16 & 0.26 & 0.36 \\
\hline \multicolumn{11}{|l|}{ Startup Core } \\
\hline Conversion Ratio & 0.97 & 0.75 & 0.53 & 0.31 & 0.08 & 0.97 & 0.76 & 0.54 & 0.32 & 0.11 \\
\hline HM Inventory (kg TRU / MWth) & 16.75 & 13.43 & 9.44 & 5.91 & 3.61 & 19.28 & 15.24 & 10.90 & 6.85 & 3.90 \\
\hline TRU Inventory (kg TRU / MWth) & 2.67 & 2.76 & 2.70 & 2.60 & 2.71 & 3.61 & 3.64 & 3.53 & 3.25 & 2.96 \\
\hline HM Makeup Feed Rate (kg/MWth-yr) & 0.38 & 0.39 & 0.39 & 0.39 & 0.39 & 0.39 & 0.39 & 0.39 & 0.39 & 0.39 \\
\hline Makeup Feed Rate (kg TRU/MWth-yr) & 0.00 & 0.07 & 0.16 & 0.26 & 0.36 & 0.00 & 0.08 & 0.17 & 0.26 & 0.35 \\
\hline $\begin{array}{l}\text { Additional TRU Inventory for } \\
\text { Equilibrium (kg TRU / MWth) }\end{array}$ & -0.22 & 0.10 & 0.38 & 0.76 & 0.85 & -0.12 & 0.25 & 0.55 & 0.76 & 0.92 \\
\hline
\end{tabular}




\subsubsection{Fast reactor transuranic conversion ratios}

Figure 6-1 shows the impact of static versus dynamic equilibrium on the percentage of electricity generated by fast reactors versus LWRs in the DSARR 1-tier analyses. Note that as the fast reactor TRU conversion ratio increases, the difference between static and dynamic increases, i.e., the larger the deviation in the dynamic growth period from the ultimate $\mathrm{LWR} /$ fast reactor ratio.

Transuranics are important for two reasons: they can substitute for uranium in fuel, and they are the primary contributors to long-term waste management impacts. TRU management needs to account for both the TRU consumed in fast reactors and the additional TRU generation avoided due to fast reactors replacing some LWRs. Each factor reduces TRU quantities by over 1,000 tonnes during the century (versus once-through). The more TRU "at work" in fast reactors, the more total TRU is reduced. Figure 6-2 shows the impact on TRU management as a function of fast reactor transuranic conversion ratio.

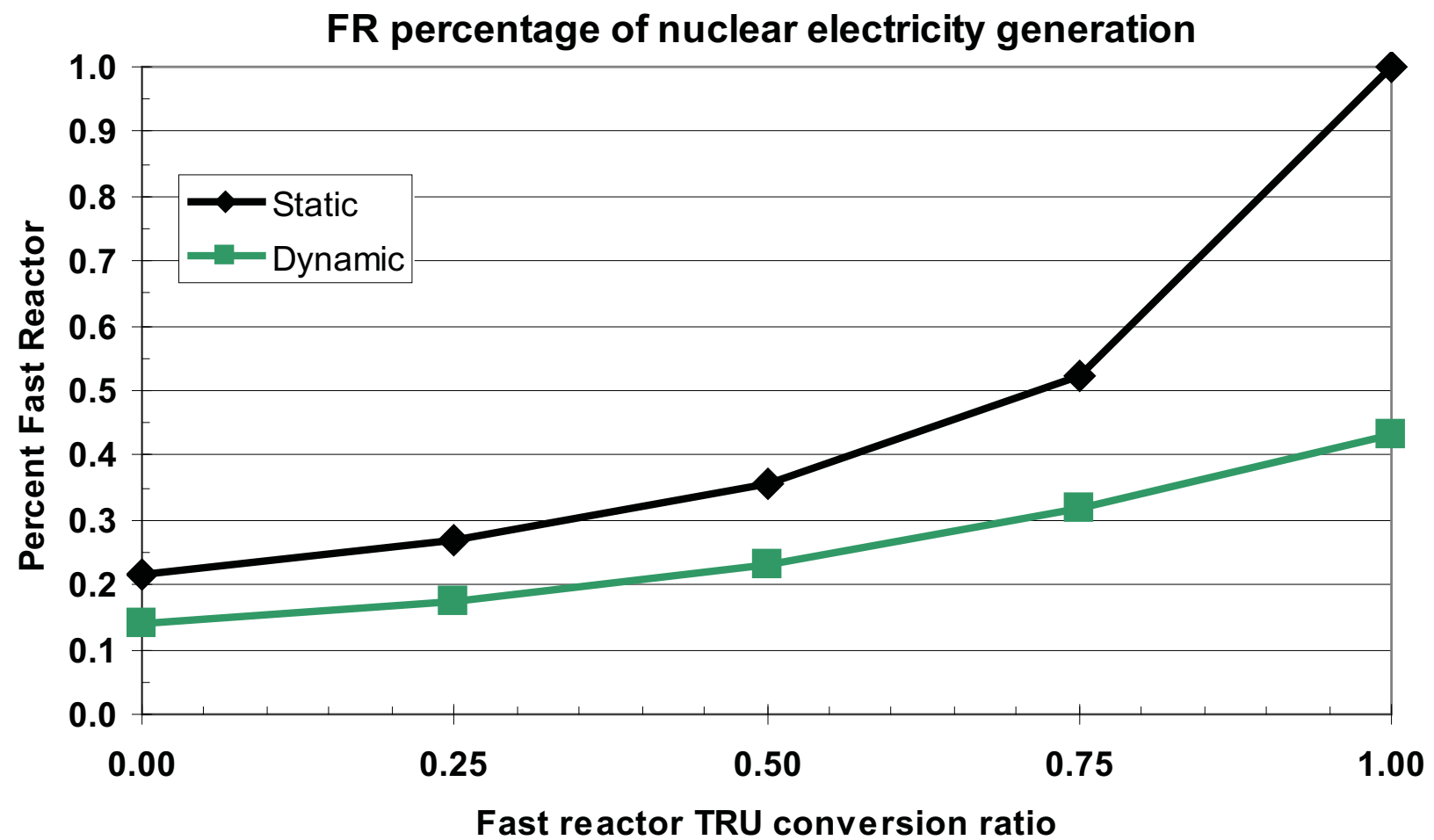

Figure 6-1. Fast reactor percentage of nuclear electricity generated for 1-tier DSARR parameters, static versus dynamic equilibrium. 


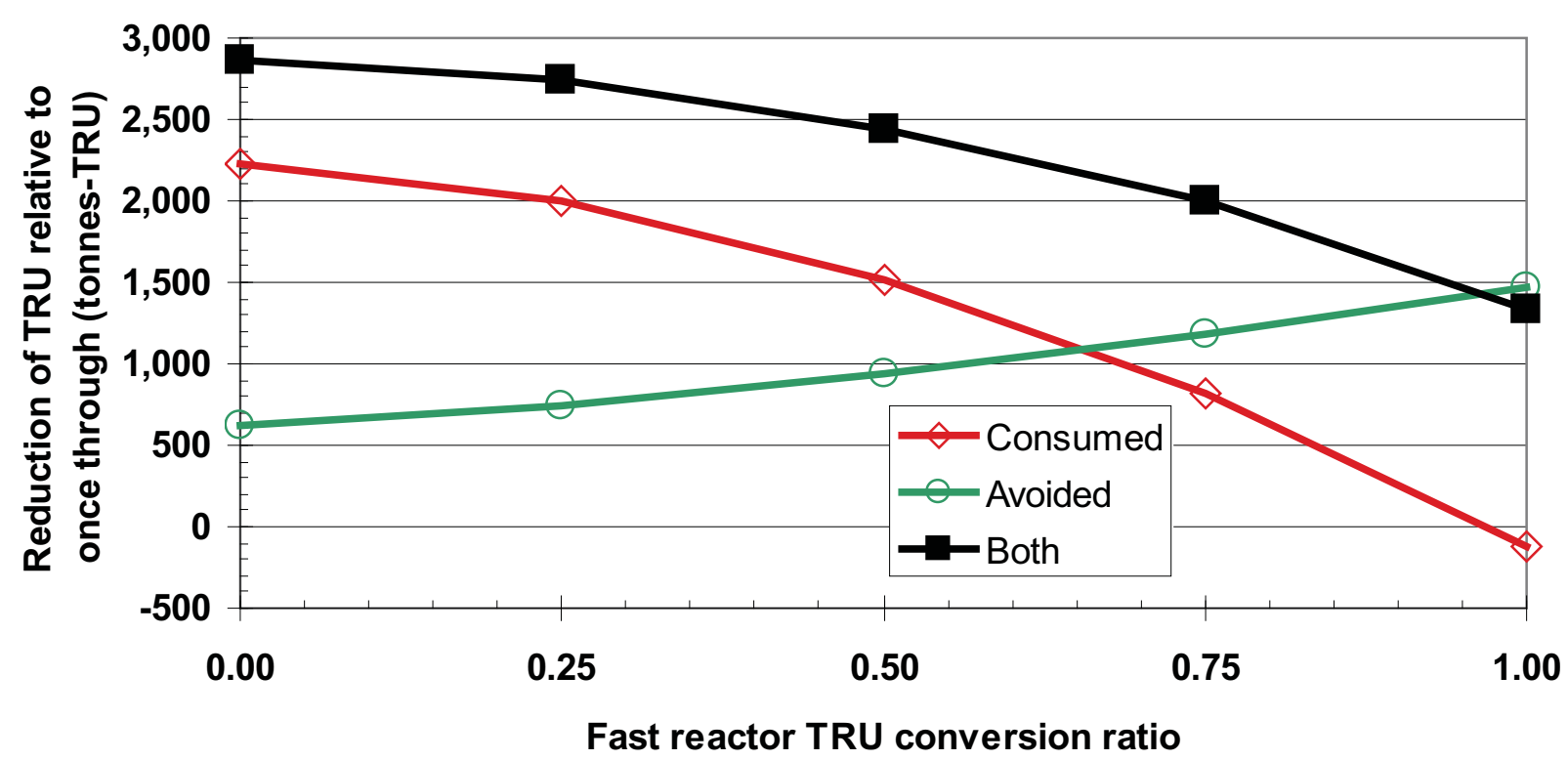

Figure 6-2. Transuranics reduction between 2000 and 2100 with a 1-tier fuel cycle as a function of conversion ratio. [DSARR2008]

\subsubsection{Dependences among conversion ratio, cycle length, and capacity factor}

One of the assumptions that is key for evaluating burner fast reactors is cycle length and the related topic of capacity factor. Generally, the more frequent the reactor must be shutdown, the lower the capacity factor. The shorter the cycle lengths are assumed in order to limit the number of control rods required and/or to limit the maximum allowable rod worths. There are other concepts which could theoretically allow for long cycle lengths. The reason for limiting the control rod worth is to the limit the potential reactivity insertion for an accidental rod withdrawal. The use of rod stops has been proposed which would be a nuclear safety grade system that would limit the maximum rod withdrawal. The rod stops would be reset periodically without requiring a refueling outage. Online refuel is another option that has not been explored, but would be possible if it were necessary to go to very low conversion ratios with very low reactivity swings.

The following equation shows the simple relationship between cycle length (CL), burnup reactivity swing rate, $(\dot{\rho})$, number of control rods $(\mathrm{CR})$, and average control rod worth $\left(\overline{\rho_{C R}}\right)$. Figure $6-3$ shows the burnup reactivity swing rate as a function of conversion ratio. There are slight differences between metal and oxide arising from differences in neutron energy spectrum. Since fast reactors were originally envisioned as breeders, which have very low burnup reactivity swing, very conservative limits on reactivity control were used and easily accommodated.

$\rho_{\text {cycle }}=C L \cdot \dot{\rho}=C R \cdot \overline{\rho_{C R}}$

There is a lot of uncertainty about what the real limits will be and what will be acceptable as far as maximum reactivity per control rod, how many control rods are practical, etc. The burnup reactivity swing for the cycle is determined by the cycle length times the burnup reactivity swing rate. Therefore, the lower the conversion ratio, the higher the reactivity swing that must be accommodated or the shorter the cycle length must be. The average control rod worth inserted in the core at the beginning of cycle is the burnup reactivity swing divided by the number of primary control rods. Therefore, to accommodate a higher burnup reactivity swing, more control rods will be required or a higher average rod worth must be 
accepted. There is significant uncertainty on what would be acceptable for managing the burnup reactivity swing and therefore what the penalty for going to lower conversion ratios will be. If a very high control rod worth is acceptable, there will be very little penalty for going to low conversion ratios as a result of accommodating the higher burnup reactivity swing.

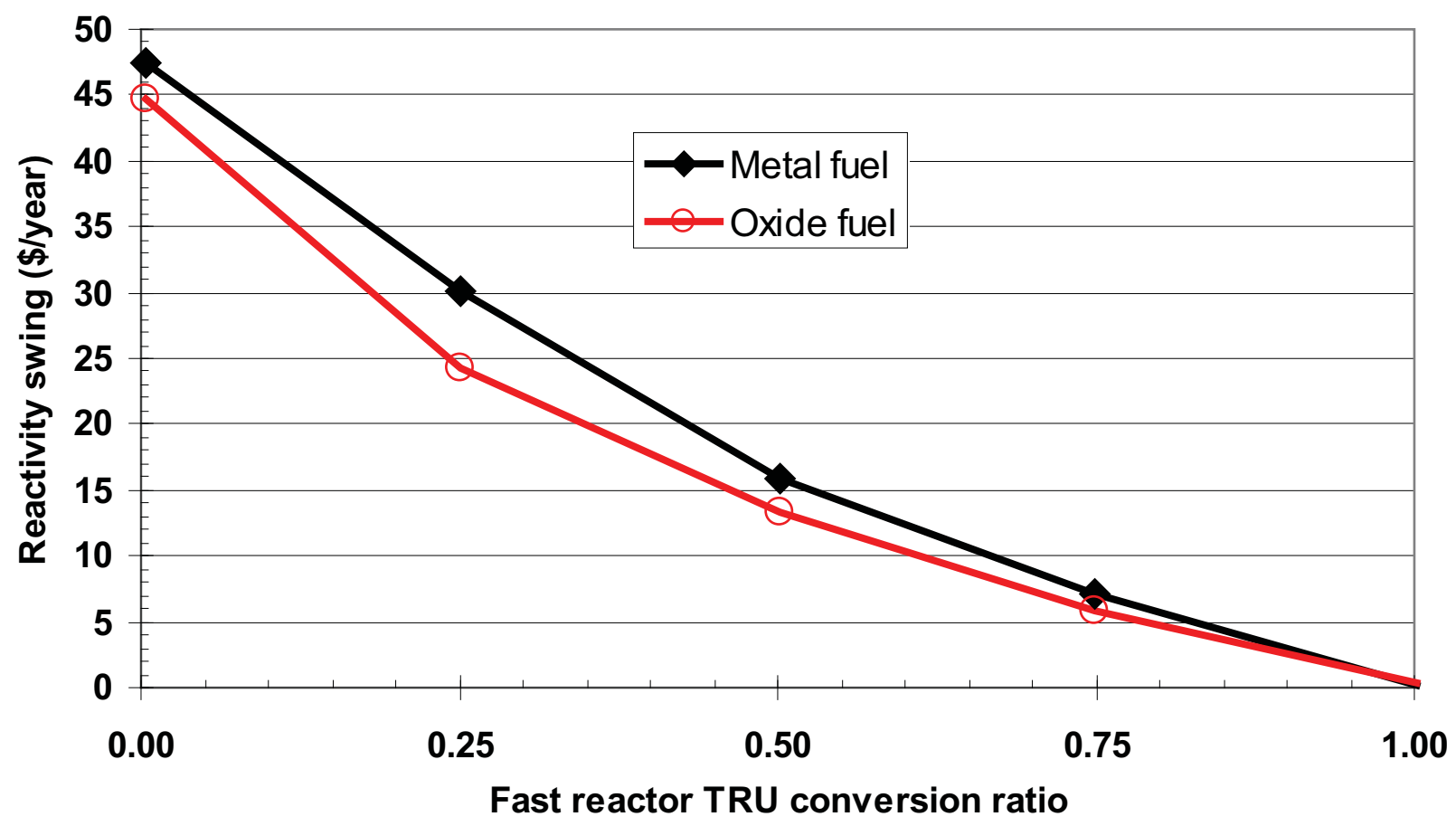

Figure 6-3. Reactivity swing as function of fast reactor TRU conversion ratio. [Hoffman2006]

The capacity factor will depend on many factors and is a function of planned and unplanned outages. Figure 6-4 shows the dependence of planned outages and maximum capacity factor (mechanical failures with assumed rates and planned outages) for a fixed, 0.5 conversion ratio, design with a variable cycle length. This graph keeps the unplanned outages, which are a function of the design, constant and shows the sensitivity to cycle length. It is recognized that the left side of the diagram represents pathological cases; one would never plan for such short cycle lengths. Nonetheless, graphing the full range provides better understanding of trends. 


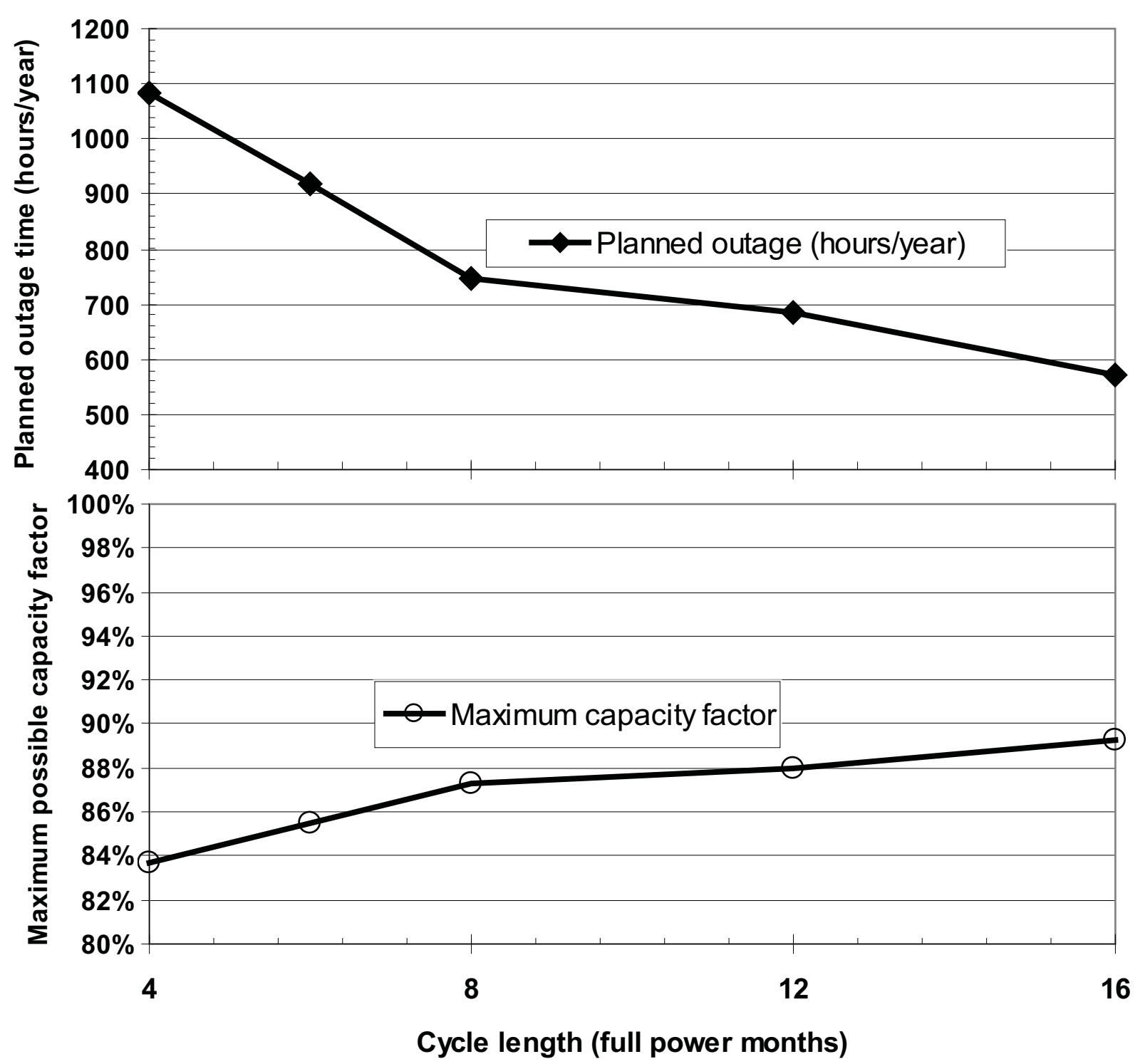

Figure 6-4. Planned outages and capacity factor as function of cycle length.

Figure 6-5 shows the maximum capacity factor for the metal fueled core design as a function of conversion ratio. The graph includes impacts of failure rates and cycle length as assumed in the analysis. This shows that the cycle length is the dominant factor on capacity factor. Failure rates from increases in fuel pins and control rods will not likely be important at lower conversion ratios, which mean that if high control rod worths are acceptable, there will be far less penalty for going to low conversion ratios. 

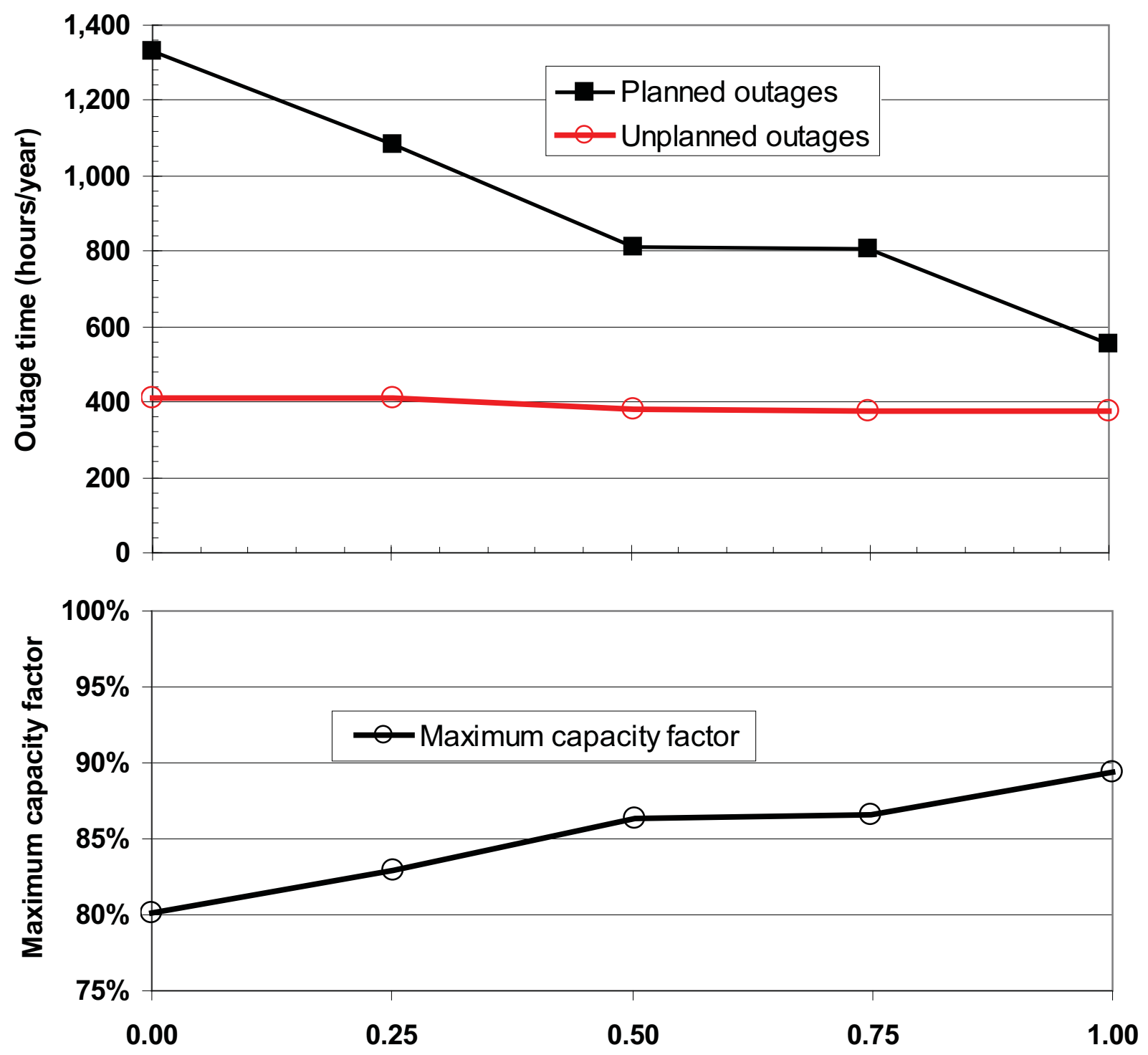

Fast reactor TRU conversion ratio

Figure 6-5. Outages and capacity factor dependence on fast reactor TRU conversion ratio.

\subsubsection{TRU enrichment dependence on conversion ratio}

The conversion ratio is essentially fixed by the average transuranic enrichment in the core. There are only small variations associated with varying spectrum and isotopic mixture that have some effect on the relationship between conversion ratio and transuranic enrichment in a fast reactor. Figure 6-6 shows the relationship. There are slight differences between oxide and metal fuel due to neutron energy spectrum. The only way to adjust the conversion ratio is to modify the design to increase or decrease the neutron leakage such that the reactor will require the desired TRU enrichment. There are different ways to do this, but the latest analyses assumed that the fuel volume fraction would be varied (essentially adjust pin diameter) to achieve the targeted conversion ratio. Generally, the conversion ratio of a reactor will vary over time as the isotopic mixture of transuranics changes. Typically, this will not be a large shift over time. The equilibrium fissile fraction of the TRU will vary from about $65 \%$ for the breakeven core to 
about $35 \%$ for the fertile-free core. The startup core will have fissile fractions determined by the spent LWR fuel which is about $60 \%$.

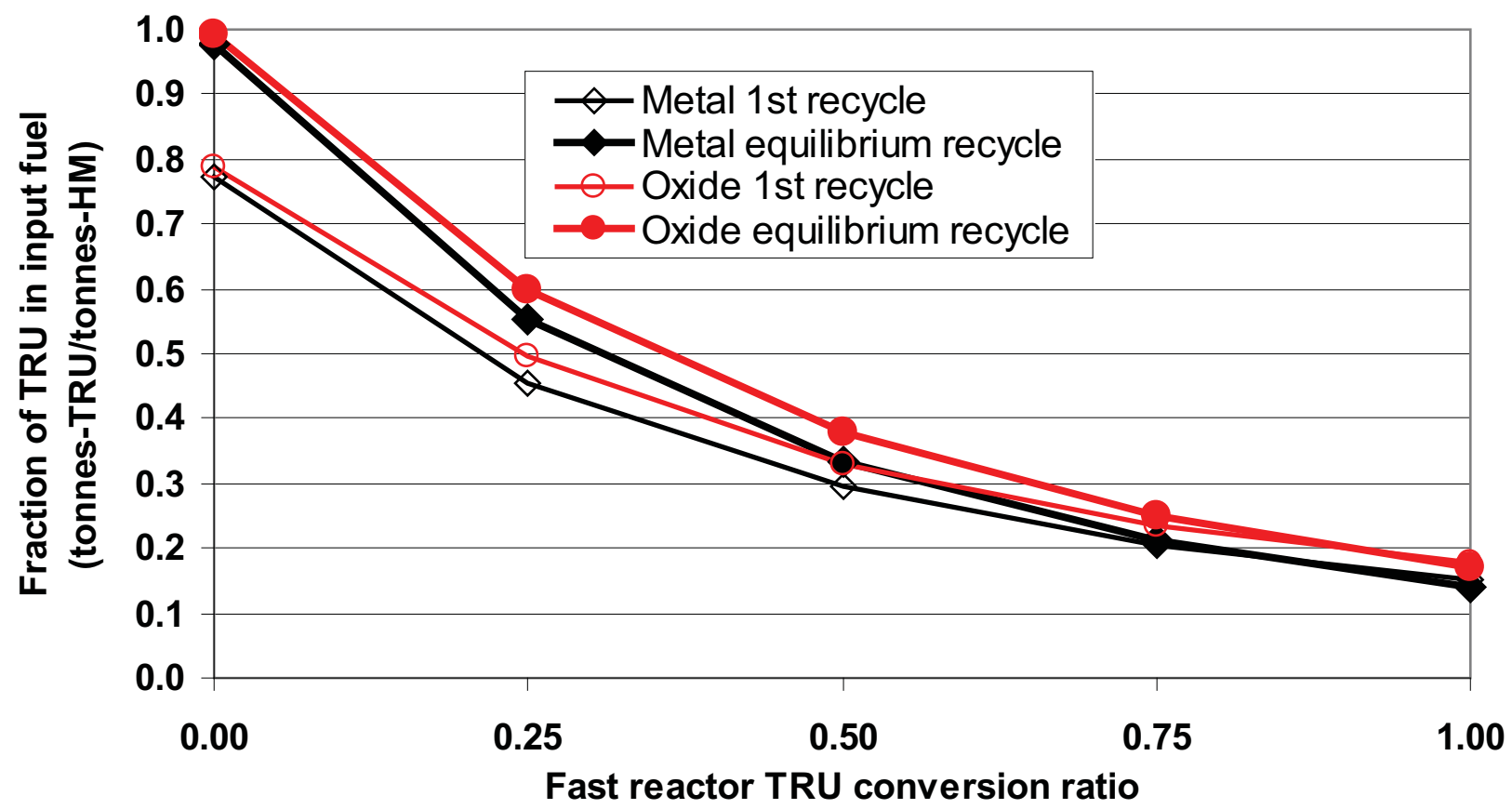

Figure 6-6. Transuranic enrichment dependence on fast reactor TRU conversion ratio. [Hoffman2006]

The data in figure 6-6 have another ramification, the amount of uranium (assumed pure) that dilutes TRU coming from separation of used fuel. The Fuels Campaign (E. Shaber, personall communication) indicates they are assuming that the TRU has significant impurities but the $U$ part of the feedstock does not as U separation is "cleaner." The Fuels Campaign must limit impurities in the finished fuel product. The assumed dilution of U/TRU is used to work backwards to the tolerable impurities in the TRU feedstock. The Fuels Campaign current TRU feedstock limits are based on a dilution factor of 2.5, i.e., fuel that is $40 \%$ TRU. This corresponds to a fast reactor TRU conversion ratio of $0.35-0.45$, see figure 67. For fuel that is intended for higher TRU conversion ratio, the dilution of TRU by U increases and the impurity limits could be relaxed. 


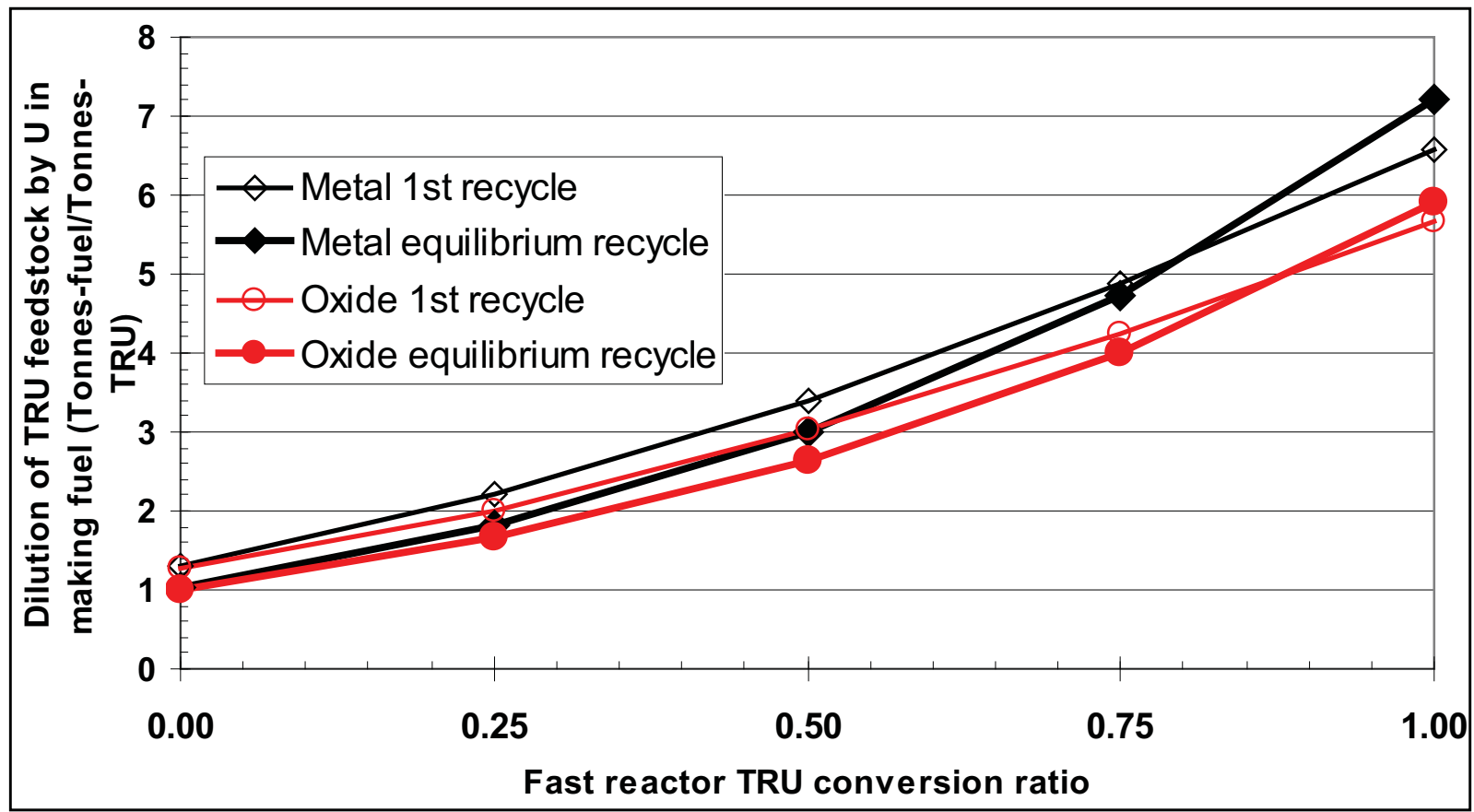

Figure 6-7. Dilution factor of TRU in total fuel as function of fast reactor TRU conversion ratio.

\subsubsection{Burnup dependence on TRU conversion ratio}

The fuel burnup (MWth-day/kg-iHM) is a strong function of fast reactor TRU conversion ratio, see figure 6-8. Figure 6-9 shows a different way of looking at the same data, the burnup expressed per mass of initial transuranic content in the fuel. When expressed per mass of TRU in the initial fuel, instead of per total initial fuel mass, one sees that the total heat released increases with conversion ratio, because of TRU bred and consumed in-situ from the initial uranium content. 


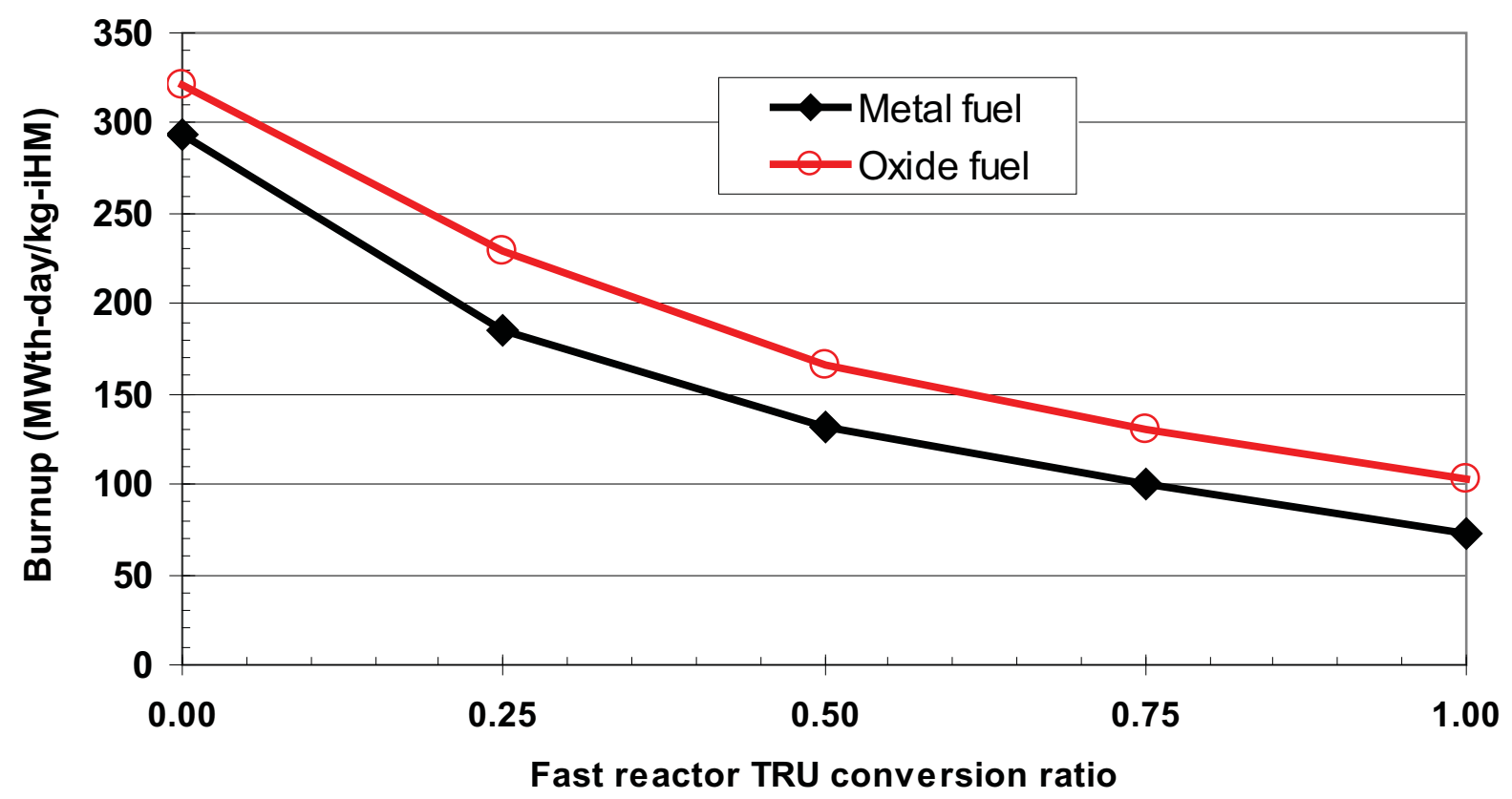

Figure 6-8. Burnup per initial heavy metal as function of fast reactor TRU conversion ratio; in these units burnup does not vary significantly from first to equilibrium recycle pass.

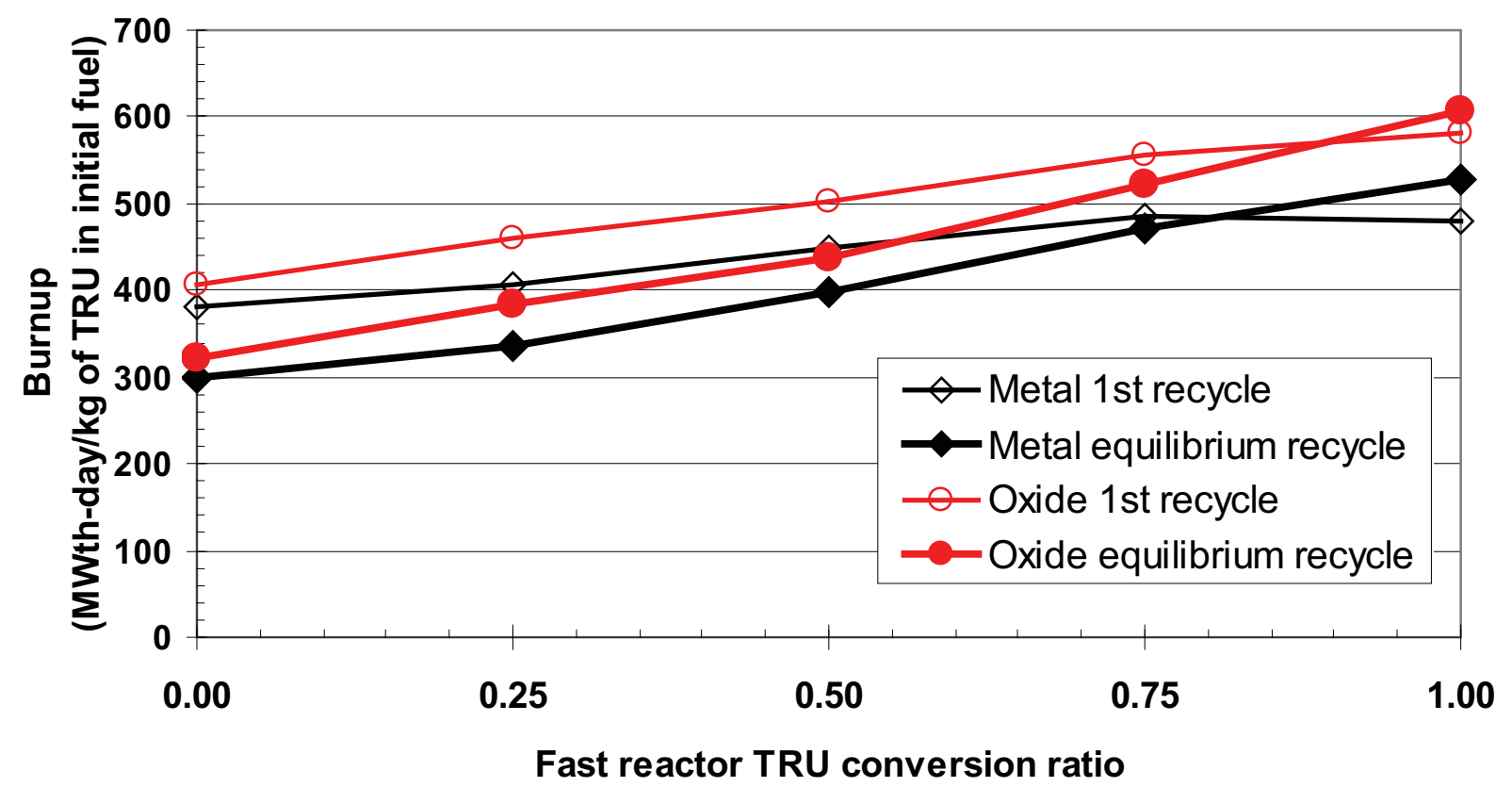

Figure 6-9. Burnup per mass of TRU in the initial fuel as function of fast reactor TRU conversion ratio.

\subsubsection{Idealized fast reactor performance}

The idealized FR will require a source of new fuel to start up the reactor and then regular refueling based on the design cycle length and design discharge burnup. Table 6-11 is the generic input for the idealized 
FR and the resulting time dependent behaviors designed to be a maximum theoretical burner (zero conversion ratio), moderate burner ( 0.5 conversion ratio), and a breakeven design (1.0 conversion ratio). This is meant to be representative of a metal-fueled fast reactor with colocated electrochemical reprocessing.

Table 6-11. Idealized fast reactor input [Hoffman2007]

\begin{tabular}{|l|r|r|r|l|}
\hline Conversion Ratio & 0 & 0.5 & 1.0 & \\
\hline Power Level & 1000 & 1000 & 1000 & MW \\
\hline Specific power & 0.278 & 0.109 & 0.059 & MWth / kg-iHM \\
\hline Capacity factor & $85 \%$ & $85 \%$ & $85 \%$ & \\
\hline Design discharge burnup & 296 & 132 & 76 & MWth-day/ kg-iHM \\
\hline Reactor lifetime & 60 & 60 & 60 & yrs \\
\hline
\end{tabular}

Once a FR is built, the requirements will be determined by the design of the reactor, especially the design goals of the FR. It will require between 66 tonne-iHM $(\mathrm{CR}=0)$ and 256 tonne-iHM $(\mathrm{CR}=1)$ of fuel over its 60 year life time. The average TRU content of this fuel will vary from effectively $100 \%(\mathrm{CR}=0), 33 \%$ $(\mathrm{CR}=0.5)$, to $15 \%(\mathrm{CR}=1.0)$. This means the TRU loaded over the lifetime of the FR is highest for the lowest conversion ratios and lowest for the highest conversion ratios. The breakeven fast reactor will load about $60 \%$ as much TRU, but nearly 4 times as much heavy metal. The reactors will utilize LWR spent nuclear fuel over its lifetime to make the initial fuel to startup the fast reactor and keep it running until recycled fuel is available and the LWR spent fuel will then provide the necessary makeup feed thereafter. The lifetime LWR SNF requirements are between 1,750 tonne-iHM $(\mathrm{CR}=0)$, 943 tonne-iHM $(\mathrm{CR}=0.5)$, and 285 tonne-iHM $(\mathrm{CR}=1.0)$. Of this material, $24 \%$ is for startup of the $\mathrm{CR}=0.0$ design and $100 \%$ for startup of the breakeven core. The rest is makeup feed to replace the TRU that is consumed during operation. However, at the end of plant life there is still a very large inventory of TRU onsite that would be used to make the fuel for a future replacement reactor.

The low conversion ratio designs have much higher burnup potential based on a peak fast fluence being the life limiting parameter for the FR fuel. This is yet to be demonstrated, but is expected to be true. The average discharge burnup will be strongly dependent on conversion ratio if this is in fact the life limiting parameter and is the reason the low conversion ratio design has a much higher design discharge burnup. The first fuel discharged will have a very low burnup relative to the design discharge burnup because it will have only been partially burned, when it must be replaced for core reactivity reasons. The core average burnup at the end of life will be less than the design discharge burnup because much of the fuel would have remained in the core for a number of additional cycles if the reactor had not shutdown. These factors will result in a significant range of burnups of the fuel that is discharged over the life of the reactor. This will reduce the average discharge burnup to approximately $95 \%$ of the design discharge burnup and the minimum batch average discharge burnup to approximately $30 \%$ of the design discharge burnup. 


\section{SEPARATION}

The nominal DSARR assumption is that the combined loss in separation and fuel fabrication is $0.1 \%$ of the uranium and transuranic elements being processed. A trade study is underway to understand the cost and benefits of minimizing losses.

\subsection{Requested Mass Flow Diagrams for 800 tonne-UOX/year plant}

Figures 7-1, 7-2, and 7-3 show the mass flow in and out of a hypothetical 800 tonnes-UOX/year separation plant. The three graphs show three possible ways the plant could be configured.

- With the mass streams sent to different waste classes per DSARR assumptions.

- Worst case (from the waste management perspective), the various fission product streams and $\mathrm{Np}, \mathrm{Am}$, and $\mathrm{Cm}$ are sent to waste.

- Best case (from the waste management perspective but not necessarily from economics), this would require extending the 10CFR61 regulation to the lanthanides and cleaning them to $<100$ nCi-TRU/g, extending 10CFR61 to Cs135 and cleaning CsSr to $<100 \mathrm{nCi}-\mathrm{TRU} / \mathrm{g}$, and recycling Zr into LWR and FR use.

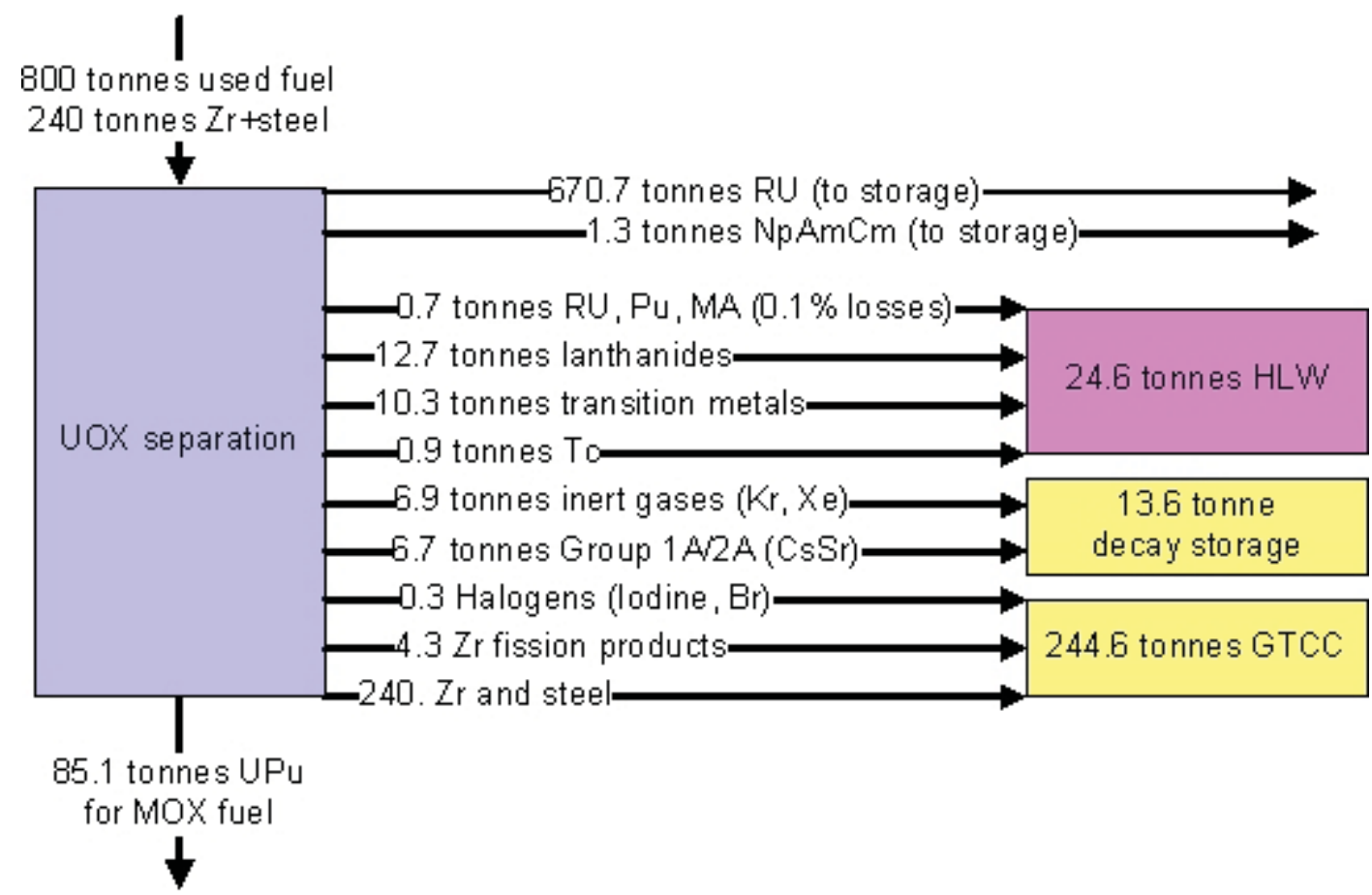

Figure 7-1. Static equilibrium for first 800 tonne-UOX/yr separation plant in the 2-tier (UOX to MOXRU-Pu to FR) strategy 


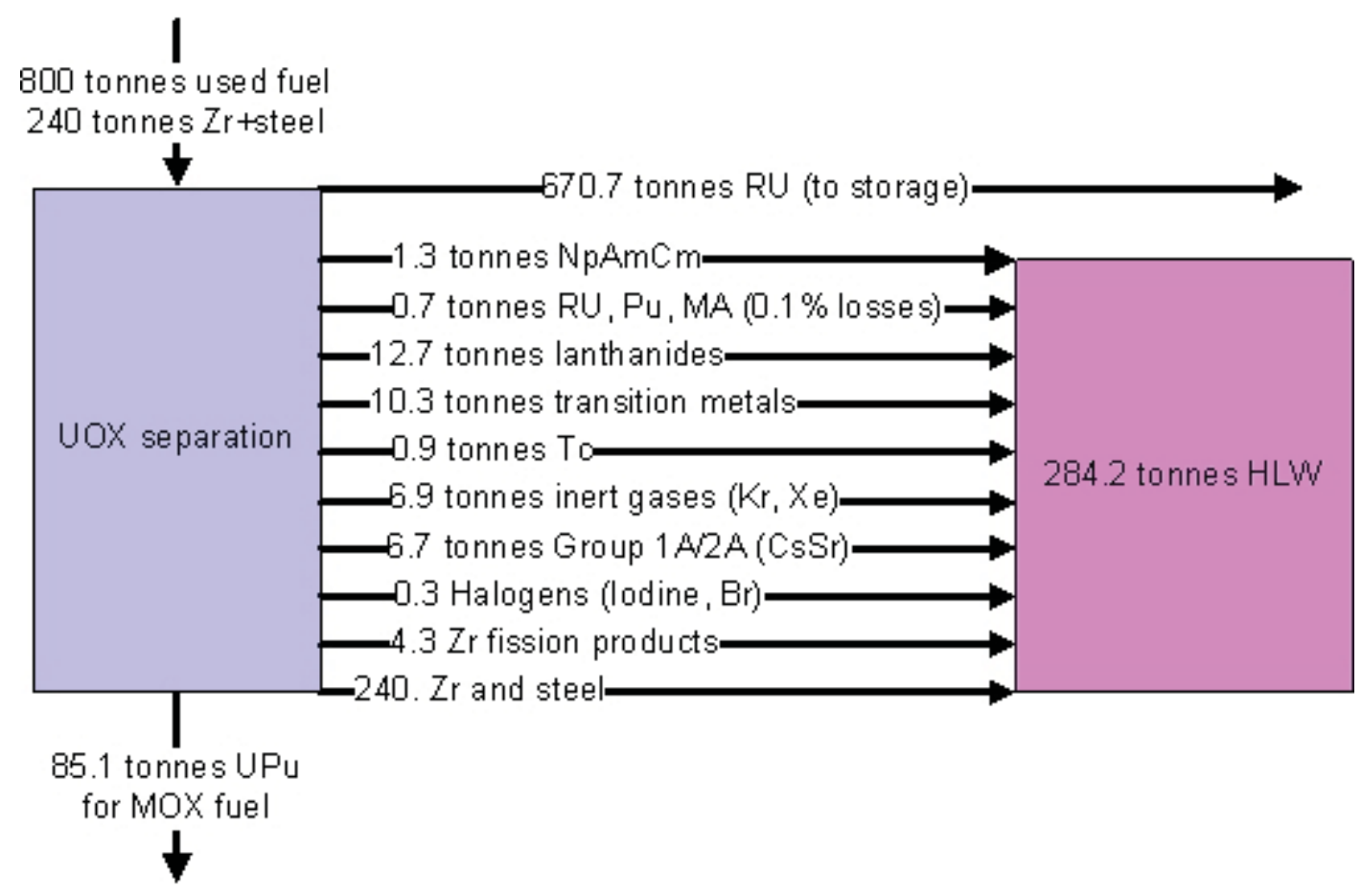

Figure 7-2. Variant of figure 7-1 (800 tonne-UOX/yr separation plant) for all waste streams and minor actinides (Np, Am, and $\mathrm{Cm}$ ) to be made into HLW.

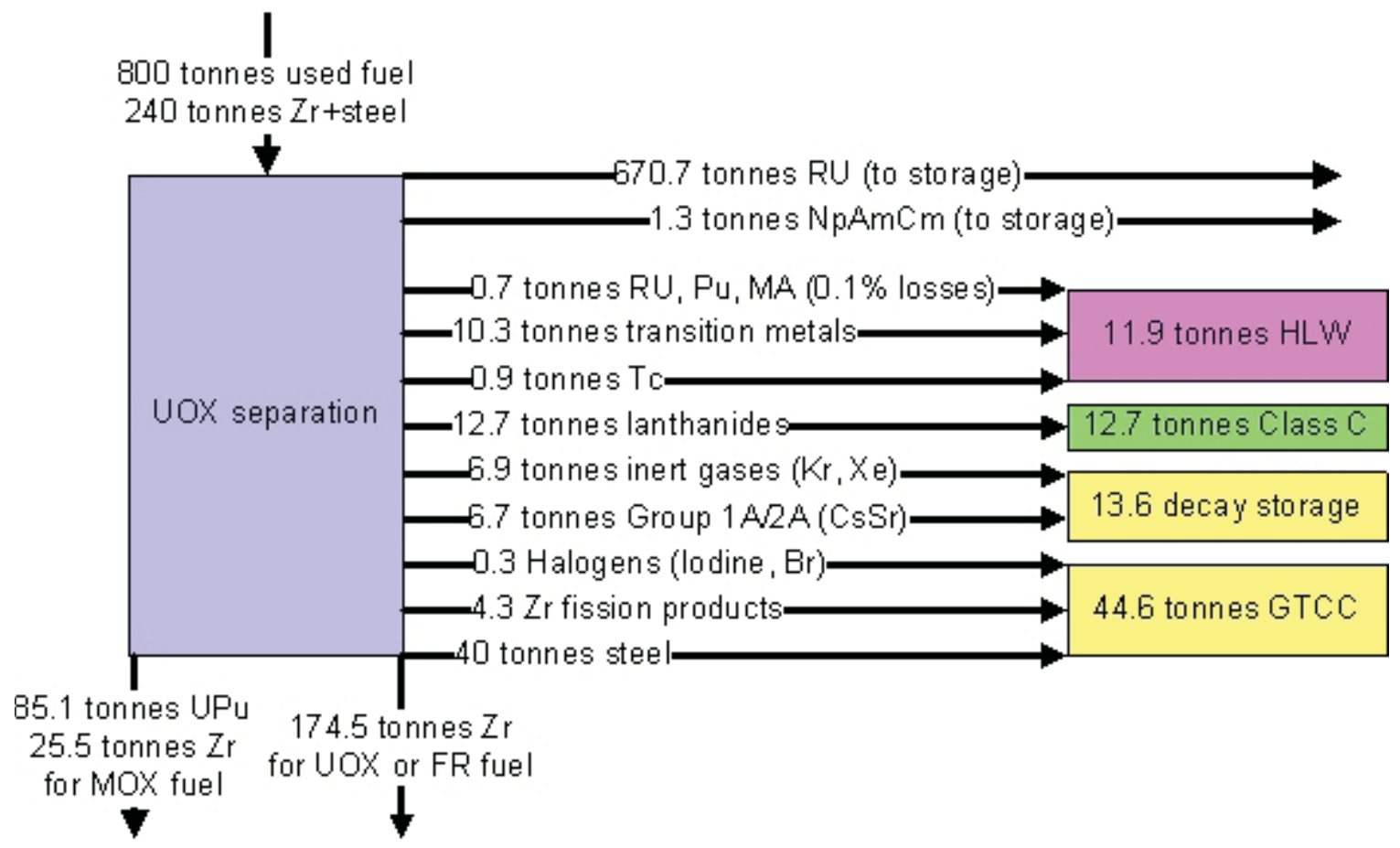

Figure 7-3. Variant of figure 7-1 (800 tonne-UOX/yr separation plant) maximizing recycle of materials and minimizing waste into HLW, requires cleaning lanthanides sufficient to meet Class $\mathrm{C}$ criteria. 


\subsection{Separation Capacity for $\mathbf{0 , 1}$, and 2 Tier in DSARR}

This section includes several graphs to present the separations capacities used for the DSARR nominal cases. For each type of graph, one version plots capacity in units of iHM and the other in units of TRU. Note how different the "TRU" and "HM" graphs appear. In particular, the fast reactor separation capacity looks small when expressed in units of "HM" but significantly large when expressed in units of "TRU." This is because $\sim 30 \%$ of the fast reactor fuel (at $\mathrm{CR}=0.50$ ) is transuranic, but only $1.3 \%$ of used UOX is TRU. As in section 5, graphs can appear different as one expresses results in "kg-TRU" versus "kg-HM".

- Figure 7-4a and 4b show the nominal 1-tier separation capacity in units of iHM and TRU.

- Figure 7-5a and 5b show the nominal 2-tier separation capacity in units of iHM and TRU. 


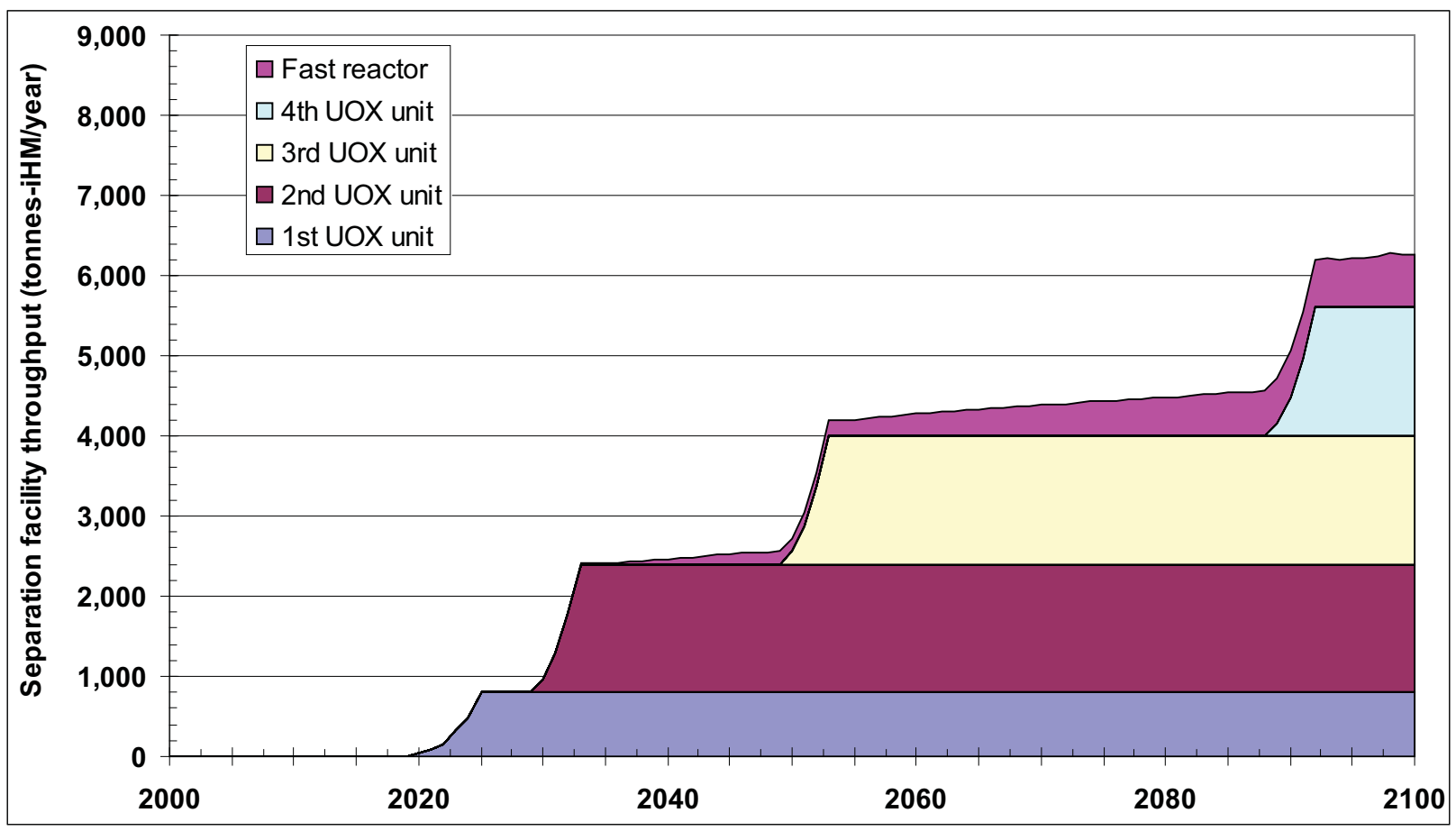

Figure 7-4a. Nominal 1-tier separation capacity for used fuel, expressed in tonnes of iHM.

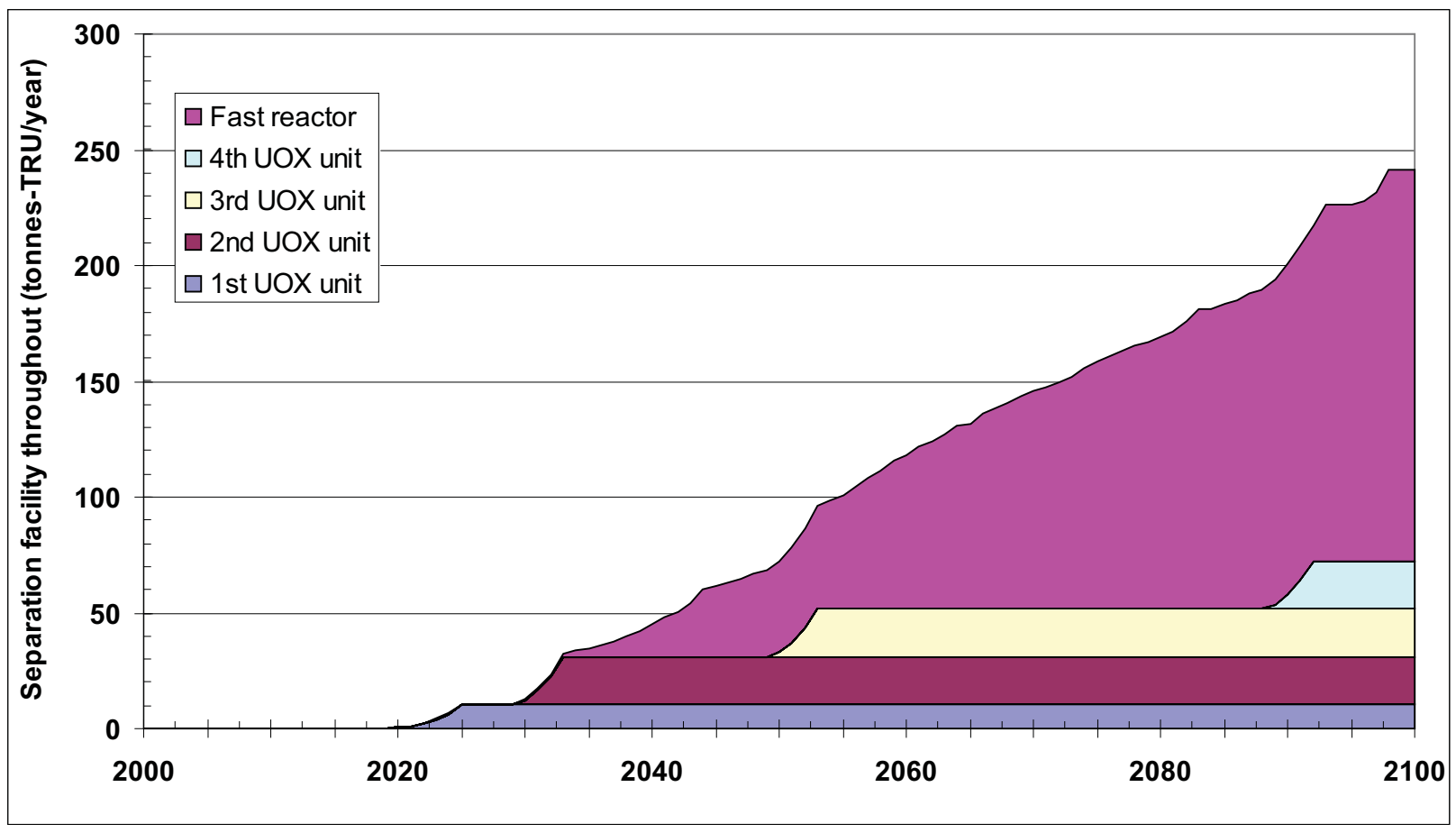

Figure 7-4b. Nominal 1-tier separation capacity for used fuel, expressed in tonnes of TRU. 


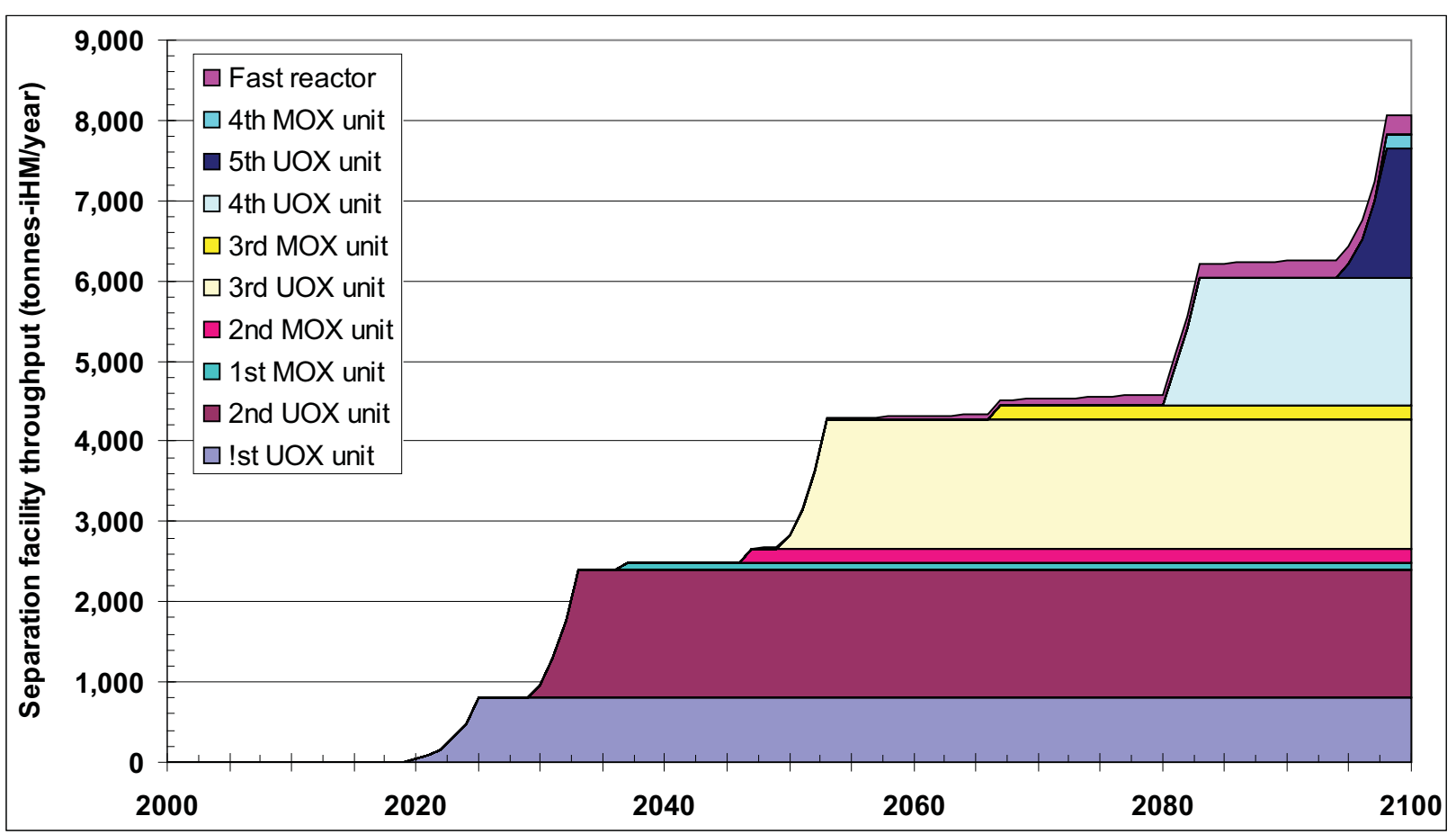

Figure 7-5a. Nominal 2-tier separation capacity for used fuel, expressed in tonnes of iHM.

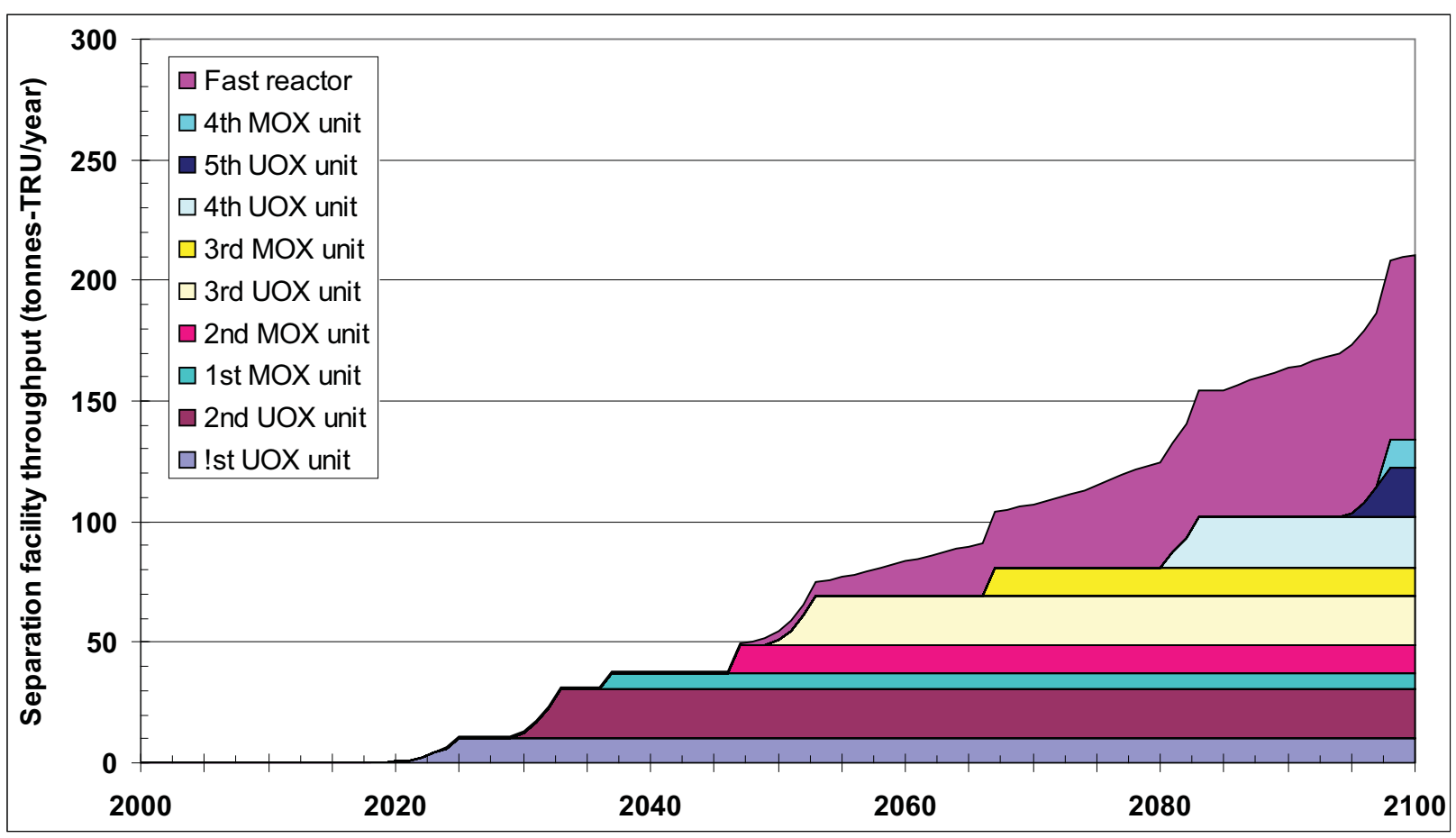

Figure 7-5b. Nominal 2-tier separation capacity for used fuel, expressed in tonnes of TRU. 


\section{WASTE MANAGEMENT}

\subsection{Basic Characterization of Used Nuclear Fuel}

Figure 8-1 shows the mass fraction of fission products (stable and radioactive), uranium, transuranic elements, and various decay products from 1 to 1,000,000 years after reactor discharge. The fuel is uranium oxide in an LWR, at $51 \mathrm{GW}$ th-day/tonne-iHM burnup. The next two graphs show fission products versus U/TRU/decay products respectively.

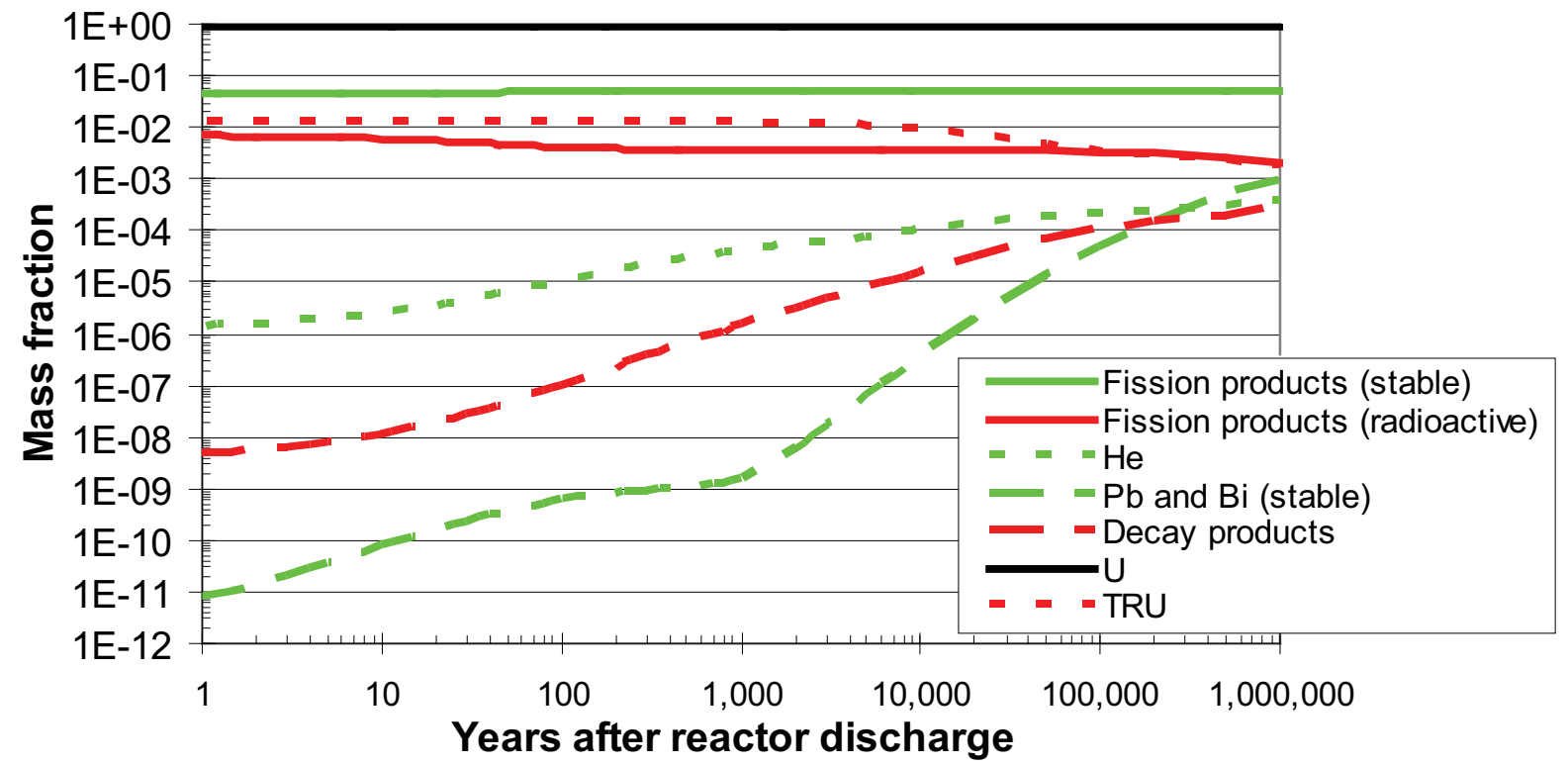

Figure 8-1. Mass of fission products, uranium, transuranics, and decay products for $51 \mathrm{GWth}-$ day/tonne$\mathrm{iHM}$ used uranium oxide fuel. $\mathrm{He}, \mathrm{Pb}$, and $\mathrm{Bi}$ are stable U/TRU decay products. Uranium is always $\sim 99 \%$ of the total mass and is difficult to see in the graph.

Figure 8-2 shows the fraction of the fission products in used nuclear fuel at $51 \mathrm{GWth}$-day/tonne-iHM burnup that is stable versus radioactive. At discharge, the fractions are $85 \% / 15 \%$, increasing to $95 \% / 4 \%$ at $1,000,000$ years. 


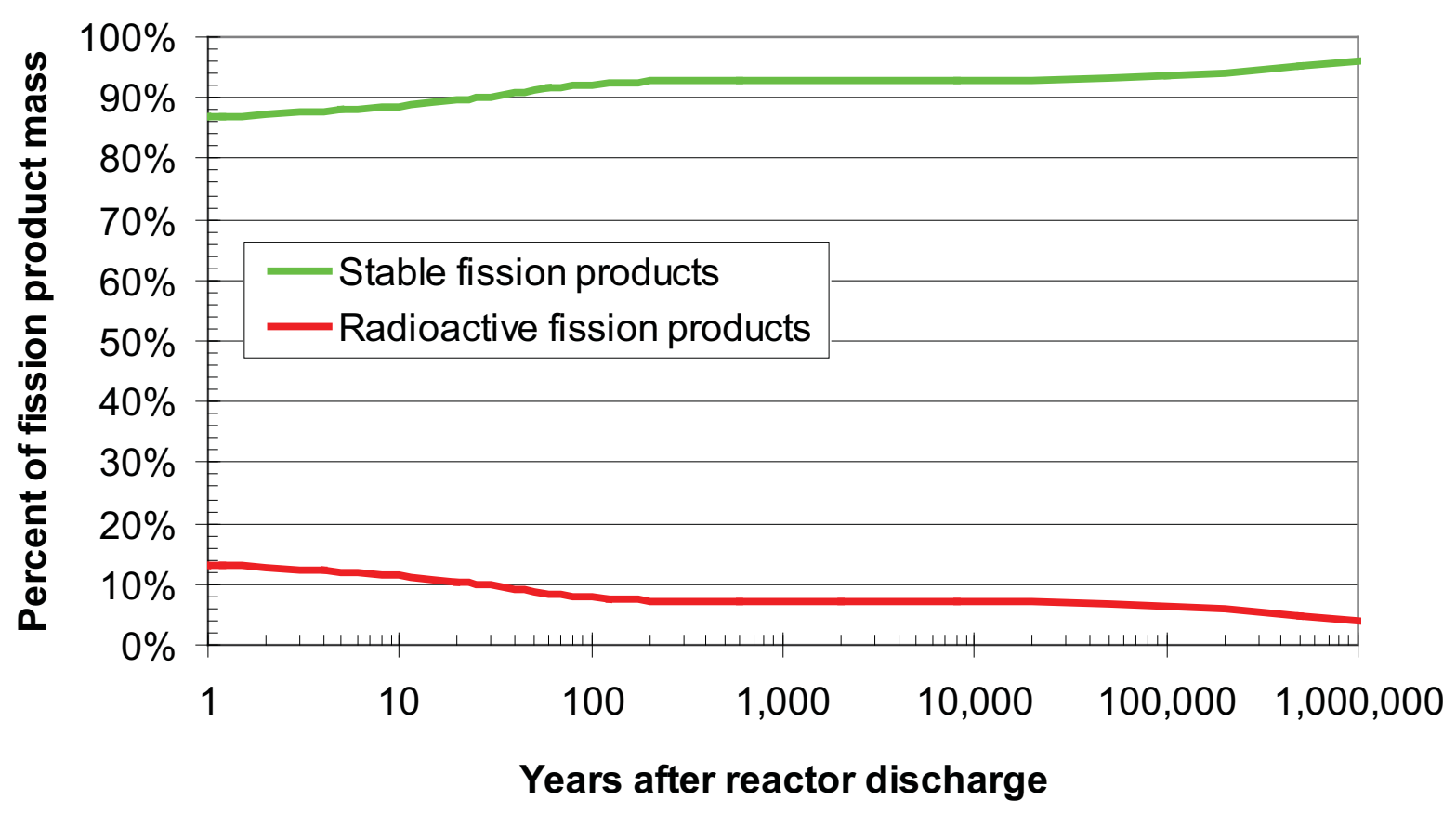

Figure 8-2. Stable versus radioactive fission products for $51 \mathrm{GWth}$-day/tonne-iHM used uranium oxide fuel.

Figure 8-3 shows the fraction of transuranic elements and decay products in used nuclear fuel at 51 GWth-day/tonne-iHM burnup that is stable versus radioactive. At all times, uranium is $\sim 99 \%$ of this mass and not shown in the figure. At discharge the TRU mass is $1.4 \%$, dropping to $0.2 \%$ in $1,000,000$ years as TRU decays back to uranium. At discharge, $\mathrm{He}, \mathrm{Pb}, \mathrm{Bi}$, and other decay products are much less than $0.01 \%$. They climb to $0.10 \%(\mathrm{~Pb}, \mathrm{Bi}), 0.04 \%(\mathrm{He})$, and $0.03 \%$ (other decay products) at $1,000,000$ years as these progeny of uranium slowly return to equilibrium with U235, U238, U236, and Np237. 


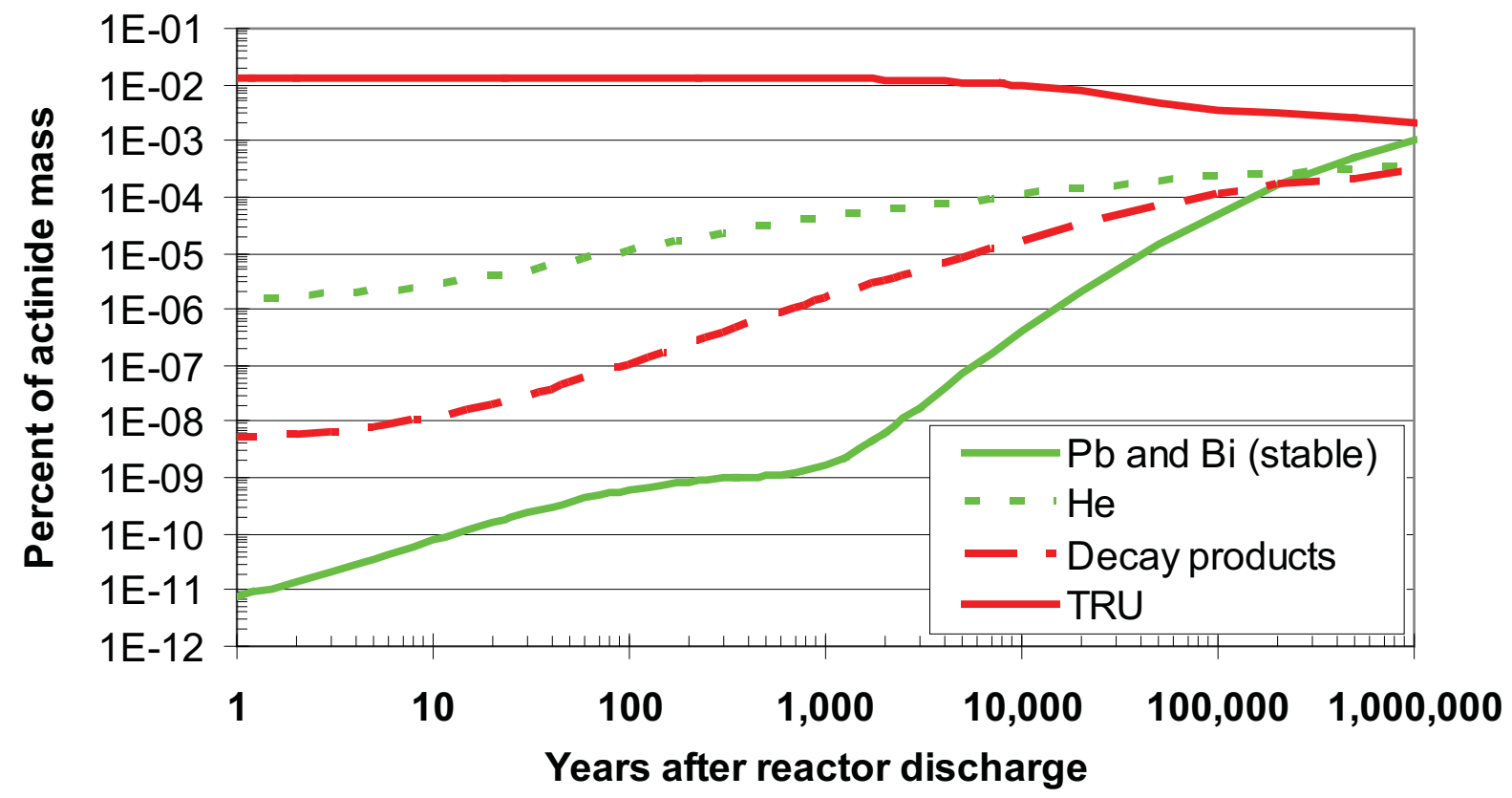

Figure 8-3. Transuranic elements and decay products for $51 \mathrm{GWth}-$ day/tonne-iHM used uranium oxide fuel. Uranium is always $\sim 99 \%$ of the total mass and is not shown.

\subsection{Used Nuclear Fuel, TRU, and Radiotoxicity}

Figure 8-4 through 8-12 show the location of used fuel, TRU, and radioactivity in the 0,1 , and 2 tier systems. In contrast with DSARR, the graphs are arranged by strategy, not by metric, i.e., the three once through graphs are shown together, then 1-tier, then 2-tier, to make it easier to see each strategy's behavior. 


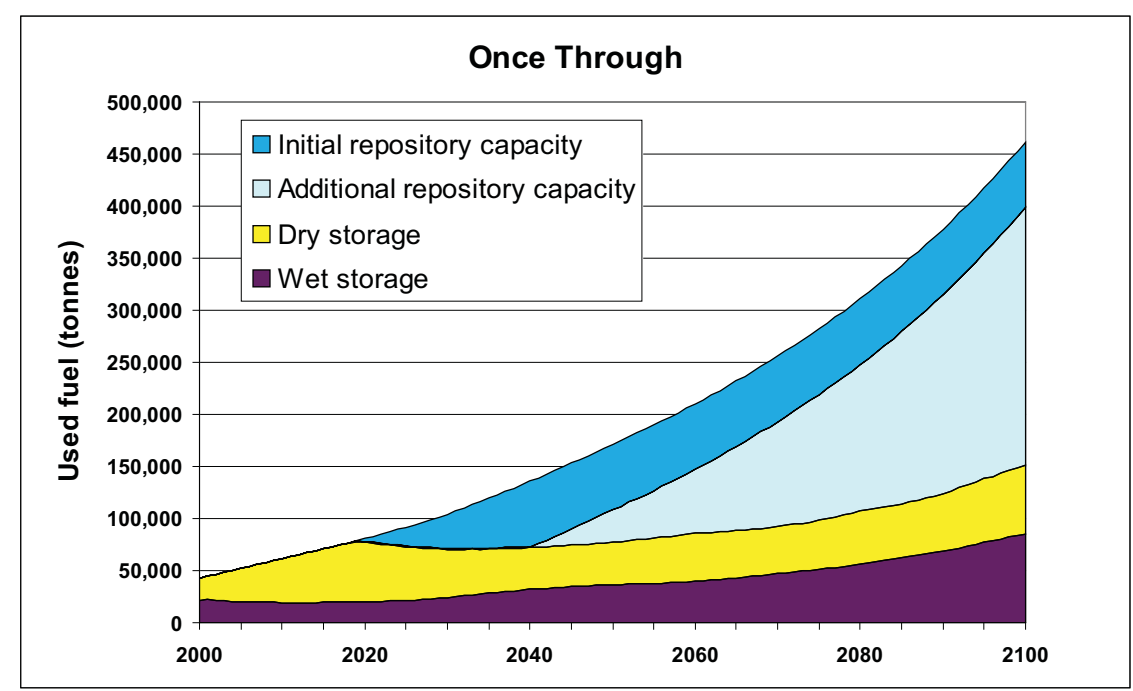

Figure 8-4. Location of used nuclear fuel for 0-tier, once through.

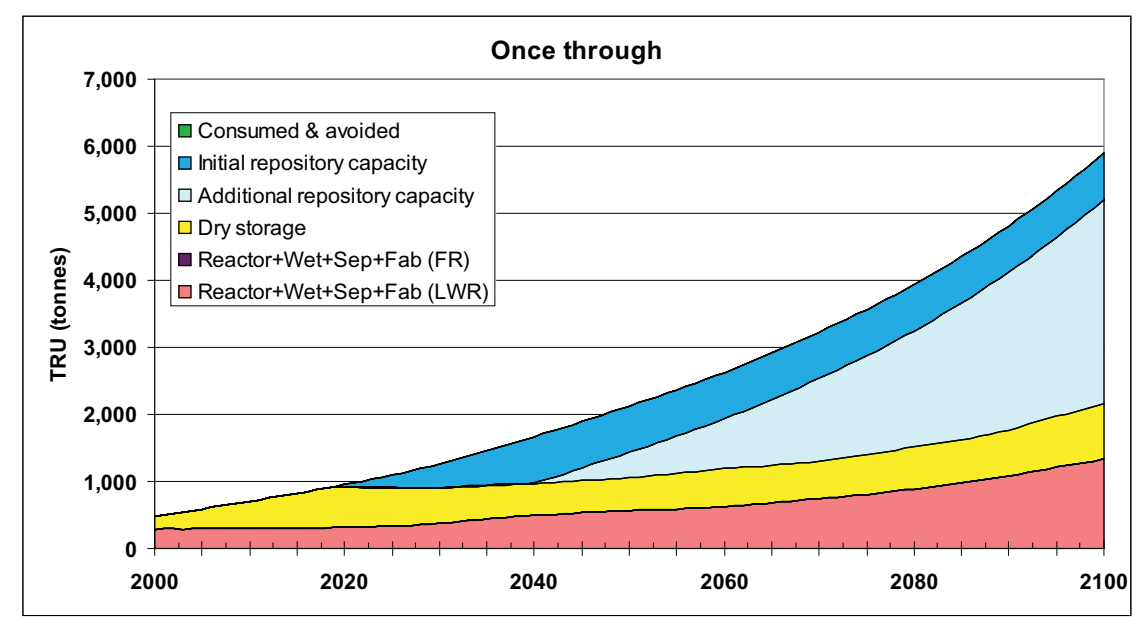

Figure 8-5. Location of transuranic material for 0-tier, once through.

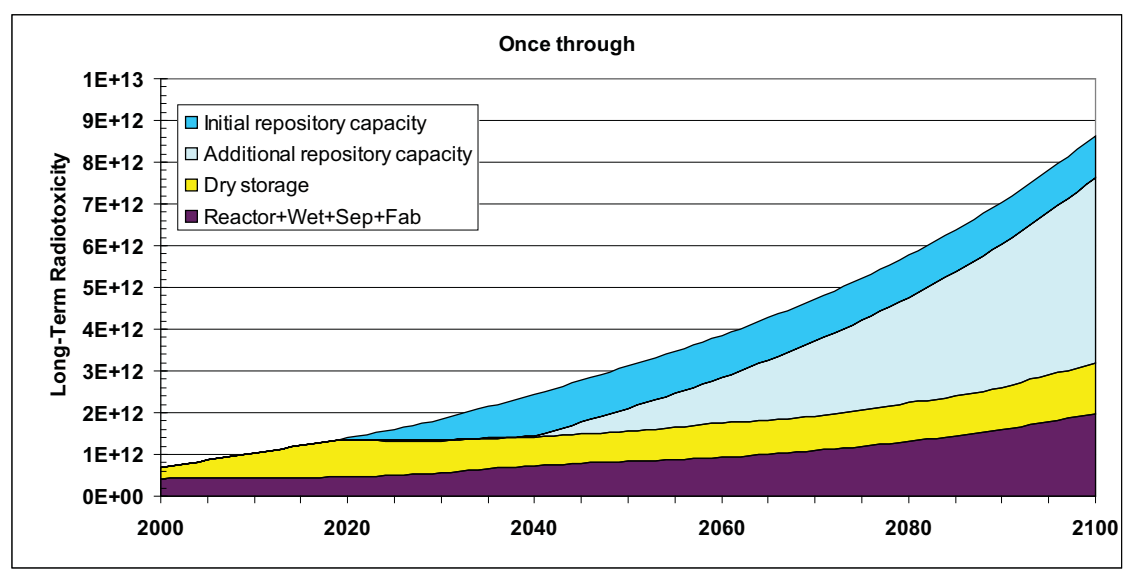

Figure 8-6. Location of radiotoxicity (evaluated 1000 years later) for 0 -tier, once through. 


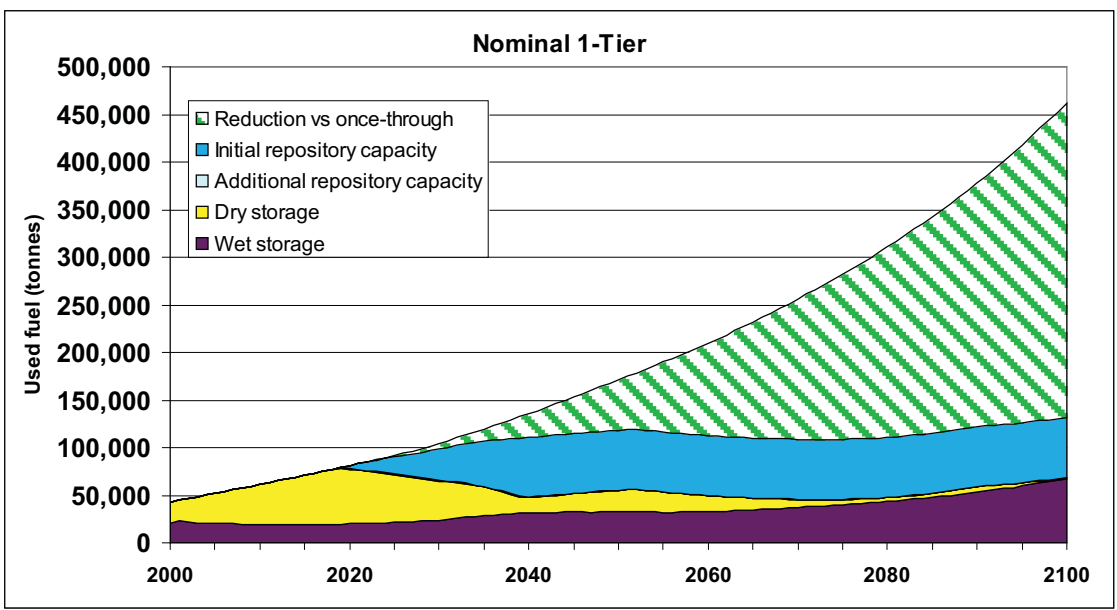

Figure 8-7. Location of used nuclear fuel for 1-tier, $\mathrm{UOX}$ to $\mathrm{CR}=0.50$ fast reactor.

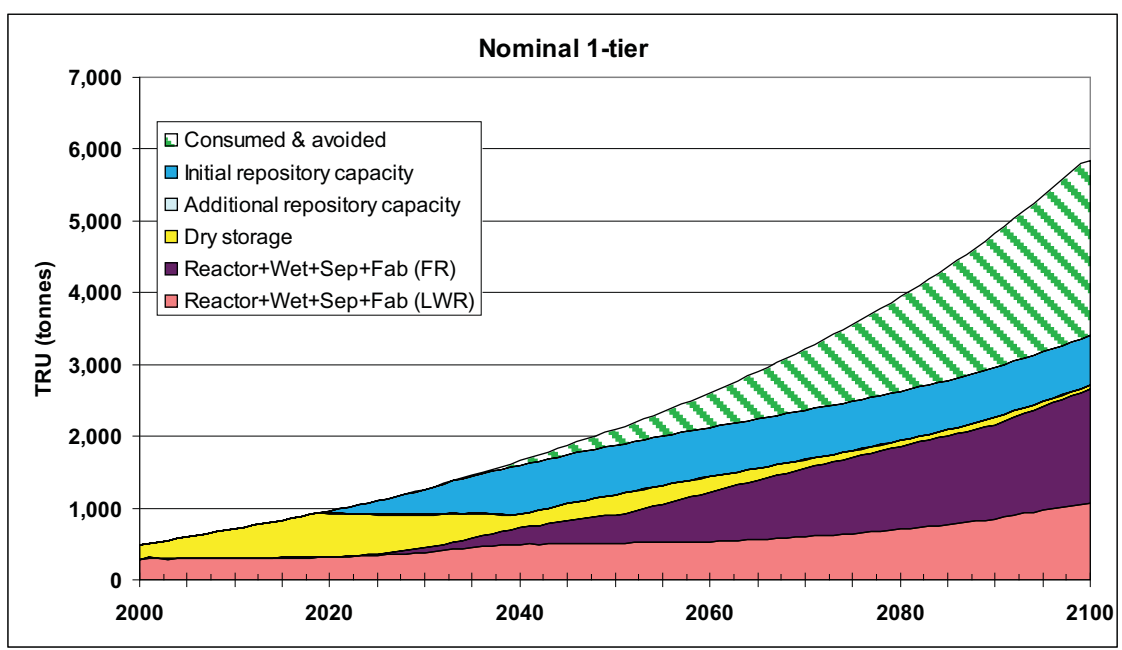

Figure 8-8. Location of transuranic material for 1-tier, $\mathrm{UOX}$ to $\mathrm{CR}=0.50$ fast reactor.

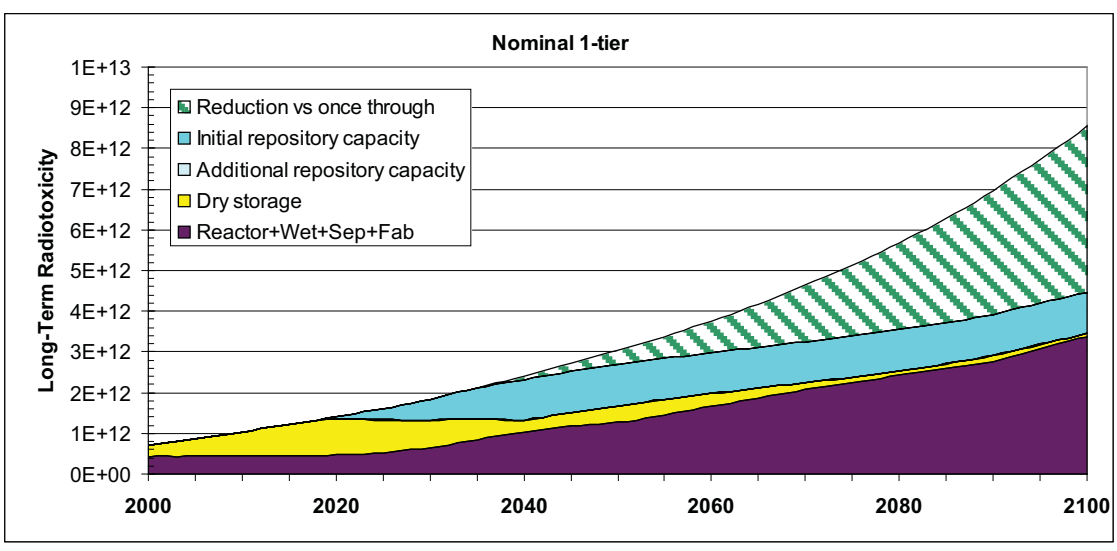

Figure 8-9. Location of radiotoxicity (evaluated 1000 years later) for 1-tier, $\mathrm{UOX}$ to $\mathrm{CR}=0.50$ fast reactor. 


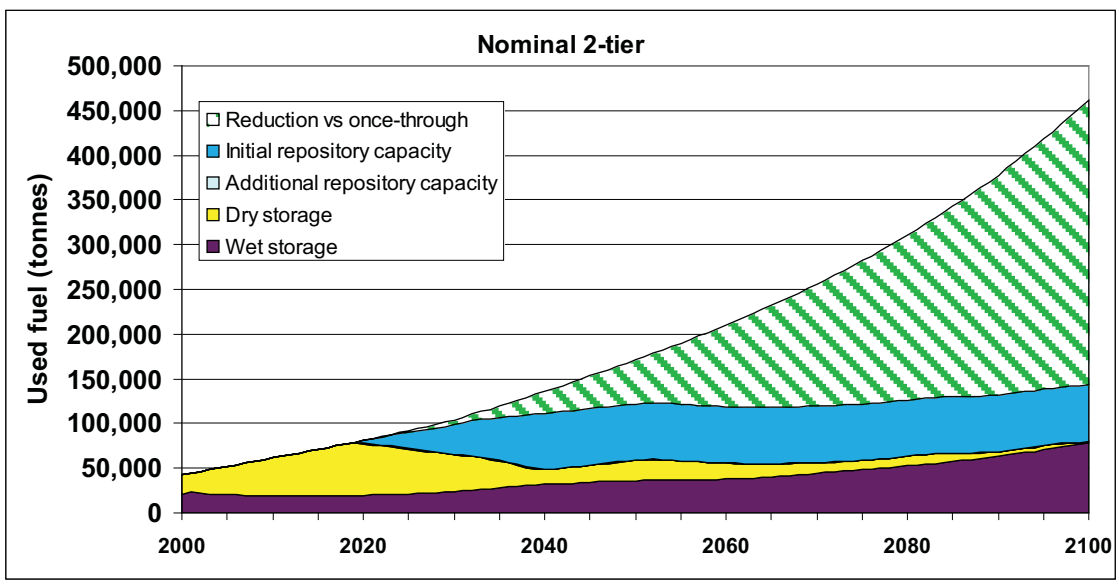

Figure 8-10. Location of used nuclear fuel for 2-tier, $\mathrm{UOX}$ to $\mathrm{MOX}-\mathrm{Pu}$ to $\mathrm{CR}=0.50$ fast reactor.

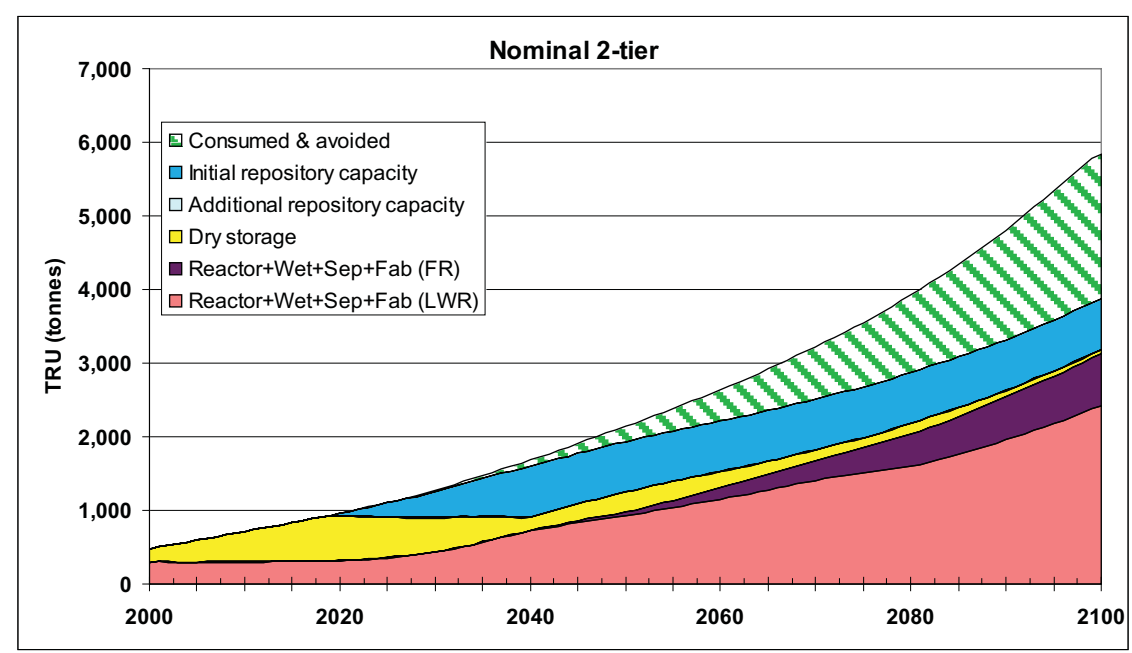

Figure 8-11. Location of transuranic material for 2-tier, $\mathrm{UOX}$ to $\mathrm{MOX}-\mathrm{Pu}$ to $\mathrm{CR}=0.50$ fast reactor.

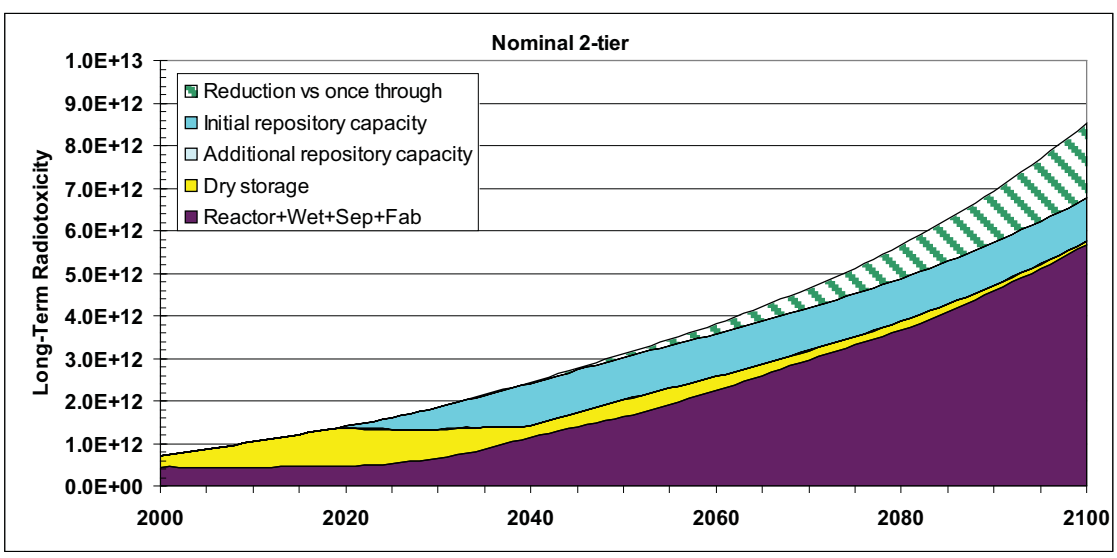

Figure 8-12. Location of radiotoxicity (evaluated 1000 years later) for 2-tier, UOX to MOX-Pu to $\mathrm{CR}=0.50$ fast reactor. 


\subsection{Radiotoxicity and Heat Impact from Minor Actinides}

Radiotoxicity is a commonly used international benchmark to describe the hazards in used nuclear fuel. It is, by definition, merely the inventory of various isotopes divided by their ingestion dose conversion factor. There is no accounting for the relative mobility of different chemical environments in the environment. The advantage of this metric is that it is site-independent, it does not matter where material may be disposed. Another advantage is that it is possible to compare hazards with natural uranium ore, regardless of its location. The "public" is known to consider natural hazards as generally acceptable. Thus, by ratioing hazard relative to natural uranium ore, one can put the longevity of the waste management burden into context.

The disadvantage of the radiotoxicity metric is that it is site independent, it takes no account of the relative mobility of different species in a specific disposal location. Thus, there is no penalty for the relatively high mobility of gases and no credit for the relative low mobility of $\mathrm{Pu}$ and other transuranics.

Figure 8-13 shows the radiotoxicity of the various groups of elements. The two groups with lowest radiotoxicity are $\mathrm{H} 3 / \mathrm{C} 14$ and the inert gases, which have the highest mobility in the environment. So, they have to be assessed even though their radiotoxicity is so low. The two plateaus in the H3/C14 curve are H3 (12 year) and C14 (5715 years). The inert gas curve is first dominated by several short-lived Xe isotopes followed by two plateaus from $\mathrm{Kr} 85$ and $\mathrm{Kr} 81$. After a few very short-lived Tc isotopes, the Tc curve is simply Tc99. The highest radiotoxicity comes from remaining four groups, Group 1A, halogens, transition metals, and lanthanides.

The following subsections go into more detail on those groups with several potentially important isotopes; there is no further discussion of $\mathrm{H} 3 / \mathrm{C} 14$ and Tc99.

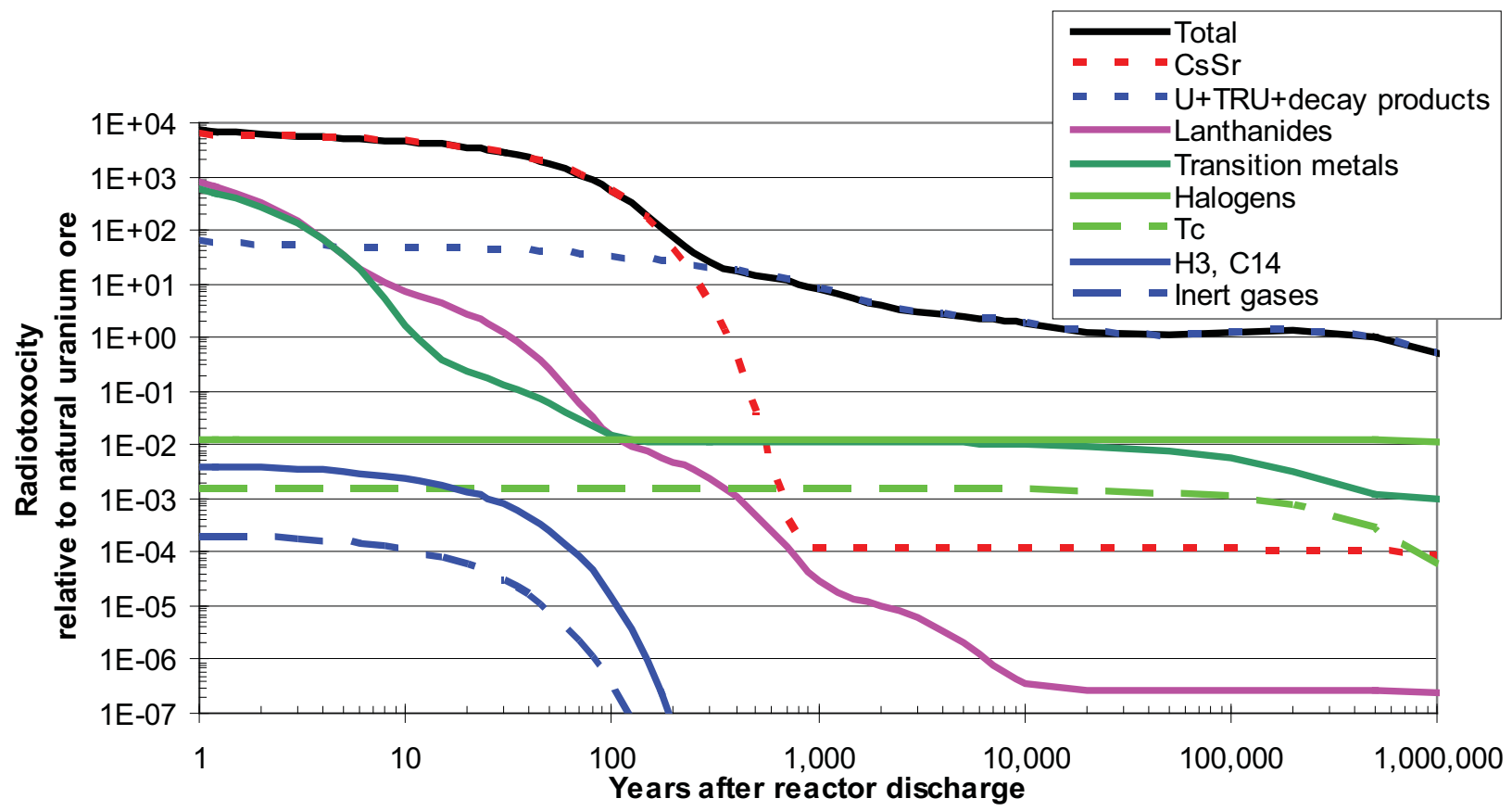

Figure 8-13. Radiotoxicity of fission product radiotoxicity from UOX-51.

The approximate time period when the disposed material is the same radiotoxicity as natural uranium ore, in which the various decay products of uranium are at equilibrium, is given in Table 8-1.[Piet2008a] When the MA are discarded (blue rows), about 20,000 years is required, with little dependence on either aging or $\mathrm{Pu}$ loss rate. When MA are recycled (green rows), a loss rate of $0.5 \%$ is adequate to bring the 
time horizon within 1,000 years. Key results are graphed in figure 8-14. Note, the recent DSARR report has a more accurate calculation of required loss rate because it uses a dynamic calculation and multiple recycles of the material.

Table 8-1. When Disposed Material Falls to the Radiotoxicity of Natural Uranium Ore (years after disposal)

\begin{tabular}{|c|c|c|c|c|c|c|}
\hline $\mathrm{U}$ to waste & Pu to waste & MA to waste & $\begin{array}{l}5 \text { years of } \\
\text { aging }\end{array}$ & $\begin{array}{l}10 \text { years of } \\
\text { aging }\end{array}$ & $\begin{array}{l}20 \text { years of } \\
\text { aging }\end{array}$ & $\begin{array}{l}40 \text { years of } \\
\text { aging }\end{array}$ \\
\hline \multicolumn{3}{|c|}{ Unprocessed UOX-51 } & \multicolumn{4}{|c|}{450,000} \\
\hline None & $100 \%$ & $100 \%$ & 320,000 & 320,000 & 310,000 & 300,000 \\
\hline $1.0 \%$ & $1.0 \%$ & \multirow{4}{*}{$100 \%$} & 21,000 & 21,000 & 21,000 & 22,000 \\
\hline $0.5 \%$ & $0.5 \%$ & & 19,000 & 20,000 & 20,000 & 20,000 \\
\hline $0.1 \%$ & $0.1 \%$ & & 18,000 & 18,000 & 18,000 & 18,000 \\
\hline $0 \%$ & $0 \%$ & & 18,000 & 18,000 & 18,000 & 17,000 \\
\hline $1.0 \%$ & $1.0 \%$ & $1.0 \%$ & 2,100 & 2,100 & 2,000 & 2,000 \\
\hline $0.5 \%$ & $0.5 \%$ & $0.5 \%$ & 880 & 880 & 870 & 850 \\
\hline $0.1 \%$ & $0.1 \%$ & $0.1 \%$ & 530 & 520 & 510 & 480 \\
\hline $0 \%$ & $0 \%$ & $0 \%$ & 320 & 310 & 300 & 280 \\
\hline
\end{tabular}

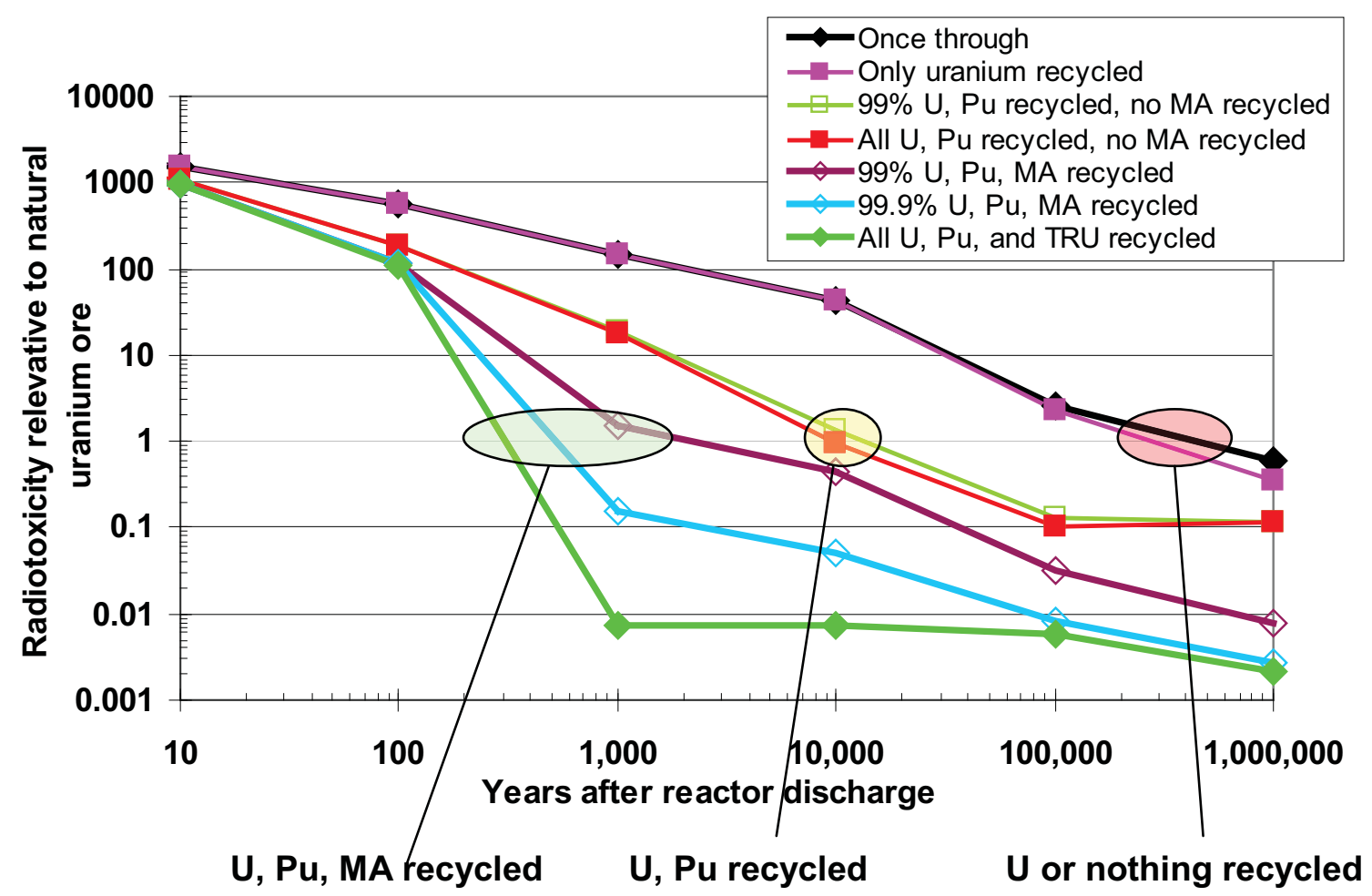

Figure 8-14. Radiotoxicity of fission product radiotoxicity from UOX-51 as function of minor actinide recycling.

The rate of heat generation impacts storage, transportation, how much mass can be put into individual containers, interim storage, and all known types of geologic disposal. Figure 8-15 shows the heat generation rate of UOX, divided into major components. Note that the dominant materials are $\mathrm{CsSr}$ and 
the actinides (uranium and transuranic elements). Figure 8-16 examines these two materials in more detail as a function of when residual $\mathrm{Pu}$ is separated from minor actinides $(\mathrm{Np}, \mathrm{Am}, \mathrm{Cm})$. At repository emplacement ( $<100$ years after discharge), CsSr dominates heat generation. The heat time-integrated from emplacement to 1000 to 2000 years is dominated by CsSr and the actinides, both of which have to be removed from residual high-level waste to obtain orders of magnitude reduction in the repository heat burden.

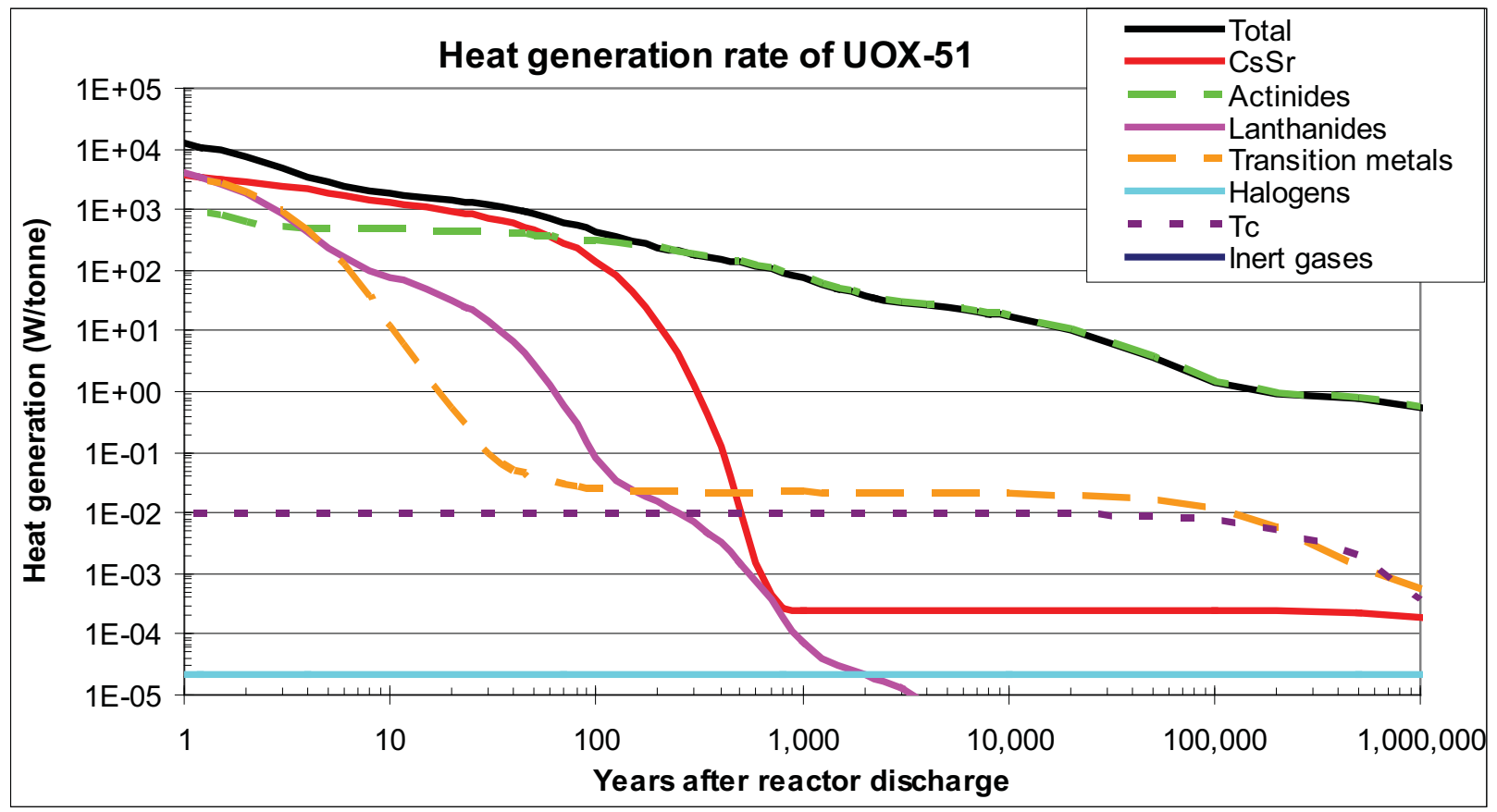

Figure 8-15. Heat generation rate from UOX-51. 


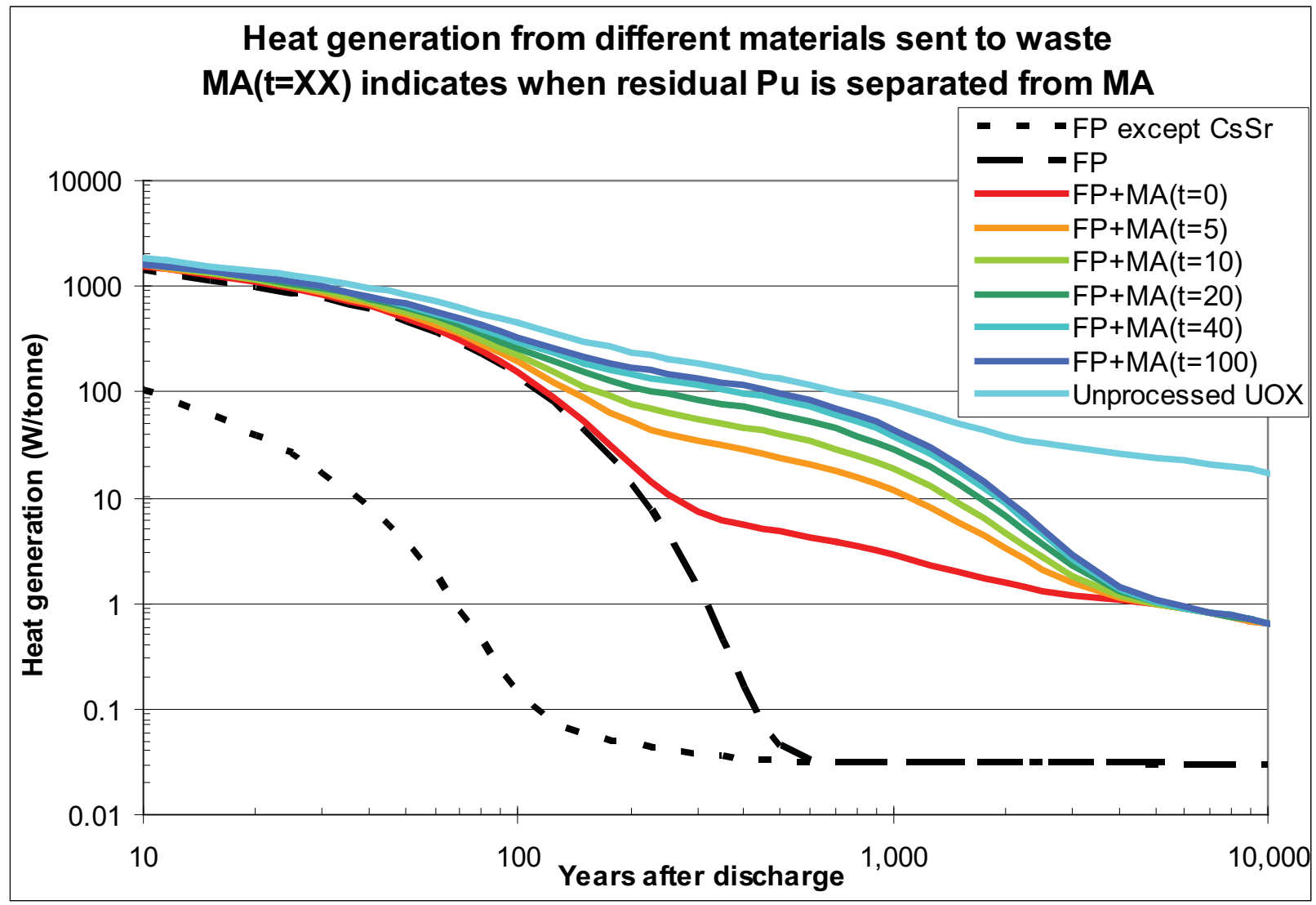

Figure 8-16. Heat generation rate from UOX-51 as function of minor actinide recycling.

\subsection{Typical Glass Log Characteristics}

Waste loading is commonly cited in $10 \mathrm{~s}$ of percent $\sim 25-40 \mathrm{wt} \%$, but this includes chemicals from separations (ferrous sulfamate and bismuth phosphate), and waste management practices, such as adding $\mathrm{NaOH}$ to neutralize acidic HLW to store in carbon-steel tanks. SNF contributes essentially no B, Na, Ca, $\mathrm{Cr}, \mathrm{Fe}, \mathrm{Li}, \mathrm{K}, \mathrm{Si}, \mathrm{F}, \mathrm{Cl}, \mathrm{P}, \mathrm{S}$ very low $\mathrm{Cd}, \mathrm{Zr}$ and many other metals so by subtracting these oxides out from the nominal compositions in Table 8-2 one can see that the nominal waste loading for current HLW glasses is quite low $<10 \mathrm{wt} \%$ at most. Generally after comprehensively subtracting the metals from cladding and corrosion, separations process additives, and glass making constituents the fuel contribution to the content of most HLW glass in the US is $<5 \mathrm{wt} \%$, closer to $1-2 \mathrm{wt} \%$. This differs markedly for what is envisioned for future flowsheets where fuels are chop-leached and cladding is disposed separately. Also, advances in glass chemistry have made it possible to attain waste loadings of actual fuel constituents at $40-50 \mathrm{wt} \%$ based on actual crucible scale tests at PNNL.

Table 8-2. Chemical Composition (Wt \%) of HLW Glasses [Table 1.5.1-14 from YMLA2008]

\begin{tabular}{|l|c|c|c|c|}
\hline \multicolumn{1}{|c|}{ Constituent } & Hanford & Savannah River & West Valley & Idaho \\
\hline $\mathrm{Al}_{2} \mathrm{O}_{3}$ & 8.28 & 7.08 & 6.04 & 7.11 \\
\hline $\mathrm{AgO}$ & 0.05 & - & - & - \\
\hline $\mathrm{As}_{2} \mathrm{O}_{5}$ & 0.03 & - & - & - \\
\hline $\mathrm{N}_{3} \mathrm{H}_{12} \mathrm{PMo}_{12} \mathrm{O}_{40}$ & - & - & - & 1.40 \\
\hline $\mathrm{B}_{2} \mathrm{O}_{3}$ & 6.16 & 6.94 & 12.97 & 10.94 \\
\hline $\mathrm{BaO}$ & 0.12 & 0.12 & 0.16 & - \\
\hline
\end{tabular}




\begin{tabular}{|c|c|c|c|c|}
\hline Constituent & Hanford & Savannah River & West Valley & Idaho \\
\hline $\mathrm{BeO}$ & 0.01 & - & - & - \\
\hline $\mathrm{Bi}_{2} \mathrm{O}_{3}$ & 0.01 & - & - & - \\
\hline $\mathrm{CaF}_{2}$ & - & - & - & 7.75 \\
\hline $\mathrm{CaO}$ & 0.53 & 1.05 & 0.48 & 0.22 \\
\hline $\mathrm{CdO}$ & 1.20 & - & - & - \\
\hline $\mathrm{CeO}_{2}$ & 0.16 & - & - & - \\
\hline $\mathrm{Ce}_{2} \mathrm{O}_{3}$ & - & - & 0.31 & - \\
\hline $\mathrm{Co}_{2} \mathrm{O}_{3}$ & 0.01 & - & - & - \\
\hline $\mathrm{Cr}_{2} \mathrm{O}_{3}$ & 1.92 & 0.09 & 0.14 & - \\
\hline $\mathrm{Cs}_{2} \mathrm{O}$ & - & 0.07 & - & 0.01 \\
\hline $\mathrm{CuO}$ & 0.05 & 0.25 & - & - \\
\hline $\mathrm{Fe}_{2} \mathrm{O}_{3}$ & 19.53 & 7.38 & 12.09 & 0.04 \\
\hline $\mathrm{K}_{2} \mathrm{O}$ & 0.45 & 2.14 & 5.03 & - \\
\hline $\mathrm{La}_{2} \mathrm{O}_{3}$ & 0.64 & 0.09 & - & - \\
\hline $\mathrm{Li}_{2} \mathrm{O}$ & 2.33 & 4.62 & 3.73 & - \\
\hline $\mathrm{MgO}$ & 0.28 & 1.45 & 0.90 & - \\
\hline $\mathrm{MnO}$ & - & 2.07 & 0.82 & - \\
\hline $\mathrm{MnO}_{2}$ & 0.25 & - & - & - \\
\hline $\mathrm{MoO}_{3}$ & 0.44 & - & - & - \\
\hline $\mathrm{Na}_{2} \mathrm{O}$ & 15.72 & 8.24 & 8.05 & 13.48 \\
\hline $\mathrm{Nd}_{2} \mathrm{O}_{3}$ & 0.51 & - & 0.14 & - \\
\hline $\mathrm{NiO}$ & 0.97 & 0.40 & 0.25 & - \\
\hline $\mathrm{P}_{2} \mathrm{O}_{5}$ & 0.11 & 0.05 & 1.21 & 0.05 \\
\hline $\mathrm{PbO}$ & 0.05 & 0.01 & - & - \\
\hline $\mathrm{PbS}$ & - & 0.06 & - & - \\
\hline $\mathrm{PdO}$ & 0.00 & - & - & - \\
\hline $\mathrm{Pr}_{2} \mathrm{O}_{3}$ & 0.08 & - & - & - \\
\hline $\mathrm{PuO}_{2}$ & - & 0.06 & - & - \\
\hline $\mathrm{Rb}_{2} \mathrm{O}$ & 0.01 & - & - & - \\
\hline $\mathrm{Rh}_{2} \mathrm{O}_{3}$ & 0.04 & - & - & - \\
\hline $\mathrm{RuO}_{2}$ & - & - & 0.08 & - \\
\hline $\mathrm{Ru}_{2} \mathrm{O}_{3}$ & 0.26 & - & - & - \\
\hline $\mathrm{Sb}_{2} \mathrm{O}_{3}$ & 0.00 & - & - & - \\
\hline $\mathrm{SeO}_{2}$ & 0.06 & - & - & - \\
\hline $\mathrm{SiO}_{2}$ & 31.63 & 54.39 & 41.22 & 54.87 \\
\hline $\mathrm{SO}_{3}$ & 0.49 & - & - & - \\
\hline $\mathrm{SO}_{4}$ & - & 0.14 & - & - \\
\hline $\mathrm{SrO}$ & 0.07 & 0.01 & 0.02 & - \\
\hline $\mathrm{Ta}_{2} \mathrm{O}_{5}$ & 0.00 & - & - & - \\
\hline $\mathrm{TeO}_{2}$ & 0.02 & - & - & - \\
\hline $\mathrm{ThO}_{2}$ & 0.05 & 0.55 & 3.58 & - \\
\hline $\mathrm{TiO}_{2}$ & 0.02 & 0.55 & 0.80 & - \\
\hline $\mathrm{Tl}_{2} \mathrm{O}_{3}$ & 0.00 & - & - & - \\
\hline $\mathrm{UO}_{3}$ & - & - & 0.63 & - \\
\hline $\mathrm{U}_{3} \mathrm{O}_{8}$ & 1.40 & 1.01 & - & - \\
\hline $\mathrm{V}_{2} \mathrm{O}_{5}$ & 0.01 & - & - & - \\
\hline $\mathrm{WO}_{3}$ & 0.00 & - & - & - \\
\hline
\end{tabular}




\begin{tabular}{|l|c|c|c|c|}
\hline \multicolumn{1}{|c|}{ Constituent } & Hanford & Savannah River & West Valley & Idaho \\
\hline $\mathrm{Y}_{2} \mathrm{O}_{3}$ & 0.00 & 0.04 & - & - \\
\hline $\mathrm{ZnO}$ & 0.03 & 0.02 & 0.02 & - \\
\hline $\mathrm{ZrO}{ }_{2}$ & 5.92 & 0.37 & 1.33 & 0.93 \\
\hline$(\mathrm{R.E.})_{2} \mathrm{O}_{3}$ footnote & - & 0.63 & - & - \\
\hline $\mathrm{Cd}$ & - & - & - & 2.27 \\
\hline $\mathrm{Cl}$ & 0.01 & - & - & - \\
\hline $\mathrm{Cr}$ & - & - & - & 0.73 \\
\hline $\mathrm{F}$ & 0.08 & - & - & - \\
\hline $\mathrm{Hg}$ & - & - & - & 0.01 \\
\hline $\mathrm{Ni}$ & - & - & - & 0.10 \\
\hline $\mathrm{Pb}$ & - & 0.03 & - & - \\
\hline $\mathrm{Pd}$ & - & 0.02 & - & - \\
\hline $\mathrm{Rh}$ & - & - & - & - \\
\hline $\mathrm{Ru}$ & - & & - & - \\
\hline $\begin{array}{l}\text { Footnote: (R.E. })_{2} \mathrm{O}_{3} \text { represents the total wt \% of the oxides of Pr, Ce, Nd, Sm, and Eu estimated } \\
\text { from isotopes. }\end{array}$
\end{tabular}

Glass canisters are nominally 10-15 ft long, and filled weight is $\leq 4500 \mathrm{~kg}$. Empty canister characteristics are shown in the second table.

Table 8-3. Approximate Mass of HLW per Canister [Table 1.5.1-15 from YMLA2008]

\begin{tabular}{|l|c|}
\hline \multicolumn{1}{|c|}{ Originating Site } & Estimated Mass (kg) per Canister \\
\hline Hanford & 3,360 \\
\hline Savannah River Site & 1,795 \\
\hline Idaho National Laboratory & 1,560 \\
\hline West Valley Demonstration Project & 2,000 \\
\hline
\end{tabular}

Table 8-4. Approximate Mass of HLW per Canister [Table 1.5.1-16 from YMLA2008]

\begin{tabular}{|c|c|c|c|c|c|c|c|c|}
\hline & $\begin{array}{l}\text { Lengt } \\
\mathrm{h}(\mathrm{cm})\end{array}$ & $\begin{array}{l}\text { Nomina } \\
\text { l Outer } \\
\text { Diameter } \\
(\mathrm{cm})\end{array}$ & $\begin{array}{l}\text { Thicknes } \\
\mathrm{s}(\mathrm{cm})\end{array}$ & Material & $\begin{array}{c}\text { Empty } \\
\text { Canister } \\
\text { Weight } \\
(\mathrm{kg})\end{array}$ & $\begin{array}{c}\text { Availabl } \\
\text { e } \\
\text { Volume } \\
\left(\mathrm{m}^{3}\right)\end{array}$ & $\begin{array}{l}\text { Nominal } \\
\text { Percent } \\
\text { Fill } \\
\text { Height } \\
(\%)\end{array}$ & $\begin{array}{c}\text { Glass } \\
\text { Volume } \\
\left(\mathrm{m}^{3}\right)^{*}\end{array}$ \\
\hline Hanford & 450 & 61 & 0.95 & SS 304L & 715 & 1.19 & $\begin{array}{c}87 \\
95 \\
100\end{array}$ & $\begin{array}{l}1.04 \\
1.14 \\
1.19\end{array}$ \\
\hline $\begin{array}{l}\text { Savannah } \\
\text { River Site, } \\
\text { Idaho } \\
\text { National } \\
\text { Laboratory }\end{array}$ & 300 & 61 & 0.95 & SS 304L & 500 & 0.736 & 90 & 0.66 \\
\hline $\begin{array}{l}\text { West Valley } \\
\text { Demonstratio } \\
\text { n Project }\end{array}$ & 300 & 61 & 0.34 & SS 304L & 181.4 & 0.83 & 91 & 0.76 \\
\hline
\end{tabular}




\subsection{Typical Dry Storage Parameters}

Dry fuel storage can be horizontal or vertical depending on the manufacturer of the storage cask system (e.g., Transnuclear, Holtec). The NRC has approved 15 designs. Spent fuel is currently in dry storage at 40 on-site or off-site leased sites with general licenses and 15 sites with site-specific licenses. These Independent Spent Fuel Storage Installations (ISFSI) currently store a total of $\sim 700$ loaded dry casks. Fuel is removed from the cooling pool and placed in dry storage by a contractor as described above. The reactor operator will buy the fuel movement and conditioning services and the necessary materials including the fuel container and the storage cask. The only scaling factor is a storage cask, which generally holds 11-15 tonnes-iHM depending on the type and design of the fuel (PWR vs. BWR). Casks are rated for maximum mass, heat, and types of material.

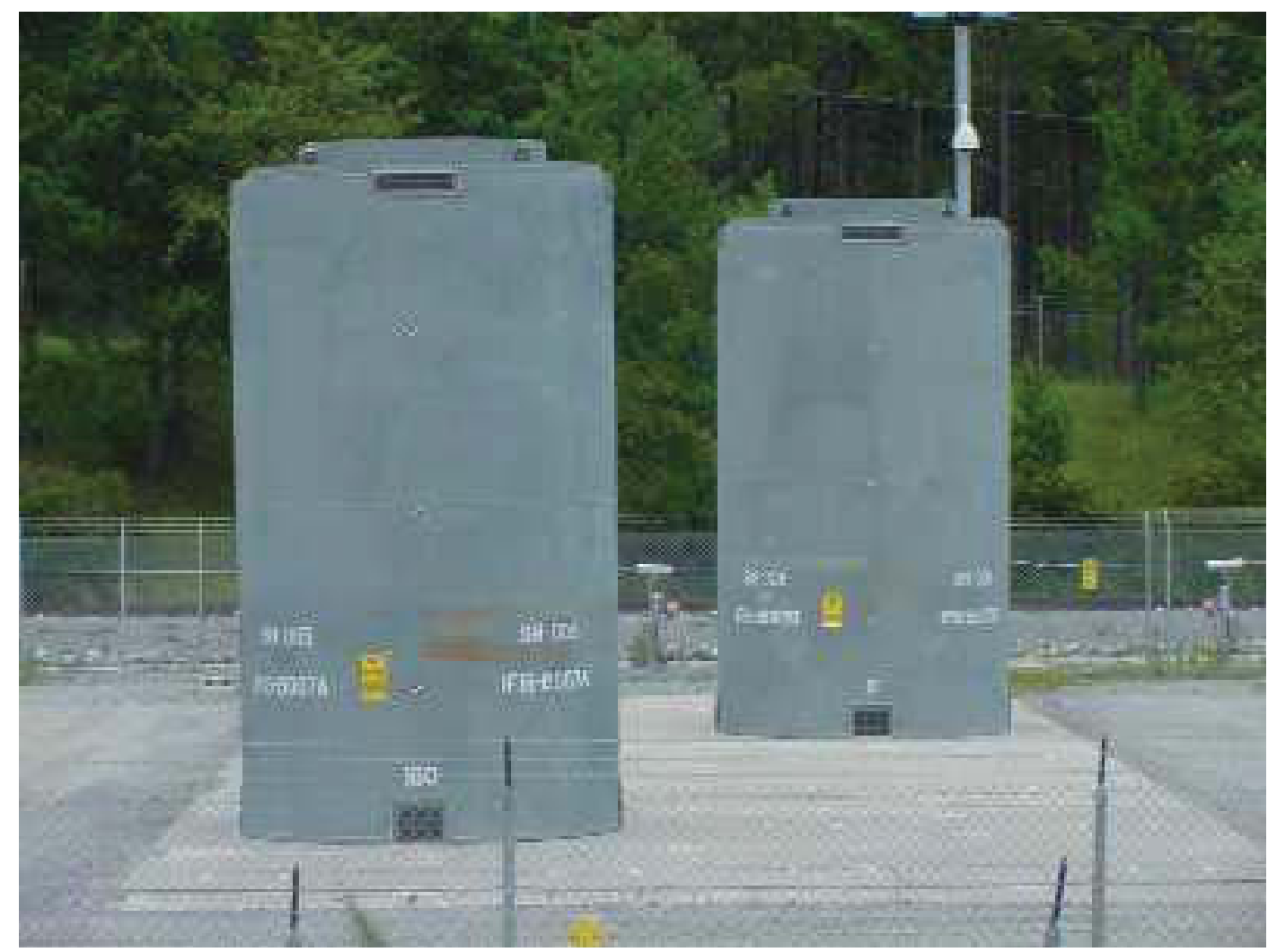

Figure 8-17. Holtec International HI-STORM dry storage casks on storage pad, note vertical storage. [from Holtec International website] 


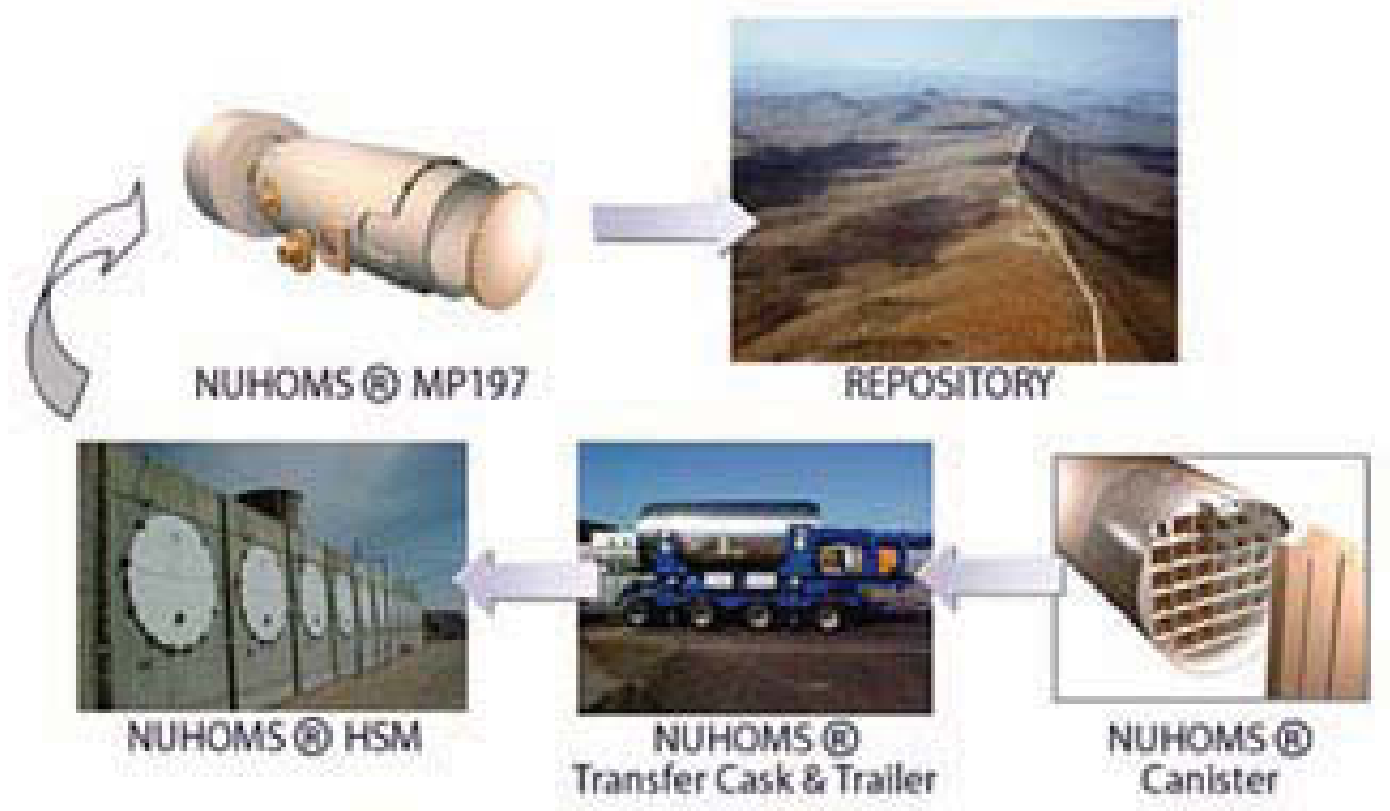

Figure 8-18. Transnuclear NUHOMS design, note horizontal storage, thereby allowing stacking. [from Transnuclear website]

An Independent Spent Fuel Storage Installation (ISFSI) is often a concrete storage pad for the concrete/metal casks which store the spent fuel. The facility also includes piping and the related instrumentation for monitoring the pressure within the casks. This pressure will vary throughout the year because of the outside temperature. The ISFSI must be licensed by the NRC in accordance with 10CFR72. The NRC shows that as of December 2008, spent fuel is currently in dry storage at ISFSIs located at 40 sites with general licenses and 15 sites with site-specific licenses. The map shows the current ISFSIs.

RW Disposal Containers - RW plans on using several disposal containers including commercial SNF, defense SNF, and defense SNF/HLW packages.

Table 8-5. Waste Package Configurations [Table 1.5.2-1 from YMLA2008]

\begin{tabular}{|l|l|}
\hline \multicolumn{1}{|c|}{ Waste Package Configuration } & \multicolumn{1}{c|}{ Capacity of Configuration } \\
\hline 21-PWR/44-BWR TAD & $\begin{array}{l}\text { Capacity: One TAD canister containing pressurized } \\
\text { water reactor or boiling water reactor assemblies }\end{array}$ \\
\hline 5-DHLW/DOE Short Codisposal & $\begin{array}{l}\text { Capacity: Five short HLW canisters and one short DOE } \\
\text { SNF canister in center location (footnote) }\end{array}$ \\
\hline 5-DHLW/DOE Long Codisposal & $\begin{array}{l}\text { Capacity: Five long HLW canisters and one long DOE } \\
\text { SNF canister in center location (footnote) }\end{array}$ \\
\hline 2-MCO/2-DHLW & $\begin{array}{l}\text { Capacity: Two DOE MCOs and two long HLW } \\
\text { canisters }\end{array}$ \\
\hline Naval Short & Capacity: One short naval SNF canister \\
\hline Naval Long & Capacity: One long naval SNF canister \\
\hline $\begin{array}{l}\text { Footnote: Alternatively, this waste package can be loaded with a 24-in. DOE SNF canister in a } \\
\text { peripheral location if the center location is empty. With this loading pattern, the remaining four } \\
\text { peripheral locations are loaded with HLW canisters. Or the waste package can be loaded with up } \\
\text { to five HLW canisters in the peripheral locations with the center location empty. }\end{array}$ \\
\hline
\end{tabular}


Table 8-6. Breakdown of Waste Package Configurations [Table 1.5.2-2 from YMLA2008]

\begin{tabular}{|l|c|}
\hline \multicolumn{1}{|c|}{ Waste Package Configuration } & Approximate Percentage by Waste Package Configuration \\
\hline 21-PWR/44-BWR TAD & $71 \%$ \\
\hline 5-DHLW/DOE Short Codisposal & $11 \%$ \\
\hline 5-DHLW/DOE Long Codisposal & $12 \%$ \\
\hline 2-MCO/2-DHLW & $2 \%$ \\
\hline Naval Short & $1 \%$ \\
\hline Naval Long & $3 \%$ \\
\hline
\end{tabular}

The Transportation/Aging and Disposal container (TAD) will be loaded with SNF at the storage site, shipped to the repository and loaded into a waste package. The TAD is welded shut when packed and then packed inside of the package without opening. This can-in-a-can arrangement is nominally $5.85 \mathrm{~m}$ long $(19+\mathrm{ft})$ and $1.96 \mathrm{~m}$ in diameter $(6.5 \mathrm{ft})$. The TAD dimensions are similar for commercial and long defense fuels. Short defense fuels use a somewhat shorter TAD. Use of the TAD obviates the need for a multi-purpose canister (MPC).

The DOE co-disposal packages are either 3.7 or $5.3 \mathrm{~m}(12+$ or $17+\mathrm{ft})$ long and $2.13 \mathrm{~m}(7 \mathrm{ft})$ in diameter.

\subsection{Illustrative Used Fuel Inventory Parameters}

Tables 8-7, 8, and 9 provide some illustrative parameters that assist in understanding the magnitude of the used fuel issue.

Table 8-7. Summary of Repository Inventory [Table 1.5.1-1 of YMLA2008]

\begin{tabular}{|l|c|c|}
\hline \multicolumn{1}{|c|}{ Type of Waste } & Estimated Number of Canisters & Tonnes of Initial Heavy Metal \\
\hline $\begin{array}{l}\text { Commercial SNF and } \\
\text { HLW from West Valley }\end{array}$ & $\begin{array}{c}\sim 221,000 \text { assemblies } \\
\sim 7,500 \text { TAD canisters } \\
\sim 75 \text { HLW canisters }\end{array}$ & 63,000 \\
\hline HLW & $\sim 9,300$ canisters & 4,667 \\
\hline DOE SNF & $\sim 2,500$ to $\sim 5,000$ canisters & 2,268 \\
\hline Naval SNF & $\sim 400$ canisters & 65 \\
\hline Total & - & 70,000 \\
\hline $\begin{array}{l}\text { NOTE: The estimated number of HLW canisters represents the canisters corresponding to the } \\
\text { allotment of 4,667 tonnes-iHM and not the total number of canisters to be produced at the } \\
\text { originating sites. }\end{array}$ \\
\hline
\end{tabular}

Table 8-8. Summary of Commercial SNF Characteristics as of December 31, 2002 [Table 1.5.1-5 of YMLA2008]

\begin{tabular}{|c|c|c|c|c|c|c|}
\hline \multirow{2}{*}{} & \multicolumn{2}{|c|}{ Initial Uranium Loading } & \multicolumn{2}{c|}{ Initial Enrichment } & \multicolumn{2}{c|}{ Discharge Burnup } \\
\cline { 2 - 7 } & $\begin{array}{c}\text { Average } \\
\text { (kg per } \\
\text { assembly) }\end{array}$ & $\begin{array}{c}\text { Maximum } \\
\text { (kg per } \\
\text { assembly) }\end{array}$ & $\begin{array}{c}\text { Average } \\
(\text { wt \% } \\
235 \mathrm{U})\end{array}$ & $\begin{array}{c}\text { Maximum } \\
\text { (wt \% } \\
235 \mathrm{U})\end{array}$ & $\begin{array}{c}\text { Average } \\
\text { (MWth- } \\
\text { day/tonne- } \\
\text { iHM) }\end{array}$ & $\begin{array}{c}\text { Maximum } \\
\text { (MWth- } \\
\text { day/tonne- } \\
\text { iHM) }\end{array}$ \\
\hline PWR & 431.0 & 546.6 & 3.45 & 4.95 & 36,242 & 69,452 \\
\hline BWR & 179.0 & 197.6 & 2.77 & 4.24 & 28,619 & 65,149 \\
\hline
\end{tabular}


Table 8-9. Thermal Power of the Average and Bounding Pressurized Water Reactor and Boiling Water Reactor Fuel Assemblies [Table 1.5.1-11 of YMLA2008]

\begin{tabular}{|c|c|c|c|c|}
\hline & \multicolumn{4}{|c|}{ Thermal Power (W per assembly) } \\
\hline $\begin{array}{c}\text { Source of Thermal } \\
\text { Power }\end{array}$ & $\begin{array}{l}\text { PWR Average } \\
\text { (25 years) }\end{array}$ & $\begin{array}{l}\text { PWR Maximum } \\
\text { (5 years) }\end{array}$ & $\begin{array}{l}\text { BWR Average } \\
(25 \text { years })\end{array}$ & $\begin{array}{c}\text { BWR } \\
\text { Maximum (5 } \\
\text { years) }\end{array}$ \\
\hline Activation products & 5 & 93 & 1 & 14 \\
\hline Fission products & 389 & 1,610 & 133 & 540 \\
\hline $\begin{array}{l}\text { Uranium, } \\
\text { transuranic, and } \\
\text { decay products }\end{array}$ & 207 & 772 & 53 & 255 \\
\hline TOTAL & 601 & 2,475 & 186 & 779 \\
\hline
\end{tabular}

\subsection{Nuclear Versus Coal Ash}

DOE requested a comparison of the coal ash produced in the U.S. in one year to the amount of used nuclear fuel. Note that coal produces 2.5 times the amount of electricity produced by nuclear power plants, $50 \%$ versus $20 \%$ of total electricity. The answer is 79 million versus 2200 tonnes. On an equal energy basis, this is a ratio of 14,000 to one. Data from [EPA1999]

Annual U.S. coal ash contains the following: [EPA1999]

4 tonnes mercury (assuming 50\% capture, balance to the atmosphere)

103 tonnes uranium

253 tonnes thorium

2923 tonnes selenium

3160 tonnes arsenic

3318 tonnes lead

6715 tonnes chromium 


\section{ECONOMICS}

This section provides some of the recent key economic results in graphical form. All are explained in more detail in Advanced Fuel Cycle Economic Analysis of Symbiotic Light-water Reactor and Fast Burner Reactor Systems; INL/EXT-09-15254; January 2009, [Shropshire2009] where many of the results are also presented in tabular form. Some of the results here are shown in revised or new graphical formats.

\subsection{Comparison of Once Through, 1-Tier, and 2-Tier}

Figure 9-1 curve shows that the total cost of electricity (TCOE) and the fuel cycle component of the power cost are expected to be higher for closed cycles (one-and two-tier) than for the open (oncethrough) cycle. On average, the TCOE is about 10\% higher for both 1-tier and 2-tier. (Note that mills/kW-hr and \$/MW-hr are the same measure of the cost of electricity.) This is a "busbar" electricity cost, so transmission costs are not included. The increase in TCOE is due both to the higher expected fuel cycle cost associated with closed cycles and the higher expected life cycle costs for fast reactors as compared to LWRs. Appendix A-3 to the Economic Analysis Document [Shropshire2009] has the flow diagrams that show the "boxes" for each fuel cycle step to which a unit cost was assigned.

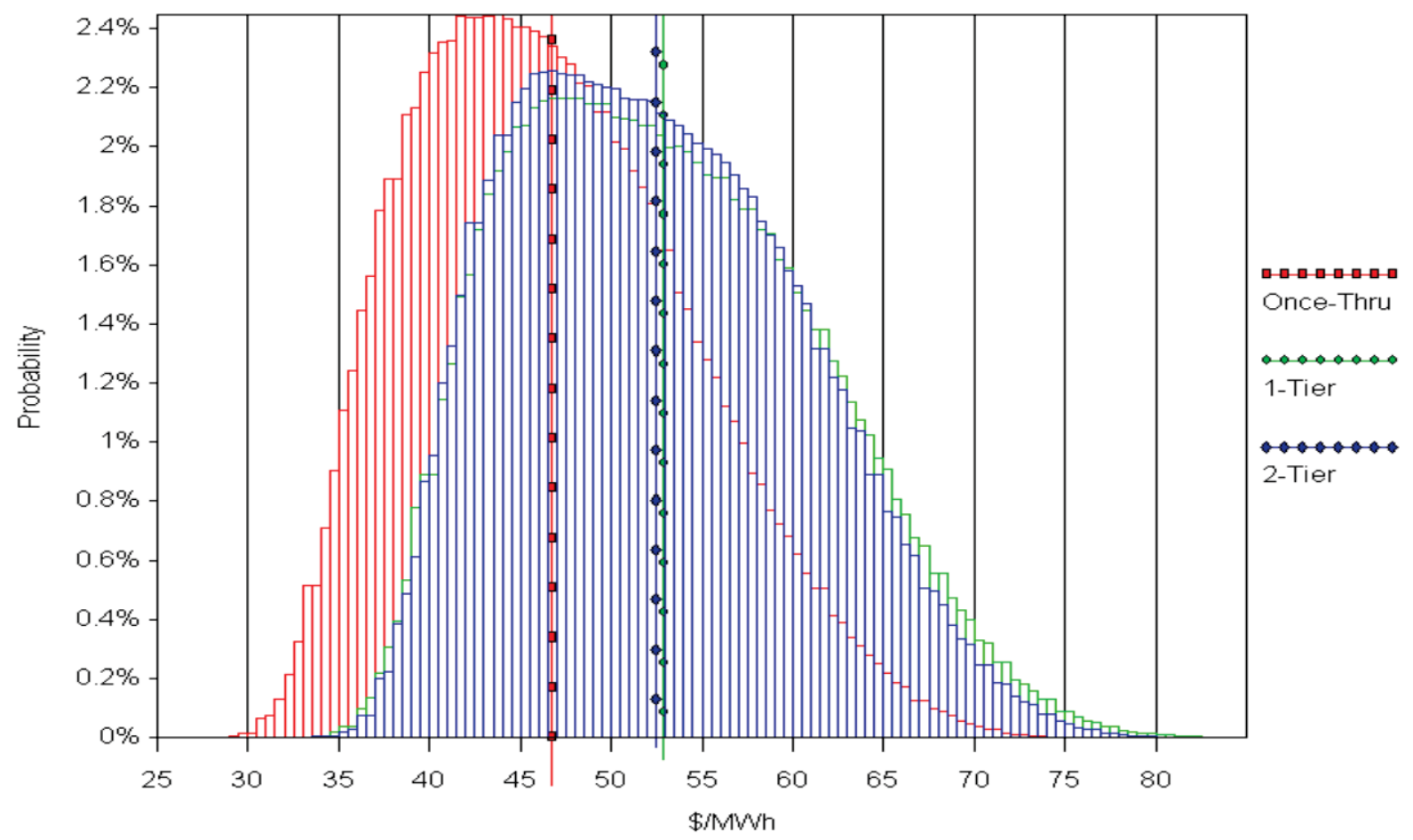

Figure 9-1. Total cost of electricity for once-through, 1-tier, and 2-tier cases. [Shropshire2009]

Figure 9-2 shows the fuel cycle component of TCOE. The fuel cycle component of TCOE is about $15 \%$ and 30\% higher for the 1-tier and 2-tier cases respectively. This increase is due to the increasing complexity of the overall fuel cycle system as one progresses from once through to the 1-tier to the 2-tier systems. Increasing complexity refers to the increasing number of fuel cycle steps (operations and facilities) required in progressing from once through to recycling. 


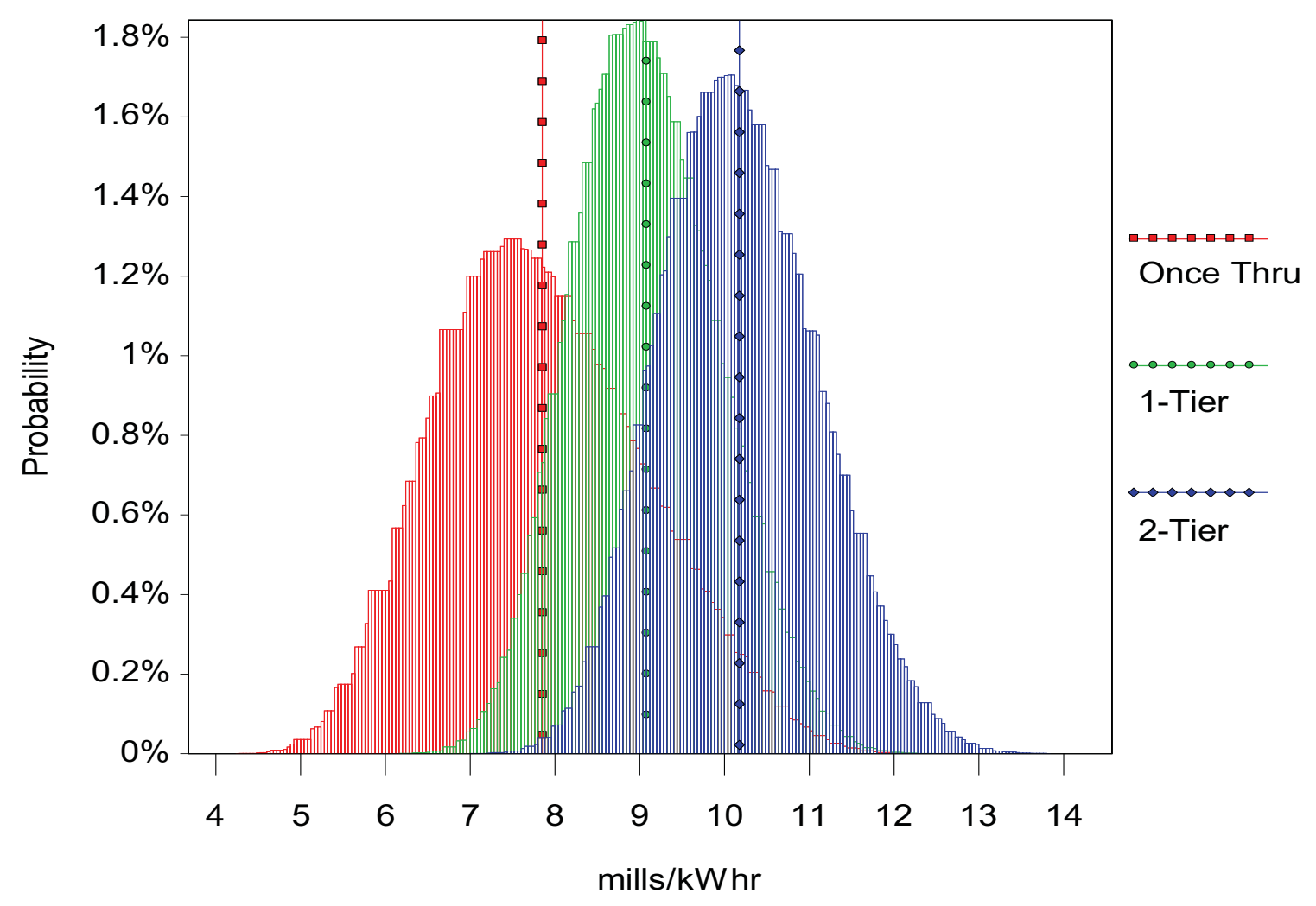

Figure 9-2. Fuel cycle cost of electricity for once-through, 1-tier, and 2-tier cases; vertical lines show the average cost of each of the three options. [Shropshire2009]

As mentioned above, the higher fuel cycle cost component for open cycles is partially due to the much greater process and facility complexity associated with recycling LWR spent fuel and the total "closed loop" recycle of fast reactor fuel. The following flow diagrams (Figures 9-3 and 9-4) show increasing complexity in going from open to single-tier (fast only) recycling to two-tier recycling (fast and thermal). 

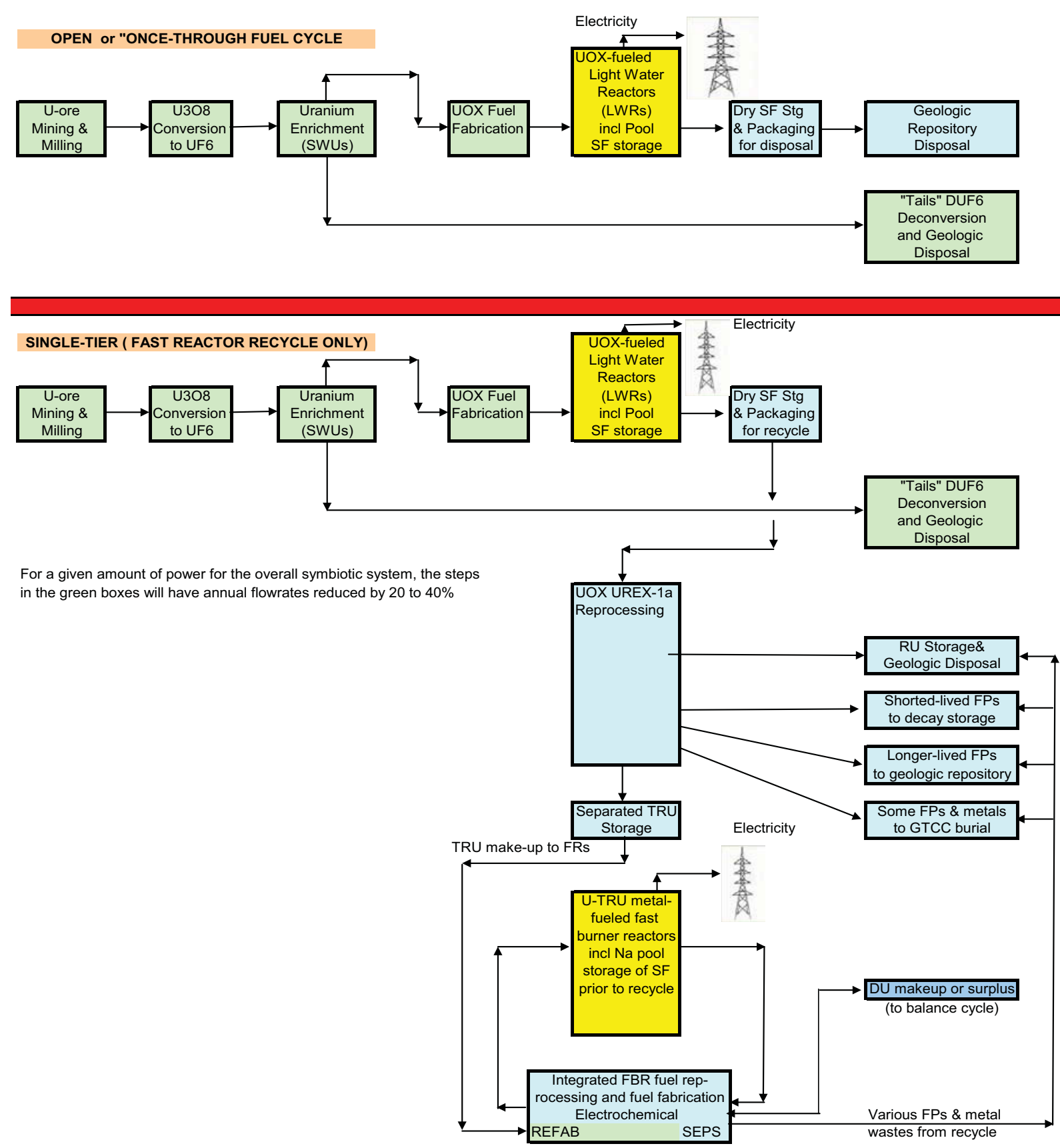

Figure 9-3. Static equilibrium economic analysis for once through and 1-tier cases. [Shropshire2009] 

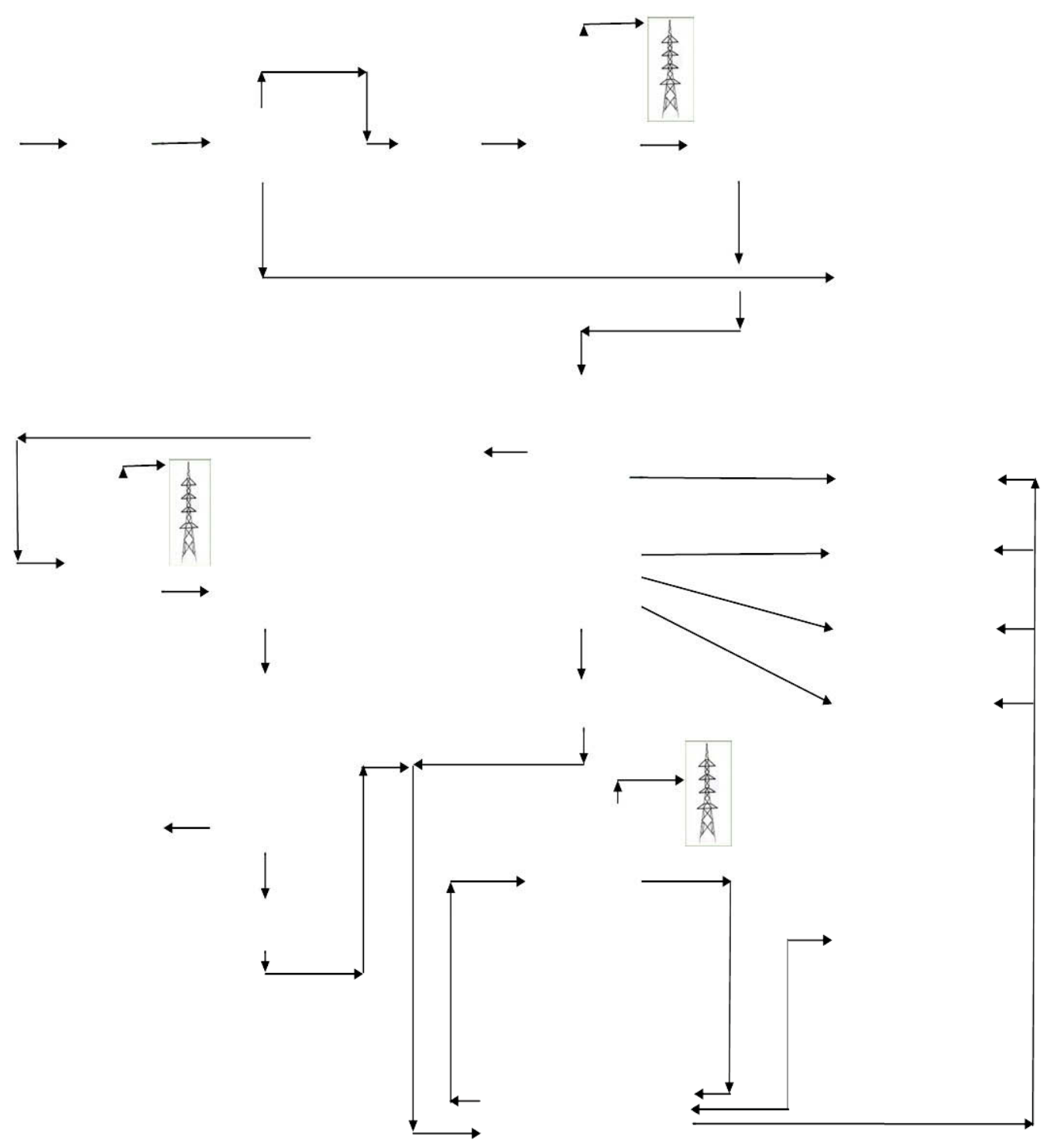

Figure 9-4. Static equilibrium economic analysis for the 2-tier case. [Shropshire2009]

Figure 9-5 shows the reactor component of TCOE. The TCOE increase in going from an open cycle to a closed cycle is driven partly by the fuel cycle complexity and by the fact that fast reactors are likely to have life cycle costs greater than those for LWRs. A probability plot for the reactor-related costs (without any fuel cycle cost component) is shown. In the open cycle, $100 \%$ of the power is generated by LWRs. For the single tier scenario $63 \%$ of the power is generated by LWRs and $37 \%$ by fast reactors. For the two tier system $74 \%$ of the power is generated by LWRs and $26 \%$ by fast reactors. The higher the percentage of power produced by fast reactors, the higher the reactor-related component of the overall TCOE. In the input data for this analysis, the ratio of the fast reactor capital cost to the LWR capital cost (capital expressed in $\$ / \mathrm{kWe}$ of capacity) varies from 1.0 to 1.43 . The nominal ratio is 1.26 . Operational costs are also projected to be somewhat higher for the FR as compared to the LWR. 


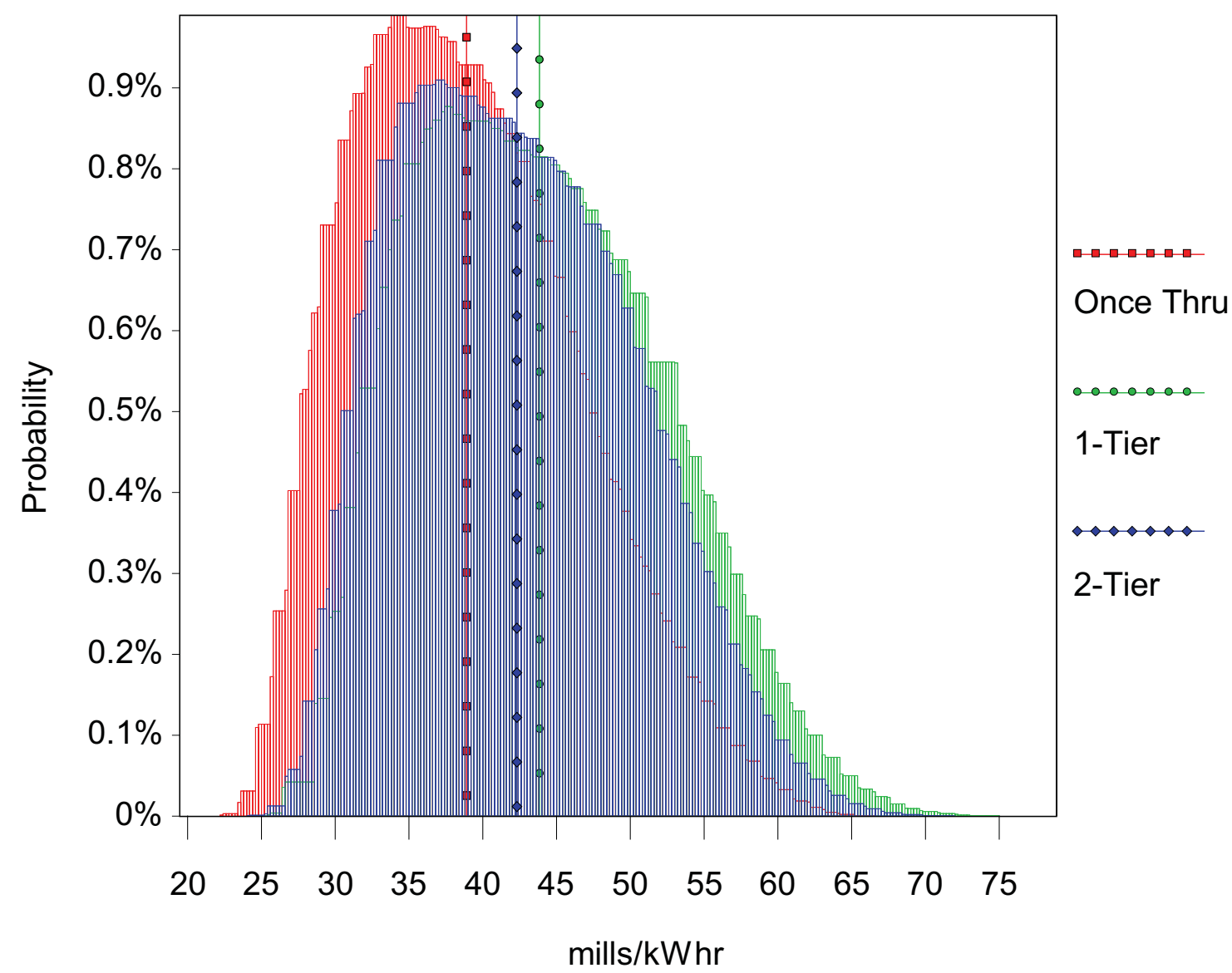

Figure 9-5. Reactor cost of electricity for once-through, 1-tier, and 2-tier cases; vertical lines show the average cost of each of the three options. [Shropshire2009]

Variability in model inputs results in the "spreads" shown above for the \$/MWhr probability curves shown above. The input data is put in the form of triangular distributions defined by high, nominal, and low values for up to 43 unit cost inputs to the EXCEL spreadsheet model as shown in Table 9-1. It should be noted that about half of these cost modules are associated with waste storage, conditioning, packaging, and disposal activities.

The cost ranges shown in Table 9-1 and subsequent graphs reflect the boundary conditions for each of the fuel cycle cost parameters. The low- and high- values represent the end points of the distribution with very small probabilities. These values represent a cost analyst's judgment of the potential upsides (low end of the cost range) and downsides (high end of the cost range) based on the references and qualitative factors.

- Low costs may result from technology improvements, improved economies of scale, and changes in estimating assumptions that are more cost favorable.

- High costs reflect increased regulatory requirements, worst-case economic conditions, and estimate limitations.

- Nominal costs are the most likely costs based on the references, contingency factors, upsides and downsides. The nominal values are where the maximum probability occurs in the frequency distribution (i.e., mode of the distribution). These costs are subject to change and are updated as additional reference information is collected and evaluated, and as a result of sensitivity and uncertainty analysis. 
Table 9-1. Key Economic Input Parameters. [Shropshire2009]

\begin{tabular}{|c|c|c|c|}
\hline & Low & Nominal & High \\
\hline Natural uranium mining and milling $(\$ / \mathrm{kg}-\mathrm{U})$ & 25 & 60 & 240 \\
\hline Uranium conversion $(\$ / \mathrm{kg}-\mathrm{U})$ & 5 & 10 & 15 \\
\hline Uranium enrichment (\$/kg-SWU) & 80 & 105 & 130 \\
\hline LWR $\mathrm{UO}_{2}$ fuel fabrication $(\$ / \mathrm{kg}-\mathrm{U})$ & 200 & 240 & 300 \\
\hline LWR MOX fuel fabrication (\$/kg-HM) & 1,000 & 1,950 & 4,000 \\
\hline Depleted uranium disposition $(\$ / \mathrm{kg}-\mathrm{U})$ & 5 & 10 & 50 \\
\hline Dry storage $(\$ / \mathrm{kg}-\mathrm{HM})$ & 100 & 120 & 300 \\
\hline Monitored retrievable storage ( $\$ / \mathrm{kg}-\mathrm{HM})$ & 94 & 96 & 116 \\
\hline Geologic repository (SNF, \$/kg-HM) & 400 & 1,000 & 1,600 \\
\hline Geologic repository (HLW FPs+Ln+Tc, \$/kg-FP) & 2,500 & 10,000 & 12,500 \\
\hline Geologic repository (activated hulls, \$/kg-metal) & 400 & 1,000 & 1,600 \\
\hline GTCC intermediate depth disposal (GTCC I+hulls, $\$ / \mathrm{m}^{3}$-GTCC) & 70,000 & 100,000 & 440,000 \\
\hline UREX+1a aqueous separation ( $\$ / \mathrm{kg}-\mathrm{HM})$ & 500 & 1,000 & 1,500 \\
\hline UREX +3 , product conditioning, 15 -yr storage for 2 -tier $(\$ / \mathrm{kg}-\mathrm{HM})$ & 700 & 1,320 & 2,080 \\
\hline Electrochemical separation + fuel fabrication $(\$ / \mathrm{kg}-\mathrm{HM})$ & 2,500 & 5,000 & 7,500 \\
\hline Recycled U/TRU product storage (\$/kg-TRU) & 7,000 & 10,000 & 13,000 \\
\hline Recycled U/Pu product storage (\$/kg-Pu) & 3,500 & 5,000 & 6,500 \\
\hline LLW conditioning, storage, packaging (solids, $\$ / \mathrm{m}^{3}$-solids) & 400 & 500 & 1,000 \\
\hline LLW conditioning, storage, packaging (liquids, $\$ / \mathrm{m}^{3}$-liquids) & 3,300 & 11,000 & 22,000 \\
\hline LLW conditioning, storage, packaging (resins, $\$ / \mathrm{m}^{3}$-resins) & 81,000 & 90,000 & 99,000 \\
\hline Near surface disposal $\left(\$ / \mathrm{m}^{3}-\mathrm{LLW}\right)$ & 450 & 1,250 & 2,500 \\
\hline Aqueous LLW-GTCC offgas absorber $\left(\mathrm{H} 3, \mathrm{Kr}, \mathrm{Xe}, \$ / \mathrm{m}^{3}\right.$-gas $)$ & 8,000 & 11,200 & 15,000 \\
\hline Aqueous GTCC ceramic conditioning ( $\mathrm{CsSr}, \$ / \mathrm{kg}$-Cs-Sr) & 5,700 & 7,800 & 12,000 \\
\hline Electrochemical LLWR-GTCC offgas absorber $\left(\mathrm{H} 3, \mathrm{Kr}, \mathrm{Xe}, \$ / \mathrm{m}^{3}\right.$-gas $)$ & 8,000 & 11,200 & 15,000 \\
\hline Electrochemical GTCC glass bonded zeolite conditioning (CsSr, I, \$/kg-Cs-Sr-I) & 5,700 & 7,800 & 12,000 \\
\hline Managed decay storage (CsSr, \$/kg-CsSr) & 10,000 & 22,500 & 35,000 \\
\hline Aqueous LLW-GTCC Ag zeolite (I, \$/m $-\mathrm{I})$ & 50,000 & 67,000 & 80,000 \\
\hline Aqueous GTCC metal alloy conditioning (ZrSS, \$/kg-metal) & 200 & 540 & 1,800 \\
\hline Aqueous HLW conditioning, storage, packaging (FP+Ln, \$/kg-FP) & 1,800 & 2,000 & 2,700 \\
\hline Aqueous metal alloy (Tc, \$/kg-Tc) & 18,000 & 25,000 & 30,000 \\
\hline Electrochemical HLW metal alloy conditioning (ZrSS, Tc, \$/kg-metal) & 200 & 540 & 1,800 \\
\hline UOX or UOX/MOX conditioning and packaging $(\$ / \mathrm{kg}-\mathrm{HM})$ & 50 & 100 & 130 \\
\hline Contact handled TRU conditioning, storage, packaging $\left(\$ / \mathrm{m}^{3}-\mathrm{TRU}\right)$ & 69,000 & 70,000 & 90,000 \\
\hline Aqueous RU disposition (\$/kg-RU) & 6 & 12 & 30 \\
\hline Electrochemical RU conditioning ( $\$ / \mathrm{kg}-\mathrm{RU})$ & 75 & 93 & 150 \\
\hline LWR overnight capital cost $(\$ / \mathrm{kWe})$ & 1,800 & 2,300 & 3,500 \\
\hline Fast reactor overnight capital cost $(\$ / \mathrm{kWe})$ & 1,800 & 2,900 & 5,000 \\
\hline Real discount rate $(\%)$ & 5.0 & 7.5 & 10.0 \\
\hline Construction time (years) & 3.5 & 4.0 & 5.0 \\
\hline LWR fixed O\&M (\$/kWe-yr) & 55 & 64 & 75 \\
\hline Fast reactor fixed O\&M $(\$ / \mathrm{kWe}-\mathrm{yr})$ & 60 & 68 & 80 \\
\hline LWR variable O\&M (mills/kW-hr) & 0.8 & 1.8 & 2.5 \\
\hline Fast reactor variable O\&M (mills/kW-hr) & 1.0 & 2.0 & 2.7 \\
\hline
\end{tabular}




\subsection{Impact of Uncertainties for Once Through, 1-Tier, and 2-Tier}

The impact of uncertainties is shown in two different ways. The first are the horizontal bar or "tornado" diagrams from data in the Economic team's report;[Shropshire2009] these denote all key uncertainties for a single fuel cycle scenario. The second mode of presentation is in the form of $\mathrm{Y}$ versus $\mathrm{X}$ plots for each input variable, where $\mathrm{Y}$ is the fuel cycle cost (mills/kW-hr) and $\mathrm{X}$ is the input variable. These denote the impact on each fuel cycle scenario from variation in a single input variable. Both modes are valuable and give useful (but different) sets of insights.

For all three scenarios, the biggest cost drivers for TCOE are the capital cost of the reactors (expressed in $\$ / \mathrm{kWe}$ of capacity) and reactor financing (expressed by the real discount rate).The following diagram for the once-through cycle shows the input variables that most influence the TCOE. The "highest leverage" inputs have the widest bars and are at the top of figure 9-6. (These types of graphs are often called "tornado diagrams" because of the shape of the stacked bars.) The message is that the reactors, both thermal and fast, are the "big ticket" items and dwarf the fuel cycle as far as their overall effect on the cost of electricity. The value to the left of each "forward slash" is the input variable at that endpoint of the range, and the value to the right is the TCOE at that value. The vertical line anchoring the "tornado" goes through the "nominal" value of that input variable that appears in the table on the previous factsheet.

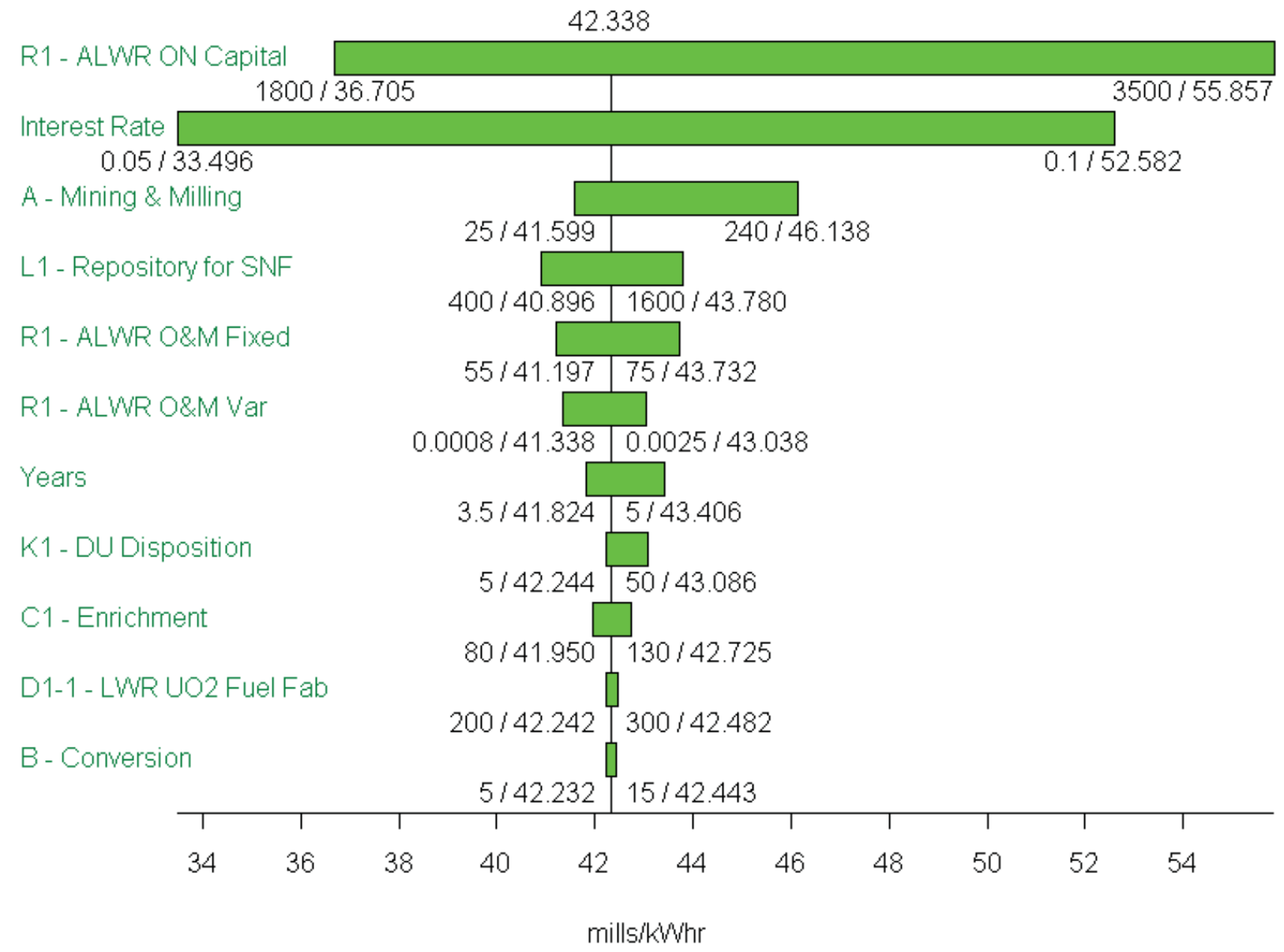

Figure 9-6. Total cost of electricity (TCOE) for once-through, showing impact of uncertainties, which are treated as independent of each other. [Shropshire2009] 
Figure 9-7 is the same as figure 9-6, except it shows only the fuel cycle costs. The "tornado diagram" for the once-through cycle non-reactor fuel cycle costs shows which steps for this fuel cycle drive its costs. The costs of source material (U-ore) and the costs of ultimate geologic disposition of LWR-related wastes (both repository-bound spent fuel and shallow burial-bound enrichment plant tails) have the most leverage. Uranium enrichment is a close fourth.

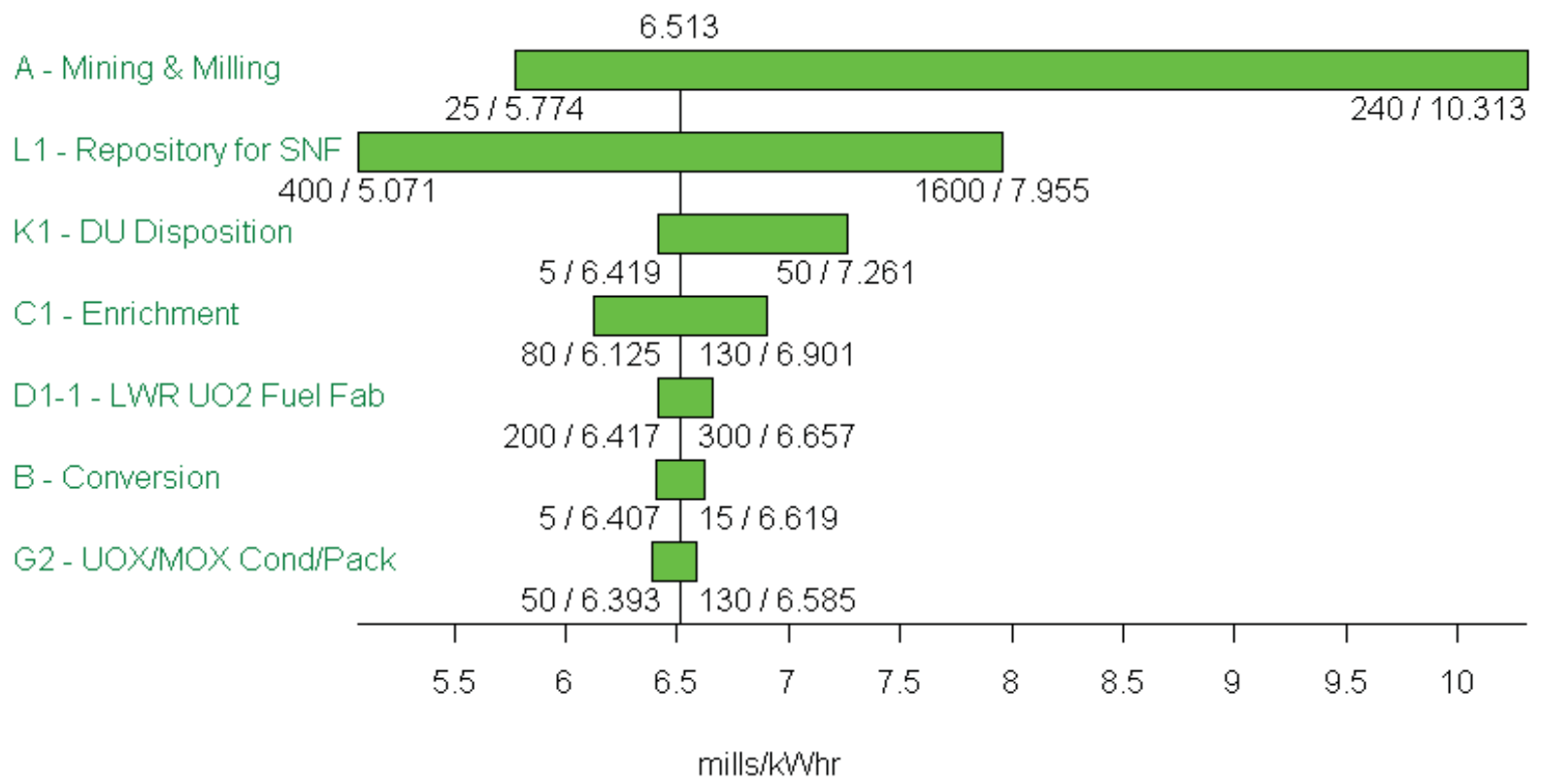

Figure 9-7. Fuel cycle component of the cost of electricity for once-through, showing impact of uncertainties, which are treated as independent of each other. [Shropshire2009]

The non-reactor fuel cycle cost tornado diagrams for the two closed cycles ( 1 and 2 tier) are very similar. The 1-tier tornado diagram appears in figure 9-8. Uranium ore cost variability is again the largest driver. The remaining large cost drivers are the costs associated with LWR fuel reprocessing, specifically separations cost and geologic disposal of the repository bound HLW products and the GTCC wastes. Note that aqueous reprocessing (third bar down on tornado) and the combined metal fuel fabrication/separation (second bar down on tornado) have the same overall system cost variability for this 1-tier scenario. Front end step costs for this cycle have less effect because of the fact that a closed cycle reduces ore, conversion, enrichment, and LWR fuel fabrication feed requirements by a significant percentage ( $>20 \%$ ) when equilibrium is reached. 


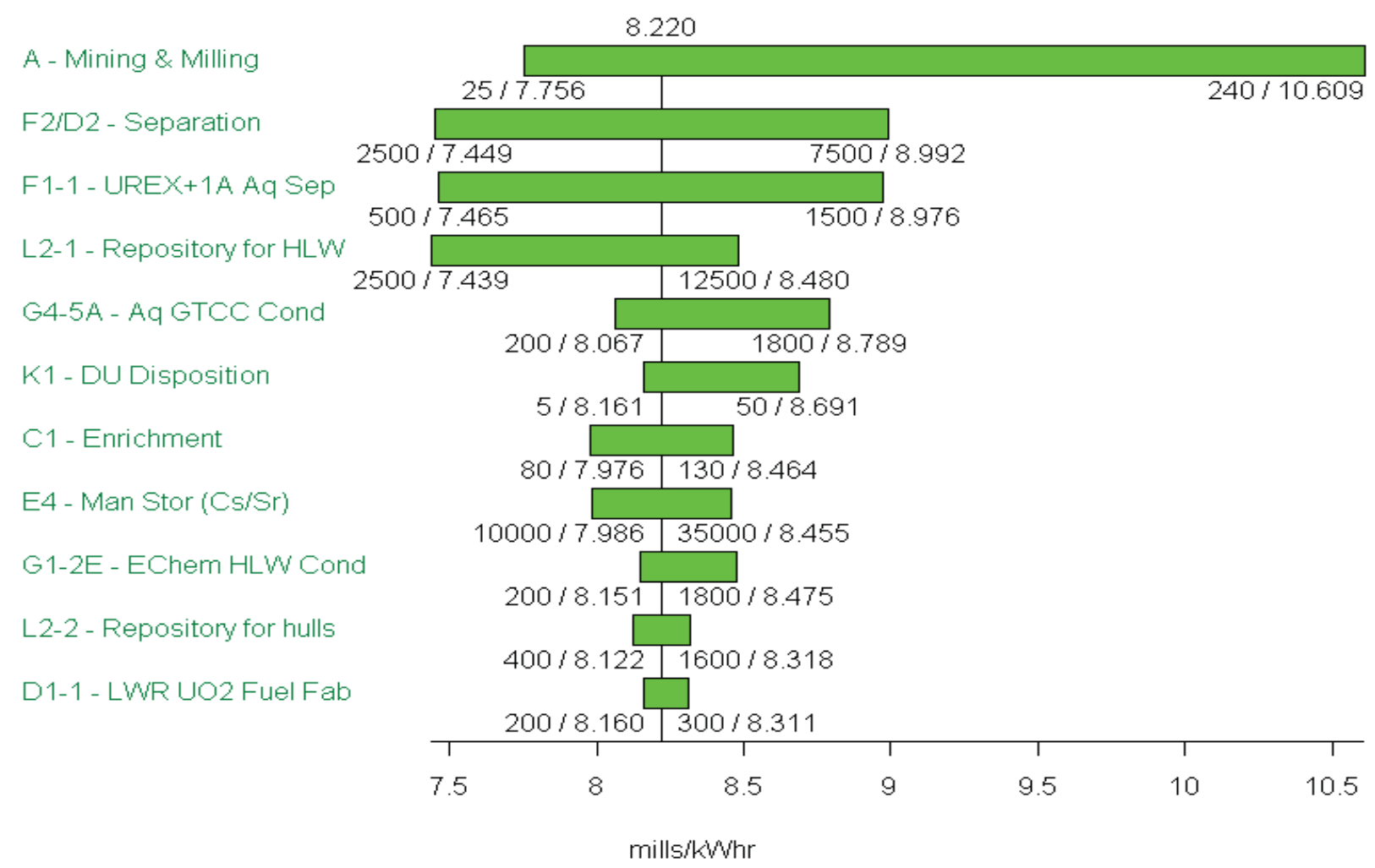

Figure 9-8. Fuel cycle component of the cost of electricity for 1-tier recycle cases, showing impact of uncertainties, which are treated as independent of each other. [Shropshire2009]

The 2-tier tornado diagram appears in figure 9-9 with the fuel cycle cost component of the TCOE again being the figure of merit. Notice that the costs are negative on this diagram; this was done in order to be able to display the variable uncertainty. The strategy must be forced to be the optimal policy so that the software will display the tornado diagram The LWR aqueous separation (Hybrid technology) variable indicates a shift in color from green to blue when moving from the nominal cost (center line) toward the high cost values. This means that the variable has the potential at some value to make the 2-tier fuel cycle cost less than the 1-tier (i.e., the optimal policy). The chart does not specifically define the cost point where the optimal cycle changes.

Uranium ore cost variability is again the largest driver. The remaining large cost drivers are the costs associated with LWR and FR fuel reprocessing (second and third bars down on tornado), specifically separations cost and geologic disposal of the repository bound HLW products and the LLW-GTCC wastes. Fabrication of the MOX fuel for "single-pass" thermal recycle is also a significant driver. Front end step costs for this cycle again have less effect because of the fact that a closed cycle reduces ore, conversion, enrichment, and LWR fuel fabrication feed requirements by a significant percentage ( $>20 \%)$ when equilibrium is reached. 


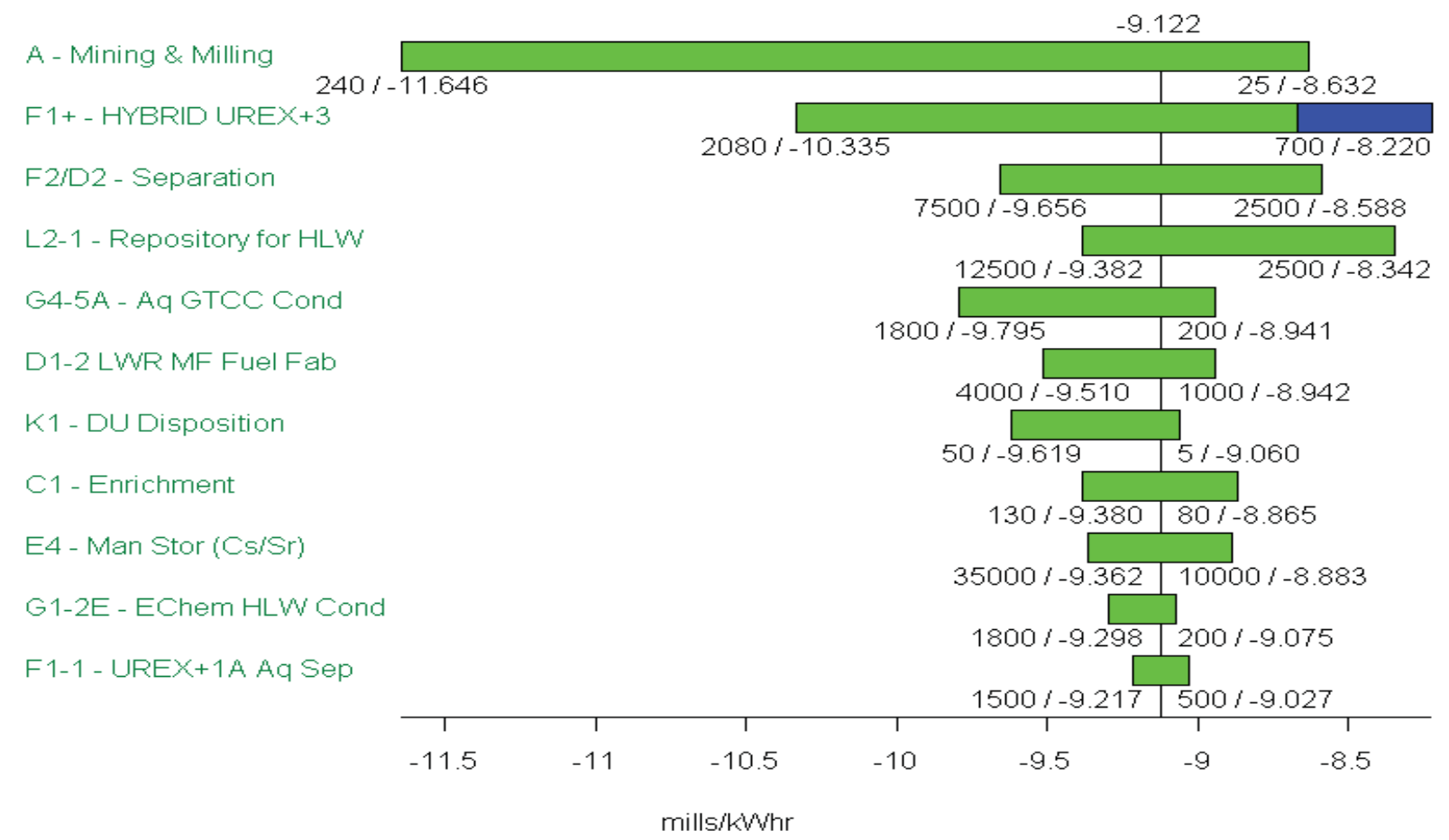

Figure 9-9. Fuel cycle component of the cost of electricity for 2-tier recycle cases, showing impact of uncertainties, which are treated as independent of each other. [Shropshire2009]

Figure 9-10 through figure 9-19 show most of the preceding information in a different "Y versus X" format. The preceding graphs looked at the dominant uncertainties for once through, 1-tier, and 2-tier respectively. The next set of graphs show the impact of uncertainties for individual variables, for once through, 1-tier, and 2-tier. Note that figures 9-10 through 9-19 are not found in previous reports.

Figure 9-10 through figure 9-19 show the output variable at "low", "nominal", and "high" values of the input variable, assumed to be independent. The definitions and values of "low", "nominal", and "high" are found in section 9.1. Straight lines are drawn through those points.

Figure 9-10 shows the sensitivity with regard to uranium cost. In a practical sense, if uranium increases, uranium enrichment cost will likely increase, which will drive up costs for once through more quickly than the figure indicates. 


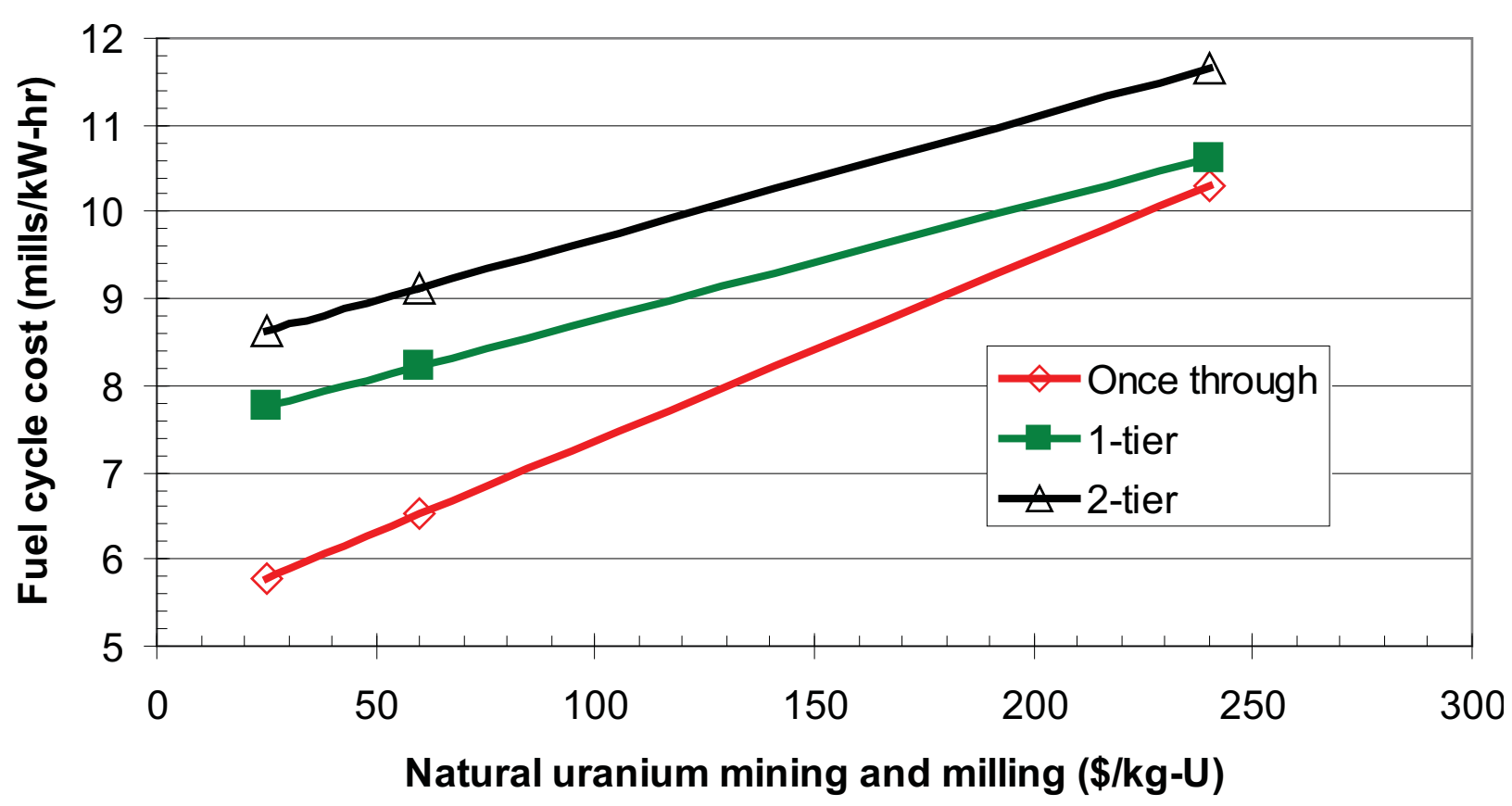

Figure 9-10. Influence of uranium ore cost uncertainty on once-through, 1-tier, and 2-tier fuel cycle cost, using data from [Shropshire2009]. Recall that most of the system-wide fuel in 1-tier and 2-tier remains nominal uranium oxide.

In figure 9-11 and 9-12, note that variation in uranium enrichment and UOX fabrication costs has little impact on the cost differential between once through and 1-tier. In figure 9-13, note that only 2-tier has MOX as part of the scenario and therefore only that case varies with MOX fabrication cost.

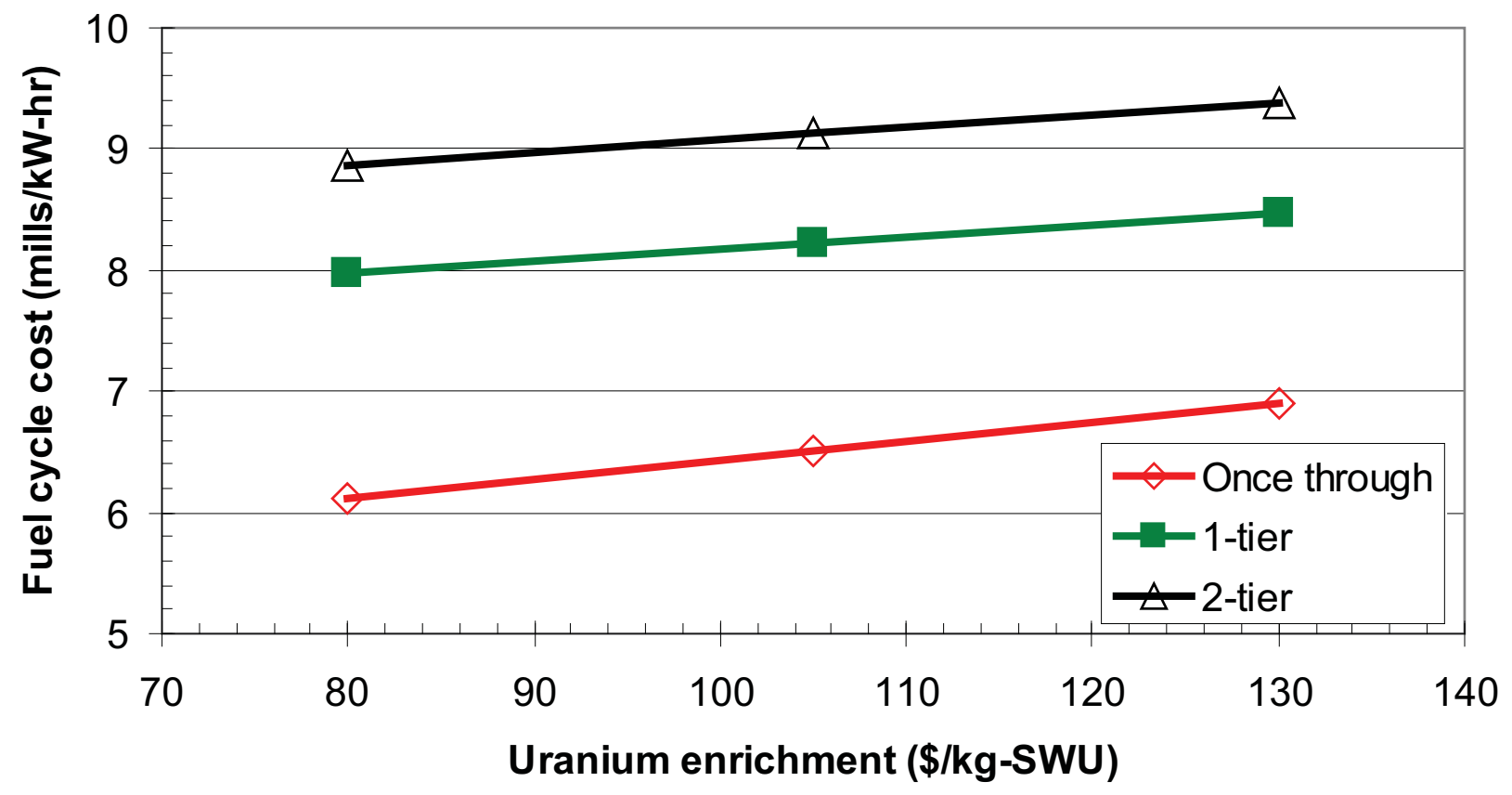

Figure 9-11. Influence of uranium enrichment cost uncertainty on once-through, 1-tier, and 2-tier fuel cycle cost, using data from [Shropshire2009]. 


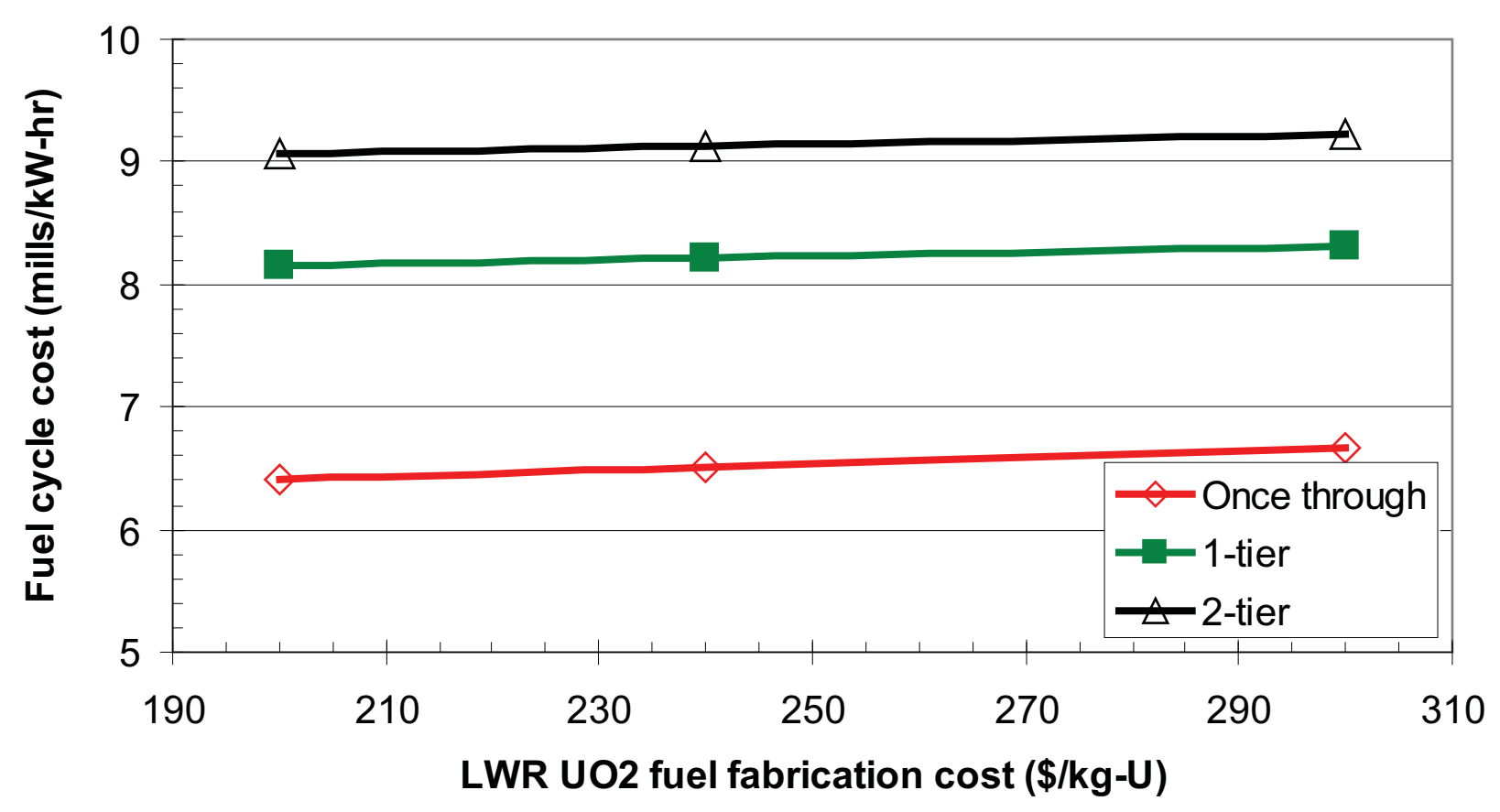

Figure 9-12. Influence of LWR UOX fuel fabrication cost uncertainty on once-through and 1-tier fuel cycle costs, using data from [Shropshire2009].

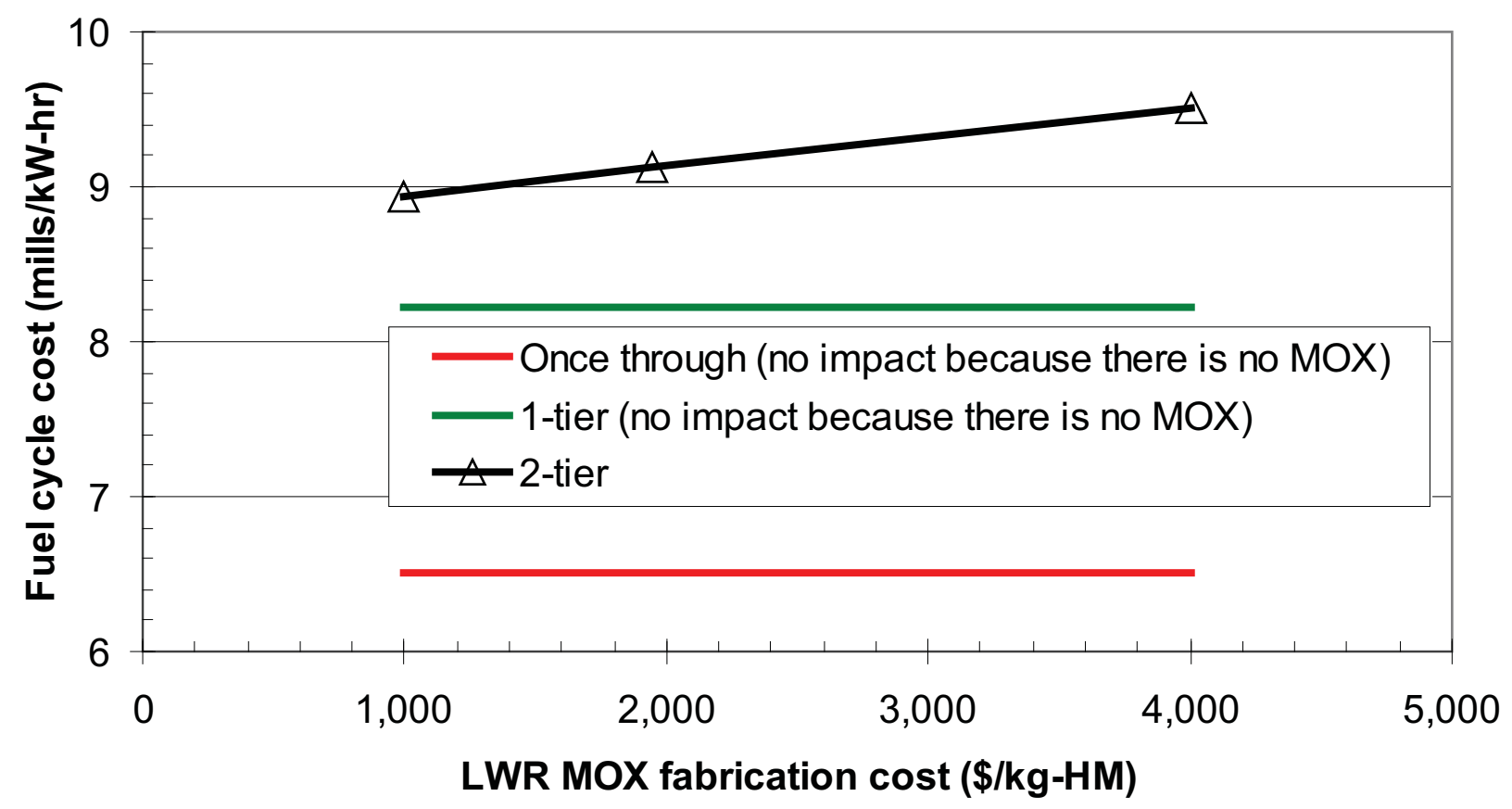

Figure 9-13. Influence of LWR MOX fuel fabrication cost uncertainty on once-through, 1-tier, and 2-tier fuel cycle costs, using data from [Shropshire2009]. No data markers are shown on once through or 1-tier because they have no MOX and therefore they have no sensitivity to this input parameter. 
Figure 9-14a and 9-14b show the impact of separation costs, aqueous and electrochemical respectively. The curves are steeper (greater sensitivity) for the UOX separation costs (UREX+1a for 1-tier, UREX +3 for 2-tier) because there is a much larger flow of material through aqueous versus electrochemical. The 2-tier MOX separation curve is relatively insensitive to cost because there is less MOX in 2-tier than either UOX or FR fuel. The mid points $(8.2 \mathrm{mill} / \mathrm{s} / \mathrm{kW}-\mathrm{hr})$ for the two 1-tier cost lines are (by definition) the same fuel cycle cost, i.e., if the nominal (mid-point) separation input cost is used for both variables, the output result is the nominal fuel cycle cost. The three mid-points $(9.1 \mathrm{mills} / \mathrm{kW}-\mathrm{hr})$ for the three 2-tier cost lines are the same. Note that the electrochemical cost includes subsequent fuel fabrication.
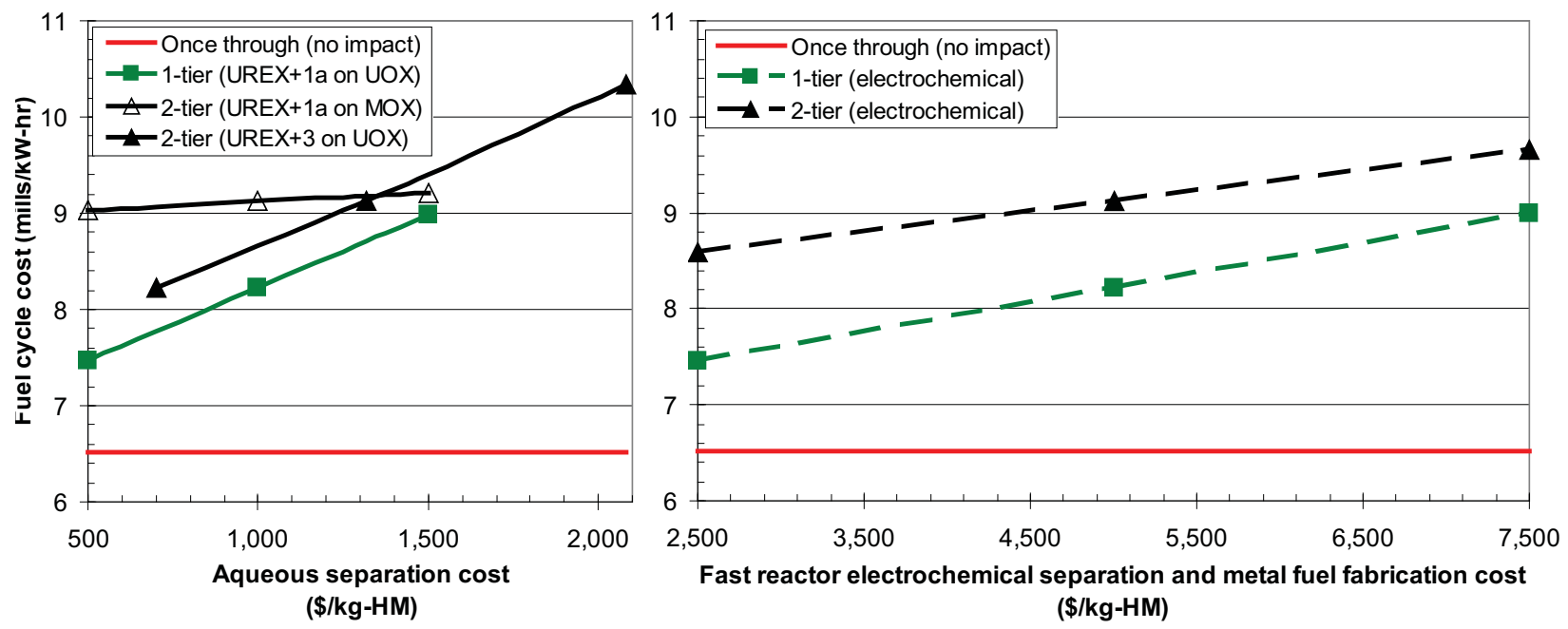

Figure 9-14. Influence of cost uncertainties of aqueous separation (a) and electrochemical separation and metal fuel fabrication (b) cost on once-through, 1-tier, and 2-tier fuel cycle cost, using data from [Shropshire2009].

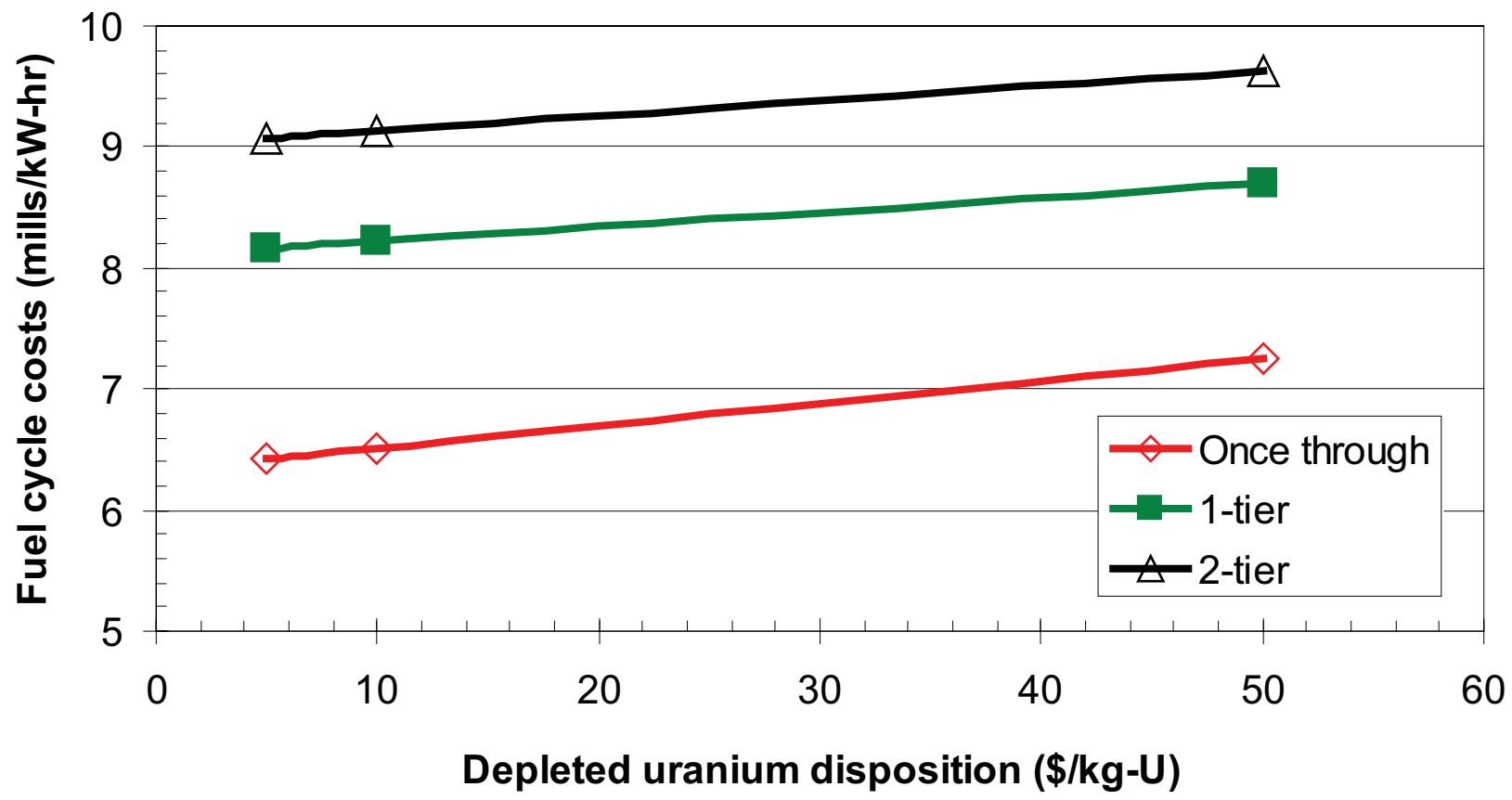

Figure 9-15. Influence of the cost uncertainty of depleted uranium disposition on once-through, 1-tier, and 2-tier fuel cycle costs, using data from [Shropshire2009]. 


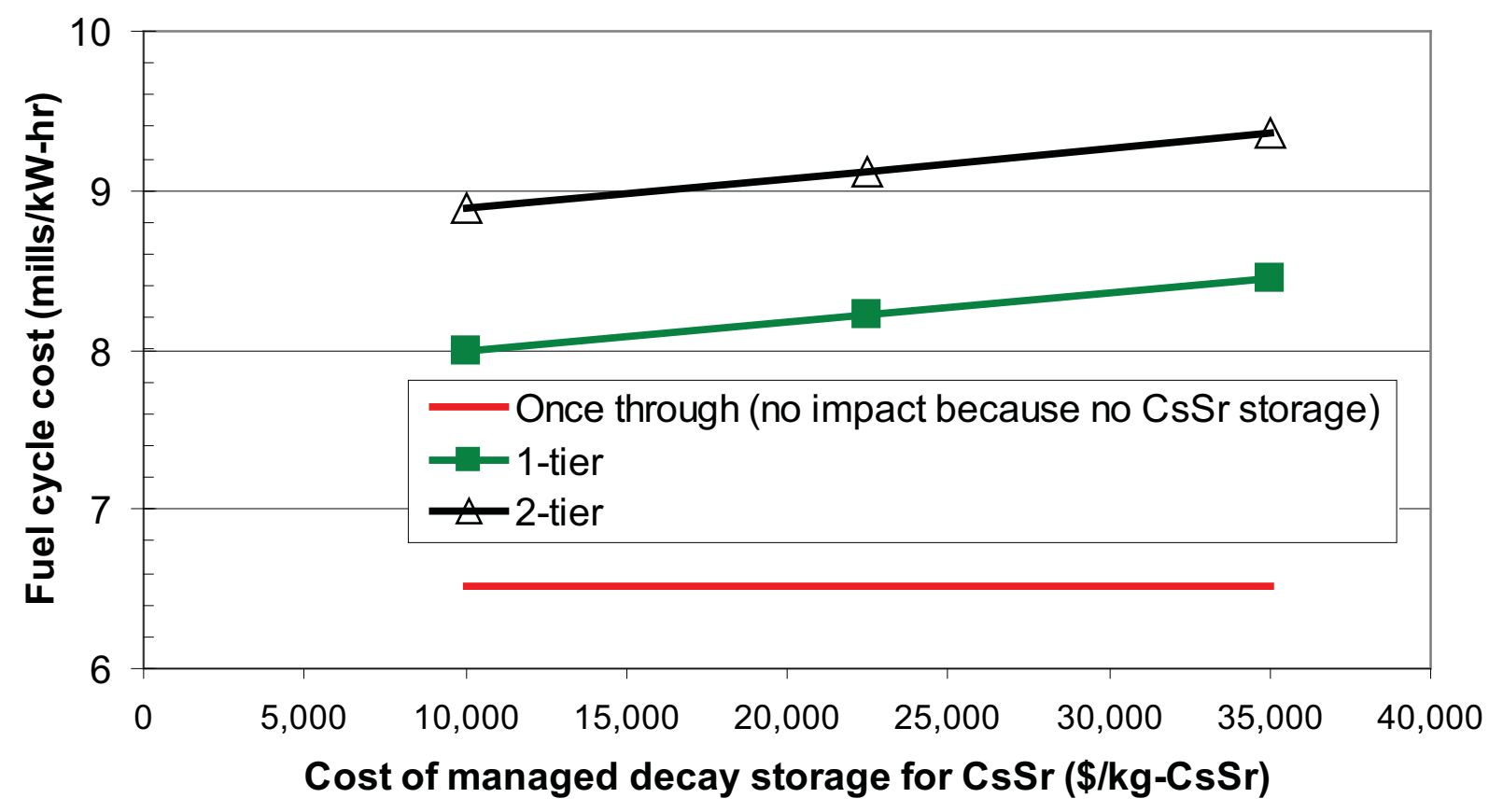

Figure 9-16. Influence of the cost uncertainty of managed decay storage (CsSr) on once-through, 1-tier, and 2-tier fuel cycle costs, using data from [Shropshire2009]. No data markers are shown on the once through curve because it has no managed decay storage, thus, it has no sensitivity to this input parameter.

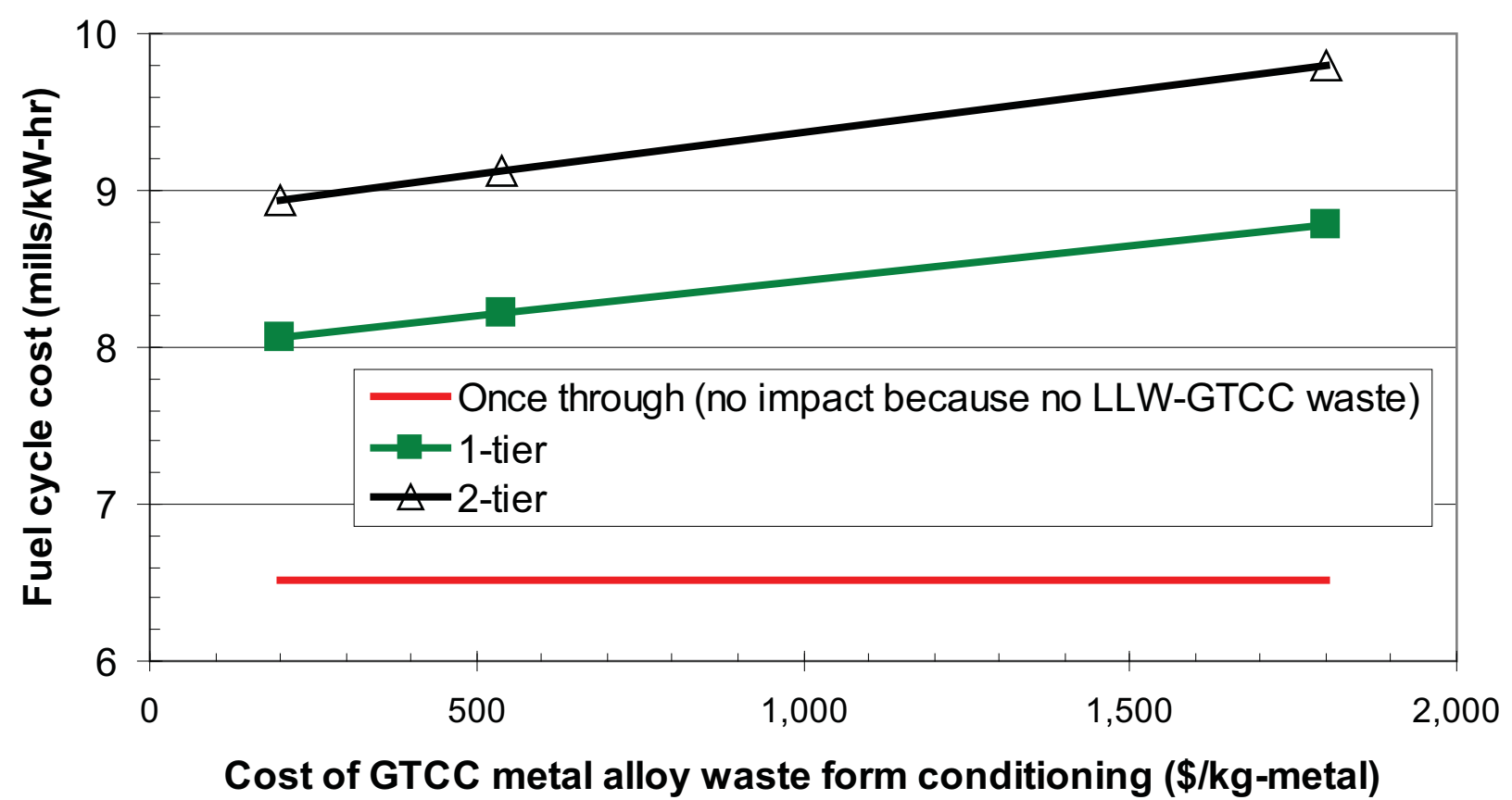

Figure 9-17. Influence of the cost uncertainty of aqueous GTCC metal alloy waste conditioning on oncethrough, 1-tier, and 2-tier fuel cycle costs, using data from [Shropshire2009]. No data markers are shown on the once through curve because it has no GTCC metal alloy waste, thus, it has no sensitivity to this input parameter. 


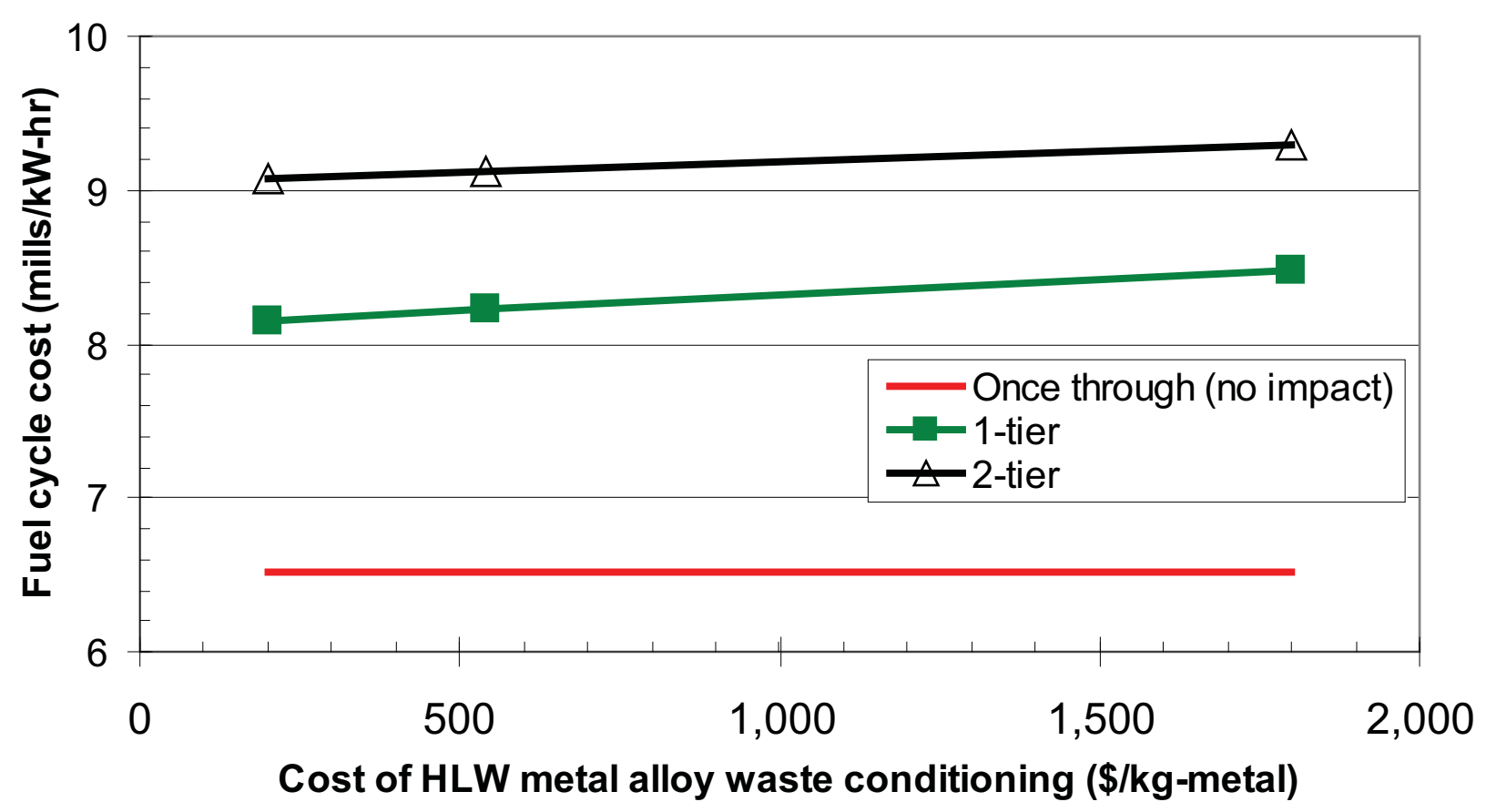

Figure 9-18. Influence of the cost uncertainty of electrochemical HLW metal alloy waste conditioning on once-through, 1-tier, and 2-tier fuel cycle costs, using data from [Shropshire2009]. No data markers are shown on the once through curve because it has no HLW metal alloy waste, thus, it has no sensitivity to this input parameter.

In figure 9-19, the once through fuel is (by far) the most sensitive to repository costs. We caution that the waste masses in the various cases different significantly. Both 1-tier and 2-tier have two separate geologic repository costs, one for fission products and one for activated metal hulls; the curve for each assumes the other geologic cost is held constant. The mid points for the two 1-tier cost lines are the same fuel cycle cost, i.e., if the nominal (mid-point) repository cost is used for both variables, the result is the nominal fuel cycle cost. Similarly, the mid points for the two 2-tier cost lines are both $9.1 \mathrm{mills} / \mathrm{kW}-\mathrm{hr}$.

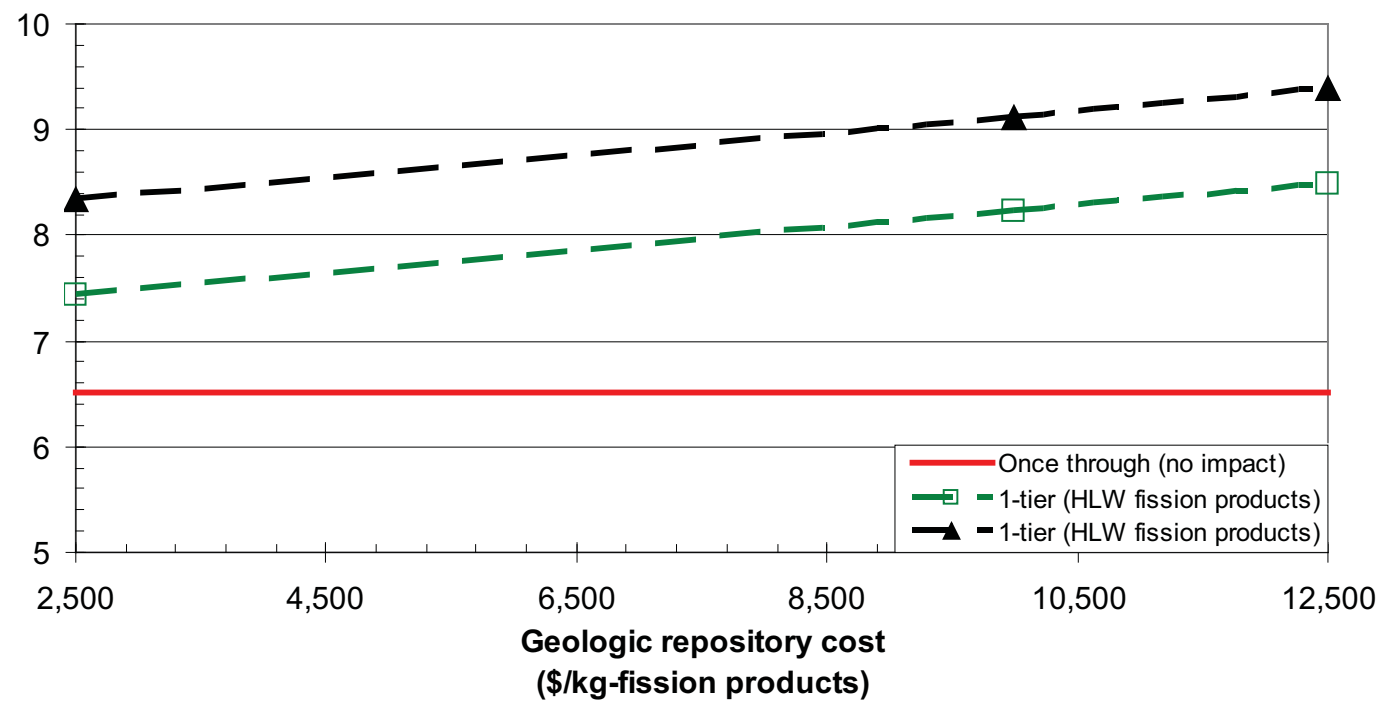

Firoure 9-19. Influence of geologic repository cost uncertainty on once-through, 1-tier, and 2-tier fuel cycle costs, using data from [Shropshire2009]. Caution, the waste masses differ significantly among

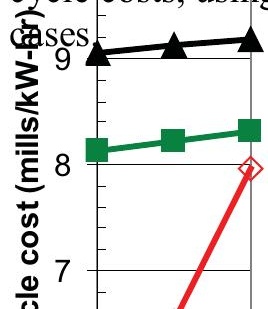




\subsection{Contribution to Fuel Cycle Cost for Once Through, 1-Tier, and 2- Tier}

For a given case it is of interest to see how each required fuel cycle step contributes to the unit cost of heavy metal charged and later discharged from the reactor(s). Figure 9-20 shows how each step of the open cycle contributes to the unit cost of UOX LWR fuel processed and irradiated.

All steps on the pie chart total to $\$ 2710 / \mathrm{kg}-\mathrm{HM}$ or $\$ 6.51 / \mathrm{MW}-\mathrm{hr}$. This data are for the "nominal" case. The first five steps on the legend are "front-end" fuel cycle steps; the last two are "back-end" steps.

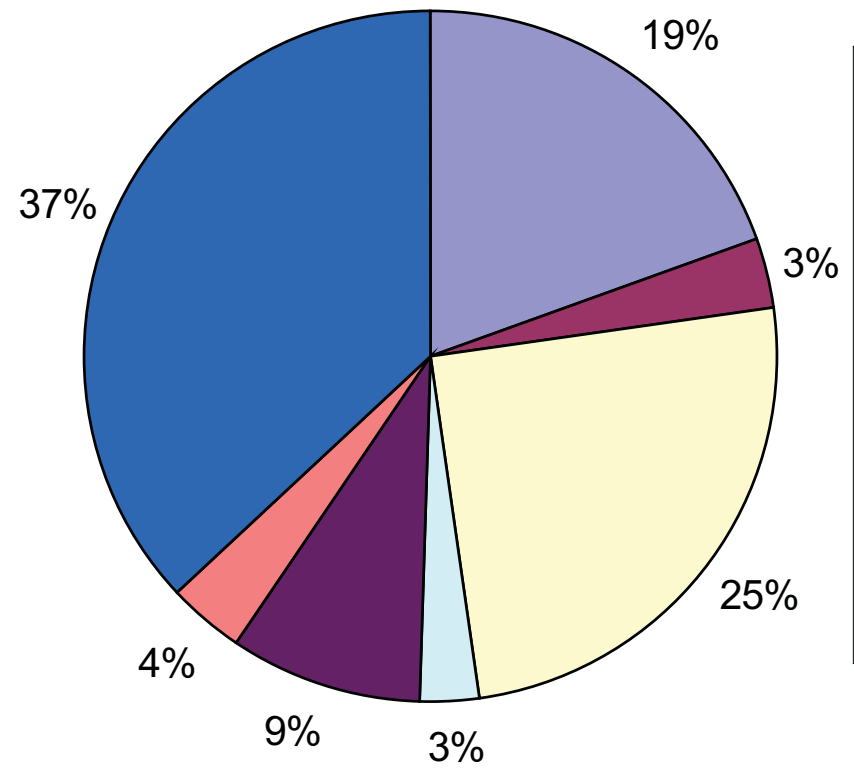

$\square$ Uranium mining and milling

$\square$ Uranium conversion

$\square$ Uranium enrichment

DUF6 conversion and disposal

$\square$ UOX fabrication

$\square$ Used fuel conditioning and packaging

Used fuel geologic disposal

Figure 9-20. Contribution to fuel cycle cost for once-through; DUF6 is depleted uranium hexafluoride, the tails remaining after uranium enrichment.[Shropshire2009]

Closed fuel cycles have many more post-irradiation steps and two types of reactor fuel to consider (LWR and FR). It can be seen that reprocessing associated costs dominate for both the LWR and FR unit heavy metal costs. Pie slice size, however, is not necessarily an indicator of overall variable sensitivity, since these pie charts are for a single "nominal case" point only.

\subsubsection{1-tier cost contributors}

The first two pie charts (figures 9-21 and 9-22) show how the cost per unit of heavy metal distributes for the thermal (LWR) reactors in the 1-tier symbiotic system. The total cost for the UOX fuel cycle (first pie below) is $\sim \$ 3900 / \mathrm{kg}-\mathrm{HM}$ or $\$ 9.3 / \mathrm{MW}-\mathrm{hr}$. Front-end fuel cycle costs (ore, conversion, enrichment, $\mathrm{DUF}_{6}$, and UOX fuel fabrication) account for around $42 \%$ of this total. Reprocessing related costs (bright blue on pie) also account for $41 \%$ of the overall LWR-UOX fuel cycle costs. Actinide storage and geologic disposal of reprocessing products account for the remaining $17 \%$. 


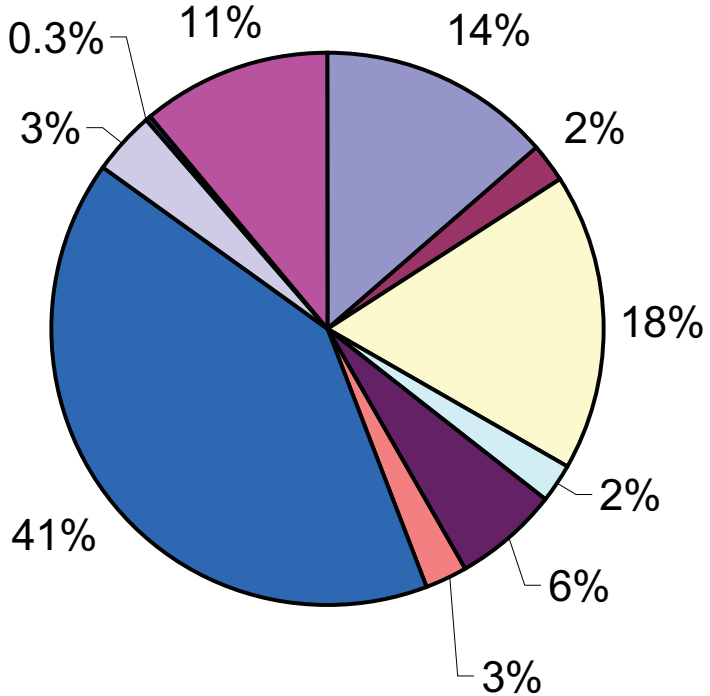

\begin{tabular}{l}
\hline Uranium mining and milling \\
$\square$ Uranium conversion \\
$\square$ Uranium enrichment \\
$\square$ DUF6 conversion and disposal \\
$\square$ UOX fabrication \\
$\square$ Used fuel conditioning and packaging \\
$\square$ Separation \\
$\square$ Actinide Storage \\
$\square$ GTCC w aste geologic disposal \\
$\square$ HLW geologic disposal
\end{tabular}

Figure 9-21. Contribution among LWR steps to fuel cycle cost for 1-tier showing that chemical separation cost dominates; DUF6 is depleted uranium hexafluoride, the tails remaining after uranium enrichment. [Shropshire2009]

Figure 9-22 shows how the $\sim \$ 1600 / \mathrm{kg}-\mathrm{HM}(\$ 3.82 / \mathrm{MW}-\mathrm{hr})$ in UREX-1a -related aqueous reprocessing costs, which total to $41 \%$ of the pie in figure 9-21) distributes among the major operations and waste handling steps.

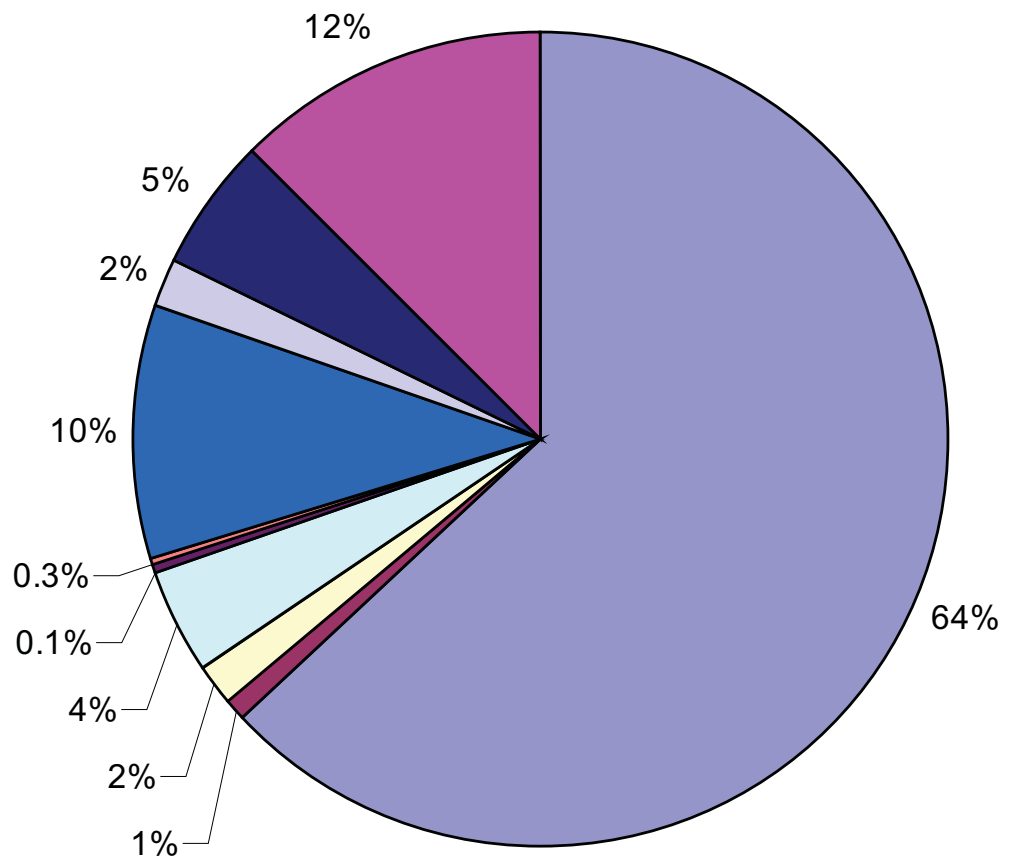

$\square$ Head-end \& separations
$\square$ RU disposition
$\square$ LLW C\&P and disposltion
$\square$ CsSr C\&P
$\square$ Volatile offgas C\&P
$\square$ lodine C\&P
$\square$ Hulls C\&P
$\square$ Tc C\&P
$\square$ Other FP C\&P
$\square$ Managed FP storage

Figure 9-22. Contribution among UREX-1a reprocessing steps to fuel cycle cost for 1-tier. [Shropshire2009] $\mathrm{C} \& \mathrm{P}=$ conditioning and packaging, $\mathrm{FP}==$ fission products.

These last two pie charts for 1-tier (figure 9-23 and 9-24) show how the cost per unit of heavy metal distributes for the fast reactors in the 1-tier symbiotic system. The total unit heavy metal cost for the 
entire FR fuel cycle (first pie below) is $\sim \$ 7700 / \mathrm{kg}-\mathrm{HM}$ or $\$ 6.4 / \mathrm{MW}-\mathrm{hr}$. In terms of HM unit cost, this is significantly higher than for UOX; however, far less of this metal fuel is required per kilowatt hour generated, mainly because of its higher fissile content in the FR heavy metal, as compared to the LWR HM. Front-end fuel cycle costs are essentially non-existent because it is not possible to separate the FR fuel refabrication cost from the reprocessing costs for this integrated "IFR" metal-based fuel electrochemical technology. Reprocessing related costs (bright blue on pie) also account for over $75 \%$ of the overall FR U-TRU heavy metal fuel cycle costs. Geologic disposal of reprocessing products accounts for the remaining costs.

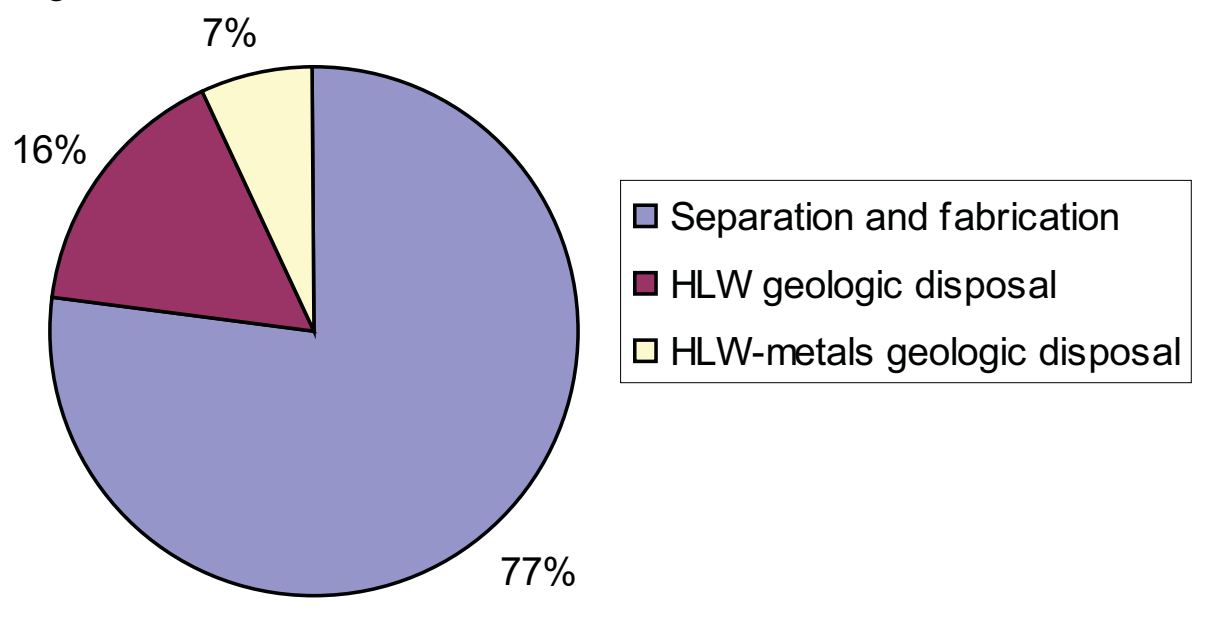

Figure 9-23. Contribution among fast reactor fuel cycle steps to fuel cycle cost for 1-tier, showing that separation and fabrication dominates disposal.[Shropshire2009]

Figure 9-24 shows how the $\sim \$ 5900 / \mathrm{kg}-\mathrm{HM}(\$ 4.9 / \mathrm{MW}-\mathrm{hr})$ in electrochemical recycle costs $(77 \%$ of figure 9-23) distributes among the major operations and waste handling steps.

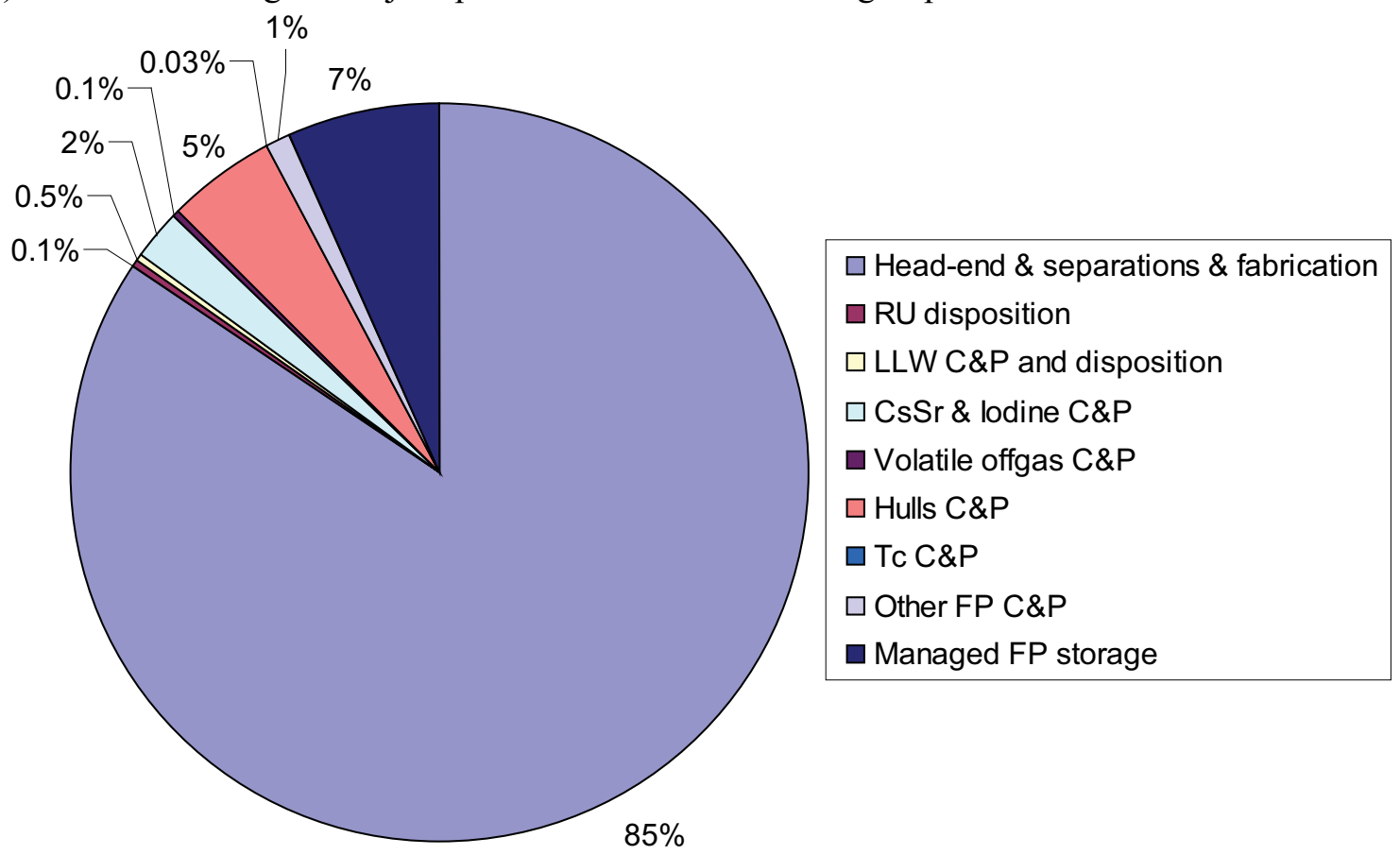

Figure 9-24. Contribution among fast reactor metal fuel separation and fuel fabrication to fuel cycle cost for 1-tier.[Shropshire2009] $\mathrm{C} \& \mathrm{P}=$ conditioning and packaging 


\subsubsection{2-tier cost contributors}

For the 2-tier fuel cycle there is a small fleet of LWR reactors burning "single-pass" U,Pu MOX derived from aqueous reprocessing of the spent fuel from the more numerous UOX-burning LWRs, i.e. a "thermal recycle" step added to the single tier fuel cycle. The following pie chart (figure 9-25) shows how the heavy metal unit cost components distribute over the various MOX-related steps. The total HM cost for the MOX portion of the 2-tier fuel cycle is $\sim \$ 5300$ per kg-HM or $\$ 12.65 / \mathrm{MW}-\mathrm{hr}$.

It can be seen that fabrication of U,Pu MOX fuel is the largest single cost. The first two steps, $(\mathrm{U}, \mathrm{Pu}) \mathrm{O} 2$ storage and MOX, constitute the "front-end" costs for MOX. The back-end reprocessing and geologic disposal steps have similar unit heavy metal costs to those associated with UOX.

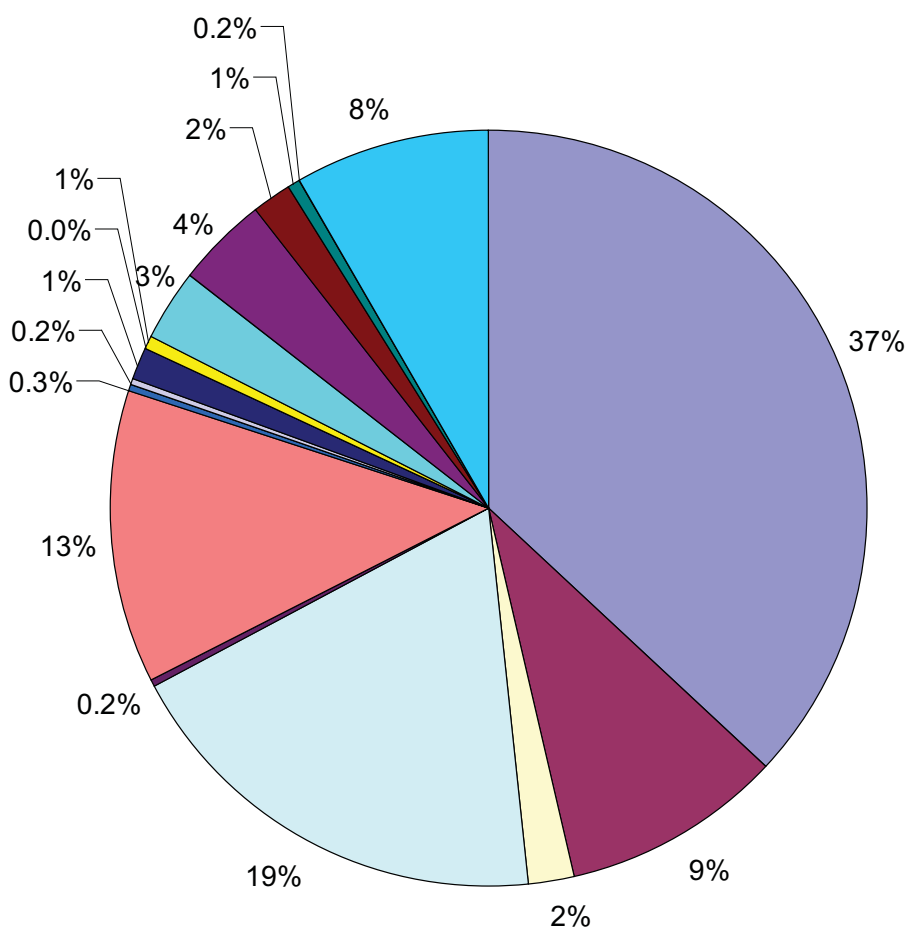

$\square$ MOX fabrication
$\square$ Pre-fabrication (U,Pu)O2 storage
$\square$ Used UOX C\&P
$\square$ Aqueous separation \& head-end
$\square$ RU disposition
$\square$ TRU storage
$\square$ LLW C\&P
$\square$ LLW disposal
$\square$ CsSr C\&P
$\square$ Volatile offgas C\&P
$\square$ lodine C\&P
$\square$ Hulls C\&P
$\square$ Managed FP storage
$\square$ Other FP C\&P
$\square$ Tc C\&P
$\square$ GTCC Interim deep disposal
$\square$ HLW geologic disposal

Figure 9-25. Contribution to fuel cycle cost for 2-tier, showing that MOX fabrication and aqueous separation dominate. [Shropshire2009]

\subsection{Closing the Gap between Recycle and Once Through}

\subsubsection{1-tier cost cap analysis}

The effects of system performance parameters (capacity factor, conversion ratio, thermodynamic efficiency, etc ) on the unit electricity cost were investigated. With this system information and the costrelated sensitivities discussed above, it was possible to determine what measures could bring "parity" (TCOE cost equivalence) between the 1-tier and open cycle. See figure 9-26. 


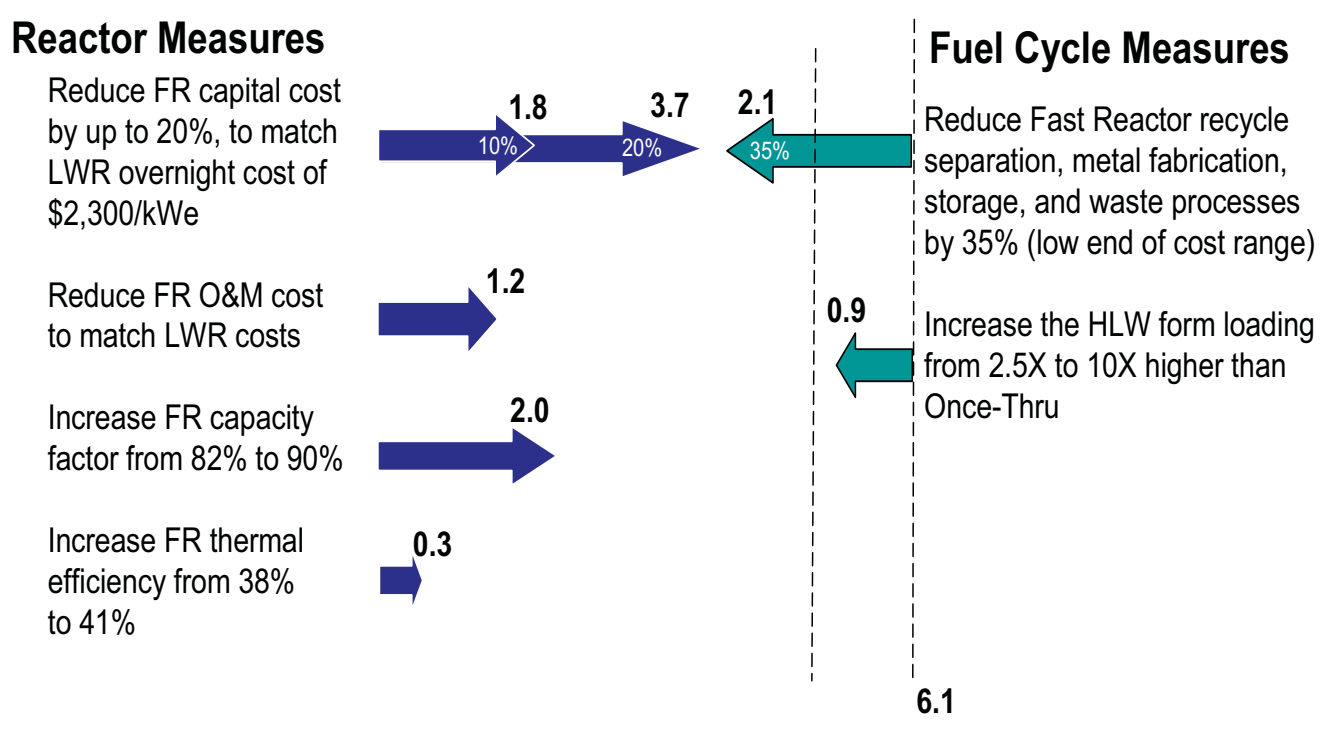

Figure 9-26. Closing the gap from 1-tier to once-through costs. [Shropshire2009]

\subsubsection{2-tier cost cap analysis}

The effects of system performance parameters (capacity factor, conversion ratio, thermodynamic efficiency, etc ) on the unit electricity cost were investigated. With this system information and the costrelated sensitivities discussed above, it was possible to determine what measures could bring "parity" (TCOE cost equivalence) between the 2-tier and open cycle. Figure 9-27 shows the measures required to close the cost gap. 


\section{Reactor Measures}

Reduce FR capital cost by up to $20 \%$, to match LWR overnight cost of $\$ 2,300 / \mathrm{kWe}$

Reduce FR O\&M cost to match LWR costs Increase FR capacity factor from $82 \%$ to $90 \%$

Increase FR thermal efficiency from $38 \%$ to $41 \%$

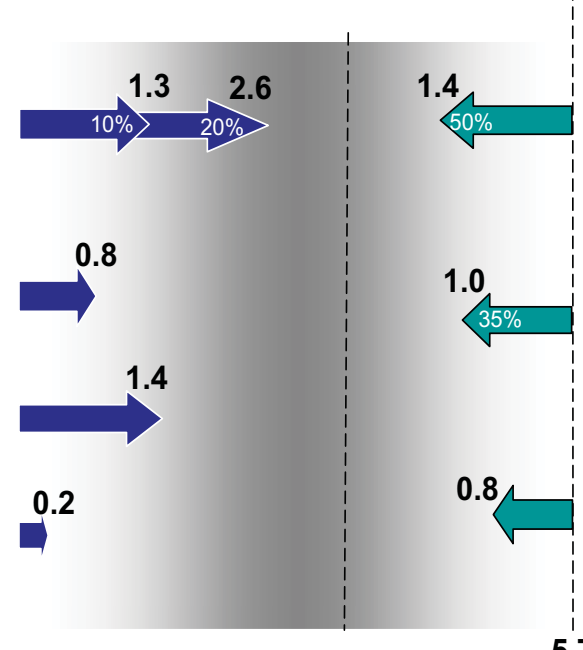

\section{Fuel Cycle Measures}

Reduce MOX Thermal Recycle Separation/MOX Fab/Waste Processes by $50 \%$ (low-end of cost range)

Reduce Fast Reactor recycle separation, metal fabrication, storage, and waste processes by $35 \%$ (low end of cost range)

Increase the HLW form loading from $2.5 \mathrm{X}$ to $10 \mathrm{X}$ higher than Once-Thru

Figure 9-27. Closing the gap from 2-tier to once-through costs. [Shropshire2009]

The width of the arrows and indicated "delta" value in $\$ / \mathrm{MW}-\mathrm{hr}$ shows how each beneficial change could contribute toward parity. Reduction of the $\$ / \mathrm{kWe}$ capital cost of the fast reactor vis-à-vis that of the LWR has the greatest beneficial effect. Note that reactor-related factors and fuel cycle related factors are considered separately. In the area of fuel cycle, it is seen that reduction in the recycle costs for MOX, including fresh MOX fabrication, has the greatest fuel cycle cost related benefit.

\subsection{Dynamic versus Static Economic Comparisons at Different Conversion Ratios}

Discussion up to this point has been on cases calculated by "static equilibrium" or "steady-state" spreadsheet analysis. The VISION dynamic model has been used to investigate the time variation of costs as the steady state is approached at a constant nuclear generation growth rate of $1.2 \%$ per year. The two figures in figure 9-28 below show the TCOE and its fuel cycle components as a function of time for the three fuel cycles of interest. In the out years agreement between the G4-ECONS based spreadsheet model and the VISION dynamic model is very good.

In this analysis, the annual costs were evaluated over time to examine the overall driving cost factors resulting from nuclear growth. In the growth cases, the initial period of expanded growth, e.g., deployment of separation facilities, and fast reactors, generates increases in fuel cycle costs and the total cost of electricity. After this initial expansion period, the systems enter into a dynamic equilibrium period where relative costs become stable. Dynamic equilibrium occurs when new FRs are brought online and the ratio between the FRs and LWR reactors becomes stabilized. Once stabilized, the relative annual cost of electricity and fuel cycle costs flatten (around 2050), as demonstrated in the figures below. 

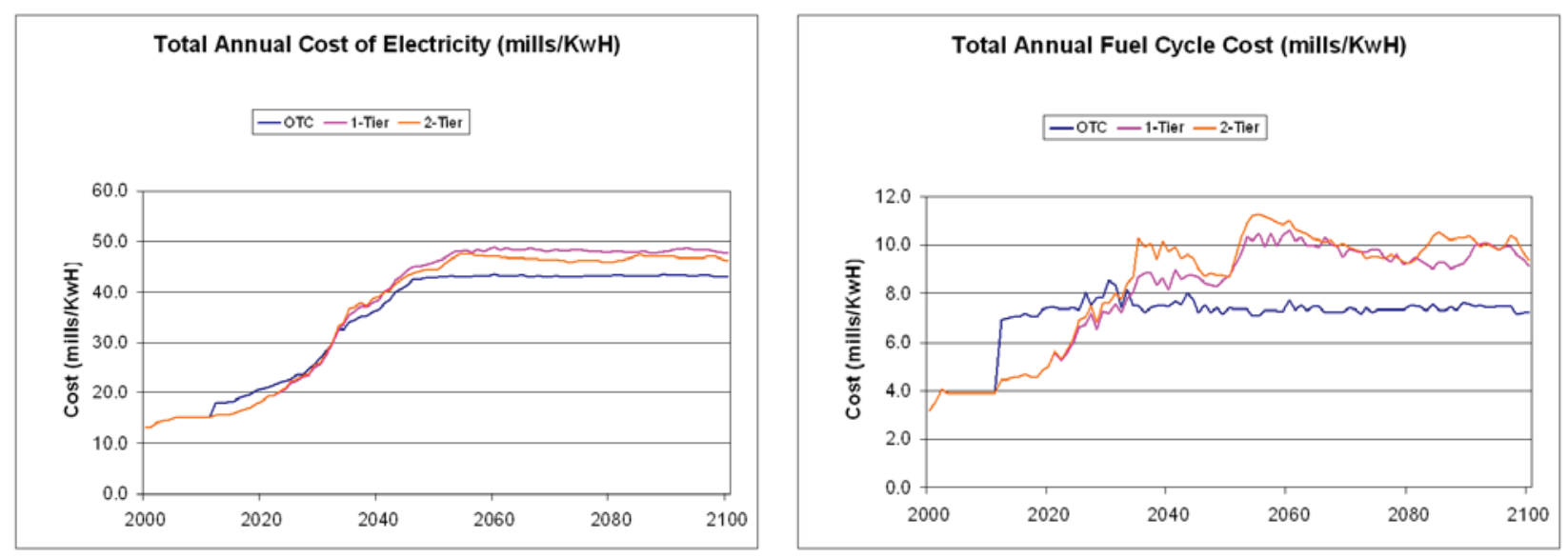

Figure 9-28. Dynamic analysis of the total annual cost of electricity and fuel cycle cost. [Shropshire2009]

Consistent with the G4 ECONS "static" spreadsheet analysis, the fuel cycle costs are highest for the 2-tier and the total annual cost of electricity are the highest for the 1-tier after the system has stabilized. The once-through scenario, as in previous cases, has the lowest annual costs. In the right side of figure 9-28, note that the OTC cycle includes all the fuel cycle costs (front-end, and back-end). The nominal back-end cost for disposal is $\$ 1,000 / \mathrm{kgHM}$ (not $1 \mathrm{mill} / \mathrm{kwh}$ ). The ramp up of costs is an artifact of VISION showing only new reactors coming on line. We did not include the costs for any of the legacy reactors.

Conversion ratio also has an effect on both TCOE and unit fuel cycle costs. As conversion ratio increases the symbiotic system utilizes a higher percentage of the more expensive fast reactors, and less TRU makeup fissile material from LWR reprocessing is required. Figures 9-29 and 9-30 shows the results of this sensitivity study from both the static equilibrium (G4-ECONs-based) and dynamic (VISION-based) models.

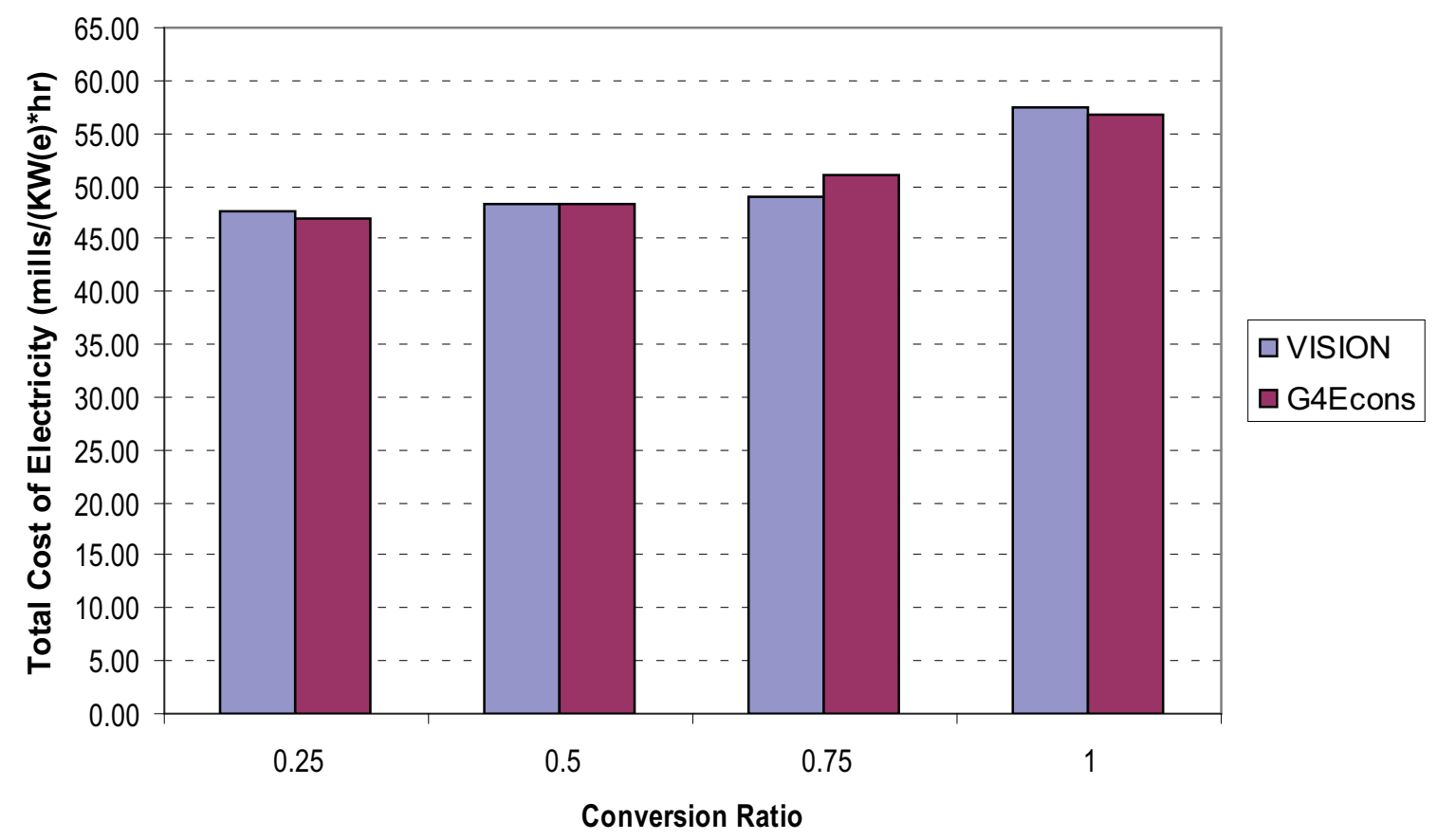

Figure 9-29. Dynamic analysis (VISION) versus static (G4-ECON) total cost comparison for different fast reactor conversion ratios. [Shropshire2009] 


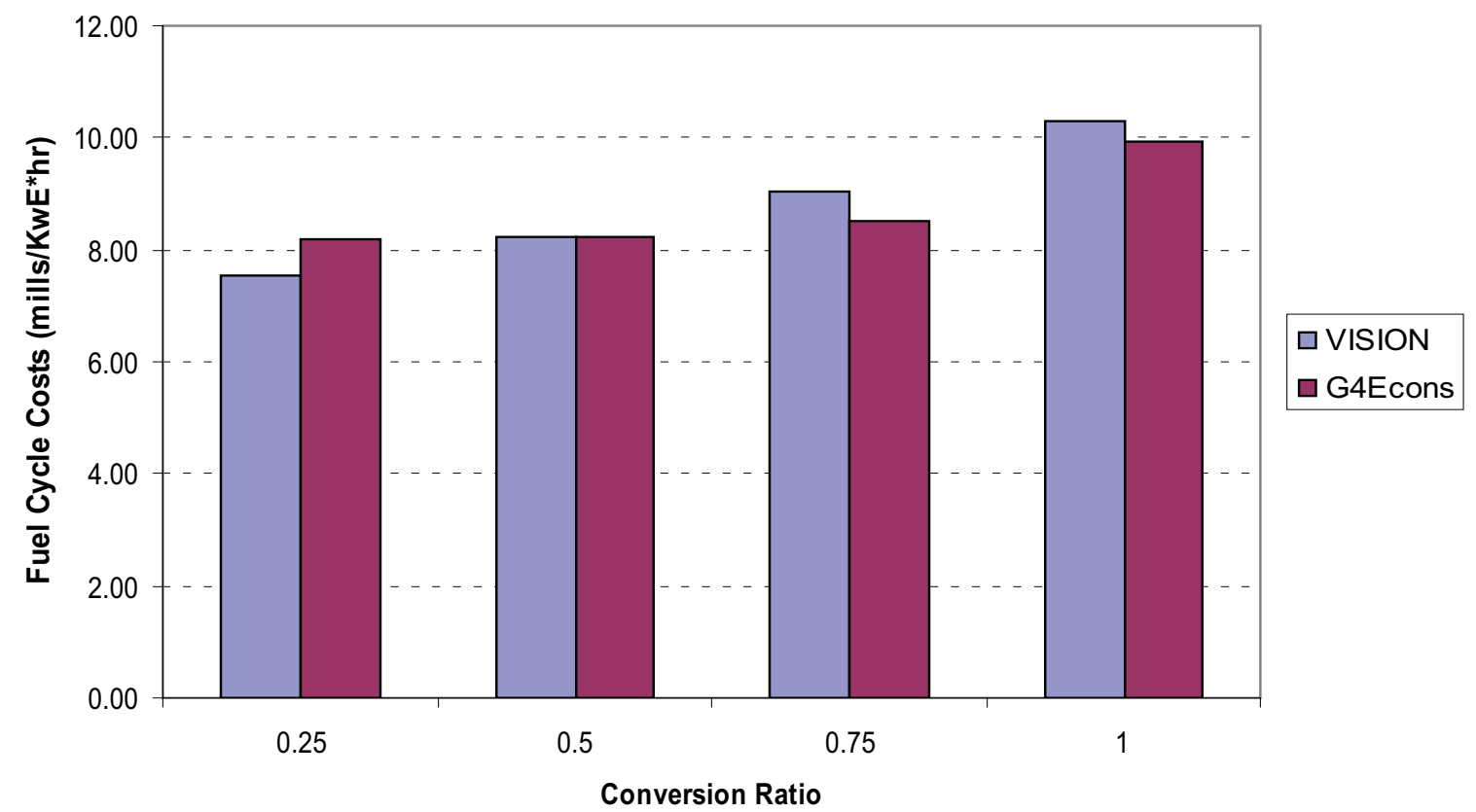

Figure 9-30. Dynamic analysis (VISION) versus static (G4-ECON) fuel cycle cost comparison for different fast reactor conversion ratios. [Shropshire2009]

\subsection{Transportation Costs}

Transportation costs were calculated in a separate study for each scenario. Figure 9-31 shows how they affect the TCOE for al three fuel cycle scenarios. The transportation-related cost is the $\$ / \mathrm{MW}$-hr number that appears above the green bar for each scenario. The values in the pies are the fuel cycle unit costs without transportation for the "nominal" cases. The transportation cost "slice" should be added to each to get an overall fuel cycle cost. It can be seen costs associated with transportation of LWR used fuel, either to the geologic repository (open cycle) or to the UOX/MOX reprocessing plants (closed fuel cycle) from the reactor(s) is the largest contributor. The fact that LWRs outnumber FRs for all cases accounts for the fact that LWR used fuel transportation costs greatly exceed FR transportation related costs. 


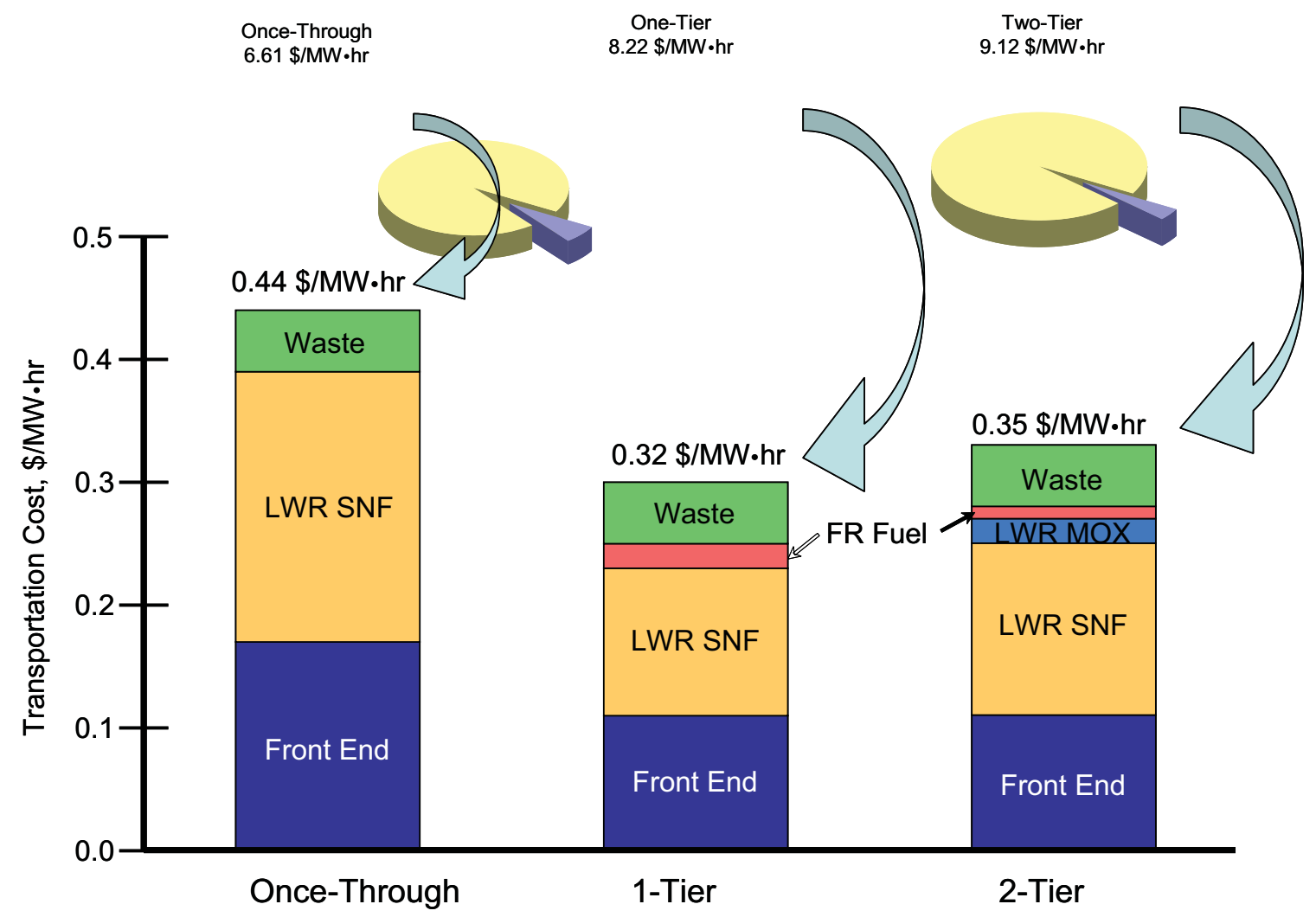

Figure 9-31. Transportation costs. [Shropshire2009]

\subsection{Comparison with Other Studies}

The results of this study were compared with those from other fuel cycle studies.[OECD2006, MIT2003] (An update of the MIT study is in progress; results expected in late 2009.) The figures 9-32 and 9-33 compare the TCOE and fuel cycle component distributions for this AFCI study side-by-side with these two studies. The AFCI input fuel cycle costs were considerably more conservative (higher) than those in other studies. 


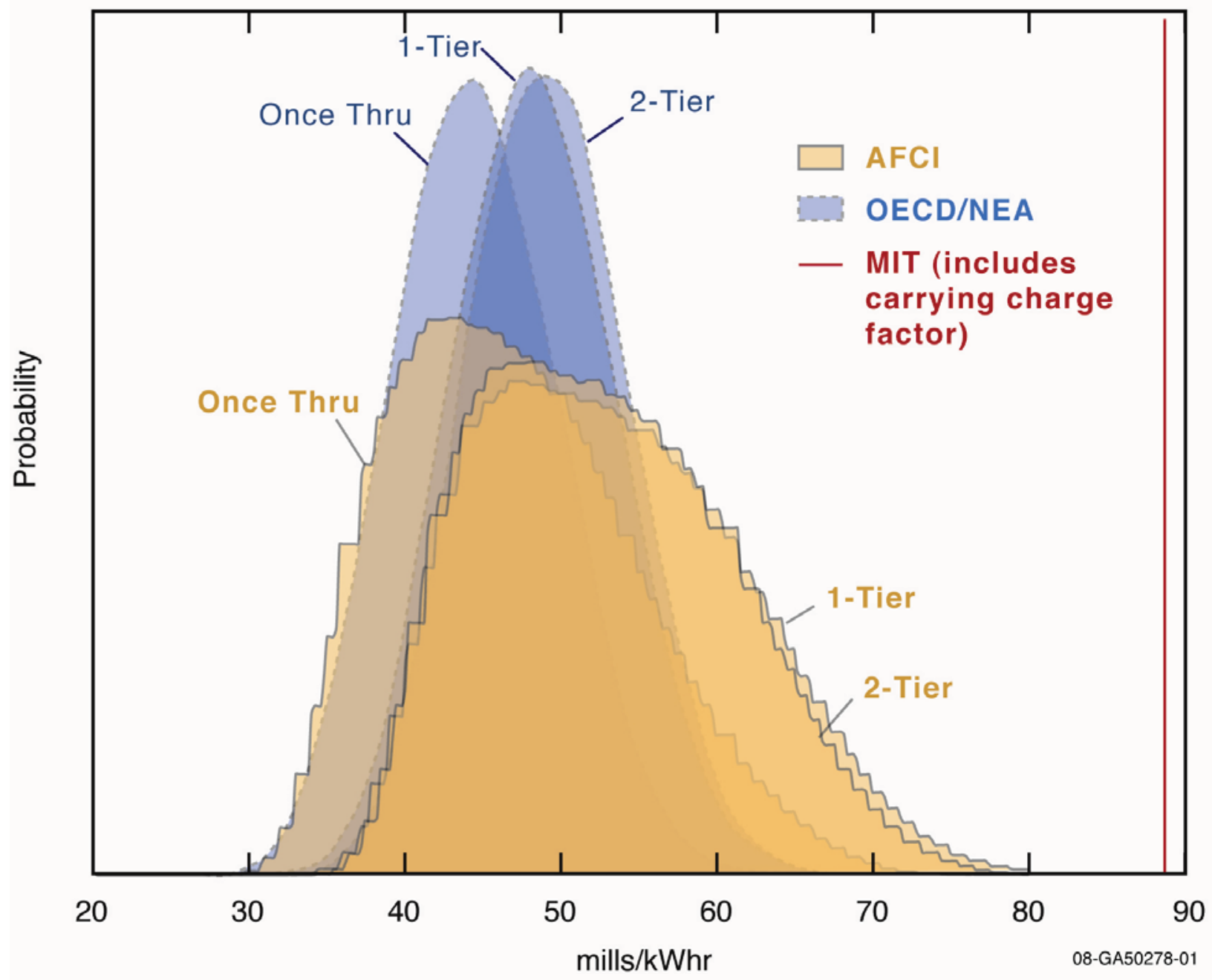

Figure 9-32. Probability distribution of total cost of electricity; all but the MIT case are a probability distribution. The MIT result is a point estimate, which is shown as a vertical line.[Shropshire2009] 


\section{Fuel Cycle Cost Distribution}

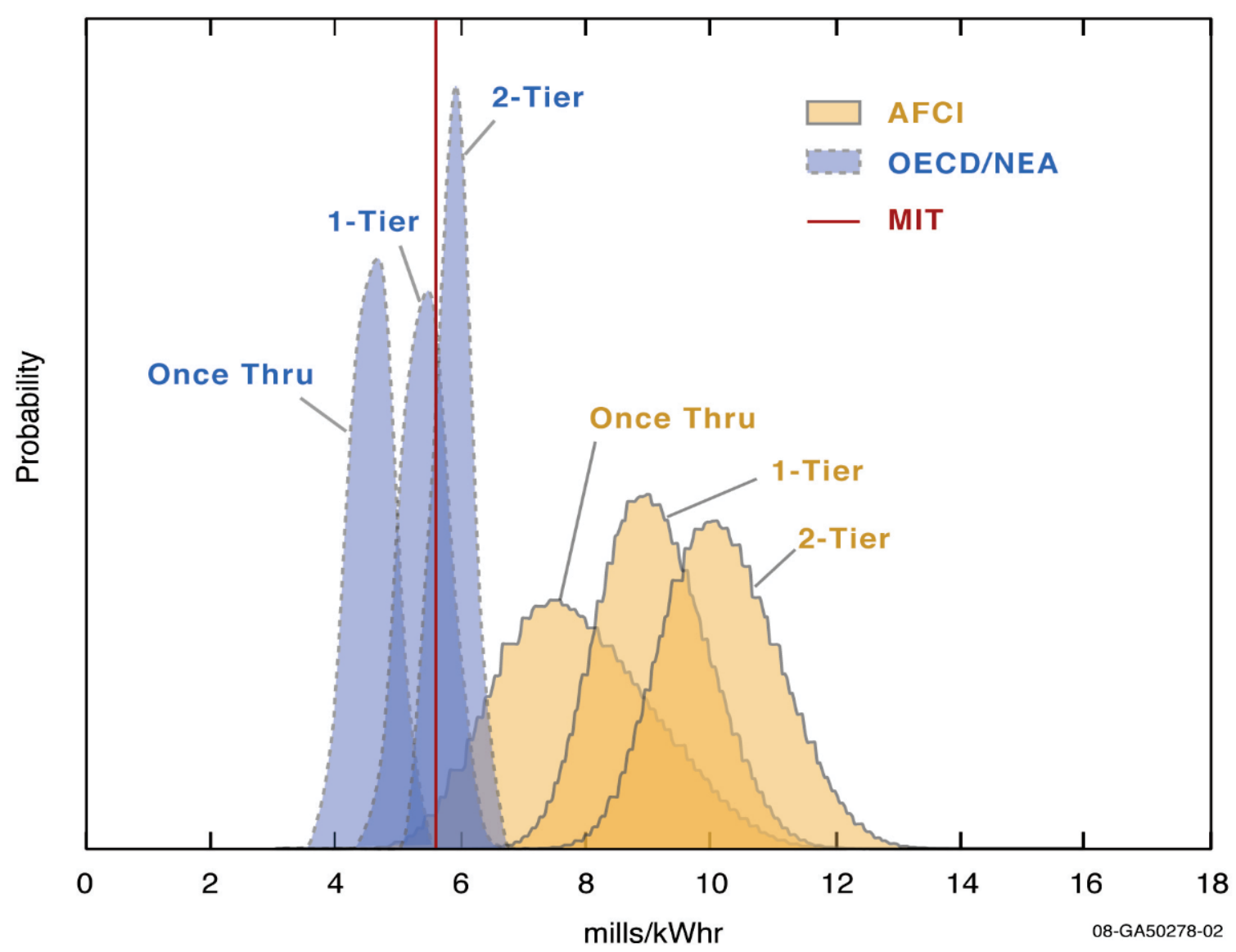

Figure 9-33. Probability distribution of fuel cycle costs; all but the MIT case are a probability distribution. The MIT result is a point estimate, which is shown as a vertical line. [Shropshire2009]

\subsection{Comparison with Other Energy Options}

The issue of the competitiveness of nuclear vis-à-vis other baseload electricity sources is of paramount importance. "Static" EXCEL TCOE models for coal and natural gas were developed and each had sets of cost-related input parameters, see figure 9-34. The MVSS TCOE distributions for these fossil technologies are compared with those for the three nuclear fuel cycle scenarios. Fossil costs are considered both with and without carbon costs (tax, regulation, or carbon capture \& sequestration). Note that natural gas has a wide distribution due to the extremely high volatility in the natural gas fuel price model input. Coal's TCOE distribution also reflects significant variation in the price of coal input to the model. 


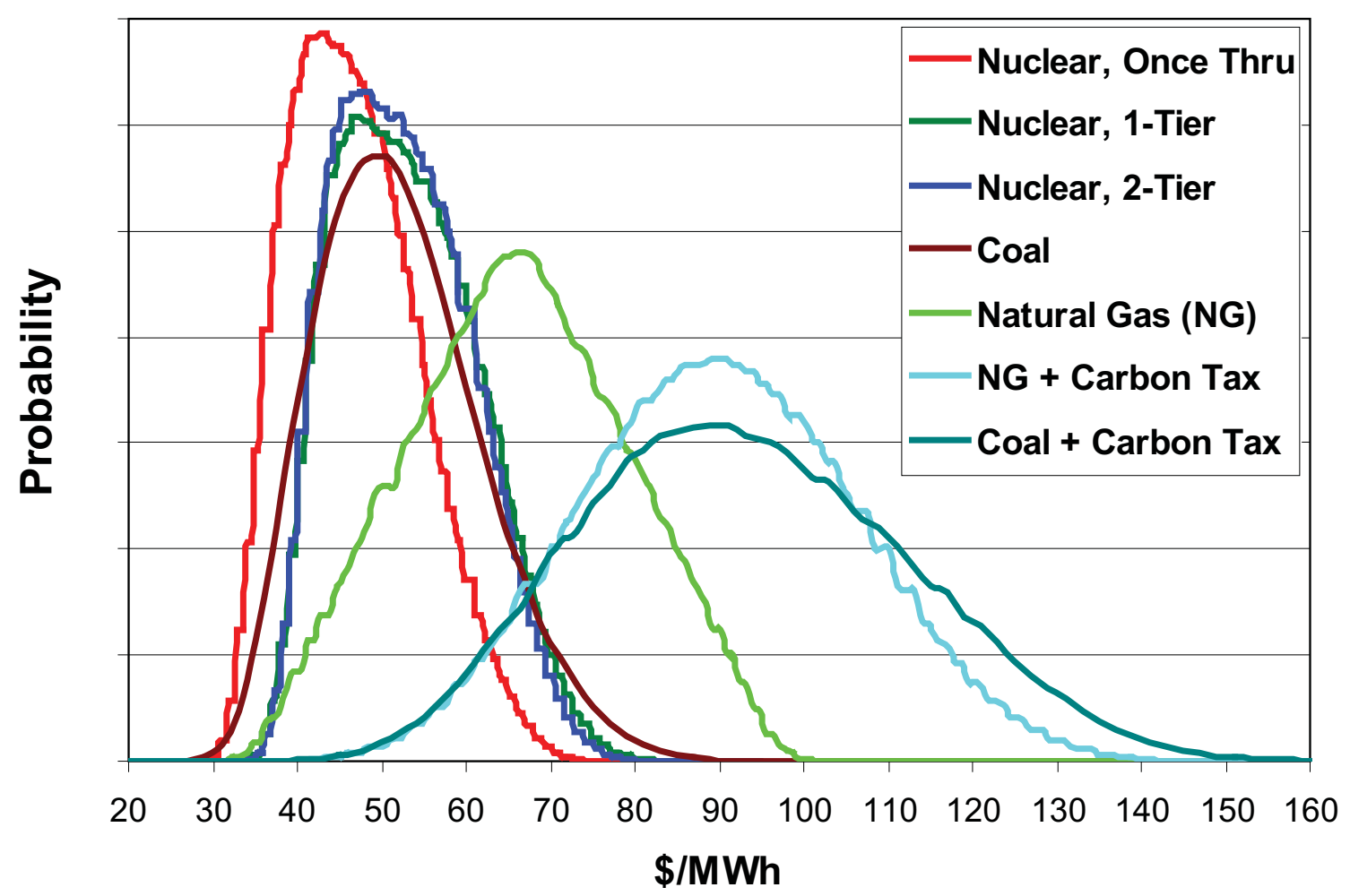

Figure 9-34. Nuclear energy TCOE compared to other future baseline energy, shown as probability distributions. [Shropshire2009] 


\section{REFERENCES}

AAA2001

ANL2004

Asgari2007

Clarke2004

Deffeyes 1978

Deffeyes 1980

Dixon2008

DOE-NE2008

DOE2007

DOE2007a

DOE2007b

DOE2006

DOE2005

DOE2004
Advanced Accelerator Applications program, Candidate Approaches for an Integrated Nuclear Waste Management Strategy - Scoping Evaluations, AAA-PDOGEN-01-0051, Revised November 2001.

Argonne National Laboratory Nuclear Engineering Division, Dynamic Analysis of Nuclear Energy System Strategies (DANESS) v.1.07 Use's Manual. Argonne, Illinois: February 2004.

M. Asgari, B. Forget, S. Piet, R. Ferrer, S. Bays, Computational Neutronics Methods and Transmutation Performance Analyses for Light Water Reactors, INL/EXT-0712472, October 2007.

J. F. Clarke, J. Edmonds, and C. Geffen, Nuclear Technology Pathways to a CarbonNeutral Energy System, Battelle Global Energy Technology Strategy Program (GTSP), 2004.

K. S. Deffeyes and I. D. MacGregor, Uranium Distribution in Mined Deposits and in the Earth's Crust. Final Report, GJBX-1(79), Department of Geological and Geophysical Sciences, Princeton University, Princeton, NJ, Prepared for the DOE Grand Junction Office, August 1978.

K. S. Deffeyes and I. D. MacGregor, World Uranium Resources, $\underline{\text { Scientific }}$ American, 242, 1, 66-76, January 1980.

B. W. Dixon, et al, Scenario Assumptions and Data for the Dynamic Systems Analysis Report for Nuclear Fuel Recycle (DSARR), Global Nuclear Energy Partnership, GNEP-SYSA-AI-SS-RT-2008-000246, June 30, 2008.

U.S. Department of Energy, Office of Nuclear Energy, Staff communications through January 2008.

U.S. Department of Energy, Energy Information Administration, Annual Energy Review 2006, Report No. DOE/EIA-0384(2006), June, 2007 - Table 8.1 Electricity Overview, 1949-2006 and Table 8.2a Electricity Net Generation: Total (All Sectors), 1949-2006.

U.S. Department of Energy, Energy Information Administration, Total electricity generation from EIA, Annual Energy Outlook, Report No. DOE/EIA-0383(2008), December 2007 - Table 8. Electricity Supply, Disposition, Prices, and Emissions (row 43).

U.S. Department of Energy, Energy Information Administration, U.S. Nuclear Reactors, data through June 2007, http://www.eia.doe.gov/cneaf/nuclear/page/nuc_reactors/reactsum.html

U.S. Department of Energy, Office of Nuclear Energy, Advanced Fuel Cycle Initiative (AFCI) Comparison Report, FY 2006 Update, July 2006.

Report to Congress - Advanced Fuel Cycle Initiative: Objectives, Approach, and Technology Summary, U.S. Department of Energy, Office of Nuclear Energy, Science, and Technology, May 2005.

U.S. Department of Energy, Energy Information Administration, Detailed U.S. Spent Nuclear Fuel Data - Table 3, http://www.eia.doe.gov/cneaf/nuclear/spent fuel/ussnftab3.html, October 2004. 
DSARR2008

EAWG2008

EAWG2007

EPA1999

FCCCG2002

Ferrer2007a

Ferrer2007b

Gombert2008

Herring2004

Hoffman2005

Hoffman2006

Hoffman2007a

Jacobson2009

Jacobson2008

Jacobson2007

Jacobson2006
Dynamic Systems Analysis Report for Nuclear Fuel Recycle, Revision 1, AFCISYSA-AI-SS-RT-2009-000053, INL/EXT-08-15201, 2009.

Economic Analysis Working Group, 2008, Draft GNEP Economic Analysis, GNEPSYSA-ECON-SS-RT-2008-000067, Draft, May 2008.

Economic Analysis Working Group, 2007, Global Nuclear Energy Partnership Economic Tools, Algorithms, and Methodology, INL/EXT-07-13293, GNEP-SYSAECON-SS-RT-2007-000354, September 2007.

Environmental Protection Agency, Report to Congress - Wastes from the Combustion of Fossil Fuels, Volume 2 - Methods, Findings, and Recommendations, Office of Solid Waste and Emergency Response, EPA 530-R-99-010, March 1999.

Generation-IV Roadmap: Report of the Fuel Cycle Crosscut Group, US Department of Energy Report, March 2002.

R. Ferrer, M. Asgari, S. Bays, B. Forget, Computational Neutronics Methods and Transmutation Performance Analyses for Fast Reactors, INL/EXT-07-12466, March 2007.

R. M. Ferrer, M. Asgari, S. E. Bays, B. Forget, Fast Reactor Alternative Studies: Effects of Transuranic Groupings on Metal and Oxide Sodium Fast Reactor Designs, INL/EXT-07-13236, September 2007.

D. Gombert; S. J. Piet; T. Trickel; J. Carter; J. Vienna; W. Ebert; G. E. Matthern, Combined Waste Form Cost Trade Study, GNEP-SYSA-PMO-MI-DV-2009-000003 and INL/EXT-08-14993, November 2008.

J. S. Herring, Uranium and Thorium Resources, in The Encyclopedia of Energy, Cutler J. Cleveland, editor in chief, Academic Press, 2004.

E. A. Hoffman, Preliminary Report on Blending Strategies for Inert-Matrix Fuel Recycling in LWRs, ANL-AFCI-149, March 31, 2005.

E. A. Hoffman, W. S. Yang, R. N. Hill, Preliminary Core Design Studies for the Advanced Burner Reactor over a Wide Range of Conversion Ratios, ANL-AFCI-177, September 29, 2006.

E. A. Hoffman, Updated Design Studies for the Advanced Burner Reactor over a Wide Range of Conversion Ratios, ANL-AFCI-189, May 31, 2007.

J. J. Jacobson, A. M. Yacout, G. E. Matthern, S. J. Piet, D. E. Shropshire, Verifiable Fuel Cycle Simulation (VISION) Model, Advances In Nuclear Fuel Management IV (ANFM IV), April 12-15, 2009.

J. J. Jacobson, G. E. Matthern, S. J. Piet, J. Grimm, VISION User Guide, INL/MIS07-13102, Rev 2.2, February 16, 2008.

J. J. Jacobson, A. M Yacout, G. E. Matthern, S. J. Piet, D. E. Shropshire, C. T. Laws, VISION 2: Enhanced Simulation Model of the Next Generation Nuclear Fuel Cycle, paper 174377, American Nuclear Society Conference, Boston, MA, June 2007 (also cataloged as INL/CON-07-12111).

J. J. Jacobson, A. M. Yacout, G. E. Matthern, S. J. Piet, D. E. Shropshire, and C. T. Laws, VISION: Verifiable Fuel Cycle Simulation Model, American Nuclear Society Conference, November 2006. 
$\operatorname{Kim} 2008$

MIT2003

NEI2009

NRC2008

NRC2008a

OECD2006

Piet2009

Piet2008a

Piet2008b

Piet2008c

Piet $2007 \mathrm{a}$

Piet2007b

Piet2007c

Piet2007d

Piet2006
S. H. Kim and J. Edmonds, The Potential of Nuclear Energy for Addressing Climate Change, GNEP-SYSA-PMO-MI-DV-2008-000179, The Joint Global Change Research Institute, Battelle, PNNL, February 2008.

Massachusetts Institute of Technology, The Future of Nuclear Power, ISBN 0-61512420-8, 2003.

Nuclear Energy Institute, U.S. State by State Commercial Nuclear Used Fuel and Payments to the Nuclear Waste Fund, updated April , 2009.

Nuclear Regulatory Commission web site, NRC: Power Uprates status tables, accessed June 26, 2008 -

http://www.nrc.gov/reactors/operating/licensing/power-uprates/approvedapplications.html

http://www.nrc.gov/reactors/operating/licensing/power-uprates/pendingapplications.html

http://www.nrc.gov/reactors/operating/licensing/power-uprates/expectedapplications.html

Nuclear Regulatory Commission, 2008-2009 Information Digest, NUREG-1350, Volume 20, August 2008.

Organisation for Economic Cooperation and Development, Advanced Nuclear Fuel Cycles and Radioactive Waste Management, NEA No. 5990, OECD 2006.

S. J. Piet, Selection of Isotopes and Elements for Fuel Cycle Analysis, Advances In Nuclear Fuel Management IV (ANFM IV), April 12-15, 2009.

S. J. Piet, Response to Request for Radiotoxicity and Repository Heat Commitment Parameters Associated with Recycling of Minor Actinides, August 1, 2008.

S. J. Piet, Comparison of Two Approaches to Calculating Radiotoxicity, August 8, 2008.

S. J. Piet, S. E. Bays, R. M. Ferrer, E. A. Hoffman, G. E. Matthern, A. M. Yacout, Description of Transmutation Library for Fuel Cycle System Analyses, GNEPSYSA-PMO-MI-DV-2009-000004 and INL/EXT-08-15053, October 31, 2008.

S. J. Piet et al, Current Assessment of the Benefits of Recycling in Thermal Reactors, INL report to DOE, February 2007.

S. J. Piet et al, Global Nuclear Energy Partnership Deployment Systems Analysis Report, GNEP-SYSA-AI-SS-RT-2007-000368, September 30, 2007.

S. J. Piet, T. Bjornard, B. W. Dixon, D. Gombert, C. T. Laws, G. E. Matthern, Which Elements Should Be Recycled for a Comprehensive Fuel Cycle?, paper 175867, Global 2007, Boise, ID, September 2007(also cataloged as INL/CON-07-12197).

S. J. Piet, G. E. Matthern, J. J. Jacobson, What can Recycling in Thermal Reactors Accomplish?, paper 175871, Global 2007, Boise, ID, September 2007 (also cataloged as INL/CON-07-12196).

S. J. Piet, G. E. Matthern, J. J. Jacobson, C. T. Laws, L. C. Cadwallader (INL), A. M. Yacout, R. N. Hill (ANL), J. D. Smith, A. S. Goldmann, George Bailey (SNL), Fuel Cycle Scenario Definition, Evaluation, and Trade-offs, INL report, INL/EXT-0611683, August 2006. 
Pope2009

Redbook2007

Shropshire2008

Shropshire2009

Steyn2003

Steyn2005

Stillman2004

Todosow2005

TVA2008

Wigeland2003

Wigeland2004a

Wigeland2004b

Wigeland2006

WISE2007

WNA2004

WND2009

Yacout2006

YMLA2008

Youinou2009a
M. Pope, S. Bays, S. Piet, R. Ferrer, M. Asgari, B. Forget, Transmutation Performance Analysis for Inert Matrix Fuels in Light Water Reactors and Computational Neutronics Methods Capabilities at INL, INL/EXT-07-12472, Rev. 1, May 1, 2009.

OECD Nuclear Energy Agency and International Atomic Energy Agency, Uranium 2007: Resources, Production and Demand, NEA No. 6345, 2008.

D. Shropshire, et al., 2008 Advanced Fuel Cycle Cost Basis, INL/EXT-06-11536, March 2008.

D. E. Shropshire, et al, Advanced Fuel Cycle Economic Analysis of Symbiotic Lightwater Reactor and Fast Burner Reactor Systems; INL/EXT-09-15254; January 2009.

J. J. Steyn, Uranium Resources: Need For 21st Century Advanced Fuel Cycles," Energy Resources International, Inc., NEI International Fuel Seminar, 2003.

J. J. Steyn, Preliminary Assessment of Global Uranium Resources, Energy Resources International Report ERI-21O3-0501, 2005.

J. Stillman, T. H. Bauer, R. N. Hill, R. A. Wigeland, Follow-Up Analyses for the ANTT Review, ANL-AFCI-132, September 2004.

Unpublished data, 2005.

Tennessee Valley Authority press release "TVA Selects Bechtel to Complete Watts Bar 2", October 15, 2007, available at http://www.tva.gov/news/releases/octdec07/bechtel.htm

R. A. Wigeland, T. H. Bauer, T. H. Fanning, and E. E. Morris, Repository Impact of LWR MOX and Fast Reactor Recycling Options, Proceedings of Global 2003, ANS/ENS International Winter Meeting, New Orleans, LA, November 16-20, 2003.

R.A. Wigeland, T.H. Bauer, T.H. Fanning, and E.E. Morris, Spent Nuclear Fuel Separations and Transmutation Criteria for Benefit to a Geologic Repository, Waste Management '04, Tucson, AZ, February 2004.

R.A. Wigeland and T.H. Bauer, Repository Benefits of AFCI Options, ANL-AFCI129, September 3, 2004.

R. A. Wigeland, et al, Separations and Transmutation Criteria to improve Utilization of a Geologic Repository, Nuclear Technology, Vol. 154, April 2006.

French Nuclear Safety Authority, décret "procédures INB" in the Official Journal of Nov. 3, 2007, as reported at www.wise-uranium.org/epfr.html, November, 2007.

World Nuclear Association (WNA) info brief 75, http://www.worldnuclear.org/info/inf75.htm, August 2004.

World Nuclear News Daily, TVEL's Mashinostroitelny Zavod (MSZ) subsidiary in Electrostal, Russia January 28, 2009.

A.M. Yacout, J. J. Jacobson,' G. E. Matthern, S. J. Piet, D. E. Shropshire, C. T. Laws, VISION - Verifiable Fuel Cycle Simulation of Nuclear Fuel Cycle Dynamics, Waste Management 2006, February 26-March 2, 2006, Tucson, AZ.

Yucca Mountain License Application, 2008.

Personnal communication, February 2009. 
Youinou2009b G. Youinou, S. Bays, A Neutronic Analysis of TRU Recycling in PWRs Loaded with MOX-UE Fuel (MOX with U-235 Enriched U Support, AFCI-SYSA-TRAN-SS-RT2009-000055, INL/EXT-09-16091, May 2009. 


\section{Appendix A}

\section{Fuel Cycle Definitions}


This Appendix is intended to contain definitions of fuel cycle terminology that may not be familiar to some readers.

Closed Fuel Cycle - A fuel cycle where the usable portion of the fuel material is recycled through reactors multiple times as efficiently as practical and recycling losses are the only portion of the fuel that ultimately ends up in the waste streams. Contrast with "open fuel cycle."

Dynamic Equilibrium - Mathematically this is the steady state condition (everything growing at same rates) for a constant growth rate scenario operating on a specific fuel cycle. At zero growth rate, the dynamic and static equilibrium produce mathematically identical results. At higher growth rates, dynamic equilibrium results show the impact of material storage time, new reactor cores, and other dynamic factors on system behavior.

Dynamic System Modeling - Dynamic system modeling tools (e.g., VISION) are idealized system models that evaluate the practical problem of deploying a specific fuel cycle or mixture of fuel cycles, with emphasis on system behavior through the transition period.

Fuel Cycle - The succession of steps involved in the generation of nuclear power, starting with the mining of the ore containing the fuel and ending with the final disposition of the spent fuel and wastes produced in a nuclear reactor.

Fuel Cycle System - The set of facilities that are coordinated to operate on a specified fuel cycle.

Partial burn - only recycle for a finite number of passes (single-pass MOX, Deep Burn, etc.).

Open Fuel Cycle - A fuel cycle where the fuel material is only used once in a reactor, then disposed. Contrast with "closed fuel cycle."

Partially-closed fuel cycle - A fuel cycle where the usable portion of the fuel material is recycled a limited number of times, then disposed.

Partial recycle - separate only select transuranic elements and send the rest to waste.

Static Equilibrium - Mathematically this is the steady state condition for a zero growth scenario operating on a specific fuel cycle. It is the integrated result for following a unit of ore as it flows through the specific fuel cycle to completion and all residual material has either fissioned or been lost or sent to waste. It is generally an idealized theoretical construct to evaluate performance of different fuel cycle options when they are run to completion. 


\section{Appendix B}

\section{Figures of Merit}


This Appendix is intended to contain definitions and explanation of the origin of important figures of merit.

\section{B-1. Dose Conversion Factors}

Dose conversion factors describe the radiological dose to an amount of radioactivity for a given exposure pathway. There can be four exposure pathways, as follows:

- Ingestion of radioactivity - dose per Bq or mass ingested (food and/or water)

- Inhalation of radioactivity - dose per $\mathrm{Bq}$ or mass inhaled

- Groundshine - dose per Bq deposited on the ground

- Cloudshine - dose per $\mathrm{Bq}$ in a volume of air

The first two are called "internal" exposure as the radioactive materials must enter the body. Once there, they reside for a period of time that depends on the chemical form and other parameters, e.g., the particle size in the case of inhalation. Internal dose factors are time integrated, typically (as here) over 50 years. Thus, the ingestion dose factor is the dose received by a typical human over the 50 years after a material is ingested.

The external dose factors describe dose from material in the air or on the ground. Alpha emitters do not contribute external dose as alpha particles do not penetrate the skin. External dose factors are not time integrated; once the contamination is removed, the dose stops.

Fuel cycle assessments are typically focused on only the ingestion pathway.

Calculations are performed with ingestion dose conversion factors dose conversion factors $(\mathrm{Sv} / \mathrm{Bq}$ ingested) from the most recent ICRP database, with no adjustments. The ICRP Database of Dose Coefficients: Workers and Members of the Public, Version 2.01, Pergamon, Distributed by Elsevier Science Ltd, ISBN 008043 8768. The following table lists the various factors used in system analysis.

\begin{tabular}{|l|r|}
\hline Se-79 & $2.90 \mathrm{E}-09$ \\
\hline Sr-90 & $2.80 \mathrm{E}-08$ \\
\hline Zr-93 & $1.10 \mathrm{E}-09$ \\
\hline Zr-95 & $9.50 \mathrm{E}-10$ \\
\hline Tc-99 & $6.40 \mathrm{E}-10$ \\
\hline Ru-106 & $7.00 \mathrm{E}-09$ \\
\hline Pd-107 & $3.70 \mathrm{E}-11$ \\
\hline Cd-113m & $2.30 \mathrm{E}-08$ \\
\hline Sn-126 & $4.70 \mathrm{E}-09$ \\
\hline Sb-125 & $1.10 \mathrm{E}-09$ \\
\hline $\mathrm{I}-129$ & $1.10 \mathrm{E}-07$ \\
\hline Cs-134 & $1.90 \mathrm{E}-08$ \\
\hline Cs-135 & $2.00 \mathrm{E}-09$ \\
\hline $\mathrm{Cs}-137$ & $1.30 \mathrm{E}-08$ \\
\hline Ce-144 & $5.20 \mathrm{E}-09$ \\
\hline Pm-147 & $2.60 \mathrm{E}-10$ \\
\hline Sm-146 & $5.40 \mathrm{E}-08$ \\
\hline Sm-147 & $4.90 \mathrm{E}-08$ \\
\hline Sm-151 & $9.80 \mathrm{E}-11$ \\
\hline
\end{tabular}

\begin{tabular}{|l|r|}
\hline Eu-154 & $2.00 \mathrm{E}-09$ \\
\hline Eu-155 & $3.20 \mathrm{E}-10$ \\
\hline Ho-166m & $2.00 \mathrm{E}-09$ \\
\hline Th-228 & $7.20 \mathrm{E}-08$ \\
\hline Th-229 & $4.90 \mathrm{E}-07$ \\
\hline Th-230 & $2.10 \mathrm{E}-07$ \\
\hline Th-232 & $2.30 \mathrm{E}-07$ \\
\hline Pa-231 & $7.10 \mathrm{E}-07$ \\
\hline U-232 & $3.30 \mathrm{E}-07$ \\
\hline U-233 & $5.10 \mathrm{E}-08$ \\
\hline $\mathrm{U}-234$ & $4.90 \mathrm{E}-08$ \\
\hline U-235 & $4.70 \mathrm{E}-08$ \\
\hline $\mathrm{U}-236$ & $4.70 \mathrm{E}-08$ \\
\hline $\mathrm{U}-238$ & $4.50 \mathrm{E}-08$ \\
\hline Np-237 & $1.10 \mathrm{E}-07$ \\
\hline Pu-238 & $2.30 \mathrm{E}-07$ \\
\hline Pu-239 & $2.50 \mathrm{E}-07$ \\
\hline Pu-240 & $2.50 \mathrm{E}-07$ \\
\hline Pu-241 & $4.80 \mathrm{E}-09$ \\
\hline
\end{tabular}

\begin{tabular}{|l|r|}
\hline Pu-242 & $2.40 \mathrm{E}-07$ \\
\hline Pu-244 & $2.40 \mathrm{E}-07$ \\
\hline Am-241 & $2.00 \mathrm{E}-07$ \\
\hline Am-242m & $1.90 \mathrm{E}-07$ \\
\hline Am-243 & $2.00 \mathrm{E}-07$ \\
\hline Cm-242 & $1.20 \mathrm{E}-08$ \\
\hline $\mathrm{Cm}-243$ & $1.50 \mathrm{E}-07$ \\
\hline $\mathrm{Cm}-244$ & $1.20 \mathrm{E}-07$ \\
\hline $\mathrm{Cm}-245$ & $2.10 \mathrm{E}-07$ \\
\hline $\mathrm{Cm}-246$ & $2.10 \mathrm{E}-07$ \\
\hline $\mathrm{Cm}-247$ & $1.90 \mathrm{E}-07$ \\
\hline $\mathrm{Cm}-248$ & $7.70 \mathrm{E}-07$ \\
\hline Cm-250 & $4.40 \mathrm{E}-06$ \\
\hline Cf-249 & $3.50 \mathrm{E}-07$ \\
\hline Cf-250 & $1.60 \mathrm{E}-07$ \\
\hline Cf-251 & $3.60 \mathrm{E}-07$ \\
\hline Cf-252 & $9.00 \mathrm{E}-08$ \\
\hline
\end{tabular}




\section{B-2. Radiotoxicity}

Long-term radiotoxicity (LTR) - The radiotoxicity of waste, independent of mobility and transport at a particular time after separation/repository emplacement. Radiotoxicity is the inventory in mass $(\mathrm{g}, \mathrm{kg}$, tonne, whatever) $\mathrm{x}$ the appropriate dose conversion factor $(\mathrm{Sv} / \mathrm{kg})=\mathrm{Sv}$ or multiplies thereof.

Radiotoxicity is a theoretical metric for quantifying the toxicity of an inventory of radioactive material, unmitigated by environmental physical or chemical limits, including solubility, natural limits on subsurface migration, or any natural or engineered barriers in the overall pathway to a receptor. Radiotoxicity does account for the chemical and physical behavior of radionuclides in the body. Radiotoxicity is relatively appropriate when ultimate disposal sites are unknown, when one wants to compare the hazard of inventories across many types of sites, or as a measure of how well a disposal site and engineered barriers must protect the environment and humans. It is therefore used in international studies because sites are unknown or one wants to compare across the types of candidate sites in multiple countries.

In principle, the lower the radiotoxicity, the less risk of potential dose due to an unforeseen failure in barriers designed to prevent dose. However, this can also be extrapolated inappropriately and result in some misleading conclusions. For example, the toxicity of plutonium is often overstated by extrapolating from the potential carcinogenicity of single decaying atoms, concluding that gram quantities can kill millions with no regard to any reasonable pathway for distribution and ingestion. Using a similar argument, silver is listed by the Environmental Protection Agency as a toxic metal, and it could be claimed that the silver in a single Sterling silver butter knife could cause toxic effects to many, but solubility constrains the actual potential ingestion pathway, and silver is still used in fine flatware. Thus, while the concept of radiotoxicity is useful to compare between two inventories, and any reduction in magnitude or lifetime is good, it may not be warranted without careful examination using a model such as the TSPA. The results must then be evaluated in a trade-study that objectively considers reduction in risk of potential dose versus cost, similar to any as low as reasonably achievable (ALARA) analysis for chemical or radioactive materials. In this study, heat management is the focus, and radiotoxicity is considered only qualitatively.

Here, the LTR is calculated at 10, 1e2, 1e 3, 1e4, 1e5, 1e6 years after disposal (with emphasis on 1e3). The underlying calculations are complex because the decay of each initial isotope (at time of separation) to various progeny isotopes must be tracked. The calculation method and data have been checked [Piet2006] versus past calculations.[DOE2005, AAA2001]

Radiotoxicity is not a regulatory parameter, it is solely designed to put matters into an understandable context - how much material lasts how long. It has the advantages and disadvantages of being siteindependent. Site parameters are not relevant. So, radiotoxicity is straightforward to calculate and can be

used to describe hazard prior to or independent of disposal site and design. This of course has the disadvantage that it does not measure the real hazard of material actually disposed at a particular place in a particular design.

\section{B-3. Heat Commitment}

Long-term heat (LTH) - The heat generated by waste in the time period from repository ventilation stoppage (minimum $50 \mathrm{yrs}$ ) to 1500 years. Past analyses have shown the peak mid-drift temperature is due to cumulative heat buildup after ventilation is ended (nominally 50 years here, the legal minimum) and occurs by $\sim 1500$ years; therefore, the integral from 50 to 1500 years is used.[Piet2006] This has been calibrated versus detailed repository heat response calculations by Wigeland [Wigeland2003, 2004a, 
2004b, 2006; Stillman2004] so that it is a good indicator of heat-limited repository capacity for the types of cases considered here. 